Accounting the Future

An Ethnography of the European Spallation Source

\title{
Ivanche Dimitrievski
}

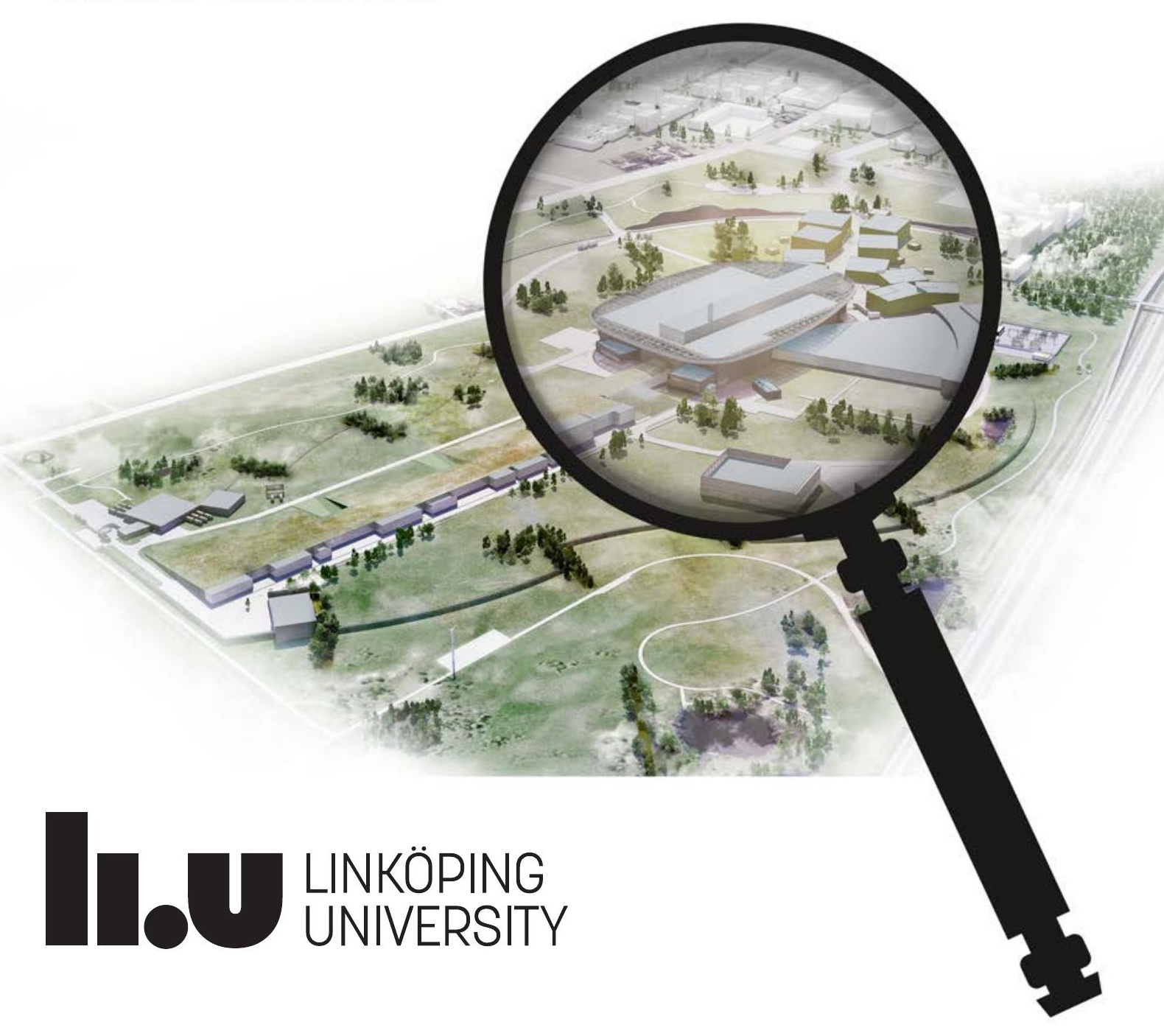




\title{
Accounting the Future
}

\section{An Ethnography of the European Spallation Source}

\author{
Ivanche Dimitrievski
}

H.UU UNKKDDNG

Linköping Studies in Arts and Sciences, No. 771

Faculty of Arts and Sciences

Linköping 2019 
Linköping Studies in Arts and Sciences · No. 771

At the faculty of Arts and Sciences at Linköping University, research and doctoral studies are carried out within broad problem areas. Research is organized in interdisciplinary research environments and doctoral studies mainly in graduate schools. Jointly, they publish the series Linköping Studies in Arts and Sciences. This thesis comes from the Department of Thematic Studies - Technology and Social Change.

Distributed by:

Department of Thematic Studies - Technology and Social Change

Linköping University

58183 Linköping

Ivanche Dimitrievski

Accounting the Future

An Ethnography of the European Spallation Source

Edition 1:1

ISBN 978-91-7685-059-6

ISSN 0282-9800

(C) Ivanche Dimitrievski

Department of Thematic Studies - Technology and Social Change 2019

Cover design by Marcus Lundberg

Cover image "Bird's-eye View of ESS" courtesy of ESS

Printed by: LiU-Tryck, Linköping 2019 
To Monika and Lucas 


\section{Contents}

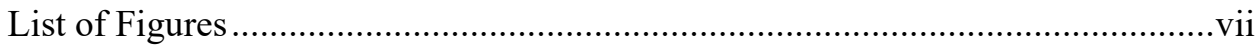

1 Introduction..............................................................................................

2 Accountable Futures? - Critical Literature Review .............................................

2.1 Sociopolitical Analyses of the ESS Landscape .............................................

2.2 Looking into Futures: A Sociology of the Future ………………………….....

2.3 Looking at Futures: A Sociology of Expectations .........................................10

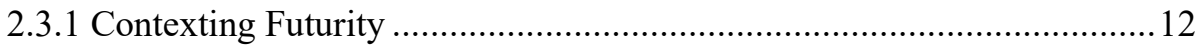

2.3.2 Enrolling Expectations .................................................................... 14

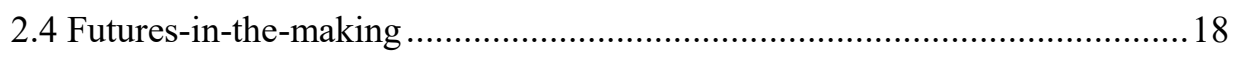

2.4.1 Making the Implicit Explicit...............................................................20

2.4.2 A Prospective Agenda for the Social Sciences........................................21

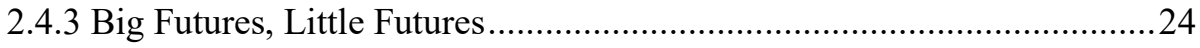

2.5 Accountability in Action ..................................................................... 26

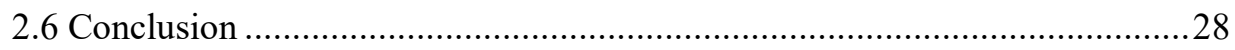

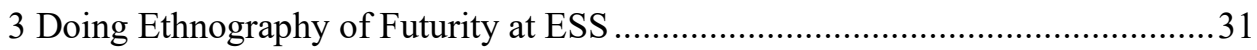

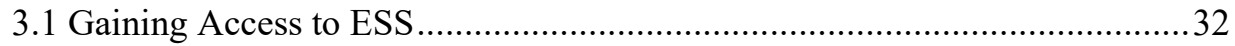

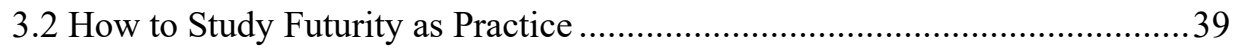

3.2.1 Examining Futurity as Documented .................................................... 40

3.2.2 Examining Futurity through Interviews ...............................................4

3.2.3 Examining Futurity through Participant Observation...............................48

3.3 Institutional Ethnography as a Method of Analysis ......................................51

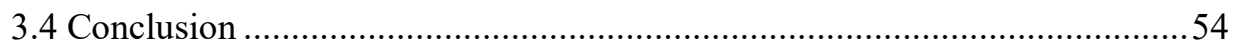

4 Accountability Practices in a Local Newspaper ...............................................55

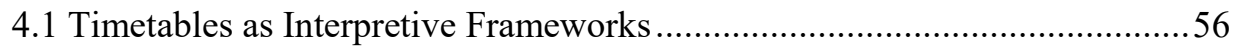

4.1.1 The "Game of Who Gets the Research Facility"......................................57

4.2 Turns of Events as Community Performance.................................................6 60

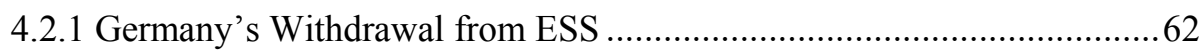




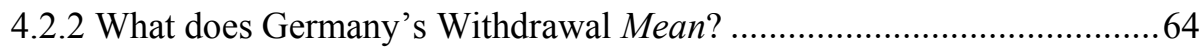

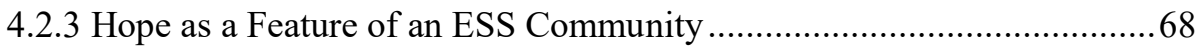

4.3 Organising Local Views about the Future ……......................................... 73

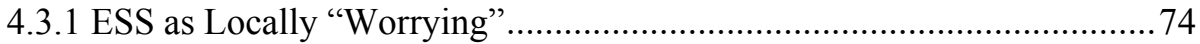

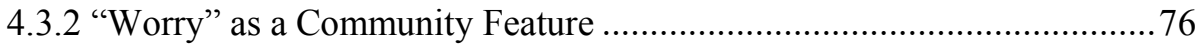

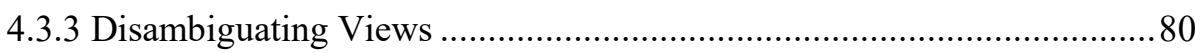

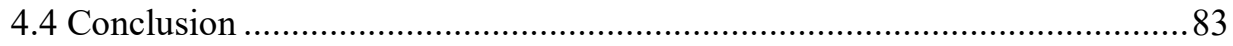

5 Performing "Coordinated Communities" through Futurity …….........................85

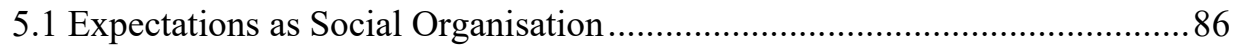

5.1.1 Accounting for Shifts in Expectations .................................................. 90

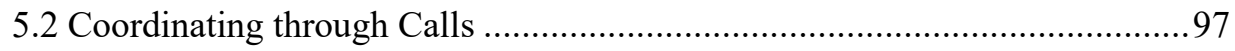

5.3 Eddard's Account of Getting Involved with ESS........................................ 104

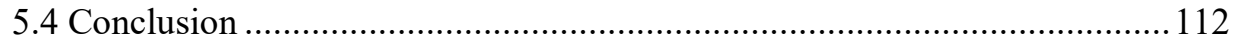

6 "Nothing to See Here" - Accomplishing Futures as Sensible ............................ 113

6.1 Some Futures More Accountable Than Others? ........................................... 114

6.2 "Future Walking" as Community Performance .......................................... 117

6.2.1 Who Can Remember Brunnshög as Liveable?..................................... 118

6.2.2 The "Future Walk through Brunnshög" ............................................... 120

6.2.3 Making Future Sight Accountable ........................................................ 123

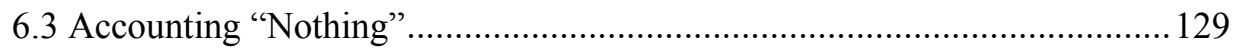

6.3.1 "Nothing to See Here" as Community Performance .............................. 130

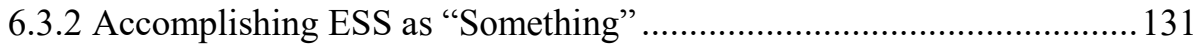

6.3.3 What is "Nothing to See Here" (Not) About? ....................................... 136

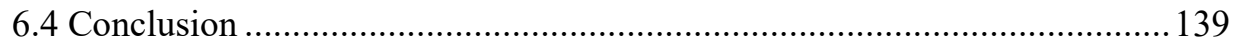

7 The Ordinary Making of the Not-Yet ............................................................ 141

7.1 Accountability Relations in Stories about a "Helium-3 Crisis"................... 142

7.1.1 Success Stories, or Who Saved Tomorrow ……................................... 146

7.2 The Everyday Practices of the Workshop as Future Making ........................ 151

7.2.1 Performing Orientation through Talk about the "Helium-3 Crisis"....... 153 
7.3 Accomplishing Thickness as a Non-Question.............................................159

7.3.1 An Occasion of Measuring Coating Thickness ...................................... 160

7.3.2 Implicating Futurity in Ordinary Practices............................................ 163

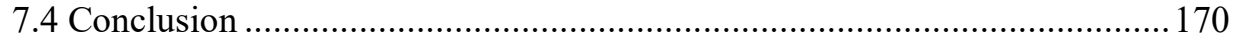

8 Conclusion: Towards a Different Politics of Futurity?..................................... 173

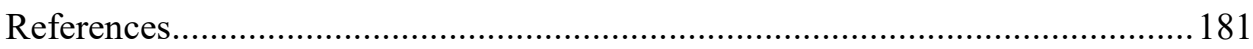

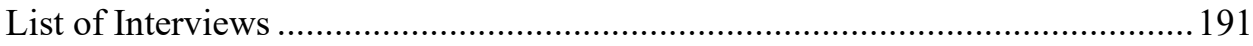

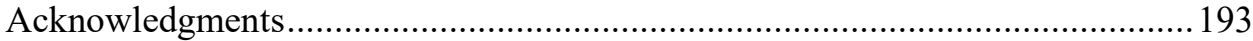




\section{List of Figures}

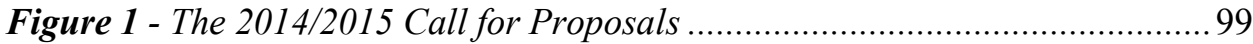

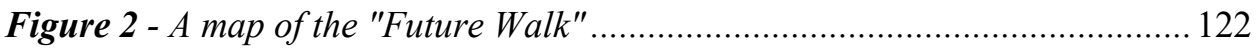

Figure 3 - Facing the first "Future Walk" signpost .......................................... 124

Figure 4 - A visual rendering of the "He-3 crisis"............................................. 143

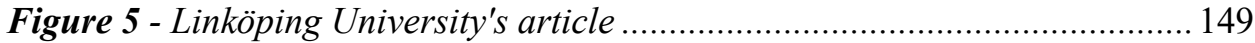





\section{Introduction}

A work day at Tema-T normally involves a "fika". We have a special room at Tema$\mathrm{T}$ designated for that occasion, the "fika-room". About nine-thirty, some of us gather there to engage in informal talks over coffee and cinnamon buns. Perhaps it was too early, but this room was empty that day in the spring of 2015. The machine was preparing my drink and as I was waiting, I noticed a note posted on the wall right next to it reading "free for the taking". Beneath it a table and a pile of books on it, some doctoral theses by graduates from the department, other anthologies by scholars around Sweden. One of these anthologies was entitled Legitimising ESS. Published in 2013, the anthology examined "ESS, the European Spallation Source - a new Big Science facility for neutron-based materials research to be built in Lund, a small university town in the southernmost region of Sweden, Skåne". ${ }^{1}$

Of course, this is not an innocent description of the European Spallation Source. Consider the acronym "ESS".

Law (1999) argues that acronyms can be thought of as devices for performing entities as (singular, stable, discrete) "things" out there, in and of the world. With regards to "ESS", the acronym relegates some of its defining properties - that it is "European", that it involves "Spallation", that it is a "Source" - to the background. While examining this entity, I learned that these qualities were also the focus points of competing interpretations. To what extent, and in what sense, is ESS a "European" project/facility, and for whom? What is "Spallation" precisely - a benign scientific procedure, taking the name of an equally benign process of ejecting fragments from a solid material, or an awkward way of saying that a nuclear power plant is being built in the south of Sweden, in Skåne, just on the outskirts of Lund - "where people live"? And a "Source" of what, in what sense, and for whom? For some of the people and groups I came across, as we shall see, ESS simply was an instrument, a source of neutrons for investigating the molecular structures of materials; for others, it was a source of innovation; yet for a third group of stakeholders, ESS was a source of anxiety, fears, and worries for the future. I wondered if using the acronym erases that complexity, heterogeneity and multiplicity. Does it evade the question of, say, "a

\footnotetext{
${ }^{1}$ In making this description I paraphrased Kaiserfeld and O’Dell (2013), the Editors of Legitimising ESS: Big Science as a Collaboration across Boundaries.
} 


\section{Accounting the Future}

source of what?" in an everyday conversation, enabling getting directly to the point - that it is a new facility, Big Science, a kind of particle accelerator, like the CERN but not really, and so on. ${ }^{2}$ I felt the need to ask, to whom does "ESS" make sense as an "acronym"? Does "ESS" provide for distinguishing members from non-members - simply from seeing whether or not such a question as "what is that?" comes about? To what extent does the acronym occasion a mobilisation of new members through explaining what "that" is, what "ESS" stands for? How indeed do representational devices, as simple as using the acronym "ESS" instead of the full name, play a part in performing communities around the future? But I am getting ahead of myself.

I began reading this anthology, Legitimising ESS, and half-way through the introduction I found myself thinking: "It might be interesting to study Big Science at ESS". However, as I continued reading through the anthology, I realised that there was no "at ESS" yet. Because ESS, "quite literally" as I discovered, did not exist. It was "still an agricultural field" (O'Dell 2013, p 69). I continued exploring the possibility of studying Big Science at ESS, but I kept getting the same advice from people I met on the way - that this was impossible. ESS did not yet exist. There was "nothing to see there". This peeked my curiosity. How is it possible to study something which does not yet exist? Is there something especially different about studying the future?

As we shall see throughout this thesis, many futures have been stated in regards to ESS, now under construction in Lund. On the positive side, for example, it is said that, in Sweden, ESS will generate a GDP increase of four billion Swedish crowns annually, as well as an employment increase of six thousand new jobs. ${ }^{3}$ At ESS, researchers will learn about how materials are constructed on the atomic level, enabling future discoveries in nanotechnology, the life sciences, pharmaceuticals, materials science and experimental physics. Using the (world's most) powerful

\footnotetext{
${ }^{2}$ Of course, acronyms are a historically situated phenomenon (Wilton 2004). In ancient times, the use of acronyms was associated (very prominently) with the Church. Also, it was restricted to such common words in this context as "God", "Jesus", or "Christ", abbreviated by their first and last letters and marked with an over-line. In the mid- to late $19^{\text {th }}$ century, an acronym-disseminating trend spread through the American and European business communities, abbreviating corporation names. Another key driver for the adoption of acronyms was modern warfare, becoming common in World War I and a part of the vernacular language of the soldiers during World War II, who themselves were referred to as GI's. In more recent times, acronyms became a constitutive component of text-messaging and of online communication. The point is that, using "ESS" makes sense today, in a time when such entities can be abbreviated and referred to in this way, as acronyms.

${ }^{3}$ Sources are documented as these versions of the future are discussed throughout the thesis.
} 
neutron beam at ESS, researchers will create a "science for society", developing and refining plastics, paints, medicines, and mobile phones. It is said that ESS is where Lund will grow; however, all municipalities in Skåne will benefit in terms of increased occupancy, new business start-ups, and from the boost ESS will give to the regional tourism industry. With ESS in it, Skåne will become the world's greatest research and innovation environment.

Some of these futures can be characterised as negative. Thus, some say that ESS will consume as much electricity as a small city, as a consequence overwhelming the local power grid. ESS will displace the local inhabitants, the people living in the vicinity. They will not be able to sell their property in the future. Instead of them, a well-educated middle class will establish themselves (in the Brunnshög area) around ESS, leaving no room for the poor and the vulnerable. Some of the toxic, radioactive waste generated at ESS will be so dangerous, it will need to be safely guarded for a hundred thousand years. In the future, living in Lund, next to the ESS facility, will feel as insecure as living next to Barsebäck - a recently decommissioned nuclear power plant in Skåne. ESS will swallow a lot of money - "like a black hole" some say. With ESS around, and in the process of coming about, some spheres of Swedish science, in particular the social sciences and humanities, will suffer financially. Their budgets are likely to shrink.

The questions which then arise are: Are some of these futures more feasible than others and if so, in what ways? Who takes care that they are done right? Who cares if or when they are not, and how do they do so? How are these futures observably and report-ably (rendered as) being accomplished? What accountability relations figure in their situated accomplishment as ESS futures? In short, to what extent, and in what ways, are these futures accountable?

In order to unpack these questions, the thesis is organised as follows. Chapter 2 critically assesses a range of social science literatures from the point of view of my interest in futures and their accountability. I seek to identify insights and directions from these literatures, helpful when it comes to addressing the relationship between futures and accountability. In this relation, I also identify and specify my main research questions. In chapter 3, I report the decisions I made as to the most appropriate methods to use. In that chapter, I also discuss how issues of access and choice of methods themselves can be seen to provide insights into the making of futures. Chapters 4-7 then present the main empirical material. In particular, chapter 4 looks at accounts of ESS in Sydsvenskan, a local Swedish newspaper. Chapter 5, examines accounts of futurity as generated in interviews and in a Call for Proposals 


\section{Accounting the Future}

of "instrument concepts" at ESS. Then, in chapter 6, I consider documentary and interview materials regarding "future walks" around ESS and a pre-organised visit to the ESS construction site. Chapter 7 looks at practices of thin film coating and doing measurements of coating thickness at the ESS Detector Coatings Workshop in Linköping. Finally, in Chapter 8, I present a summary of the main theoretical contributions of my work. I pull together the empirical findings across the different areas of my investigation, to consider some of the political implications resulting from this work. 


\section{Accountable Futures? - Critical Literature Review}

How best to examine the making of futures? What kinds of underlying processes generate and sustain robust versions of the future? This chapter critically reviews the social science literature relevant to addressing the topic of futurity and examines the extent to which it can help us answer those questions. I begin with an examination of the social science literature published on ESS itself. Following this, I examine sociologies of the future. Then, I evaluate how Science and Technology Studies (STS) scholars address the future as a topic. As we shall see, a variety of STS scholars maintain that there is a need for an alternative approach to understanding the future which, instead of looking "into" the future looks "at" the future, namely at the activities, practical work through which futures come into being, come to prevail over other futures, and in the process have specific forms of influence on emerging science and technology. The chapter continues by looking at how various scholars have theorised "futures-in-the-making". Then, I present literature that helps me articulate the notion of accountability. The chapter concludes by identifying the main research questions to be addressed by the thesis.

\subsection{Sociopolitical Analyses of the ESS Landscape}

Three published anthologies gather the existing social studies of ESS. These are In Pursuit of Promise by Hallonsten (2012a), Legitimising ESS by Kaiserfeld and O'Dell (2013), and New Big Science in Focus by Rekers and Sandell (2016). The contributors to these anthologies have diverse disciplinary backgrounds, and examine ESS in a variety of aspects. Thus, Stenborg and Klintman (2012) study "organised local resistance", the activities of local environmental groups against the prospect of building the ESS facility in Lund. Hallonsten (2012b) looks at the history, politics, and sociology of Big Science to provide a broader context for understanding (and problematising) the ESS project as "a case with specificities as well as generalities" ( $p$ 82). Sandell (2013) looks closely at instrument-design practices at ESS, addressing the various tensions arising between, on the one hand, "imagining the future" - the kinds of questions that the future instruments might be able (or need) to answer - and, on the other, "living in the present" - i.e. relying on what technically works today. Linné (2013) examines ESS as presented in the local news media, in 


\section{Accounting the Future}

particular Sydsvenskan, and discusses "possible consequences" of this coverage on local public opinion. Kaijser (2016) scrutinises the sustainability discourse around ESS, reflecting upon the various ways in which this discourse relates to a Swedish, and perhaps Lund-particular, environmentalist "mindset". Haider and Kjellberg (2016) use ESS as a lens through which to address the practical work, functions, and policies that enable the collection of data and their processing before the actual research can be carried out. Their main research question is "when are data" namely, at what point in the making of data do they become "data"? As we can see, these are diverse studies, addressing diverse topics, and to different ends.

One commonality I noticed while reading these anthologies, especially with respect to the first two, was their attendance to politics through representation. For example, opening In Pursuit of Promise, Hallonsten (2012a) argues: "nobody knows what the ESS is going to look like; nor what it is going to do, what it is going to deliver, at what cost, and for the benefit of whom" (p 12). Nobody knows that because, locally at least, the ESS project "lacks transparency and precedents to guide the interested" ( $\mathrm{p}$ 14). The decision-making processes behind it, the procedures for achieving its goals, moreover, are shrouded in "intense secrecy"; they have taken, as well as continue to take place "behind closed doors" (ibid). In this way, Hallonsten describes an ESS which, insofar as "the general public" is concerned, is out of reach. Nobody, according to him, knows about ESS but also, importantly, little can be found out about it. He says "little documentation exists" on the project, except for "colourful pamphlets and very general writings in governmental documents" ( $p$ 15). His point is that the existing, publicly available ESS documentation provides little in the way of enabling informed public attitudes concerning the facility.

Linné (2013) makes a related point. He examines the metaphor of "competition", often used in local media when reporting on ESS. According to Linné, "when the competition for ESS is in the foreground, there is less focus on what the competition is about" (p 95) - namely, the ESS facility itself. Representing the political processes behind ESS as a "competition", he argues, provides for ignoring nuances and makes it "harder to pose critical questions", for example "why the ESS is needed and why it should be in Lund" (ibid). Linné's point is that, inadvertently perhaps, local media play a crucial role of de-politicising local publics; interpolating them as mere spectators to a "game" out there, instead of (doing the right thing and) enabling their involvement in the political process behind ESS as participants. Liljefors (2013) makes a similar argument concerning the metaphor of "giant microscope" and rhetoric of scale used when describing ESS. 
For the most part, the existing social science studies of ESS portray it as a social problem. The concept of "ontological gerrymandering" becomes relevant in this regard. According to Woolgar and Pawluch (1985), "the successful social problems explanation depends on making problematic the truth status of certain states of affairs selected for analysis and explanation, while backgrounding or minimising the possibility that the same problems apply to assumptions upon which the analysis depends" ( $p$ 216). The reoccurring assumption in the three ESS anthologies is that ESS is not-yet (O'Dell 2013), a target as yet to start moving (Hallonsten 2012a); that simply, ESS is in the future. With this as a baseline, any definitive rendering of ESS becomes a subject of doubt. If, as future, ESS is fundamentally uncertain, then any certainty-claiming statement about it must either reflect its authors' particular interests or be the result of successful rhetorical work (as provided for by, say, the metaphor of "competition").

Interestingly, what makes these analyses possible is also precisely what some of the scholars here mobilise in articulating those analyses as significant. Thus, Hallonsten (2012a) writes: "we contend that broader interest among the general public, while not particularly vivid needs only be awakened, and in this respect, the publication of this book is timely. It is reasonable to suggest that the rather odd non-interest in the substance of issues related to ESS among the general public is likely to wane as the project approaches the start of construction." (p 13). Hallonsten is suggesting that, given the not-yetness of ESS, there still is a time for change, for waking up public interest, which "this book" takes as its aim. We can see that these analyses rely on an un-specified sense of ESS as future. Before considering political implications, we need to examine the social processes performing that sense. To what extent does the social science literature on futures help us understand those processes, and accountability in relation to those processes?

\subsection{Looking into Futures: A Sociology of the Future}

According to Bell and Mau (1971), the future in some respects is "as real as the past" (p 7). For example, they argue, "we know both in much the same way", namely "through our conceptions of them" (ibid). In that sense, according to them, the future is "as real as the present too" - except for that "momentary experience in the present in ways that transcend the organization of sense data into articulate and meaningful 


\section{Accounting the Future}

units for a given actor at a given time and place" (ibid). ${ }^{4}$ There is, however, according to Bell and Mau, an important sense in which the future differs ontologically from the past and the present. The past and the present, they argue, can be known as there is or there has been something out there to know; more or less accurately, and within the limits of our senses and equipment, they are determinable. But when it comes to the future, argue Bell and Mau, nothing of a particular sort has happened yet nor may happen at all and, however real our conceptions of it, the actions set in motion to bring it about, and however certain we are of its coming, the future remains fundamentally, radically and incorruptibly open. Bell and Olick (1989) summarise the point like this:

There is no knowledge of the future. Yet the only really useful knowledge in making our way in the world is knowledge of the future. The past is over and done with. It is a closed book. Although we can change our ideas about the past and can rewrite history, the past itself does not change. The only thing we can influence by our actions is the future. The future is open. (p 126)

Note the distinction made between the past, present, and future themselves and our conceptions of them. More critically, I return to this distinction in the next section. Here, Bell and Olick make it as a basis for arguing that, any investigation into the realm of the not-yet cannot have, as its object the future itself, but must derive it by looking into the present or the past in this way to identify possible, or probable, and even preferable futures. Thus, Bell and Mau (op. cit.) argue that the future is "prepared in the present" and so, it "may be known through the actions - or inactions - and their effects that will bring it into being" (p 9). Similarly, Waskow (1967) proposes that "the threads of change stretch back into the past" and that "the future will be woven from threads of change that we already have before our eyes, and can therefore study" (pp 177-8). Also, according to Bell and Mau (op. cit.), our conceptions or, to use their term, "images of the future" - not only are real but also "more or less orient human behaviour and social action" and thereby, may "give insight into what alternative futures are being prepared in the present" ( $p$ 10). Indeed, they argue, these images themselves "may constitute some of the alternative

\footnotetext{
${ }^{4}$ Bell and Mau (op. cit.) remind us that we will never know "most of what goes on in the present at other places", and what we do presume to learn of it is gained through reconstruction of it by others. Our impressions of the present, as they put it, are "incomplete", even if such reconstructions are "on-the-spot radio or television reports", since such reports are necessarily selected and edited, if by no more than "a choice of the eyewitness interviewed or the camera angle" (p 7)
} 
possibilities for the future" (ibid). ${ }^{5}$ Finally, as a basis for producing valid claims about the future, Bell and Olick (op. cit.) suggest looking into the "real, present possibilities" for the future. These, they argue, are "clearly visible" in such concepts as "soluble, heatable, expandable, combustible, observable, shrinkable, workable, electable" and so on (p 122). ${ }^{6}$

Bell (1996) insists that "prediction" should constitute a key concern in future studies. But by prediction, he does not mean producing definitive factual claims. Rather, prediction for Bell is principally about "positing the future" - namely, making presumptively true assertions about the future that would turn out to be true if the conditions and auxiliary assumptions on which they are based were met. Similarly, Waskow (op. cit.) argues that our role as future investigators is fundamentally political, and should enable choice by way of making "seriously possible worlds" available for consideration. He uses the term "possidiction" to denote - not the most likely future scenarios that the present "threads of change" may bring into being, but rather projections of how certain such "threads" might be made to flourish, given certain kinds of political action. Not predictive accuracy per se, the telos of such

\footnotetext{
${ }^{5}$ Bell and Mau (op. cit.) define the term "image of the future" as referring to "expectations about the state of things to come at some future time" ( $p$ 23). These, according to them, may vary in different ways. Thus, they may be general or specific, intimate and personal or widely shared, old or new, sacred or secular, long-term, "and therefore of possible sustained importance in directing behaviour", or short-range. What is more, according to Bell and Mau, "images of the future" may be characterised according to "the pessimism or optimism of their content" and "the assumption contained in the images concerning the factors that will influence the actual future" (p 24). Thus, they argue, "critical differences in human behaviour" can be seen "to result from images that are basically pessimistic compared to those that are optimistic and from images that put man in the image as a causal factor compared to those that do not" (ibid). What Bell and Mau propose makes sense in the abstract; however, they only elaborate this on the level of a proposition. They do not show, for example, how specific empirical instances may be seen to provide for such analysis.

${ }^{6}$ Bell and Olick (op. cit.) provide as an example: "a fragile glass may never be broken, but it is a real, present possibility that it could become broken. It really is breakable" (p 122; original emphasis). It is easy to see their point in this example. Indeed, that the glass could/might/will break is a convincing, reasonable, and appropriate consideration of a "real, present possibility" for the future given that glass, and therefore glasses generally, really are breakable. The point becomes less clear, of course, when the same logic gets applied onto the social world. For example, it makes little sense to say that a certain somebody will experience a room as comfortable, given that the room is, prior to finding it in this way, as its essential property, regardless of what one thinks about it, always already comfortable. Bell and Olick introduce the concept of "real, present possibilities" for the future as other to that of "images of the future"; these concepts, in other words, map on the essential distinction made between, on the one hand, our conceptions of the future and, on the other, the future itself. Others (e.g. Van Lente 2012), as I show in the next section, have in more or less elaborated ways seen this distinction as problematic.
} 


\section{Accounting the Future}

processes as Bell (op. cit.) articulates it is practical value and usefulness: "helping people to explore their alternatives, to decide what future they want, and to design effective action to achieve it" (p 45). ${ }^{7}$

These sociologies of the future can be regarded as highly elaborated instructions for looking into futures. They tell us that getting and doing the future right - i.e. predicting and achieving it as predicted, is fundamentally difficult, but they cannot help us understand, for example, how or to whom specifically it matters that the future is gotten or done right; or who, in specific instances, can be seen as liable for its right getting and making. Knowing and achieving the future tend to be portrayed as shared, universal interests, and their problematic elaborated and resolved theoretically. As a result, these authors tell us rather little about the social practices enacting accountable futures. Next I turn to how the topic of futurity is handled by STS scholars.

\subsection{Looking at Futures: A Sociology of Expectations}

In introducing a "sociology of expectations", Van Lente (2012) re-examines the distinction between future conceptions and the future itself. According to the previous accounts (Bell, Bell et al, and Waskow), we can never know the future itself factually; however, if our conceptions of it are grounded properly in the "real, present

\footnotetext{
${ }^{7}$ The concern with helping people to see "alternative futures" is a prevalent one in some of the existing social studies of ESS. Thus, according to Hallonsten (2012a), ESS is and continues to be "a promise, to be advertised and sold as such to various audiences and with a variety of [...] expectations attached" (p 12; original emphasis). These promises and expectations, he says, are "produced and spread by regional policy-makers and pundits, media, and lobbyists hired to pave the way for the smooth adoption of this international megaproject by a sparsely populated country in the north [...]" (ibid). The problem, as he sees it, however, is that "the general public" readily accepts them as facts. It is our "responsibility" as social scientists, then, argues Hallonsten, to analyse problems of this sort - not merely to meet academic interests, but crucially also as a "public service" ( $p$ 13). Interestingly, realising such a purpose translates practically into constituting what could be understood following Bell and Olick (op. cit.) as the "real, present possibilities" for the future. Consider Kaiserfeld and O'Dell (2013), for instance, reporting: "for politicians, the hope is that all of this will lead to economic and regional growth" (p 17; emphasis added). The term "hope" - not only qualifies the stated ends, but also suggests in this case a contrary possibility as the likely. Kaiserfeld and O'Dell then specify this possibility in arguing as a follow up: "there is always the risk that these two facilities will become little more than isolated islands on the outskirts of Lund, attracting a few thousand scientists each year, but little else" (ibid).
} 
possibilities" for the future, then we may be able to articulate, as Waskow terms it, "seriously possible" futures. Van Lente calls this "a realist perspective", according to which a distinction can be made between an expectation or a promise and the "real" state of affairs. In fact, he asserts, "it is not possible to decide a priori whether the promises of some technology are "true", or for that matter "real", "seriously possible" - instead, they can "either be accepted as meaningful and are acted upon which leads to some new developments that will differ more or less from what was promised - or can be ignored, and then no developments follow" (p 775). According to Van Lente, "it is only retrospectively possible to determine whether or not a promise is 'true' and at that time such knowledge is probably not needed anymore" (ibid). ${ }^{8}$ For Van Lente, then, the important question to ask concerns the ways in which particular "images of the future" get to count as the future itself. Or, as Brown (2003) puts it, what are the ways by which a certain "story or plot" becomes (or fails to become) "a more widely shared normative anticipation of the future" (p 6)?

Crucially, Van Lente (2012) points out that "the active exploration of the future is by no means a privilege of foresight methods" (p 769). Anticipation, he says, occurs in many more domains, being intrinsic to professional practices; circulating amongst engineers, board rooms, research institutes and policy circles. According to Van Lente, "formal assessments" of the future are surrounded by, and often necessarily draw on, "informal" assessments. I take this to propose several important features that bear upon my question of how futures are done accountably. Firstly, we can read Van Lente as saying that anticipation is a form of practice, "formally" exercised in foresight but also "informally", in various other contexts. Secondly, that foresight assessments of the future are "formal" (I read organised, systematic) does not, as Van Lente argues, mean that such assessments hold a special position over defining what

\footnotetext{
${ }^{8}$ Moreover, as the two resonate, Woolgar's critique of the concept of "affordance" (namely, the capacity of objects to constrain the ways that they can possibly be used or the things that may happen to/with/because of them as they are used) can be characterised as applicable vis-à-vis the term "real, present possibilities". Thus, according to Gibson (1982), "the affordance of something is assumed not to change as the need of the observer changes" ( $p$ 409). He argues, for example, that "the edibility of a substance for an animal does not depend on the hunger of the animal", and "the walk-on-ability of a surface exists whether or not the animal walks on it" (ibid). Bell and Olick (op. cit.) propose similarly: the breakability of the glass stands, as its independent property, regardless of its use or our conceptions of it. However, as Woolgar (2002) points out, the term "affordance" (and by analogy, that of "real, present possibilities") can be seen as a shorthand for "the consensual outcome of interpretation" (p 265). According to Woolgar, "the (common sense) claim that objects are not routinely the target of limitless, unbounded interpretation is explained by recourse to invoking a property of the object (its affordance), rather than by, say, initiating an inquiry into the social basis for patterned interpretation" (ibid).
} 


\section{Accounting the Future}

counts as "the future". This is an empirical question, and our attempt to answer it does not even need to start with "formal" anticipation practices. Initially, as Brown (2003) proposes, we need to examine how specific "future scripts are stabilised around a specific set of [anticipation] practices" (p 6). We should find Van Lente's distinction between "formal" and "informal" anticipation practices useful, especially as it sensitises us to the ordinary, mundane ways of constituting the future. Note, however, that Van Lente does not specify what anticipation as "informal" practice entails or indeed, how to identify it in the contexts that we examine. If "professional practices" are, as Van Lente argues, intrinsically anticipatory, to what extent does it make sense to speak of anticipation as a particular practice? I will return to these questions later on in this chapter (see footnote 13, on p 18, this chapter). Indicatively at least, Van Lente and Brown inform the overall take this thesis assumes of examining the practices through which actors accomplish accountable futures.

\subsubsection{Contexting Futurity}

Brown et al (2000) argue for an alternative approach to prospective technoscience, that "does not postulate on the probability of one future against another", nor does it generate "normative prescriptions about particular futures" ( $p$ 4). This approach would turn the analytical gaze instead towards "the phenomenon of future orientation itself" (ibid). They claim that, the focus for such an approach is not "the future per $s e$ " but rather "the 'real time' activities of actors utilising a range of differing resources with which to create 'direction' or to convince others of 'what the future will bring" (ibid; original emphasis). Brown et al so call for shifting "the discussion from looking into the future to looking at how the future as a temporal abstraction is constructed and managed, by whom and under what conditions" (ibid; original emphases).

We can think of this call as for a shift from an essentialist concept of the future which frames it as a discrete temporal domain, consisting of a definitive set of members (e.g. possibilities, probabilities), with fixed properties (e.g. of radical indeterminacy, uncertainty, or openness), and which predicates particular ways of knowing it (e.g. by prediction) - to the future as performed in practices.

Brown et al (2000) argue moreover that "it is not simply that the future is always uncertain and so possible in multiple forms" ( $p$ 5). Note that this can be seen to counter Bell and Mau above, who argue that the future is in itself, as a feature of what it $i s$, uncertain. Rather, Brown et al suggest that, the future, of science and technology for example, is "actively created in the present through contested claims and 
counterclaims over its potential" (ibid). The uncertainty of the future, according to them, derives from the "unstable field of language, practice, and of materiality in which various disciplines and actors compete for the right to represent near or far term developments" (ibid). ${ }^{9}$ I consider this as a move of characterising certain features of the future (namely, its uncertainty) as pertaining to features of the broader context of accomplishing futurity. In this vein, for example, Nowotny (2016) argues:

Taming the future remains a precarious and difficult task [...] Data enable us to follow the modelling of traffic behaviour live; tracking the eye movements permits the identification of potential consumers; pooling data in the life sciences based on observations of biological functions and the development of biological entities from the molecular level up to the organism provide the basis for future breakthroughs $[\ldots]$ None of these certainty-generating devices can prevent holes to be punched into their computational outputs. [...] Just as past extrapolations meet their limits when surprises hold in store what has been unthinkable before, tipping points may suddenly disrupt the complacency of business as usual. The reason is simple. It is the incorruptible non-linear dynamics of complex systems. (pp 31-32)

For Nowotny (2016), one such "complex system" is the global climate, another the airport transportation system, and a third the global financial system. In these, she argues, "cumulatively larger and larger changes will occur due to small changes in the initial conditions" ( $p 47$ ), making tipping points and surprises a permanent feature of our dealings with them and so, defying the making (in a final sense) of their future in the present, say, by means of prediction. We may observe a similar allusion to "complexity" and "non-linearity" as explanatory of the uncertainty of the future in Geels and Smit (2000), who argue that, one reason why "images of the future" fail to meet reality is their tendency to over-simplify socio-technical scenarios. For

\footnotetext{
${ }^{9}$ The framework of "competition" renders as natural a certain version of the actors, as competitors, occupying definitive positions within an overall "struggle" over political and material resources, and using promises to "convince" or "win" others over, namely their resources, in making a particular something "reality" or to prevent its coming into being. With Star (1991) - who says of Latour's (1983) rendition of Pasteur's success, "this is only one kind of multiplicity, and one kind of power, and one kind of network" (p 81) - we can think of "competition" as one way of narrating technological/scientific emergence. It excludes other ways of narrating emergence and, analytically it excludes the excluding of those other ways. Rather than taking "competition" as the de facto (natural) context (of the future) in which futures are done, we should consider the extent to which futuring practices involve performing social organisations and interactive contexts. What kinds of social organisations are these? What interactional resources get mobilised in the practices providing for accountable futures? What kinds of exclusions are rendered in this way?
} 


\section{Accounting the Future}

example, in their view, "images of the future" often describe a situation in which a new technology completely replaces the old, whereas, in reality, such situations are "more complex", with multiple technologies ending up as co-existing. Another reason behind their failure, as Geels and Scot argue, is that "images of the future" always emerge in relation to the broader cultural concerns of their time, as well as shift with emerging concerns and new technologies.

We may read from these accounts that uncertainty is not an essential property of the future, but rather of the context (be this a competitive unstable field, or a complex system, or a shifting, and shifty, time) in which (competing) actors claim futures. While differently attributing uncertainty, the resulting point remains the same: that since we cannot in advance know the outcome of the competition, or fully capture the complexity and dynamics of the complex system, the future remains for us always and necessarily uncertain. I find this problematic to the extent that it misses an opportunity - to examine, say, situated performances of certainty and uncertainty. If practices perform futures, then we should see no reason to locate this feature of the future outside those practices, in the context that (allegedly) encompasses them. And in this connection to ask: what particular accountability relations provide for the certainty/uncertainty of the future in the particular practices articulating it?

\subsubsection{Enrolling Expectations}

Brown (2003) makes an appeal to our "familiar experiences" of high-shooting expectations in different areas of technological innovation. "We are today", he argues: "wholly accustomed to being daily bombarded with (often competing) claims about the seemingly limitless potential" of emerging technologies (p 3). Brown makes notice also of our "equally familiar experiences" regarding "unfulfilled promises, the awkward absence of future benefits, treatments, rewards, and profits" (ibid). Similarly, Geels and Smit (2000) gesture to a sense in which we all have seen how expectations always accompany technological development; how we have all realised, in the course of our lives, and as a rule, that expectations tend to misrepresent the future itself, as it turns out eventually. Not always and not merely the reflection of expecters' short-sightedness, Brown and Geels and Smit argue that the specific features of expectations are better seen as meant, as designed to influence particular social processes in technological development.

Thus, according to Van Lente (2012), expectations, "rather than being descriptive statements that may be true or false" are, in fact, "statements that do something" ( $\mathrm{p}$ 772; original emphasis). Van Lente proposes, for example, that, when uttered at a 
shareholders meeting of a company, the statement "this material promises a reduction in electrical resistance of $30 \%$ in two years" is "a request to continue support for the firm to develop such material" (ibid). And if spoken by the head of a laboratory in this company before its R\&D department, "it creates an obligation for the researchers: they should be able to meet this specification within two years" (ibid). In line with Van Lente, this "transformation of a promise into a requirement", i.e. "the promise-requirement cycle", is a central mechanism in the dynamics of expectations (ibid). ${ }^{10}$ Through this (hypothetical) scenario, Van Lente proposes three "transformations"; namely, of a statement about the material as promising (which is not the same as promising, or stating a promise) into a request to_, an obligation for, and a requirement. Van Lente does not, however, tell us what precisely provides for such a "transformation". ${ }^{11}$ What, then, in the (hypothetical) situation that Van

${ }^{10}$ Brown (2003) claims that the following two features constitute an expectations dynamic. Firstly, "the requirement to enunciate a story, a vision of the future and a means of getting there" ( $p$ 6). More usually, he argues, these stories, visions, and means will display "differing degrees of linearity and flexibility" (ibid). Secondly, according to Brown, "the promise will, almost necessarily, be exaggerated in order to command sufficient interest to enrol necessary allies and secure investment" (ibid). But inevitably then, "as time passes and circumstances change, unforeseen problems emerge, and early hype gives way to varying levels of disillusionment" (ibid). When this occurs, argues Brown, the "hopeful clusterings" and "communities of promise" will "fall apart and can be seen to migrate to new fields unsullied by hype's eventual disappointments" (p 6). Pollock and Williams (2010) consider this claim as dramatizing. For example, they argue that it is unlikely that all expectations of the future are "accountable" in this way and to the same degree. They maintain, for example, that "longer-term predictions $[\ldots]$ may project too far into the future and be couched in too many techno-scientific uncertainties for any group to be held responsible for their non-materialisation" ( $\mathrm{p} 4$ ). According to Pollock and Williams, such longerterm predictions should be seen as having "low accountability". On the other hand, what they refer to as "infrastructural knowledge" is, in line with Pollock and Williams, "authoritative" and (of necessity) "highly accountable". I take this as an invitation to examine the accountability of ordinary, apparently meaningless "statements" about the future - or, as Pollock and Williams terms them, "visions let lose". I do this in chapter 6, in relation to the statement "nothing to see here".

${ }^{11}$ A more concrete characterisation of the connection between expectations and the particular social actions that arise in relation to them can be found in Michael (2000), who traces it back to the content of expectations, and in particular to various content "parameters". Thus, Michael elaborates on the parameter of "distance". Unsurprisingly, he says, "images of the future" often involve a specification of how distant it is from the present. "Is it the future of a few weeks' time, of a few years' time, or of a few centuries' time?" ( $p$ 24). Michael argues that, the rhetorical effect of this parameter is "fairly obvious", namely "great distance of a future bad facilitates a more 'relaxed' set of responses; shorter distance suggests more energetic efforts" ( $\mathrm{p} 25$; added emphasis). The obverse, he argues, applies to a future good. According to Michael, by flexibly specifying the distance of the future, actors may shape action and thereby, technological developments. For example, "a future represented as far distant can be used to warrant slowness of action", while "a 


\section{Accounting the Future}

Lente constructs, provides for reading/hearing the descriptive statement (about the material in question) as an accountable statement (e.g. of somebody thus being rendered accountable for accomplishing it)?

A further specification of the role of expectations in processes of techno-scientific development can be found in Van Lente and Rip (1998). They argue that "expectation statements" are key tools of coordination, especially in contexts where a central control is lacking - e.g. in situations of a nascent, not-yet established, technological field. ${ }^{12}$ Thus, according to Van Lente and Rip, expectation statements contain a "script", indicating promising lines of research and technological development "to be undertaken by the enunciator of the statement and/or by others" (p 19). When scientists and technology developers "ventilate" these statements, and others (e.g. industry or governmental actors) "accept" them, according to Van Lente and Rip, "a basic mould for activities in the emerging social world [of that] technology is created" (ibid). Because the expectation statements contain a script of a future world, they also "position the relevant actors [...] exactly as characters in a story" to be played out (ibid). According to Van Lente and Rip, an actor who rejects the role allocated by the script must react, either by protesting against the role, or by contesting the very nature of the expectation. The mutual positioning of the actors in

near future can warrant swift action" (ibid). One issue with the distinction Michael makes between near- and far-term futures concerns his characterisation of them as denoting a "fairly obvious" property of the future - namely, its distance. It follows that when specified as in "a few weeks' time", this future is (unsurprisingly, obviously) near, and when specified as in "a few centuries' time", it is (unsurprisingly, obviously) far. We can see, however, that the obviousness derives in this case from the particular juxtaposition and relational ordering of these two futures. If the next future was not specified as in "a few centuries' time" but as in "a few seconds' time", then the first future would read as (unsurprisingly, obviously) far; that is to say, Michael's exemplification of various distances renders their sense as accountably (i.e. observably-reportably) "obviously near-" and "far-term".

${ }^{12}$ Note that "expectation statements" is a concept. It does not singularly refer to actual "statements" of expectations and neither necessarily to "expecting" as a particular activity (of, say, expecting a child). For example, addressing Moore's Law concerning the doubling in complexity of the integrated memory chip, Van Lente and Rip (1998) refer to it as observation, claim, extrapolation, perception, law (and Law), yardstick, assumption, prophecy, expectation, promise, and idea. Van Lente and Rip characterize all these as "expectation statements". In a similar vein, Van Lente and Bakker (2010) argue that "promises" are "positive expectations" (p 694). And, Nowotny (2016) asserts in passing that "potential" is "another word for promise" (p 95). On a semantic level, all these terms can be seen as interchangeable - indeed, potential can be seen as just another word for promise, and promise can be characterised also as (positive) expectation. With this, however, the analysis misses the specificity of "expectations" and "promises" as phenomena in the real world. 
relation to the script or story-line creates "an agenda for the activities in the [technology] world" - thus coordination (ibid).

These are some of the more problematic features of the latter accounts. Firstly, we can see that the various specifications of the role of expectations hinge on a double sense of statements about the future as both "descriptions" and "expectations". When articulating this role, Van Lente and Van Lente and Rip define expectations as descriptions of future scenarios, and locate the basis for their effects in their content. On the one hand, this renders irrelevant their character as expectations. If the content solely matters, then it is of little importance whether the future statement intends an expectation or not. Van Lente then suggests that they are heard as "obligations for" or "requests to" or "requirement", but does not show how the hearing works in this case. On the other hand, not all descriptions of the future constitute expectations (or indeed, requests to, obligations for, requirements); at least not all of us will casually read or hear them in this way. By casually, and on basic level, characterising any description of the future as "expectation", we lose track of the practices rendering those descriptions as "expectations" by somebody, for somebody, in particular ways, and so on. This analytical tactic is not helpful then, when asking, for instance, who, in particular settings holds the definitional privilege over future statements, and how. Who has the authority over defining what is being heard when a particular future is being described, and how? In other words, it does not help us address the accountability relations rendering the sense of the future as "expectation", or "promise", or "just promise" or "just expectation", etc.

Secondly, Van Lente and Rip's account of the coordinative role of expectations suggests a sense in which, once actors "ventilate" (whatever this means) expectation statements, "others" will somehow automatically jump into their role as scripted. On the one hand, we may ask: how do particular members of these "others" establish that the scripted role pertains to them specifically? What kinds of "expectations" is Van Lente talking about, that have the capacity unambiguously to target people? On the other hand, the account suggests that, once the relevant actors "accept" the scripts, this then automatically leads to the realisation of those scripts. Still, we may ask: is somebody accountable for making sure that the scripted roles are played out to specification? And how is this done? This question is important, especially as the context in which this is played out, according to Van Lente and Rip, is one in which central control is lacking. 


\section{Accounting the Future}

\subsection{Futures-in-the-making}

In its futurity, argues Adam (2004a, 2004b, 2005, 2006a and 2006b), much of this world is not material in the conventional sense but is marked by latency and immanence. This, says Adam (2005), is "a world of deeds under way that have not yet materialized as symptoms, not yet congealed into matter" (ibid). It consists of processes, which are "ongoing, producing layers and layers upon layers of past and present futures as well as future presents and pasts" (ibid). In its orientation to the present, argues Adam, social science consistently fails to capture such a world inthe-making. This failure, she says, has produced a "crucial disjuncture between the seemingly unbounded capacity to produce futures that can extend over thousands of years, the lack of knowledge about potential outcomes and impacts of these creations, and the socio-political inability and/or unwillingness to take responsibility for the futures of our own making" (ibid).

Adam commends the sociology of expectations for having contributed in significant ways to our understanding of futurity; specifically, in pointing out that "the future" does not simply reside in the mind - rather, in complex socio-material networks where actors use "futures" practically, to do things with them. Nevertheless, anchored in the empirical tradition of STS, the sociology of expectations, she argues, has "inevitable problems with the future as the empirically inaccessible realm of the "not yet"" (p 7). By examining the future from the position of "the present", according to Adam, scholarly work in the sociology of expectations "sidesteps the issue whether or not futurity and the 'not yet' can be studied in any form other than an ideational sphere" (ibid). ${ }^{13}$ Adam asks in this regard, "does the future need to become

${ }^{13}$ A self-critique that explicitly echoes Adam's above can be found in Brown et al (2003), who reflect on "the analytical tendency of STS scholarship [...] to focus on statements, discourses or speech acts which explicitly manifest future-oriented representations (visions, metaphors, or promises)" ( $p$ 8). In their view, "we need to ask whether we sometimes have an unduly cognitive or mentalistic approach to acknowledging representations of the future" (ibid). For me, this selfcritique and self-reflection relate to another important feature of these scholars' academic work on the future; namely, the suggestion that, in dealing with such phenomena as "expectations", we are dealing with practices, only to find such phenomena being addressed as statements. Similarly, Jasanoff and Kim (2009) and Jasanoff (2015) characterise the imagination as an organised field of social practices; still, we do not find in their work accounts of imagination practices, rather of statements argued to be reflecting individual and shared imaginations. Jasanoff (op. cit.) evokes yet another sense of the imagination - as a uniquely human capacity/faculty, when, in a critique of ANT's "preoccupation with hybridity" which, according to her, "risks establishing a troubling normative equivalence between nonhuman and human agents", Jasanoff argues: indeed, "gifted writers can make anything speak, in the sense that their stories give voice to that thing"; indeed, "maybe a mosquito can speak or be ventriloquized by an exceptional storyteller"; but, says Jasanoff 
present or past before it can be studied?" and also, is looking at the future in fact "a look at the present and the past in the form of present futures and past futures?" ( $p$ 8 ; original emphases)

According to Adam (2005), the present-oriented focus in STS makes for omitting the pertinent question of "future presents". These, she says, are "deeds under way". They are "marked by latency and immanence", and constitute "the future of processes" set in motion by "socio-political, legal, scientific, economic, and everyday [...] practices" ( $\mathrm{p} 2$ ). The future, in other words, not only is imagined but importantly also in-the-making on its way to emergence and, as such, in Adam's view, rather than being detached from it, we are always already immersed in it as participants. As participants, she says, we carry responsibility for the outcomes of our futuregenerating actions, even if those outcomes are not or cannot be imagined in the present. Namely:

When we start from a position, which accepts that sociological knowledge is constitutive then we also have to recognise that we are implicated as creative participants in the world we seek to "discover" [...] To consider seriously our obligations towards "futures of our making" requires that we change our sociological understanding not just of the subject matter but also the nature of the discipline and the role of the social scientist from external observer and analyst to implicated facilitator of a more just social world [...] (pp 12-13)

As future-makers, argues Adam (2005), sociologists need to "render the invisible visible", to "make future presents tangible", to "give form to the "not yet", and to "provide analyses that take the future seriously as supreme realm of social practice and transaction" ( $\mathrm{p}$ 14). And doing this, according to her, requires shifting to a teleological perspective to pose, not how but why questions. In particular:

This way of understanding temporal relations is directed to human purposes, goals, expectations, value orientations and responsibility. Here the future is regarded to be the "cause" of the present and the temporal flow moves in the opposite direction from that of scientific causality, that is, from the future to the present. [...] In the world of future-based causality, conventional scientific and political quests for control become inappropriate. Other quests come to the fore. Questions of ethics and aesthetics are

evocatively, "can the mosquito imagine?" (p 17). In this doctoral thesis, and drawing on a method by feminist sociologist Dorothy Smith of "institutional ethnography" which I address in the next chapter, I approach such concepts as visions, or expectations, or promises, or imaginations, etc., etc., as particular interpretations that need to be defended by way of re-embedding them in the actual practices in which they arise originally, and which practices these terms (are said to) express. 


\section{Accounting the Future}

given room to flourish. Thus, when the temporal silences begin to get expressed and the invisible is given form, reality begins to resonate with the immanent process-world beyond empirical accessibility [...] Only with teleological causality is it possible for sociologists to extend themselves into the future, not just for the purpose of taking account of values, goals and aspirations, but, more importantly, to place themselves in the future and to view the present from that perspective. (pp 11-12)

The sociology of expectations, in Adam's (2005) interpretation, looks at how descriptions of the future (i.e. the future as presently stated, imagined) shape ongoing social and technological developments. Their concern, as Adam reads it, is with how this happens. Adam, in turn, considers the implicit, underlying, taken-for-granted purposes, goals, expectations, and value-orientations constituting "the future present" - namely, that because of which "the present" (what is at hand) unfolds as it does, and which this "present" accomplishes. The "future present" may originate in present societies, but also in long-gone societies and people. Some of the questions we may ask with Adam are: Because of whose futures (i.e. causes) we participate in our present? Are those futures also ours? Should they be and why? If we choose not to engage with such questions, according to Adam, we are not taking responsibility of those "futures" that, through our participation in their realisation, become futures "of our own making". The next sections presents three works in STS that, I believe, speak to Adam's concerns.

\subsubsection{Making the Implicit Explicit}

De Laat (2000) argues that "traditional futures methods used in decision making around technological research often tell us only half of the story" (p 200). Using such methods, foresight researchers anticipate for us future macro-evolutions and scientific breakthroughs; they sketch up the "boundary conditions" that predicate their arrival; and may even assess some of the undesired effects of technological development. Yet, argues De Laat, foresight researchers have "great difficulties telling us simply what the world will look like if a policy maker, a researcher or an engineer, decided to promote this or that technological choice" ( $p$ 175). As an alternative, De Laat suggests adopting a "constructionist view" for exploring and directly engaging as a participant with foresight-in-action. According to him, this view proceeds from knowing that foresight methods are used in some settings and that there, they apparently do make a difference. He argues: "future studies and their results are both embedded in, and constituent of, decision making processes" (p 201). Say, an S-curve, he says, may be used by a company to position its products on the market and thus, it provides incentives for action. The S-curve could be seen as 
"pushing" the present in one direction and so "helping" a particular future to come into being.

According to De Laat (2000), social scientists as future investigators should help actors yield "images of the future", in particular by making their own as well as competing "future scripts" explicit. His point, he says, is simple; namely, that "every technical choice implicitly involves a hypothesis on how, socio-technically, the future may be organised" ( $p$ 176). Thus, not just a technical matter, a decision to fund research on an electric vehicle battery implies, as De Laat puts it, that "at the pump, electricity will replace gas, that the battery will replace the car's tank, and that the driver is patient enough to wait for a (long, long) refill at an electricity-station" (ibid). De Laat argues that, by making such implicit "future scripts" explicit social scientists may help the actors in question better to define the "new worlds" their technical choices imply and require for becoming, and which worlds those actors must then achieve. I take De Laat's point as illustrating a tactic for socialising predominantly technical "images of the future", although I am sceptical as to the extent to which it may be seen as a move of making implicit future scripts explicit. For example, his illustration of an implicit future-script can be characterised (instead) as a socially elaborated version of the technical choice to fund an electric-vehicle battery.

\subsubsection{A Prospective Agenda for the Social Sciences}

Macnaghten et al (2005) propose that we could read the history of sociology in terms of the missed opportunities to establish an active role in the development of technologies, from personal automobility to the splitting of the atom and computing. Being "at an early, and hence undetermined, stage of development", nanotechnology offers a unique possibility "to build in social science insight from the outset" - that is, "before innovation processes become locked in" - thus contributing to its "future shaping" (p 269). Existing nano-programmes already provide for realising such a role, yet ordinarily limit it to "downstream questions" - inviting the social sciences in their ability "to scrutinise only the impacts or effects of the technology" ( $\mathrm{p} 273$; original emphases). According to Macnaghten et al, this results in a late arrival - i.e. "after significant commitments are already made" (p 274) - and renders mute any chance of making difference. The possibility of having a "real purchase" on the future shaping of nano-technology, they argue, lies instead in a fully integrated, "upstream engagement" of the social sciences in the innovation process itself. ${ }^{14}$ They

${ }^{14}$ This role, as Macnaghten et al (2005) specify it, entails a particular view of how technologies develop. It is important, they argue, that whatever role "we" play in the shaping of technology "we" 


\section{Accounting the Future}

see their role there, not as one of "telling scientists what to think" but as of "rendering scientific cultures more self-aware of their own taken-for-granted expectations, visions, and imaginations of the ultimate ends of knowledge" as well as "rendering these more articulated, and thus more socially accountable and resilient" (p 278).

Macnaghten et al identify five key areas to constitute "a prospective agenda for the social sciences". This agenda is intended to rehabilitate social scientists as actors in (and not merely observers of) technological innovation.

The first key area is unpacking of the alternative ways in which actors imagine nanotechnology. According to Macnaghten et al, imaginaries are "materially powerful" - they "do shape practices, relationships, and commitments", and making these explicit provides for a wider "reflective, accountable attention and debate", potentially to "the benefit of science as well as society" ( $p$ 279; original emphasis). The second key area includes providing "appropriate models of engagement" that afford the diverse inputs to such a debate - and specifically, public inputs - influence over (and not merely a place in) upstream processes. If, as "key sites of undeliberated shaping of future worlds", such processes are to be "elicited, debated, and maybe amended", social science, according to Macnaghten et al, needs to develop

must play it early on. The view of development that fixes that position as necessary is that of technologies as flexible in their early stages, and less so later on. While to Macnaghten et al such a view suggests the necessity of early arrival, in Selin (2008) it revives the possibility of prediction (at least in certain respects). She argues, while the prevailing tendency among STS scholars is to reject technological determinism, studies in this field often "leave room" for the latter in interesting ways. Selin stresses as a key STS insight that, "while the early stages of technological development are flexible and subject to improvisation and change, the latter stages of technological adoption tend to freeze and make rigid the socio-technical network relations" ( $\mathrm{p}$ 1883). According to Selin, this "emerging irreversibility" or "network hardness" suggests that "the future is not wide open" rather, it is "always already structured in important ways" (ibid). It follows for Selin that the future is "not completely indeterminate" and so, it could be seen as granting a "talk of predetermined elements". Still, as Grint and Woolgar (1997) point out, this view of technological development can be seen as underestimating "the significance of actors' interpretations and uses of the technology" ( $p 21)$. Inasmuch as technology embodies social aspects, they argue, it does not transit from a less to a more stable and determinate object, but rather is "unstable and indeterminate" throughout. This is not to say that, contrary to what Selin finds, technology, and by suggestion the future, is uncertain. As I read them, Grint and Woolgar are not making a claim about a nonproblematic ontological feature of technology, namely its stability and determinacy. Rather, they invite us to consider the ongoing social practices (i.e. uses and interpretations) performing technology, and its futures, in particular ways. 
participatory frameworks that productively integrate the voices of both experts and the public (p 282).

A third specification of the role of social science involves innovating new governance and regulation models that add to the prevalent focus on risk assessment a heightened sense of purpose and alternative. According to Macnaghten et al, we need to ask to that end: Why these technologies and not others? What others are there? Who needs them and, what human purposes are driving them? Relatedly, a fourth intervention focuses on tracing budding regulatory frameworks today, on a "global" scale, in the hope of identifying emerging inequalities and so, devising timely corrective measures. Elsewhere, Barben et al (2008) propose the notion of "anticipatory governance" to frame such questions; namely, "the ability of a variety of lay and expert stakeholders [including STS scholars], both individually and through an array of feedback mechanisms, collectively to imagine, critique, and thereby shape the issues presented by emerging technologies before they become reified in particular ways" ( $p$ 993). Finally, as a fifth way to participate in futuremaking, Macnaghten et al call for developing new theoretical models of technological emergence that seek to "move beyond conceptualising the future in terms of prediction and control" (p 285). Drawing on studies of future imaginaries, they argue that "the emergence of new technologies" could be seen instead as characterised by "complex and heterogeneous cycles of hope, expectation, hype, and disappointment, which are connected with material realities" (p 286). Providing an understanding of those "cycles", according to Macnaghten et al, may offer technology developers and policy makers invaluable insight in "how new technologies may materialise and become 'stabilised' as transportable 'actor networks"” (ibid).

The above accounts by Adam, De Laat and Macnaghten et al call for joint, and inclusive deliberation on futures, as well as for taking responsibility for futures of "our making". Their call can be appreciated in the context of ESS for instance, in which, as Hallonsten (2012a) argues, joint, inclusive deliberation is "urgently needed" ${ }^{15}$ Still, we can see that their specification of how such a call may be realised

${ }^{15}$ According to Hallonsten (2012a), ESS is and continues to be "a promise, to be advertised and sold as such to various audiences and with a variety of promises and expectations attached" ( $\mathrm{p} 12$; original emphasis). The problem, as Hallonsten sees it, is that "the general public" readily takes these promises and expectations for facts; and moreover, is disinterested in more "fundamental" issues concerning ESS, for instance, in the lines of do we really need this. According to Hallonsten, social scientists have a "responsibility to critically analyse issues of this sort, not only to satisfy academic interests but also as a public service" (ibid). 


\section{Accounting the Future}

builds on an assertion about future statements as "doing something", which, I have argued in the previous section of this chapter, further builds on un-interrogated assumptions concerning the accountability of such statements. In this regard, we may problematise the argument that jointly deliberating on futures, say, through public debate, will make a difference to the particular paths technologies take. We can ask, for example, what prevents such debates from being "just debates", and the alternative futures so generated, "just alternative futures", "merely alternative imaginations", and so on? For Michael (2017), as I elaborate next, an alternative way to "doing something" begins with the ordinary, mundane practices of everyday life.

\subsubsection{Big Futures, Little Futures}

Michael (2017) argues that an analytical distinction can be made, in a preliminary way, between "big futures" - namely, "those futures that imply very substantial, qualitative changes (e.g. some sort of epochal 'break'), that are widespread and farreaching, whose spatio-temporal horizons are relatively large-scale" - and "little futures", i.e. futures that entail "much smaller, more circumscribed changes, whose impact describes a relatively tighter spatio-temporal horizon" (p 510). In particular, he uses the term "little futures" to connote "the local unfolding of everyday life" and to point to "the processes of emergence that are attached to mundane social (and technological) processes and practices" (ibid). Michael asks: "Given the sense of a panoply of 'big futures', how are 'little futures' to be accounted for? How do we discuss everyday processes of emergence in relation to the seeming parade of grand social transformations?" (ibid). Michael points to a tendency in contemporary society (but also in social science) to privilege "grand futures", particularly those of traditional actors - such as the media, policy-makers, and industry analysts, while marginalizing the mundane, ordinary practices involved in futuring, the daily, routine and local work of say scientists and technicians and "their" futures.

Michael suggests that one way to answer such questions is to consider mundane technologies and practices as "the 'media' of big futures" ( $p$ 516). Thus, drawing on Lefebvre (1947), he argues that even a woman buying a bag of sugar can disclose not only such things as her class background or the "state of the markets" but also "the sum total of capitalist society, the nation and its history" as well as point to "the big future immanent in these" (ibid). And thinking with Shove (2003), who analyses everyday practices of cleanliness and comfort that entail use of such technologies as shower heads, heating appliances, washing machines, and so on, Michael argues: "these mundane technologies can be critically regarded as contributing to all manner of environmental problems" ( $p$ 516). In these accounts, according to Michael, the 
critique of everyday life reveals the "big futures" that attach to the consumption of, variously, sugar and water. Still, in these accounts, according to him, the mundane is represented as a mere illustration of a "big future", respectively Marxian and environmentalist. Michael proposes that, "while we can use a mundane technology - and the little future of its everyday use - as a route to capturing [...] big futures, we can also attend to the potential for the little future of everyday technologies to yield (as opposed to exemplify) big futures" ( $\mathrm{p} 516$ ).

Michael proposes a "speculative analytic" for exploring such potential. In particular, he discusses wheeled luggage. The everyday use of wheeled luggage implies, according to him, new forms of collective adaptation characterized by new distributions of attention and patterns of bodily movement and interaction. For example, the design of two-wheeled luggage makes necessary that the traveller frequently glances over the shoulder to check that it is not getting in the way of other travellers' legs as he or she pulls it. At the same time, backward glancing means that the traveller pays less attention to what is ahead, increasing the possibility of tripping over other travellers' luggage. Michael takes this case as an opportunity to speculate on how this "little future" of wheeled luggage (i.e. of accomplishing unobtrusive pulling of the luggage) can be seen as constituting "an emergent big future". Thus, he says, the researcher can "cultivate a sensibility attuned to the possibilities immanent to the use of wheeled luggage" ( $p$ 518). The researchers, following Michael, can do this experimentally, for instance, by re-designing the technology (in this case, the wheeled luggage) to make its features and functions appear ambiguous, playful, and opaque. The purpose of doing this, as Michael puts it, is "to lure their users into exploring the potentialities that inhere in particular situations" (p 519). Michael draws a list of tentative "re-designs" of wheeled luggage for accomplishing such a purpose; for example:

Design luggage that communicates or 'talks' to other luggage: within a certain compass, proximity leads luggage to verbally greet other luggage, or otherwise engage in more or less nonsensical conversations; (p 519)

Have publicly visible screens built into wheeled luggage that display [...] the traveller's stress or happiness through, for instance, emojis (emotions might also be conveyed through biometric 'bodywork' of the luggage that can visually pulse thus showing the traveller's heart rate). (p 519)

According to Michael, should any of these "little futures" of wheeled luggage-use "cohere" or generalize across sites and situations, we can speculatively map possible 


\section{Accounting the Future}

"big futures" - for example that of "technosociality"; namely, a future in which mundane technologies such as wheeled luggage constitute a socio-material opportunity for sharing travellers' common embodied experiences.

Two features of this account bear on my research question about accountable futures. Firstly, Michael sensitises us to the ordinary, mundane practices of future-making, what he calls the "little futures" of everyday life. And secondly, he points out, in a way that the other scholars examined here do not, that everyday life can be seen as a route to "big futures". This invites the important question of how "little" and "big futures" relate with one another. For example, should we see "big futures" as merely external (mis)representations of a differently-oriented, small world of everyday, ordinary "little futures"? Or, should we see "big futures" as the emerging (perhaps unintended) products of pursuing "little futures"? For Michael, yielding "big futures" represents a potential in the pursuit of "little futures". This, however, does not help us understand the role and importance of the accountability practices involved. Namely, how are "little futures" accountably accomplished as (in relation, pertaining or not pertaining to) "big futures"? That is to ask: How are ordinary, mundane practices achieved so as to be observable-reportable as future-making?

\subsection{Accountability in Action}

Ethnomethodology has developed the notion of "accountability" to identify members' methods of accomplishing the orderliness and sense of local processes. Members themselves and for themselves constitute the "observability and reportability" of what has happened or is going on, in how they take it up as a matter for anyone to find and recognize (Smith 1987). According to Lynch (1993), the accountable display of social order is not produced by a cognitive schema, a set of beliefs, or a society in the mind. Instead, it is identical with the concerted order of driving in traffic, the recognizable and routine orders of moves in a game, and the visible order of service provided by the evident line-up of bodies in a queue. Lynch decomposes the concept of accountability, as used in ethnomethodology, into a set of proposals: 1) "social activities are orderly"; 2) "this orderliness is observable"; 3) "this observable orderliness is ordinary"; 4) "this ordinarily observable orderliness is oriented"; 5) "this orientedly ordinary observable orderliness is rational"; and 5) "this rationally oriented ordinary observable orderliness is describable" (pp 14-15; original emphases). 
We can think through these proposals by way of example. People walking on the streets is evidently an orderly, non-random, social activity. Its orderliness is visible to an external observer, say, in seeing that people do not go about constantly bumping into one another, but also to the people walking on the streets. This activity also is ordinary, in that (say) it does not require special expertise to see it. Anyone who knows how to participate in the activity can appreciate its features, and recognise it in this way as that activity (as different from, say, a street crowd striking). The activity also is oriented and rational. A mere glance provides for seeing that people will turn left or right, or not, or that they will bump into each other. Finally, walking on the streets is describable and instructable - for example, to young children, learning how to walk on the streets - and thus is reproducible. Understood in this way, according to Lynch (2000), accountability is a "ubiquitous and unremarkable" feature of all social action (p 32). It is akin, he says, to Latour's (1988) "infrareflexivity" - namely, the cross-referential, semiotic linkages that proliferate within and between texts - "except that it refers not to networks of semiotic entities but to proto-semiotic practices and local interactions through which signs, objects and signed-objects achieve identity and sensibility" (p 33).

With respect to ethnomethodological studies of accountability, Neyland and Woolgar (2002) argue: "it is not always clear whether accountability involves the mere 'recognisability' of action [...] or whether it also involves sanctionable consequences (for example as a result of the deficiency of your action you will be penalised)" (p 265). These, they argue, are "two analytically distinct senses" of accountability and ask: "Can some kinds of practical action be understood as directed to specific audiences with particular kinds of accountability relationship in mind? Can some practical actions be more accountable than others, and for whom?" (ibid) In the ethnomethodological sense of accountability, according to Neyland and Woolgar (2002) and Woolgar and Neyland (2013), it is assumed that some kind of audience is always implicated. Instead of assuming the accountability of action, they suggest looking at accountability in action. Namely, as Neyland and Woolgar (2002) put it, the idea is to look at the ways in which "the performance of community establishes the moral order that can be seen to provide the reference point for the mess of flows and connections" ( $p$ 272). To whom, then, and how, does the future make sense and in what ways? I.e.: To what extent does futurity, as social practice, have/intend an audience? What is the relationship between futurity and community performance? How are accountability relations assigned, distributed, and assumed in organising communities around (or through) particular futures? How are 


\section{Accounting the Future}

accountability relations accomplished through discourses about the future in the context of ESS?

\subsection{Conclusion}

The aim of this chapter was to examine the extent to which the existing social science literature helps us answer the question of the ways in which futures can be seen as accountable. My critical assessment of the existing literature suggests that, in examining this question, we need to look at the practices performing futurity. Rather than representations, to be examined for their accuracy, various scholars point out that futures can productively be understood as practical performances. When looking at futures, in other words, we should look at the forms of action and agency constituting senses of the future in the present. The existing literature also sensitises us to the "informal" ways - endogenous to particular examined settings, of performing the future. It suggests that, in examining how futures are done, we should not look solely into such "formal" practices as, say, foresight. Finally, and relatedly, the literature invites us to consider the role of the "little futures" of everyday, local practices which, as is suggested, tends to be disregarded - in public discourses of the future prominently, but also in the social science literature engaging with the topic.

Simultaneously, however, and while it appeals to a sense of the future as ordinary shared and familiar - the reviewed literature tells us rather little about the practices performing and maintaining that sense, the discursive processes enacting the future as the particular presence we all know and can relate to in the dealings constituting our everyday life - reading newspapers, responding to calls, taking walks, or fingerrubbing silicon plates at work. Few of the reviewed scholars make the claim that "statements about the future" play a crucial role in technological and scientific development, for instance coordination, yet this claim, as I showed in this chapter, builds on non-specified assumptions as to the accountability of such statements. The terminology the reviewed scholars use to characterise such statements was identified as slippery. Using the terms "promises", "expectations", "visions", "imaginations", etc., interchangeably and as mere semantic synonyms misses their specificity as phenomena produced and consumed in the real world. Finally, while indicating that the future is not only imagined but also achieved in and through ordinary, mundane (technical and scientific) practices, the literature explains little about how such practices can be seen as future-making; in other words, how ordinary practices are performed so as to count as making the future. 
This literature review shows that the following main research questions need to be addressed:

1) What accountability relations can be seen to provide for sustaining our sense of familiarity with the future?

2) How do performances of futurity, and of accountability relations as part of it, accomplish a sense of communities as coordinated?

3) What accountability relations provide for making assertions about the future (sound, seem, read as) sensible?

4) In what ways, and to what extent, can ordinary, mundane practices, the local work of scientists and technicians, be seen as future-making?

In order to unpack these questions, the thesis is organised as follows. Chapter 4 looks at accounts of ESS in the local Swedish newspaper Sydsvenskan to examine how these accounts provide for generating and sustaining Sydsvenskan's readers' sense of familiarity with the future. Chapter 5 looks at accounts of expectations generated in interview and other settings to examine how performances of accountability relations can be seen as achieving ESS communities as coordinated. In chapter 6, I use documentary and interview materials from "future walks" and a pre-organised visit to the ESS construction site to examine the ways in which accountability relations are performed in such settings and how these make statements about the future sensible. Finally, chapter 7 looks at practices of thin film coating and doing measuring of thickness at the ESS Detector Coatings Workshop, to examine the ways and extent to which mundane, ordinary practices can be seen as future-making. First, however, we need to consider in the next chapter the work of methods and the issue of access. 


\section{Doing Ethnography of Futurity at ESS}

The aim of this thesis was to examine how accountability relations are performed through discourses about the future in the context of ESS. Following Griffith and Smith (1987), I understand discourse as "an organisation of relations among people participating in a conversation mediated by written and printed materials" (p 100). Conceptualised in this way, the term "discourse" does not just refer to the texts, documents, or broadly the accounts, of this conversation and their production alone, but also to the ways in which "people organise their activities in relationship to them" (ibid). ${ }^{16}$ With this in mind, my overall research strategy was to examine accounts of futurity as they were articulated and used in the ESS context, i.e. to examine how (the practices through which) people, in the variety of settings constituting "the ESS context", wrote, read, heard, and saw the future.

My approach to examining this was ethnographic. In a traditional sense, the term "ethnography" denotes a prolonged immersion of an outside observer in the daily activities of a (geographically delimited) tribe. My study, as shall become apparent, contains some elements of such immersion. However, with "ethnography", I primarily seek to capture a different aspect of my study; namely, the importance of bracketing our familiarity with the examined object. Following Latour and Woolgar

\footnotetext{
16 This approach is different from Fairclough's (1992) critical discourse analysis. Like in Smith (1974, 1983, 1987, 1990, 2001, 2006), in Fairclough "discourse" - i.e. the processes through which texts are produced (created) and consumed (received and interpreted) - is seen as an important form of social practice which performs worlds, including social identities and relations. However, in contrast to Smith, who suggests that all social practices are completely discursive, Fairclough insists that "discourse", which concept he reserves for text, talk, and other semiological systems, is but one among many other aspects of social practice in a dialectical relationship with each other. It follows that not all social phenomena have linguistic/discursive character. For example, shopping involves both verbal interaction with a salesperson and some kind of economic transaction; in other words, "talking" and "paying" are two moments, or actions, articulated together in the practice of shopping. In Fairclough's perspective, these two moments, or actions, are seen as following fundamentally different logics, respectively a linguistic/discursive and economic/non-discursive one, and therefore cannot be analysed using the same set of theories and methodological techniques. Rather, in Fairclough's perspective, "talking" will be analysed using linguistic analytical tools, thus relying on language theories, while "paying" will be subjected to economic analysis of, say, the exchange of money for goods, drawing on economic theory.
} 


\section{Accounting the Future}

(1979), I regard it as instructive to apprehend as "strange" those aspects of activity which are (all too) readily taken for granted. How do futures make sense? What are the processes underlying the sense-making? Not merely referring to the process of gathering data on-site, then, I understand "ethnography" as a commitment to an investigation and explication of people's actual practices and social relations (Smith 1974, 1983, 1987, 1990, 2001, 2006).

In this chapter, I present reflections on how I did the ethnography, the methods of documents review, interviewing, and participant observation I used in the process, the empirical material I collected in this way, and the framework of "institutional ethnography" which, following Smith (1987, 1990, 2006), I used when analysing this material. Especially at the start of fieldwork, gaining access to ESS was a key concern, but also, crucially, as I show in the next section, a source of insight into accountability as performed in this context.

\subsection{Gaining Access to ESS}

Fellow social science scholars who had already had the opportunity to study ESS ethnographically provided what I want to call "living maps" of this field. I was talking to one in 2015, Leanna Svensson (pseudonym), who, listening to my concerns about access, advised that I just sent emails directly to the people at ESS. Her advice can be seen as performing a possible procedure for "gaining access to ESS". We can think of this procedure as involving: 1) finding an ESS contact (i.e. a name and address, which are publicly available, or at least available to me at this point); 2) writing up an email to that person, and this involves inter alia orienting to assumptions as to what might count as an "access-gaining email" (e.g. describing the prospective investigation in a way that the person, reading the email, might find interesting, or relevant, or useful, as opposed to just saying "can I come and study you?"); and 3) adhering to accepted conventions of email communication, which involves, at the very least, sending an email and waiting for a reply. I decided to follow my fellow's advice and tried to gain access to ESS in this way, through emails.

The ESS website was useful to this end, as it made available participant profiles, with names and contact details, statements of scientific career and interest, as well as preliminary specifications of how they or their work figured formally in the ESS organisation. In the emails, I would specify my STS background and institutional affiliation, the specific interests of the ethnography, as well as how these aligned to 
the prospective informant's. ${ }^{17}$ I did not receive many responses and, where I did, the response typically was negative. "I do not wish to participate in this study" made frequent reading during this time. Some of the ESS correspondents used the emails as occasions to deliberate on the ethnography's disciplinary framing and to propose then a more appropriate starting point. One wrote, for instance: "I would suggest that you contact Leanna Svensson (pseudonym), who is in what I believe is your field of study" (email communication, 2016 October 5). Leanna, this correspondent noted, had, on a variety of occasions, studied "us at ESS" and had a "good overview". They were "happy to help", but she thought I should "start with her".

The correspondent seemed to be introducing a main ethnographic figure - the gatekeeper. According to Stocking and Chinnery (1982), "there have always been gatekeepers to the field - 'men on the spot!' whose particular positions in the field and practical regional ethnographic knowledge enabled them to oversee the aspiring anthropologist's entrance on a particular ethnographic mise-en-scène" (p 3). In designating a gatekeeper, the email is supposed to be read as helpful. I am referred to Leanna, who is "in my field" (thus is relatable), who has studied "us at ESS" and has a "good overview" of the organisation, and who therefore constitutes a good starting point for my entrance to ESS. This is not how I read the email. For me, it was a way of keeping me out of ESS without rejecting entrance. It did this by deferring accountability. Rather than the correspondent, the email performed Leanna as accountable for knowing about gaining ethnographic access to ESS, for example as a possibility (or an impossibility), or as a practicality (i.e. what it takes); for knowing, moreover, what can (and cannot) be accessed ethnographically, in what ways and to what extent. Not simply introducing another obstacle - or better put, another step - on my way to gaining access to ESS, we can understand the email as performing relations of accountability and thereby an ESS organisation to follow (and adhere to) as the process of "gaining access to ESS".

The ethnography was becoming stuck in a loop of continuous referrals back and forth between, on the one hand, ESS people, who thought that I should begin with

${ }^{17}$ It turns out that the term "Science and Technology Studies" rings the wrong bells with outsiders. In 2016, emailing one "instrument scientist" at ESS about the possibility of interview concerning his experience as "instrument concept" developer and proposer, he replied kindly: his "instrument concept" was already under construction and the team behind it complete. The team, he said, had discussed my "application" and, unfortunately, had come to the conclusion that they could not afford "an additional scientist for this project" (email communication, 2016 October 12). He noted that, in the future, the team might "need a second scientist" - suggesting I was welcome to apply then - and wished me good luck in my "further search for a job position". 


\section{Accounting the Future}

colleagues, and on the other hand, fellow social science scholars, who thought that I should begin with ESS people. Stuck in this loop, I was focusing my attention on ESS as documented in the local media, in particular, in Sydsvenskan (see below, $\mathrm{p}$ 40). I was also looking at publicly available ESS-internal documentation. Frequently, I was visiting the ESS website and Facebook page, reading technical and progress reports, various informative posts, letters concerning events, calls for proposals, as well as descriptions of ESS, its history, people and their role in it as an organisation, as a way of gaining a sense of ESS, preliminarily, before actually doing fieldwork there. Just as I was engaging deeper with ESS as documented, however, I suffered a sense in which ESS was not yet real to me. The documents referred to various events happening out there, people and activities, of which I was not a part. Reading through them I could gain a particular - "edited" - sense of what happened, but as a putative ethnography I needed to witness the happening personally. In trying to study ESS ethnographically, I needed to become part of those events, people, and activities.

In 2015, I participated in a multidisciplinary workshop entitled Exploring New Big Science. The workshop was happening on the premises of Lund University, in Lund, and mobilised a variety of scholars, Swedish and international, as well as representatives of the ESS and MAX IV ${ }^{18}$ future facilities as audience. I took this workshop as opportunity to present my initial thoughts on using ESS as a case for examining accountability relations, but also, in parallel to this, as an occasion for doing fieldwork. I wanted to understand how futurity was being performed in such settings as the Big Science workshop. One member of the audience, a Historian of Ideas, raised his hand in the discussions part, after my presentation. He suggested that I picked the wrong time to study the future. The future, according to him, was interesting as a topic, but some time ago, when "nobody" knew whether or not ESS would happen. But now, "they" were building it. The history of how "we" got to that point was, in his view, the more interesting thing to investigate. Just as I thought that, finally, I was accessing ESS, there it was - this well-meaning Historian, and his reflection, keeping me out of ESS and its futures. Not only was this not the place to study ESS futures, but also neither was it the time. I should do something else.

\footnotetext{
${ }^{18}$ According to Rekers and Sandell (2016), MAX IV is "a synchrotron radiation facility, a Swedish laboratory where X-rays are used to investigate the properties of materials" (p 10). They argue that "construction work began in 2010, and the facility will start to operate in June 2016 and be fully operational in 2026" (p 11). As an organization, argue Rekers and Sandell, "the MAX IV laboratory has been part of the research milieu in Lund for over 25 years and falls within the organizational structure of Lund University" (ibid).
} 
What I have presented here are not simply methodological problems of gaining access to a social organisation to study it. The problems - of being stuck, of missing the interesting things, of always being elsewhere and else-when - derive from a social organisation that I encountered when trying to engage with ESS through its people, and are particular to it. In this regard, it is relevant to mention Moerman's (1965) insightful paper "Who are the Lue?" There, Moerman elaborates on the problematic of giving an adequate answer to the question "Whom did you study in the field?" Moerman says, in the case of the Lue: "The green sarong which sometimes distinguishes the Khyn from their Lue neighbours may elsewhere characterise the Lue. [...] Among the traits which distinguish the Lue in Chiengkham are internal recessed fireplaces which are also built by lowland Karen, threshing techniques shared with the Yuan of Wanglung, a pattern of dibbling which is actually used quite widely, a jacket of the sort worn by the Lahu in Burma, and a sarong which, when sold to the Kha, becomes the traditional skirt of the hill people." ( $p$ 1218). On the surface, Moerman simply seems to suggest that it is impossible to identify "the Lue" in terms of the uniqueness of their material culture. However, he makes a different point; that this confusion of who wears what, who uses what, constitutes "the Lue" as the ethnographer knows them. This is different from Law (2007), who argues that, far from faithfully reporting the dynamics of a stable, independent reality out there, methods are intimately involved in the production and delineation of this reality. My fieldwork experience suggests a somewhat opposite interpretation: that my various interactions with ESS people acheived a particular ESS social organisation as the method of "gaining access" to this organisation. Anything external to this organisation - that is, any form of engagement with ESS that did not adhere to it - simply did not count as doing "gaining access to ESS". In this connection, it is relevant to reflect on the notion of being stuck.

Talking with Ericka Johnson, my second $\mathrm{PhD}$ supervisor, about being stuck, she said: "Ivanche, just take the train and go to Lund!" She was suggesting that, principally, I was not stuck. Indeed, I could take the train, go to Lund, talk with the people on the streets about ESS and its futures, and get interesting insights into ESS, for example, as an object of the locals' imagination. Nevertheless, at the point when Ericka gave me that encouraging advice, I could not even begin to imagine that just taking the train to Lund and talking with people on the streets about ESS, could constitute a possible way of gaining access to ESS. I reacted: "How do you mean 'just go there'? I cannot do that!" I could not do that because, by this point, ESS had become a particular formal organisation for me, and the way to get to this organisation was also formal. I had internalised by then a procedure for "gaining access to ESS" through 


\section{Accounting the Future}

emailing, which involved finding contacts, writing and sending emails, waiting for replies, and replying to those replies, and doing this over and over again until somebody replied "Yes. We are very excited to have you studying us. When can you come?" For me in other words, the ostensibly simple thing of just taking the train and going to Lund had to be sanctioned by (persons at) ESS before being done. So, just taking the train and talking to the people I met in Lund, on the streets, did not count as "gaining access to ESS".

Ultimately, my way out of being stuck involved finding a contact that could follow that procedure on my behalf. This was Brandon Dickson (pseudonym).

Brandon is a Senior Strategist and my former employer at the Innovation Department of Skåne's Regional Council. I conducted an applied anthropology project for them in 2012, as part of my Master's studies at Lund University. The organisation wanted ethnographic insight into how youth of the region did innovation - in particular, what "we" could do to facilitate and to increase it towards (strategically) producing a next generation of regional entrepreneurs. As part of that project, I would spend time interacting with young people, attending their creative activities at schools, in youth organisations, on the streets, and so on. At times, I would do office work at the Region's premises, using break times and chance hallway meetings as occasions informally to communicate my findings to the civil servants there. It is in this context that I first learned about "ESS in Lund" as a vision. Some talked of ESS as the region's "springboard for future growth" - a local happening that could (and with the proper supporting structure in place, would) make Skåne Europe's most innovative region. I could find similar renderings in the organisation's written material. Thus, a 2009 Region Skåne report envisions a year 2030 when "everybody is discussing the story" of how ESS and MAX IV have successfully transformed Skåne into a "science centre" renowned for its "intellectual and imaginative tourism" (p 7). It writes, the question 2030's "everybody" is asking is: "How could one get so much more than 'just research' from two facilities?" (ibid). ${ }^{19}$

\footnotetext{
${ }^{19}$ Brandon believed that youth was of central significance to achieving such a future. It was important for him that youth saw a future for themselves with ESS and MAX IV in it - and not as "just researchers" there, but also, more importantly, as "entrepreneurs" and "innovators". Note that Brandon, and other civil servants like him, took for granted that the future ESS and MAX IV facilities would "do great science" and produce "major", that is Nobel Prize-winning scientific achievements. The crucial issue, they thought, was transforming that science and those achievements into "great innovations". A major step to be taken then was, to inventory the current perceptions among youth concerning science (e.g. what they thought science was and what they
} 
Seeing a potential access to ESS through Brandon, in the spring of 2016, I emailed him and arranged a meeting. This would take place in Malmö, in a bar at the city's Central Station. When we met, Brandon informed me that the Innovation Department no longer existed; he, and the others I knew there were now under a different subunit of Region Skåne. He also noted that, if I wanted to gain a proper insight into how ESS actually came about, the premises of Region Skåne were not that place. Others, according to him, could tell this "story" better. Brandon pulled out a pen and, on a coffee napkin, began assembling a short list of possible interview contacts. They were all, he said, his "very good friends" - thereby providing a sense of warranty to their realisation as "contacts", i.e. that they could make themselves available - and, furthermore, they were all of them "in this from the very beginning" and so, of a certain intimate understanding about ESS. If anyone willingly could tell me anything - interesting, important, relevant, not-yet said, and so on - about how ESS actually came about (as well as where it was going), it would be these few key individuals. Consider that, at the time of the meeting, "stories" involving ESS were already unfolding, e.g. in local newspapers such as Sydsvenskan. The study contacts, Brandon thought, must be able to report a fresh intelligence on the subject matter. This is the list ${ }^{20}$ as Brandon presented it in a follow-up email (2016 April 22):

Arya Lindqvist, senior advisor ESS, former Governor of Skåne

Kevin Karlsson, former minister for research and education, former head negotiator for ESS

Tom Larsson, former minister for higher education, senior advisor at Svenskt Näringsliv

Thomas Persson, CEO Invest in Skåne

Jon Linden, process leader - "Smart Materials"

Robert Lundberg, former Chancellor Lund University

thought they could do with it) and to these then add innovation and entrepreneurship as possibilities of the future. To this end, Region Skåne commissioned, through Brandon, a number of ethnographic research projects - culminating with my own, and three others preceding it. Each of these projects generated presentations and reports in different forms as key deliverables. Some of these, Brandon told me, were "best-sellers" - that is, well read at Region Skåne and about - and allegedly positively had intervened in how regional policies addressed these issues.

${ }^{20}$ All personal names on the list are pseudonyms. 


\section{Accounting the Future}

Samwell Nilsson, professor at Lund University, former project manager for one of the projects in TITA (how do businesses view ESS)

Denis Abrahamson, professor at Lund University on Nano materials (in TITA and "Smart Materials" from the beginning)

Brandon concluded the list open-endedly, with the following note:

More business people you will get from Arya and Jon (possibly Thomas also), international people from Arya and Thomas, researchers from Denis Abrahamson. You will get names for Maxlab IV from Arya, she can also help with contacts at other facilities in Europe (to contrast and check).

The list can be thought of in terms of a snowball strategy for doing fieldwork. A first informant - Brandon, is being approached for his connection to ESS. Brandon then points to others, as well as suggests different types of informants (e.g. "business people" and "researchers") that these others might provide upon request. In contrast to a prevalent understanding of snowballing as instrumental, a mere "technical" matter, Noy (2007) understands snowballing as relying on and partaking in "the dynamics of natural and organic social networks" (p 329). According to him, "at stake is not only a flowchart which consists of individuals and their names, but nexuses of social interactions where social agents and structures are being reproduced" ( $p$ 337). Following Noy, we can read the list above as performing a sense of where, or rather with whom, knowledge about ESS and the future in this context lies, i.e. a sense of the social spatiality of futurity in this context, as well as a sense of that knowledge as something discoverable through interviews (as opposed to, say, foresight methods of prediction). Not just listing potential interviewees, the list also performs knowledgeable agents or, at the very least, a sense of how or why the listed persons might be seen as knowing something about ESS and the future - as a former Governor of Skåne, as a former head negotiator, and so on, generally in being "in this from the very beginning". In short, the list performs a social organisation to follow through doing interviews as "gaining access to ESS and its futures". A story of ESS and its futures may be heard elsewhere, by others, but might be best recovered from that social organisation.

What, then, does my experience of gaining access to ESS tell us about futures and accountability? Looking at performances of accountability relations, we can examine whose versions of the future (or how the future is done) matter, and the ways in which they do or do not. We can think, for example, of Brandon's characterisation of the listed informants as being "in this from the beginning" as constituting a kind of 
political right over accounting for the future. This insight is important as it contrasts with the idea that simple accessibility to material and rhetorical resources determines actors' power over defining what counts as the future (Brown et al 2000). The constituted right can be seen as providing for determining the future as we, social scientists for example, know it as much as the actors' relative accessibility to material and rhetorical resources. ${ }^{21}$

\subsection{How to Study Futurity as Practice}

The overall aim of this thesis was to examine accountability relations as performed through discourses about the future in the context of ESS. As indicated at the start of this chapter, following Smith (1974, 1983, 1987, 1990, 2001, 2006), I understand "discourse" as practical activities and specifically, as activities conducted through and in relation to accounts in various forms. This has important implications for my choice, and framing, of the research methods I used to do the ethnography. To study futurity ethnographically in the ESS context, I used documents, interviews, and participant observation. Rather than as windows to futurity out there, to informants' implicit, personal or shared understandings of what the future was, is, or will be, I understand documents, interviews, and participant observation, as providing occasions for performing futurity and, as part of that, for performing accountability relations.

To that extent, I share a methodological ground with Atkinson and Coffey (2011), who argue: "documents are not neutral, transparent reflections of organisational or occupational life" ( $\mathrm{p}$ 77). In their view, documents are better understood as actively constructing "the very organisations they purport to describe" (ibid). Similarly, with regards to interviews, Atkinson (2015) argues "we cannot treat interview data as unproblematic forms of representation or reconstruction [...] as sources of information about informants' personal 'experience"' (p 95). Instead, according to him, "we need to appreciate that interviews are occasions in which are enacted particular kinds of narratives, and in which 'informants' construct themselves and others as particular kinds of moral agents" (p 96). Finally, participant observation is not merely a way of getting a first-hand sense of ESS practices, but also, as I see it, an occasion for the documentation of accounting futurity as part of those practices.

In the following sections, I present the material the ethnography produced.

${ }^{21}$ I return to this point in chapter 8. 


\section{Accounting the Future}

\subsubsection{Examining Futurity as Documented}

One question this thesis addressed was how futurity was being used in the processes of (de)forming, (re)organising, and (dis)mantling relationships between different entities through documents as texts. More specifically, my objective was to understand accountability relations as organised publicly. This means that, when it came to documents, I was focusing mostly on publicly available documents.

A key setting in the broader ESS context for investigating "documentary realities" (Smith 1974, 1983, 1990, 2001) is the daily newspaper Sydsvenskan. The newspaper is primarily distributed in Sweden's southernmost region Skåne. There are important reasons to focus on this setting, if only for the fact that Sydsvenskan has published more on ESS than any other local or national Swedish newspaper. For example, comparing Sydsvenskan to other dailies in Sweden - namely Dagens Nyheter and Svenska Dagbladet - Linné (2013) points out that, in the twelve years period between 2000 and 2011, during which Sydsvenskan had published a total of 443 articles with ESS as the subject matter, the other Swedish dailies together had published 36 merely, none of which, as Linné discovers, had made the front page in either paper. It follows for Linné that, in Sweden at least, and while promoted as a project of "national importance", ESS is foremost a "local concern".

More importantly, Sydsvenskan constitutes a casual meeting point between ESS and the local public-as-readers. Reading or thinking about ESS in and through Sydsvenskan constitutes a prominent way in which the public, local readers of this newspaper, can relate to ESS in particular ways. Sydsvenskan's texts constitute a key medium for organizing such a public capacity. ${ }^{22}$ We can think of Sydsvenskan's texts as making-known as "something" what, initially and primarily, was for many local constituencies simply and merely "that thing they are building next to the

\footnotetext{
${ }^{22}$ As it will become apparent in chapter 4, pre-organised meetings between ESS and the general public constitute another way in which these two parties can relate to one another. It is relevant to note, however, that, as Kaijser (2016) finds, these meetings are mostly attended by publics with special interest in ESS, for example environmental groups expressing concerns about the facility and the ways in which it might affect the surrounding nature and people. Thus, while the meetings are supposed to bring together ESS and the general public, for the most part these meetings attract specific publics, i.e. publics with special interests. For me, who has not attended them, and for the general public - of say, locals who do not necessarily have special interests in ESS, not so much as to attend the meetings - Sydsvenskan is like a window to those meetings, producing various accounts of their attendance, participating actors, dynamics, overall sense, including accounts of what particular participants have said or commented, how, and so on. Chapter 4 presents analysis of some such accounts.
} 
highway". ${ }^{23}$ These texts are interesting to examine, then, not just because they have covered ESS significantly, but because, in so doing, and perhaps in significant ways, they have contributed to shaping ESS locally as a matter of public concern.

To gain access to Sydsvenskan's accounts, I used the electronic media archive of Linköping University, Mediaverket. Originally, the accounts were in Swedish. My analyses were of the accounts as translated in English. The translations are my own. This means that the analyses of Sydsvenskan's texts, as done and presented in this thesis, interpret what already is an interpretation of the Swedish texts into English. Certainly, the translations have been checked for their adequacy by consulting with Swedish-speaking friends and acquaintances, specifically for the extent to which the translated accounts and the original sound equivalent. Nevertheless, some nuances were inevitably lost, others added, in and through the process of translation. The English words in my translations do not merely represent the Swedish accounts behind them, but also perform those accounts in particular ways: bringing in layers of understanding that the original accounts might not provide. If the analyses of Sydsvenskan's texts were done by a Swedish native, they might have recovered from them other senses, not available to me, given I am not a native Swedish-speaker and given my limitations of how well I manage the Swedish language. My analyses of Sydsvenskan's texts, therefore, should be read as analyses of texts as they were available to me - for how they were making ESS and futurity in this context available to $\mathrm{me}-$ as their reader.

Of course, language is not simply a methodological issue. This became apparent in relation to another set of documents I used in this thesis, pertaining to the "Future Walk through Brunnshög". This is a walk-route, which, organised by Lund City Council according to a do-it-yourself principle, takes different groups of walkers to and across Lund's north-east, where ESS is being built today. A set of documents, constitutive of the "Future Walk", comes in the form of signposts (see Figure 3, p

${ }^{23}$ I am mobilising this characterisation from my interview with Samwell Nilsson (pseudonym; 2016 May 10), a professor in social science at Lund University. In this capacity, he participated in a VINNOVA-funded project, TITA, seeking, among other objectives, to generate different ways of making ESS relatable for the citizens of Lund. In this connection, according to him, the problem was not that ESS was "unknown" to Lund's citizens. He argues that the public in fact knew ESS, but in a particular way - namely, as "that thing they are building next to the highway" and so, as something which was just noticeable, simply out there. The problem, according to Samwell, concerned the possibility that ESS ultimately will end up being "just like the head-office of Sony Eriksson" situated in the vicinity of where ESS is being built now, something that citizens "just pass by". The somethingness of ESS will be addressed as a topic in Chapter 6. Here, I am using Samwell's characterisation as a basis to frame Sydsvenskan involvement in the public discourse. 


\section{Accounting the Future}

124). In articulating futures, these signposts: 1) make texts available in Swedish and in English; 2) use text boxes as textual devices to articulate Swedish and English separately; and 3) neatly position the text boxes next to one another - one on top of the other. In this way, the signposts perform a sense in which the Swedish and English texts are equivalent articulations of the same thing that the signpost conveys to the walkers. That strategy of textually performing the future is repeated throughout the "Future Walk", with the important implication that it provides for disregarding the nuances (if any) - no matter how subtle, relevant or irrelevant - that the words of either language bring into the articulation. This, in turn, accomplishes the sense that, regardless of who it is that does the walking, the signposts provide for them the same sense as that other walkers have gained reading the other text box. They are all connected together in relation to having done the walk, and having done the same reading that others have on other occasions and other times. Not merely a methodological problem, then, language seems to have a role in the performance of communities around the future in this context.

Some of the documents I analysed were written exclusively in English. One of these was the 2014/2015 Call "Proposing Instruments for ESS". I discovered it online, as a webpage, while surveying the ESS website in 2015. Not simply a vehicle for communicating ESS to different (external and internal) publics, I read this website as a key medium for organising work at ESS. The 2014/2015 Call for "instrument concept" proposals was especially interesting in this regard, since, following the 2012/2013 and 2013/2014 Call rounds, it was "the last" one to consider instruments for the initial suite of sixteen. This was interesting as it performed the Call as a last chance for becoming a member of ESS by means of proposing "instrument concepts" to be built in the future facility. And, as I show in Chapter 5, this turned out to be of particular importance for some proposers of "instrument concepts". Doubleday (2007) has examined calls for proposals in the context of nanotechnology vis-à-vis accountability. According to him, calls for proposals can be read as displays of organisations' accountability to the state for public funds and to wider society for the social aspects of nanotechnology. Here, I analyse the 2014/2015 Call as a coordination device, and as such a device, for how it distributes accountability amongst the implicated actors. To what extent and in what ways can we consider this Call as an instance of community performance?

Few more documentary sources are important to note. In chapter 2, for example, I made reference to three anthologies constituting the existing body of social scientific studies of ESS. These were In Pursuit of Promise by Hallonsten (2012a), 
Legitimising ESS by Kaiserfeld and O'Dell (2013), and New Big Science in Focus by Rekers and Sandell (2016). There, I used these anthologies, not as ESS documents, but primarily as theoretical references. In the process of studying futurity at ESS, however, I oriented to these anthologies - not only, not simply, for how ESS was studied by academics, but also for the particular sense of ESS as a setting these anthologies were performing. Consider in this connection O'Dell (2013), who writes: "If you head out to conduct fieldwork and approach the actual site of the ESS, there is not a trace of Big Science to be seen anywhere." ( $p$ 69). This sentence is instructive of what prospective ethnographers, such as myself, will find when approaching "the actual site of the ESS". The point is similar to the advice I got while trying to figure out a way of studying scientific practices "at ESS" - that there was "nothing to see there" (see introductory chapter, p 1). O'Dell continues: "In the distance cranes, tractors and dump trucks can be seen frenetically working on the foundations of MAX IV, but at the ESS site one can only see the wheat growing. It is still an agricultural field." (p 70). To an important degree, this ethnographic description influenced my research process. For example, taking this description for granted, the future became a topic for me just as ESS the case to address it. Now, however, it is important to consider this description more closely and critically.

Notice the spatial designations in O'Dell's description. There, at "the actual site of the ESS", O'Dell could not see Big Science anywhere. There, he could only see the wheat growing. It still was an "agricultural field". While claiming ESS as not-yet existing, O'Dell's description performed the kind of "ESS", the kind of Big Science there, which was unexaminable by ethnographic fieldwork. In retrospect, I feel inclined to suggest that O'Dell, perhaps, looked for Big Science in the wrong place. Indeed, that ESS is somewhere - in a specific (imaginary or real) building, with a particular (planned or actual) location - and sometime - in a more or less specified future, after some stated date, say, on a timetable or otherwise - could be seen as a practical accomplishment; the upshot of activities working to situate "the ESS" spatially and temporally, to perform it as a spatially- and temporally-particular entity. But at the moment of reading O'Dell's description, I actually took "there" to mean anywhere, and "then" for the extended present. This and similar such descriptions in the anthologies framed my expectations of the field - of what I could find there, what I could take as a basis to rely on when entering the field - which, in turn, led me to some productive surprises (see chapter 6, pp 132-133).

More generally, we can consider the three indicated anthologies as working out the accountability of ESS in the particular settings in which these anthologies are being 


\section{Accounting the Future}

read. The titles of the anthologies themselves can be seen to do such work, for example, rendering ESS accountable as a "promise" (thus evoking a sense of stakeholders out there to whom something is being promised); as something that needs legitimation; as "new"; as "Big Science". In sum, these anthologies can be understood as ESS documents, constituting a sense of who can know what about ESS and its futures, and how.

I have used a range of other texts, including various ESS-related web-based articles and announcements, an informant diary, and email correspondences. Merz and Knorr Cetina (1997) used email exchanges between scientists to address "deconstruction" as a procedure for distributing the "hardness" of mathematical work. They characterise emails as a "device", but also, importantly, as a kind of workplace; a setting through which mathematical work gets done. While their paper does not address accountability relations explicitly, it demonstrates emails as a key medium for performing accountability as a dimension of solving mathematical problems together. Namely, the emails can be understood as a work-setting where "who is accountable for what", e.g. specific work tasks or writing the next email, gets determined. The email correspondences I have used, of course, are not the same as those Merz and Knorr Cetina analyse. While they focus on scientists' emails, as part of the scientists' daily life at work, the ones I use in this thesis constitute moments of fieldwork interaction between me and the (prospective) informants. The same can be said about the informant diary. That they do not represent natives' work exclusively, however, does not subtract from their value as empirical material for understanding accountability. As I take it following "institutional ethnography" (Smith 1974, 1983, 1987, 1990, 2001, 2006), the difference between these texts and the others described above is not the ethnographer's absence - for in each case I am implicated in the texts as a reader - but rather, that here, the ethnographer is made present as a particular figure, as the one for whom the text has been written in the case of the informant diary or as a correspondent in the case of the email correspondences. This provides for examining how accountability is performed (assigned, assumed, distributed) in relation to that figure. Chapter 6 exploits and builds on that provision.

\subsubsection{Examining Futurity through Interviews}

To gain a first-hand, detailed understanding of how accounts of the future are being generated, how accountabilities are being assigned and assumed in this process, we need interviews. Interviews provide a possibility for examining how informants perform relations of accountability as part of construing accounts of their personal 
experience with ESS. Proceeding from the idea that experience arises in relation to informants' standpoint at ESS as an organisation, and in order to gain a sense of accountability as performed by differently located individuals, I selected a diverse group of people - each involved with ESS in specific ways and to different extents. For example: from a Nobel Prize committee member, "taken" by ESS to prepare Lund University for using the possibilities that ESS will provide in the future, to a social science scholar at Lund University, mobilised by ESS to provide insights into the locals' "mindset" in making the facility relevant for them in the future.

I "targeted" specific interviewees on four occasions. One such interviewee was Eddard Jensen (pseudonym) - an "instrument scientist" at ESS and a proposer of ESTIA, one of the future ESS instruments. The second was Jaime Falk (pseudonym) - an architect by profession, civil servant at Lund City Council, and the designated guide for the "Future Walk". Interviewing them was important, as it provided me with the possibility to gain a sense of how insiders read the texts I met during my fieldwork - respectively the Call for Proposals and the documents of the "Future Walk". The third "targeted" interviewee was Brienne Jacobsen (pseudonym), at the time Head of the ESS Detector Coatings Workshop in Linköping. I met this name several times during my fieldwork, often in relation to a "success story" of how Brienne's work on helium-3 alternatives had "saved" ESS from a potential standstill. That is to say, the various references of Brienne I encountered (e.g. in interviews or in announcements) performed her as accountable for the future of ESS. I wanted to gain a sense of Brienne's own perspective on this. At the same time, I used the interview with her as an opportunity to negotiate the possibility of doing participant observation at the ESS Detector Coatings Workshop. Finally, the fourth "targeted" ESS interviewee was Brandon Dikson (pseudonym) - a strategist at the Regional Council of Skåne, whose input to the realisation of my research at ESS I have covered in the previous section of this chapter.

A few of my interviews, however, came about opportunistically, while doing participant observation in various ESS sites (see below). Thus, I have conducted an interview with Catelyn Hagen (pseudonym), a Science Communicator for ESS, whom I met while "shadowing" a business visit to the ESS construction site; Bran Karlsson (pseudonym), a neutron scientist from the Institut Laue-Langevin, France, whose boss had sent him to Linköping's Coatings Workshop to oversee the coating of their "blades"; and two "detector scientists", Aegon Jansson (pseudonym) and Aerys Jönsson (pseudonym), I met while doing participant observation at the ESS Detector Group in Lund. I did the remaining interviews upon informants' 


\section{Accounting the Future}

recommendations, responding to the question of: "With whom should I speak about the future as understood in the context of ESS?" In this way, I was referred to Samwell Nilsson (pseudonym), a social scientist at Lund University; Robert Lundberg (pseudonym), a physics professor at Lund University, and formerly the Chancellor, but also formerly a Director General for VINNOVA; Arya Lindqvist (pseudonym), Strategic Advisor at ESS, and formerly the Governess of the Skane region; Jon Linden (pseudonym), a political scientist and a civil servant at Skåne's Regional Council - Region Skåne; Aemon Löfgren (pseudonym), a member of the Nobel Prize Committee for Chemistry, also a chemistry professor at Lund University; Sansa Lindberg (pseudonym), a doctoral candidate in crystallography, student of the latter chemistry professor; and Davos Svensson (pseudonym), a professor in thin film physics at Linköping University.

Discovering early on that questions about the future directed interviewees away from talking about their experience, leading instead to highly abstract speculations as to the significance of ESS in the future, reasserting over and over again that ESS will do great things, I began refraining from asking such questions. Instead, my interview tactic became one of posing as a first question the interviewees' "stories" of their experience with/as part of ESS. I asked them to start "from the very beginning", when they encountered ESS for the first time, and thereby I tried letting futurity come up naturally as part of the narration as it unfolded. I found this tactic to be useful, as it generated energy. The interviewees enjoyed telling their stories, remembering (or self-questioning their memory of) the events, recalling the people they met on the way, and giving voice to the feelings and the impressions. In some instances I used what I want to call "probes" - that is, questions specifically aiming to encourage reflection on the interviewee's part about the future in some aspects (e.g. how did the expectations change?) but then only when the informant's experiential narrative provided for asking such a question. I found that, when located against the stories, questions about the future invited articulations of futures as they were experienced, as expectations or feelings that were encountered in some ways, thus more interesting and sociologically rich reflections on futures than the highly abstract speculations about the significance of ESS in the future I got when starting off with a question about the future.

In total, then, I conducted fifteen interviews (for a List of Interviews see pp 191192), each about an hour long. The interviews were un-structured, largely informal, and predominantly non-directive. Several more features are important to mention. 
The interviews were done in a variety of settings. Some of these settings can be characterised as informal, for example public cafeterias, lunch rooms, and coffee shops at train stations; other settings were more formal, for instance private offices and meeting rooms. The sense of their formality, of course, derives not only from where the interviews were done, but also from their temporality - as just before catching the next train, over lunch or coffee, in between (and outside of) work times, etc. The choice of interview setting was in each case the informants.

Elwood and Martin (2000) argue, "the interview site itself embodies and constitutes multiple scales of spatial relations and meaning, which construct the power and positionality of participants in relation to the people, places, and interactions discussed in the interview" ( $p$ 649). According to them, the "micro-geographies" of the interview are like a "window on salient power structures operating in a particular community, among particular social actors" (p 652). Therefore, argue Elwood and Martin, it is important to reflect upon the choices of site, for example, in terms of what those choices can tell us about the community, individuals, or the places involved in the research. The very social relations that are the subject of research, according to them, "may be highlighted in micro-geographies where the research is carried out" (ibid). Not merely circumstantial features of interviewing, then, we can think about the various choices of interview site as already telling us something about futurity and accountability. For example, we can argue that the choice of interview site performs (or displays an orientation to) futurity as something that can be talked about within the chosen kind of settings; as something that can be addressed informally, as well as appropriately over lunch or over coffee, outside or in between work, on the way home while waiting for the train; that the informants can be seen talking about this topic.

This point is different from Pollock and Williams (2010) and Michael (2000) who argue that parameters of the content of futures determine the extent to which futures can be understood, seen, sensed as accountable. What I am showing here is that a sense for the accountability of futures arises before any content gets specified in the context of the interviews. Also, the siting and the timing of the interview can be seen as ways through which the informants manage their accountability to the organisations they represent. Not only is the interview done outside the space and time of work, but also the siting and timing perform the interview, the futures articulated as part of it, as something which is done/said outside work, on the way home, and so on. The organisations the informants represent cannot as a result hold them accountable for those futures, i.e. without in the process violating the boundary 


\section{Accounting the Future}

between work and non-work, work- and non-work setting. More broadly, we can characterise this as a move of laicising futurity - of appropriating futurity as of the private/public/in-official domain.

The recording of the interviews records, not only the verbal interaction between the interviewer and interviewee but also the sounds of the settings; sometimes their silence (with the occasional opening of a door and coughing), other times noise (made by people chatting, rolling suitcases as travellers rush to catch their train, and the sounds of train arrivals and departures). While transcribing the interviews, for the most part, I focused on the verbal interactions of the interview, removing the sounds (and silences) as noisy background. On one occasion, as I shall specify in chapter 6 (see $\mathrm{p} 123$ ), these sounds and silences turned out important.

\subsubsection{Examining Futurity through Participant Observation}

One of the research questions this thesis examined concerned the ways and extent to which the everyday, mundane practices of making ESS materially could be analysed as future-making. What kinds of connections can we make between the "little futures" (Michael 2017) of accomplishing ESS locally, in particular sites and over particular times, and the grand, highly abstract "big futures" of, say, public discourse? More importantly, who, in the ESS setting, is accountable for making such connections, how, and in what ways? To answer these questions, we need to look at accountability for how it is played out among the people of ESS proceeding with their daily work and routines in particular places over time. In this connection, documents and interviews are limited. We also need participant observation.

Particularly interesting ESS sites to examine in that regard are the ESS Detector Coatings Workshop in Linköping and the ESS Detector Group in Lund. These two settings are involved in a process of inventing a "next generation" neutron detection technology, replacing the helium-3-based (and nuclear-weapons-related) neutron detectors of today with detectors using arguably cheaper, supposedly more benign, virtuous even, neutron-detecting alternative. This is boron-3-enriched boron carbide. Somewhere-somehow, in the midst of the largely ordinary practices of doing thin film coating and assembly of neutron detector prototypes, the participants in these practices are accomplishing a "big future" where neutron science is independent of nuclear technology or, at least, less dependent on the market prices dictated by the relative scarcity of helium-3. My aim in approaching these two sites was to examine the accountability relations providing for that sense. 
Located in Linköping, the ESS Detector Coatings Workshop is an in-house manufacturing facility, developing coatings for the building of ESS detector prototypes. The Coatings Workshop was officially inaugurated in $2014 .^{24} \mathrm{I}$ did fieldwork there in the spring of 2017, during a period of six work weeks spanning January and February. Throughout my stay at the Coatings Workshop, I acquired an understanding as to how coating was done there. I could see that, in significant ways, the work of the Coatings Workshop oriented to making coatings usable, readable, examinable, recordable and workable - in short accountable - for somebody else, e.g. "the guys in Lund", and later on, during the processes of assembling the neutron detectors. I decided to follow the coatings there, at the Detector Group in Lund, and see how that was being played out.

At the start of fieldwork, the informants asked me about my knowledge of Swedish language. I told them that I mastered a basic level, but felt more comfortable conversing in English. While I was present at the Coatings Workshop, the informants were conversing in English. Even when I was not involved in the conversations, they were conducting their conversations in English. This can be understood as their way of making the setting available to ethnographic observation; of performing the setting as ethnographically observable. Sometimes, out of habit or otherwise, they were switching to Swedish. I took this as their way of delimiting the ethnographically observable setting and, on that account, decided to exclude all recorded instances of "talk in Swedish" from the analysis. For the same reason, I have excluded instances of recorded "private talk over the phone".

Participating in the activities of the Coatings Workshop made note-taking difficult. Nevertheless, with the aim of understanding accountability relations as they were performed in interaction, through the Coatings Workshop's practices, it was important to capture those interactions in detail. To solve that issue, I began using an audio-recorder. With the participants' permission, I was continuously recording all verbal forms of interaction in the setting. I would turn the recorder on the moment I stepped into the Coatings Workshop, and turned it off on the way out. Thereby, I was producing an eight-hour-long recording each day, for a period of six work weeks. Of

${ }^{24}$ The Coatings Workshop was inaugurated by Tyrion Andersson (pseudonym), at the time ESS Research Head. Brienne Jacobsen (pseudonym), who became the Coatings Workshop's Head, told me that the Coatings Workshop was never again as crowded with people as on the inauguration day, and that it was a rare occasion when "so many people from Lund" visited these premises at once (Interview, 2016 December 2). A champagne bottle ornamented in the colours of the Swedish flag was still displayed at the Coatings Workshop during my fieldwork there as an inaugural memento from that day. 


\section{Accounting the Future}

course, verbal interaction is inextricably linked to non-verbal forms of interaction. I have reconstructed some of it through memory, while transcribing the relevant audio recordings. In addition, I have used a video camera, installed in one of the Coatings Workshop's corners, to keep a visual record of things happening.

While doing participant observation in these sites, I maintained the tactic of not asking explicit questions about the future. As in the context of interviews, I was letting futurity come up, for example in the course of talk, as the various participants engaged in their activities. This research tactic, however, turned out to be problematic in this context. Each day I suffered a sense that futurity was not happening in these settings. I could notice instances of futurity only at the end of the day, at home, while going over the recordings of that day. On the one hand, this suggests that I was entering these settings with certain presumptions as to what counted as "futurity". For instance, when somebody said "we will do that tomorrow", I did not thereby observe futurity in action. Rather, I was letting such performances pass unnoticed, waiting for the grand, "big futures" I had learned by this time to become a topic of talk in the settings. On the other hand, not being able to recognise futurity was to do with my position in the settings as a participating observer. When somebody said "we will do that tomorrow" I heard that statement for how it was organising mine and others' work. "Okay. We can leave this for now." - is what I thought. Being implicated in the performances of futurity, in other words, made it more difficult straightforwardly to observe futurity as a performance.

In addition to these two settings, I have conducted one-day participant observation of a visit to the ESS construction site by two representatives of the Finnish mining industry. Jon Linden (pseudonym), organiser of this visit, had invited me to participate in the event, as an observer, after asking him about such a possibility during my earlier interview with him. While the visit was at the ESS construction site, it did not involve a tour of the site. It involved a presentation of ESS, in the office premises at the site. The visit continued to the MAX IV facility - where the presentation followed a tour of the facility. One way to characterise my participant observation in this case is as "shadowing". Czarniawska (2008) uses this term to denote "following a person through his or her working day" (p 10). In her conceptualisation of this term, she differentiates it from "participant observation" as understood traditionally in anthropology - namely, being stationed somewhere, playing some kind of role. In that relation, "shadowing" is for Czarniawska a form of "non-participant observation". It is relevant to note that this differentiation is somewhat conservative. For instance, Atkinson and Hammersley (1995) argue that 
this seems to imply that the non-participant observer plays no role at all. Of course, this is not what Czarniawska is saying. According to Czarniawska (2008), the method of "shadowing" produces a kind of "psychic discomfort" that the ethnographer can use as a source of insight. So the ethnographer's presence matters in some way, plays a role. My point in this regard is different. During the presentations of the facilities, I was introduced as "an anthropologist", as someone who is "here to observe us", or humorously as "our fly on the wall". Not simply revealing/indicating my role in the setting, these introductions performed my presence there as of a "shadow"; thus, as somebody who could (on the particular occasion, say, during the presentations) be disregarded, unengaged, and so on. Moreover, these designations can be understood as performing the visit as between the ESS and industry representatives, and thereby as being about them. In these senses, the participants themselves, and not me, did the "shadowing". This, in turn, provided for the implication that the others, the industry representatives for example, present at the meeting, were accountable for engaging. My point, then, is that, we can set aside the traditional division between participant and non-participant observation, and instead look more closely at how roles are being assigned in the setting, in the field, during and as part of observing. This, as I have shown here, can tell us something about the topics we study, including relations of accountability.

\subsection{Institutional Ethnography as a Method of Analysis}

The aim of this thesis was to examine the relationships between futurity and accountability in the ESS context. My approach to documenting this relationship was ethnographic. Using the ethnographic methods of documents review, interviews and participant observation, I generated fifteen interviews with "ESS people", gathered a diverse set of publicly available ESS-internal and -external documents, and produced a six work-weeks' worth of (audio and video) recordings, as well as about two hundred photographs, capturing the interactions of participants relative to three main ESS locations. To make sense of this material in relation to my thesis aim and research questions, I drew on the work of feminist sociologist Dorothy Smith (1974, $1983,1987,1990,2001 \& 2006$ ) and more specifically, her method of institutional ethnography. In this section, I present a brief outline of this method.

Smith (1987) introduces the method of institutional ethnography to commit us to an "exploration, description, and analysis of social relations" ( $p$ 160). Within this methodological framework, "institution" is not another word for "organisation" or 


\section{Accounting the Future}

"establishment", nor is it an objective entity that intervenes in people's lives. It is instead understood to be constituted in "social relations" which, argues Smith (2001), are "situated historically in the ongoing, never-stand-still of the social" (p 160). The "institutional" in institutional ethnography plays the important part of guiding the researcher to move analytically from the ethnographic description of the local to the explication of the "social relations" that coordinate actual people's knowledge and activities. "Social relations" as a notion, proposes Smith (2001), should help us focus "away from formulations that presuppose the objectification to attend to how local settings of people's work is coordinated into sequences in which others are active elsewhere and at other times" (p 162).

According to Smith (2001) we can regard "social relations" as essentially, but not exclusively text-mediated and that it is foremost texts that provide their "capacity to exist beyond particular times, places, and people's doings" (p 164). Texts, in Smith's view, are "definitive forms of words, numbers or images that exist in a materially replicable form" (ibid). As material presences, she says, texts make possible "the appearance of the same sets of words, numbers or images in multiple local sites, however differently they may be read and taken up" (p 160). Thereby, according to Smith, texts provide for "the standardised recognisability" of people's doings as organisational and for their coordination across multiple settings and times.

The "social relations" underlying texts, argues Smith (1983), are not directly accessible to us and are "invisible in, though they shape, the texts" (p 321). Following Smith (1983 \& 2006), the analysis of texts aims to discover in the text ${ }^{25}$ the social relations of which we are practitioners. Namely, through our analysis we seek to explicate "our own tacit practices, our own methods as members, discovered in

\footnotetext{
${ }^{25}$ The analytic approach in institutional ethnography requires that the research argues only on the basis of what can be empirically discovered about things actually happening. Rankin and Campbell (2009) argue, by contrast to other qualitative methods, the institutional ethnographer avoids developing thematic analysis, collapsing the data into broad categories, generic concepts, or generalizable patterns. Instead, according to them, the analytic story requires the researcher to supply convincing evidence to account for the experiences that have been described by informants. The researcher's task, namely, is to persuade readers 1) that any contradictions discovered and examined are "real" in the sense of being performed and experienced in the setting, 2) that the coordination of the setting that the unfolding research exposes is also performed in relations discoverable in and beyond, but entering into, that setting, and 3) that the evidence of coordination of the local setting - which is the knowledge product of the research - establishes to everyone's satisfaction "how things actually work". In this way, an analytic account supersedes any informant's experiential account but without displacing or denying their experience.
} 
features or properties of a text" (p 322). Analysis of texts, in other words, makes explicit what we know how to do. And we show what it is that we know how to do through our analysis.

For Smith (1983), it is the reader who brings the text to life as meaning for them. The relation between text and reader, according to Smith (ibid), takes the form of "almost a special kind of inner speech, a 'conversation' within the reader" (p 322). It is in that sense subjective. Nevertheless, it also clearly, she argues, is social. The readers use interpretive schemata ${ }^{26}$ in finding the sense of the text. These they have learned as members of their society located as they are and participating in determinate social relations, including those of the discourse in the context of which their interpretive work is done. In analysis, therefore, we should be concerned to locate the controlling frameworks and interpretive schema provided by the social relation which the text originally intended, i.e. was written to intend.

An important analytical concept in Smith $(1974,1983,1987,1990,2001 \& 2006)$ is "social organization". She uses this concept in a manner which leaves the question of planning or purpose open. Smith (1990) compares "social organisation" with the economic concept of a market which, according to her, "makes possible the analysis of the activities of numbers of individuals buying and selling as a social organisation which is unintended by its participants and which produces 'market phenomena' as an unintended consequence" ( $p$ 24). For Smith, the concept of "social organisation" constitutes a means of making explicit the various steps and activities that intervene between the reader/hearer of an account and the "original events" and, moreover, of showing how the acceptability of the account as such-and-such an account (e.g. as factual) is provided for. The question when doing analysis of accounts in line with Smith, and which analytical question I sought to answer in this thesis when making sense of the accounts of futurity, is how accounts perform "social organisation".

\footnotetext{
${ }^{26}$ This, as Smith (1983) argues, presupposes that the text intends an "interpretive schema" or "schemata" which we command. Where the text intends a schema we do not know how to operate, and cannot learn to operate it, the text is so far "dead to us". The text can be said to intend an interpretive schema (while not necessarily a particular interpretation) when such a schema enters into the process of producing the text. In the process of writing, making corrections, in thinking again about how to address a topic, in thinking through a topic so that it can be first thought, then expressed, adequately, clearly, and well, a text is developed which depends upon and intends the interpretive schema which has entered normatively into its creation. In the production of the text, according to Smith, the same circular process is at work as that which arises between text and reader. Hence, the text can be said to intend interpretive procedures as those practices and methods of reading which will read it for the sense which it intends.
} 


\section{Accounting the Future}

\subsection{Conclusion}

The aim of this chapter was to explain the choices I made as to the most appropriate methods to use in examining performances of accountability relations through discourses about the future in the context of ESS. This question required a particular understanding of discourse which, in line with Griffith and Smith (1987) and Smith (1974, 1983, 1987, 1990, 2001 \& 2006), I approached as practical activities conducted through textual accounts. Approaching discourse in this way compels us to broaden our understanding of what counts as empirical material. For instance, I showed that "gaining access", "interview site", and "language", typically addressed as methodological concerns, turn out to be a key sources of analytic insight. I argued that my approach to examining accounts of futurity in the context of ESS was "ethnographic" in two senses. Firstly, in that I used the methods of review of ESS documents, interviews with "ESS people", and participant observation at different ESS sites to gain a first-hand understanding of futures as talked about and related to in the various local contexts constituting "the ESS". Secondly my approach to analysing the accounts generated in this way was also ethnographic. Drawing on Smith (1974, 1983, 1987, 1990, $2001 \&$ 2006) and, in particular, her method of institutional ethnography, this thesis examined accounts of futurity for the ways and extent to which they could be seen as performing "social organisation" and, as part of this, relations of accountability. In the next chapter, I present the first body of empirical analysis. 


\section{Accountability Practices in a Local Newspaper}

My critical literature review showed that, while scholars make appeals to a sense of the future as ordinary and familiar they tell us rather little about the practices performing and maintaining that sense, the discursive processes involved in enacting the future as the particular presence we all know and can relate to in the dealings constituting our everyday life - reading newspapers, taking walks, or finger-rubbing silicon plates at work. The methodology chapter showed that Smith's (1974, 1983, $1987,1990,2001,2006)$ concept of "discourse" - as practical activities done in and in relation to texts, or broadly accounts - is particularly useful for addressing issues such as the latter. This chapter looks at accounts of ESS as rendered in Sydsvenskan, a local Swedish newspaper (see chapter 3, pp 40-41), to examine the discursive work organizing particular public understandings of the future as it pertains to ESS. My main research question is: how are accountability relations performed so as to provide for generating and sustaining readers' sense of "the future"? Sydsvenskan figures prominently in the existing scholarly texts on ESS, the three anthologies (Hallonsten 2012a, Kaiserfeld \& O’Dell 2013, and Rekers \& Sandell 2016) addressed in the previous chapters, but mainly as a source of information. In line with institutional ethnography, this chapter examines how the accounts of ESS in Sydsvenskan perform "social organisation" (Smith 1990), the various steps that intervene between the readers of the accounts and "the future".

I begin with a Sydsvenskan article reporting on a potentially open-ended "delay" concerning the decisions on ESS location. In articulating the decisions as delayed, the article performs the temporal organisation of ESS as existing public knowledge. I then trace this knowledge back to an earlier Sydsvenskan article, reporting on the formation in 2002 of ESS Scandinavia, the Swedish consortium lobbying for Lund as a suitable location for ESS. The article enters ESS Scandinavia's formation in what it specifies as a "game of who gets ESS" (Sydsvenskan, 2002 March 23). In so doing, it also makes available the temporal orientation of this "game", and provides in this way for establishing an interpretive framework for making inferences about the events following the formation, including that of the "delay". I continue with articles configuring the "delay", looking specifically at how that configuration enacts ESS communities. The "game" of getting ESS is presented as unfolding on a translocal level, elsewhere. Continuing, I consider the shifting of this "game" to the local 


\section{Accounting the Future}

level; namely, how Sydsvenskan's texts make "the game" available as of a particular significance locally, for the public-as-readers. I examine Sydsvenskan's social distribution tactics, enacting a social landscape of local views regarding the facility.

\subsection{Timetables as Interpretive Frameworks}

On the $30^{\text {th }}$ of January, in 2003, Sydsvenskan announced a delay in the decisions concerning ESS location. Here is the announcement:

The decisions on where ESS will be built are delayed for a year or more. According to the previous timetable, the decisions for the construction of ESS would come in 2004 and the location would be nailed down the following year.

Sydsvenskan, 30 January 2003

On its surface, this announcement seems to provide support for Geels and Smit's (2000) and Brown's (2003) argument that futures regularly differ from earlier expectations. In terms of that argument, the above announcement reads as demonstrating such a regularity. For the regular readers of Sydsvenskan, however, this announcement, as I show here, means something in particular, it provides for a specific understanding to emerge as to what might follow in the future with respect to ESS. In order to see how that might be, we need to examine this announcement for how it performs a delay. We need to address the practical accomplishment of this announcement, achieving the sense of the indicated decisions as (nothing else but) "delayed". The following constitute some of the key features of this announcement as a performance.

Note that, not only are the decisions announced as delayed, but also their sense as temporally organised is invoked in a specific way as part of the announcement's articulation. The invoking involves in this case making a reference to "the previous timetable" and in the aspect specifying a no-longer applicable temporal framing. The item "the previous timetable" enters the articulation as simply a reference, elaborating the prior statement of delay. This provides for discounting "the previous timetable" as part of an explanation for the different timing of the decisions. For example, we may entertain an alternative possibility of the decisions happening at a later time as a consequence of readjustments in "the previous timetable". In that version of events, the decisions are not so much "delayed" as they appear, simply, differently timed. We can see, then, that a delay is as much a statement of what 
happened with the decisions on ESS location as it is an effect of how that statement is being organised.

Note also that, the articulation of the announcement performs a reader that already is familiar with ESS as organized in particular ways. We can locate that appeal to familiarity against the definite form in which the announcement specifies "the decisions" and "the previous timetable". No additional elaboration is provided, suggesting it is not needed, for recognising "decisions" and "timetable" as constitutive features of ESS. In that connection, the announcement can be read as performing the reader as accountable for knowing, already at the point of reading it, about such things as "the decisions" or "the previous timetable". This in turn provides for reading the elaboration of the "delay" as a kind of reminder for the reader, of what the reader already should know. To the extent that the general public knows ESS along these lines, and knows it through Sydsvenskan accounts of ESS, the announcement also suggests a sense in which the publicity of that kind of knowledge is discoverable in earlier Sydsvenskan issues. When drawing inferences as to what the "delay" might mean for (the future of) ESS, regular readers of Sydsvenskan can re-member (i.e. mobilise on the occasion of reading in making sense of the announcement) "the decisions" and "the previous timetable" as they know them from earlier elaborations. For us, however, who are not regular readers of this newspaper, the memory-work must involve going back to earlier Sydsvenskan issues to find out. I do this in the next section.

\subsubsection{The "Game of Who Gets the Research Facility"}

On the $23^{\text {rd }}$ of March, in 2002, Sydsvenskan reported the establishing of ESS Scandinavia - the Swedish consortium lobbying internationally for getting ESS, characterised as "the decade's greatest European research initiative", to Lund. Getting ESS was a "game" and the forming of the Swedish consortium strategically an important move in it. It meant, as this report's heading suggested, taking "A Small Step Closer to ESS". This step was "small", especially as getting ESS involved competing against Europe's "major players" - England, Germany and France. Each with their own candidate location, these players held decisive positions in "the game of who gets the research facility". But if they could not come to terms with one another, then, according to Sydsvenskan, it all indicated that the choice for placement would fall on Scandinavia and, in particular, "little Lund".

According to the report, the strong academic environment, high-tech infrastructure, and good cultural climate made Lund a "perfect alternative" for ESS. At the same 


\section{Accounting the Future}

time, as was suggested in the report, ESS was a "perfect alternative" for Lund. Thus, Lars Börjesson - the chairman at ESS Scandinavia - reported for Sydsvenskan: "You cannot say no to this. Everybody around will benefit from it." And Lars Granath the director of Lund City Council - found: "It is not like Lund to say no. Not now and not ever." Having ESS in Lund was "hardly a question" for them but, as Sydsvenskan observed, so too generally, for the citizens of Lund as well as for the local politicians. In terms of this report, the important issue really was getting the facility there. Sydsvenskan concluded the report with the following figure:

\section{FACTS}

The facility can be put to use in ten years

22 March 2002 - ESS Scandinavia Consortium formed in Copenhagen.

17-18 April 2002 - The Swedish Research Council and Lund University host a conference on ESS and neutron technology in Lund.

16 May 2002 - ESS Scandinavia submits an official application in Bonn.

2003 - ESS Europe makes a decision on location.

2004 - Construction starts.

2010 - The facility is ready.

2012 - The facility is in use.

Sydsvenskan, 23 March 2002

The figure makes available the temporal organisation of the course of action of which the reported event - namely, the forming of ESS Scandinavia - is a part. In that organisation, the reported formation is not so much "A Small Step Closer to ESS" as it is a first step, among others, pertaining to getting the facility and specifically, to getting it to Lund. The FACTS are facts of "the game" and are presented from the perspective of how ESS Scandinavia plays it. All other (potential or actual) players are removed from it. The forming of ESS Scandinavia, the hosting of a conference on ESS and neutron technology in Lund, and the submitting of an "official application" in Bonn - all are made available as this player's moves within that "game". How other players play is not specified here. While this player - ESS Scandinavia - is particularised, the implicated others are made available only as countries, and in kind as "major", thus as opposed to "little Lund", providing for a sense of the "game's" dynamics. 
When encountering this figure for the first time, I read it as a timetable. Yet, the instructing category here is "facts" not timetable. I took it as a timetable because, in performing the memory-work of matching "the previous timetable" against one such, I was looking through Sydsvenskan articles for something like a timetable. I was exercising my capacity, as a member of a culture that makes and orients according to timetables, to recognise timetables, and in so doing, I found one. We can consider, then, that the memory-work involves in this case overriding the instructing categories of the FACTS figure to see it also as a timetable.

Consider the FACTS figure above as "the previous timetable", specifying as one of its constituent features "2003 - ESS Europe makes a decision on location". Within that figure, and as so locked within its relations of contingency, each stated event is simultaneously the preceding event's orientation and the next event's condition of possibility. This provides for the interpretation that a given itemised event is only expectable as such upon the realisation of an immediately preceding another. For example, that "construction starts" and starts somewhere may be read as expectable in 2004 only to the extent that previously, during 2003, ESS Europe - the "parent organisation" - actually "makes a decision on location". The conditional relationships tying the various items of the figure together into a sequence provide for reading this event as an "obligatory passage point" (Callon 1986) for the start of construction and thereby, for all else stated to follow. All that follows, furthermore, is so interlinked with that event that, whatever happens in relation to it, for example a delay, becomes conceivable as affecting the entire specified succession.

It is relevant to note that I am not, in this way, trying to produce a logical inference about what the delay of the decisions concerning ESS location might mean. Rather, I am demonstrating that following the textual organisation of ESS in Sydsvenskan, as a form of memory practice, provides for accomplishing a local interpretive framework (as that just outlined) for making inferences about what follows (or might follow), given, say, the delay. It provides for re-membering the FACTS figure as "the previous timetable" when reading Sydsvenskan's announcement of the decisions as delayed. More than simply stating a delay, the announcement becomes readable as proposing that ESS generally (and not just the decisions on location) is delayed. The textual organisation of ESS in Sydsvenskan makes thinkable a situation where the "game of who gets the research facility" continues, and potentially endlessly, to no resolution.

The readers' sense of the future as it pertains to ESS gets further reworked in ensuing configurations of the delay in Sydsvenskan. The published articles provide for that 


\section{Accounting the Future}

sense by way of organising the delay as a consequence, and nothing else but that, of an unexpected turn of events.

\subsection{Turns of Events as Community Performance}

I met specifications of "turns of events" frequently, while reviewing the social science literature dealing with the topic of futurity. For instance, according to Brown (2003): "If we cast our minds back, gene therapy, it was once thought, would entirely dispense with the need for pharmaceutical medicines and compounds. [...] As it happens, gene therapy has turned out to have niche applicability in terms of expanding our understanding of viral vectors [...]" (p 11). For Brown, the case of gene therapy exemplifies a familiar tendency: "We are no doubt familiar with several or more salient examples of early ambition giving way to disillusionment and any number of applications have turned out radically different to the way many people once anticipated." (p 4). Also, Nowotny (2016) argues that "tipping points" constitute an important reality check. While techno-scientific practices of prediction claim the future with certainty, she says, "surprises" and "tipping points" remind us that the future, as a horizon of human expectations and ambitions, is fundamentally and inevitably "open". She calls this "the cunning of uncertainty". Alternatively, we may examine "turns of events" as performance. How are "turns of events" achieved practically? And what is their significance?

The following case is not from Sydsvenskan. I reconstruct it from my interview with Sansa Lindberg (pseudonym) and from her diary. This material helped me see "turns of events" as community performance.

In the interview, Sansa Lindberg (January 31 2017) tells me she is a doctoral student at Lund University, conducting a project in the field of crystallography. She had been invited by a "neutron group" from Copenhagen to join their one-week visit during February 2017 to the ILL, Institut Laue-Langevin - a spallation facility in Grenoble, France. The group was going to perform an experiment there, and needed Sansa's expertise for it, especially as it concerned "the growth of crystals". As her doctoral project primarily used radiation, this was going to be Sansa's first encounter with neutrons. She had never visited a spallation facility before and, for that reason was excited about the presented occasion. ${ }^{27}$ Sansa had kindly agreed to keep a diary for

\footnotetext{
${ }^{27}$ Instances such as this can be understood as coinciding with a broader ESS strategy of "preparing the next generation of neutron researchers". As the ESS website (2017) explained it, this involved
} 
me while there. In it, I asked that she recorded her experiences, more specifically focusing on the expectations she had for the visit and how they played out, i.e. on the noteworthy, interesting, and surprising moments in this visit. After a while, she returned with an email, attaching a five-page long report in the form of a diary containing various descriptions as well as images for illustration.

The following diary entry recounts a "problem" that Sansa and her team had encountered while doing an experiment:

Day 6 starts with good measurements from overnight but the problem that one axis movement stopped in the early morning. The beam had to be switched off so that we had the chance to go into the experiment station and check if some of the rotors are blocked. It turned out that the problem was the beam stop being in the wrong position. The air pressure valve keeping it at its level failed, which caused a break in some safety cycle resulting in a full stop of the movements. The beamline scientist, who came in to take a look at the problem, fixed the safety click switch with duct tape, to circumvent the safety cascade. Thereafter the experiment could be taken up again.

Sansa's diary, 2017 March 20

The specific form of this description (as a field-entry in a five-page long diary) and the described occasion's features selected for its construction (as a case of something turning out different than expected) are specifically intended for communication. In other words, the description distinctly is the product and part of an ongoing interaction: between Sansa, who participates in the experiments at the ILL, and me, who Sansa knows is interested in the surprising moments while there. When selecting an occasion to report through her diary, Sansa is anticipating that interest. She demonstrates it in describing the occasion as exemplifying a surprising moment.

If we look closer at the features of this demonstration, we can see that the course of the occasion described is rendered as in conformity with that of a scientificallyproper problem-solving procedure. A problem is located. A hypothesis is formed as to the cause of that problem. Follows an examination, through which that hypothesis gets tested. In examining it, the hypothesis gets refuted. The actual cause behind the

providing young scholars from diverse scientific backgrounds with the chance of participating in actual experiments at neutron sources in Europe and around the world. The aim thereby was to occasion forming of research networks that, in the future would invite various kinds of involvement with ESS. In the interview, Sansa told me she knew ESS mainly through "discussions" with friends and colleagues and, while curious about the facility, could not immediately see its relevance when it came to her own work in crystallography. She was hoping that her visit to the ILL will be illuminating in that regard. 


\section{Accounting the Future}

problem is found. Only then does the problem get fixed. And importantly, it is not Sansa and her colleagues that are fixing the problem themselves. Rather, it is the beamline scientist who does this. On the surface a surprising "turn of events", the description performs an organizational setting. It performs an idealized version of the process by which problems get solved in the ILL setting, and as part of this performs accountabilities: i.e. who, in this setting, is responsible for identifying, checking, determining, and ultimately, fixing problems when (or as) they emerge. More than exemplifying fundamental features of futurity (Geels \& Smit 2000, Brown 2003), we can understand then "turns of events" as community performance.

What actors and interactional resources then does Sydsvenskan use in performing a sense of the future of ESS as "turning"?

\subsubsection{Germany's Withdrawal from ESS}

When addressing the delay, Sydsvenskan articles provide an explanation for it which is made to do with "the depressed economic situation in Europe" (2003 January 30). I take this as an attempt on the part of Sydsvenskan of anchoring the delay in the popular discourse of the time - namely, that rendering an economic downturn in various euro-zone countries during this period. Throughout the early 2000s, Sydsvenskan and other local and national Swedish media had reported a financial recession swaying across Europe, and striking Germany especially - a key European economy and incidentally, also a focal contender in the so-called "game of who gets the research facility" (Sydsvenskan, 2002 March 23). By way of causally relating it with the delay, the Sydsvenskan articles provide for taking this "depressed economic situation" as the game's emerging circumstances. Consider these excerpts:

This week, the German Minister for Research and Education, Edelgard Bulhman, informed his government on the costs that the ESS project would bring about and, according to Nature, recommended that Germany withdrew from it for the time being. (Sydsvenskan, 2003 February 7)

When the superpower Germany announced in January that it was for the time being withdrawing from the project due to economic reasons, it deflated the European in ESS. Today, it is very uncertain if and when a decision on location will be taken. (Sydsvenskan, 2003 March 19)

The Swedish government has not taken a stance concerning the proposal to place the research facility in Lund. And it is not in a hurry now that Germany has withdrawn from the project. This is the attitude at the Swedish Ministry of Education. (Sydsvenskan, 2003 March 19) 
These three excerpts report a single event occurring in January 2003. As stated in the first report, Edelgard Bulhman - the German Minister for Research and Education had informed his government of the costs that involvement with ESS would produce for Germany and thereby had recommended that the country withdrew its ESS candidacy. With the second report, Germany is presented as having, presumably on this Minister's recommendation but specifically "due to economic reasons", announced a temporary withdrawal from the project. Finally, in the third instance, Germany's withdrawal is mobilised as an event that already had, in definitive terms taken place in explaining "the attitude" at the Swedish Ministry of Education with respect to the indicated proposal. Thus, what appears initially as a recommendation to act in a particular way, to withdraw, later is made available as an announcement of such an action on the part of the recommended party and finally, as an action that already had taken place. The event is performed so as to provide for reading the three instances as a sequence of consecutive events - action, reaction and outcome together performing a sense of emerging development.

Sydsvenskan articulates this development in relation to the "economic situation" in Europe characterised as "depressed". ${ }^{28}$ Importantly, we can see that, in so doing, Sydsvenskan performs this relation as accountable. Thus, not just specifying a recommendation, the first instance above involves a statement of who, in this ESS setting, is accountable for recommending in relation to the "economic situation" that is, the German Minister for Research and Education, as well as a statement as to

\footnotetext{
${ }^{28}$ An "economic situation" as potentially detrimental to ESS as a project is just as much a point in some of the social science studies of ESS. Thus, Kaiserfeld and O'Dell (2013) report how, in the period preceding the publication of Legitimising ESS, "the various actors linked to the ESS project were still endeavouring to secure its funding" ( $\mathrm{p} 11)$. At the same time, they argue, "the global economy is weak, and the Eurozone faces numerous problems and challenges as Greece is under pressure to implement a series of austerity measures to keep its economy afloat, and the Spanish banks have been forced to borrow to survive" (ibid). If this "economic situation did not improve", indeed "if it worsened", argue Kaiserfeld and O'Dell, "there was a possibility that the financing of the ESS would collapse, ultimately preventing the ESS facility from ever being constructed" (ibid). What we see here is a move of situating a finding (that the funding is not yet in place) into a selected set of circumstances presented as emerging (namely, the "economic situation") to the effect of problematising ESS as happening. Similarly, we read in Hallonsten (2013): "in the case of the ESS, still technically and organizationally 'in its infancy', quite a few things lie between now and the start of operations, let alone success on all accounts" (p 49). Among these "things", Hallonsten mentions "possible financial collapse and a further deepening Euro crisis" and "the possibility that any large European country might reorient its science and innovation policy" (ibid). What Kaiserfeld and O'Dell and Hallonsten propose makes sense in the abstract. However, we need to ask: To what extent can an "economic situation" be seen as accountable in the ESS setting? Who can say if, that ESS is/has been/will be affected and how?
} 


\section{Accounting the Future}

whom in this setting the Minister is accountable to, namely "his government". We can read the reference to Nature as accomplishing the Minister's recommendation as "the recommendation". Moreover, it is this Minister's recommendation concerning what the German government should do that counts in the process of deciding whether Germany should continue or withdraw from "the project".

The second report performs the accountability of the "economic situation" (and by extension, the accountability of the Minister's recommendation) by way of respecifying it as "economic reasons". It suggests that the "economic situation" has already been accounted for in the process leading up to the announcement of the withdrawal. Also, this report suggests a manner of how this announcement counts in ESS as this setting. It is not simply Germany that makes such announcement, but Germany as a "superpower". We can see a performance of accountability in the third instance too. Not just reporting the Swedish Ministry's "attitude" concerning the ESS proposal, it also enacts Germany's withdrawal as accounting for that attitude and more specifically, for the speed with which the Swedish Ministry is taking "a stance" concerning the ESS proposal.

\subsubsection{What does Germany's Withdrawal Mean?}

Sydsvenskan performs Germany's withdrawal so as to provide for a sense that it means something. That it means something arises in relation to three features of its performance. Firstly, the three instances above accomplish Germany's withdrawal from the project as significant; at least significant enough to account for the project's dynamics in Sweden. Secondly, we can see that, in articulating a development, Sydsvenskan characterises ESS as a "project". This characterisation amounts to a reading of the withdrawal as an occurrence within ESS as a broader "European" setting (involving as such, other countries, and other governments) but also, importantly, as a process which, therefore, does not necessarily (or automatically) conclude with Germany's withdrawal. Indeed, the claim "today, it is very uncertain if and when a decision on location will be taken" (Sydsvenskan, 2003 March 19) can be read as attending to ESS as a process, providing for a consideration of Germany's announcement of its withdrawal from the project as potentially announcing an impending conclusion to this process. And thirdly, each of the instances above features as an opening, located in the introductions of Sydsvenskan articles. Their positioning in these articles, then, already provides for their reading as propositions, that they are written or meant to suggest something, which something, albeit not specified there precisely, is under consideration and gets elaborated more concretely in the articles as they follow. Here is one such elaboration: 
[... "This means that ESS will not be located in Germany. But there haven't yet been discussions as to whether or not Germany would continue participating in the project or pay for a facility elsewhere. And we hope they will," says Anders Björhammar, a spokesperson for ESS Scandinavia.

This Scandinavian lobby group, promoting Lund as a suitable location for the facility, is still hopeful that the project will happen.

"We believe that there is a need for a neutron source in Europe. The sources built in Japan and the United States will not suffice. But right now, the project is on hold for economic reasons. How long, it is impossible to say," according to Anders Björhammar.

What does this mean for Lund's chances? "We think this improves our chances. We have a competitor less."

But Anders Björhammar's optimism is not shared by everyone:

"It looks dark. Building a European project of this scale without the support of Germany seems unrealistic. In these contexts, Germany weighs as heavily as ten Swedens," says Torsten Åkesson, one of the researchers who has been very interested in ESS, even though the facility would not be relevant for his research.

Torsten Åkesson is a professor of elementary particle physics at Lund University, but is currently working extensively in Switzerland. [...]

Sydsvenskan, 2003 February 7

In producing this report, Sydsvenskan mobilises multiple actors and in specific ways: 1) Anders Björhammar, as a spokesperson for ESS Scandinavia; 2) ESS Scandinavia, as "this Scandinavian lobby group, promoting Lund as a suitable location for the facility"; 3) Torsten Åkesson, as a professor of elementary particle physics at Lund University who "has been very interested in ESS" and has been interested "even though the facility will not be relevant for his research"; 4) the researchers, potential beneficiaries of ESS, including Torsten Åkesson; 5) "everyone", namely Torsten Åkesson and other like-minded researchers, thus excluding ESS Scandinavia and Anders Björhammar, their spokesperson; 6) ESS, as a project, a facility, and an object of competition; 7) Germany and Lund and Sweden as competitors; 8) the neutron sources in Japan and the US, as existing alternative locations of neutron spallation; 9) Lund University and Switzerland, as where Torsten Åkesson is respectively a professor and does his research currently; 10) invoked but unspecified actors having a "need" for a neutron source in Europe, and unspecified actors as yet to engage in "discussions" concerning Germany's position in the project; and finally, 


\section{Accounting the Future}

11) Sydsvenskan, as the author of the report but also the reporter (made present through the question "What does this mean for Lund's chances?").

With the exception of Sydsvenskan-as-actor, we can see that the mobilisation involves a specification of how each actor relates to ESS; as well as a specification of the actors as they relate with one another. Thus, we can read the text as performing a particular constellation of entities, a community of actors around ESS. Sydsvenskan is not part of this community. The text positions Sydsvenskan as this community's observer. In that sense, Sydsvenskan's presence in the text objectifies the ESS community - as out there, being observed/asked about. It is important to specify three more characterisations of this community.

Firstly, Åkesson's specification of "these contexts" - i.e. where "Germany weighs as heavily as ten Swedens" - provides for a sense of the community's power dynamics. Secondly, the text not only cites Åkesson's and Björhammar's statements with regards to what "this" (i.e. Germany's withdrawal) means, but also presents their statements so as to illustrate a tension within the ESS community pertaining to that question and, moreover, articulates it as along a line of optimism vs. pessimism. That such a tension exists, that these statements contrast, that they contrast in terms of optimism/pessimism, and that this contrast exemplifies a tension as a constituent feature of an ESS community is an effect of how Sydsvenskan organises the text. Thirdly, the particular organisation of this community, as performed through the text, provides for a differential distribution of the statements' weight. Björhammar is optimistic, seeing Germany's withdrawal as a table-turner to the benefit of Lund, but so in view of his stake in the ESS project as a located spokesperson of ESS Scandinavia. The text provides for reading this statement as a feature of the overall work of "this Scandinavian lobby group" of promoting Lund as a suitable location for ESS and, as part of that, ESS generally. By contrast, Åkesson is pessimistic, seeing Germany's withdrawal as doing a bad turn to the project and by extension to Lund's prospects of hosting the facility, but importantly, from a position where he does not have any apparent interest in being pessimistic at all. The text provides for taking Åkesson as making his statement despite himself. After all, as the report indicates, this physics professor has been "very interested in ESS" - and by implication, also supportive - even when, in the absence of the facility's perceived relevance for him and his research, he might have had the opposite attitude.

The text adds additional weight to Åkesson's statement by mobilising his characterisation of the project's current state vis-à-vis Germany's withdrawal as "dark" in articulating the report's title as "A Dark Future for the ESS Project". The 
construct of "dark future" carries the connotation of "poor prospect", in this way to suggest that ESS might not have a future. The framing of the "depressed economic situation in Europe" (Sydsvenskan, 2003 January 30) as constituting the project's circumstances renders this future expectable; as what anybody would expect given those circumstances and, moreover, given that those circumstances already have, as it is alleged, effected a potentially open-ended delay. Note that the expectability of a "dark future" for the project is predicated on framing the delay as a matter of external influence $o n$ the project (something that has happened to it) and not, say, as resulting from an internal consideration of its changing environment. We can read, for example, Björhammar's account "right now, the project is on hold for economic reasons" as performing a deferral - that is, a kind of deliberate postponing of the project until the "economic situation" improves. In this sense, the delay (or Germany's withdrawal) is not so much indicative of a "dark future" as it is a move towards securing a future in face of emerging circumstances (including Germany's withdrawal). One way in which the text above overrides such a reading can be located against its framing of "hope".

As part of Björhammar's statement the term "hope" expresses how ESS Scandinavia relates to Germany's participation in the project. Note that here, the text makes problematic Germany's participation in the project on account of the "depressed economic situation in Europe" affecting it, which motivates their withdrawal from the project as a contending host. Björhammar's statement suggests that this does not exclude the possibility that Germany in fact participates in the project, but in a reframed capacity. As the larger proportion of the funding for ESS is provided by the hosting country, Germany's withdrawal can be understood as a re-enactment of their participation in ESS, from (paying more as) a contending host to (paying less as) a partnering country, "supporting a facility elsewhere". As the text unfolds, however, Sydsvenskan re-specifies this as a case of ESS Scandinavia "still hoping that the project will happen". We can consider the following two effects. Firstly, the text reframes the object of "hope" to become the happening (or not) of ESS, i.e. its future, and, what is more, characterises that "hope" as optimism. This, secondly, renders Björhammar's statement contrastable to Åkesson's, which enacts a view of the future as looking "dark". As a consequence, the two statements appear to enact alternative views of the future, focusing attention on the differential positioning of the articulating actors in the performed community. One a spokesperson for ESS Scandinavia, viewing what he views from that viewpoint, and the other a researcher, really wanting ESS to happen, but failing to see it. In this way, we may argue, the text configures Björhammar's statement of "hope" as just hope. 


\section{Accounting the Future}

\subsubsection{Hope as a Feature of an ESS Community}

It is relevant to stress that, in showing how Sydsvenskan accomplishes Björhammar's future claim as just hope, we are not also claiming that "hope" is a necessary mode of futurity. ${ }^{29}$ Rather, we are looking at the textual procedures accomplishing "hope" as a relevant feature of an ESS community that locally thereby is organised. For the regular reader of Sydsvenskan, the term "hope" is a reoccurring designation of the relationship between ESS Scandinavia and ESS in various aspects. That is to say, "still hoping" evokes other occasions on which ESS Scandinavia has been characterised as hoping. Consider the following example:

The Scandinavian lobby-group, ESS Scandinavia, which was advocating for Lund as a suitable location for ESS, had hoped for a decision at the beginning of next year. But now, it is clear that the depressed economic situation in Europe is delaying the project.

Sydsvenskan, 2003 January 30

The text provides for taking that - not only delayed, the decisions were, prior to this delay, and on its occurrence, also hoped for. A new terminology is introduced - of hope - to characterise a previously unavailable relation between the invoked actors constituting ESS Scandinavia, "the Scandinavian lobby group", and what gets reported as delayed - namely, the decisions. We can take that the characterization of the decisions in their temporal specificity as hoped for is Sydsvenskan's way of recovering retroactively the speculative character of earlier future claims. Thus, originally stated as FACT, the decisions are made available as somebody's hope once taken for a fact. The effect so achieved is akin to what Van Lente (2012), Geels and Smit (2000), and Brown (2003) call a "hype-disillusionment cycle" - i.e. that a period of illusion (when actors take hope for fact) is then followed by a period of disillusion (when the true nature of the future claim as hope, and not FACT, becomes apparent). We can think, then, of the term "still hoping" as Sydsvenskan's way of

${ }^{29}$ Hallonsten (2013) argues that much of what the public knows about ESS as facts is, in fact, "discourse". One of the claims he analyses is that "the ESS will become the world's best neutron source" ( $p$ 47). While this claim appears factual, he argues, there are no guarantees that ESS, indeed, will become the world's best. Hallonsten argues that this and such claims need to be understood in a qualified form such as "it is the ambition of the ESS project to be the world's most advanced" (p 49). Note that, in this way, Hallonsten maintains an essentialist understanding of the future which predicates particular modes of knowing it, in this case ambition. Hallonsten shares this proposition with Bell and Mau (1971), and to a certain extent Brown et al (2000) and Nowotny (2016), who all, in different ways, locate futurity against such notions as imagination, expectation, promise, and hope, etc. 
reminding the reader that ESS Scandinavia "had hoped" before; that their hopes had failed in the wake of the ensuing "depressed economic situation in Europe" delaying the project; and that, despite ESS Scandinavia's beliefs and conviction in the contrary, and so as a matter of potentially another "turn of events" in the future for them, ESS might nevertheless not come to be. This analysis, however, does not help us understand why hoping for the decisions to happen at a particular time was relevant as a way to relate to those decisions, as against to, say, factually, or by expectation, assumption, and so on. It does not help us understand how the delaying of the project in face of the "depressed economic situation in Europe" matters, and specifically for ESS Scandinavia. ${ }^{30}$ Consider in this connection the next excerpt:

[...] Now the consortium which aims to get the ESS facility to Lund must go on a diet. The reason for this is that the deadline concerning deciding on ESS has expired and is expected to be dragged for up to five years. ESS Scandinavia has to lose weight so as to last for longer than previously thought.

"The delay is partly due to the fact that Europe does not have the world's best economy right now. But I also think that the first estimate of how long it would take was excessively optimistic. On both the Scandinavian and the European side,' says KarlFredrik Berggren, who has been project manager for ESS Scandinavia since the turn of the year.

"From the outset, the hope was that the building of ESS was to be determined already this year. With that timetable, the effort was appropriate," says Karl-Fredrik Berggren.

But when it comes to several years, the work of the consortium must be reduced. For example, the Regional Council's money has run out. There will be no more

\footnotetext{
${ }^{30}$ That ESS Scandinavia "hoped for the decisions" is not the same as saying that it "expected" those decisions. In line with Smith $(1974,1983,1987,1990,2001,2006)$, the difference must be located against the textual organization itself, not established in the abstract. For example, consider this excerpt from Sydsvenskan: "A year ago, there were four candidates in addition to Lund: German Halle and Julich, and Oxford and York in England. Then, the experts were expecting a decision already in the following year. When the superpower Germany announced in January that it was for the time being withdrawing from the project due to economic reasons, it deflated the European in ESS." (2003 March 19). We can see that the text attributes "expectations" to a specific type of actor - "the experts" - which is a characteristic way of attributing "expectations" in this newspaper. We cannot use hope and expectation interchangeably, as synonyms, because Sydsvenskan distributes them differently in performing ESS as a particular kind of community with those features. Some in this community, such as ESS Scandinavia and the particular actors constituting it, hope for the decisions. Others, such as "the experts", whoever they may be, expect the decisions.
} 


\section{Accounting the Future}

contributions from the Region this year, and if there will be any next year, it will not be decided until autumn. [...]

Sydsvenskan, 2003 July 26

As part of the work of construing this report, Sydsvenskan mobilises the following figures: 1) ESS Scandinavia, as "the consortium which aims to get the ESS facility to Lund"; 2) ESS, as the facility, object of the getting but also of decision-making; 3) Karl-Fredrik Berggren, "who has been project manager for ESS Scandinavia since the turn of the year", thus as a newcomer to this community; 4) the Regional Council, as a financial contributor to the "work of the consortium" (if others have contributed monetarily to this effort, this is not specified); 5) a cast of unspecified actors including actors involved in the ESS decision-making process, actors expecting that the decisions on ESS will be dragged over the course of the next five years, actors having previously been thinking about the length of the decision-making process, actors constituting "the Scandinavian and European side", actors hoping that the building of ESS will be determined "this year", and actors involved in performing "the effort", re-specified then as "the work of the consortium"; finally 6) Sydsvenskan, as the voice behind the report. We can see that, with the exception of Sydsvenskan, each of these actors is specified in relation to the decisions on ESS. In this way, we can argue, the text locally organizes an ESS community around those decisions. Two features of this community are performed as key.

Firstly, the text enacts the ESS community as an oriented community. For example, it specifies the indicated "effort", i.e. "the work of the consortium", as performed in relation to a timetable. Also, the text specifies this orientation as expectation, thought, estimate, and hope. It does not specify the actors relating to the timetable in those ways. The text provides, however, for the outright exclusion of two actors: Sydsvenskan, who is an impartial observer and not a member of this community, and Karl-Fredrik Berggren, who is a member but relevantly, also a newcomer. Their accounts are positioned as observations, commenting on the orientedness of the community hitherto, and in that sense, we can think of these accounts as objectifying the community, the community's "effort" and "work", and their orientation. That the text is presented as being about ESS Scandinavia provides for attributing those "effort" and "work" to this actor and for taking the mentioned expectation, thought, estimates, and hope as features of that "effort" and "work".

Secondly, the text enacts the ESS community as a dependable community. Thus, we read that, not only was the "effort" appropriate given the timetable, but also 
dependent on money, other actors in the setting providing those money, i.e. the Regional Council, their decisions to provide (or not) money for the "effort" (and its continuation), and the temporal limitations of that decision-making process. Two more textual features contribute to the configuration of the "effort" (and thus the community) as dependable. One is that, the text establishes reduction (evocatively presented initially, as having to "go on a diet" and needing to "lose weight") as the necessary effect of the delay, and not, for example, finding new sources of money, or increasing the efficiency of the effort for a more resourceful use of scarce monetary assets. The other feature is that, the text suggests that the effort of lasting longer is the same as that Berggren specifies. This provides for the reading that the consortium has been engaged in a work of getting ESS to Lund, which, due to the delay, continues as such past its specified date of completion but with less money for $i t$. If there is a possibility that the ensuing "effort" is a different kind of effort - e.g. one which requires less employees, other (less resource-intensive) kinds of lobbywork, or indeed, if it is a kind of effort that does not involve lobby-work at all but, say, just surviving until lobby-work needs to re-start - this is not specified.

Retroactively, the text enacts an organisation that had known all along that, if a decision on ESS was not taken at the particular time specified, then the effort up to that point must continue past that point. It enacts an organisation that had known that, while also knowing their monetary constraints. It enacts an organisation that, in knowing these things, was using up its money. It is in relation to that orientedness and dependability that ESS Scandinavia can be seen to "hope for" the decisions to happen at a particular time.

We have seen how articulating futures involves community performance. But to what extent are these futures accountable? Are they purely imaginative statements of what might come, relevant only in the moment, as provocations, as news, and so on? Or, is there somebody or something which is said to be in place to make sure that those futures indeed happen or that they do not? And, how can we answer those questions by looking at reading practices in Sydsvenskan?

The following Sydsvenskan text was published on the $14^{\text {th }}$ of April, in 2013. It is entitled "High Expectations and Many Question Marks" and documents a variety of actors' thoughts concerning the future facility. "It will be the world's best research and innovation environment," says Eva Dalman, a manager at the Brunnshög Project (see chapter 6). Also, according to Hans Eriksson, a CEO at Svedala Mekaniska: "It is very positive that we have this in the region. One can count on this enabling a lot of work for all subcontractors - from gardeners to technicians." And for Lena 


\section{Accounting the Future}

Ytterberg, a local business developer, the future ESS facility means development possibilities for the neighbouring towns and villages. "But what if ESS does not happen?" asks Sydsvenskan. Lena replies: "But it will. It will happen. We believe in the project because it is good for the whole region. You cannot draw back now." In relation to this statement, Sydsvenskan reports:

[...] But the fact is that it is possible to draw back.

The ESS project has been put in a briefcase before. The European dream of a stateof-the-art spallation facility goes well back in time, says Thomas Kaiserfeld, a Professor of History of Ideas and Literature at Lund University. He has followed the process from the 1990s onwards.

"It was said that the ESS could begin to be built in 2002, 2006, and 2009. When 2002 rolled out, the Germans pulled out and then everything fell apart. They would invest in other facilities in Germany."

In a new anthology, Legitimising ESS, for which he [Kaiserfeld] is an editor, Lundbased researchers describe the complex process that lies behind the construction of a research facility of this size. Thomas Kaiserfeld does not believe that things will be different now.

"I could say that by the end of the year there will be another delay," he says. [...]

Sydsvenskan, 2013 April 14

Not only does Sydsvenskan report futurity in relation to ESS, but also provides for a sense of this futurity as accountable; namely, as something that somebody (in this case Thomas Kaiserfeld, but also the mentioned Lund-based scholars) monitors, over time, identifying and recording systematically and rigorously which specified futures happen and which do not happen, and on that basis, projecting new futures, fixing possibilities, etc. We can think of this excerpt then, as enacting ESS futures as accountable in Lund as a setting that includes such researchers as Kaiserfeld, keeping track of ESS and its futures. To use Pollock and Williams' (2010) formulation: not merely "visions let loose", not futures just "launched into the ether", these are futures that are vigilantly monitored, kept in check, and that accounting work, importantly, also is published. Readers, in other words, need not read back through Sydsvenskan to investigate which specified futures came about and which did not. They can simply turn to Legitimising ESS that, as is alleged in the text above, has already done that work for them. Here, Sydsvenskan mobilises the anthology as a token of accountability. 


\subsection{Organising Local Views about the Future}

I have examined the accountable production of futurity in accounts of ESS in Sydsvenskan. I have looked at the interpretive schemes Sydsvenskan provides for accomplishing a sense of ESS as "happening" or "not happening" in the future. But what kind of future is this specifically? And how is this future related to ESS as the entity it is (or is not), where it is (or is not), and what it does (or does not do)? I examine these questions in the remainder of this chapter.

Building on a content analysis of Sydsvenskan articles, Linné (2013) draws an analogy between "the dramatic reporting on ESS" in Sydsvenskan and the ways that media typically report on sporting events (p 93). He finds that, on multiple occasions, Sydsvenskan describes the negotiations concerning ESS as being "an international contest between different countries" (ibid) and ESS itself as "a prize to be won" (p 95). Moreover, the interviews with main actors in this negotiation process, argues Linné, "resemble interviews with sport stars", emphasising "how they managed to win the ESS competition and succeed in their mission" (p 94). But ESS as a prize of a competition, according to Linné, has nothing to do with "the facility per se, or the science" (p 95). Rather, argues Linné, it portrays ESS as "desirable" and so, it can be seen as serving certain actors' interests, say, those of ESS Scandinavia and other "pundits"; as appeasing "tensions" arising domestically around the project of getting ESS to Lund. Linné goes on to point out that this particular style of reporting in Sydsvenskan effects a diversion from "the factual issues" pertaining to the project.

Relatedly, Lund-based policy scholar Hallonsten (2012a) reports on "the rather odd non-interest in the substance of issues related to ESS among the general public" ( $p$ 13.). He says, the project had and still has "the potential of being enormously controversial in Sweden" and "by all accounts should have raised the eyebrows and voices of local and national environmentalists" (p 18.). But strangely, and unlike "comparable" other projects in Sweden, it did not. The criticism, finds Hallonsten, mostly stemmed from a single, local environmentalist body - a local off-shoot of the Swedish Society for Nature Conservation, LNF. And their campaign, which is "expectable" he says, and normally would mobilise a critical opposition, on the contrary was widely criticised for being "anti-progress" (ibid). In this sense, argues Hallonsten, ESS should be understood as a kind of "anomaly" in the Swedish context. Note that, the argument is not that ESS did not provoke any debates. Rather, it is that these debates, and to Hallonsten's surprise, were modest. In fact so modest, argues Hallonsten, that defensive strategies on the part of ESS were redundant. 


\section{Accounting the Future}

Linné's, Hallonsten's and the accounts of other Swedish scholars (e.g. Stenborg \& Klintman 2012, Linné 2013, Von Platen 2013, Liljefors 2013, and Kaijser 2016) reporting on the anomalous facility share a sense of conflict or tension unfolding in the background, variously made available as being between "opponents" and "supporters" orienting to diverging visions of what is to come. Many, these scholars find, welcome ESS - dreaming of a future in which the facility will resolve the "grand challenges" of today. And fewer others - but still, others - oppose it, anticipating nightmares of radioactive pollution, land degradation, and other forms of environmental catastrophe. In these articles, the "debates" about ESS figure in the abstract. For example, Hallonsten (2012a) says he is looking at "the general public" for how these debates play out, but a grounded sense of where this is happening, and how that situatedness might matter, largely is missing. In the next sections, I study the ESS "debates" as organised for public scrutiny in Sydsvenskan.

\subsubsection{ESS as Locally "Worrying"}

To start with, these are some of the focal points in Sydsvenskan's texts. As "facts" about ESS, we may read that:

a) The facility is planned to be built on Odarslövsvägen - from the beginning, mostly a farmland area in Lund's north-east outskirts;

b) The facility will study materials in their structural makeup, with "spallation" as the differentiating scientific process;

c) Spallation involves bombarding protons into a mercury-based target. As they hit the target, the protons will eject neutrons from it; and

d) This entire process will involve radiation.

The scholarly literature on ESS draws on these as "facts" when articulating why locally some have come to rebel against the project's realisation in Lund. For example, Kaijser (2016) reports that "local resistance has primarily been directed at ESS, with very little opposition to MAX IV" (p 86). According to her, this situation "seems to be related to the fact that ESS is the bigger facility, with greater demands for energy and land and causing greater ionizing radiation and using more chemicals" (ibid; emphasis added). It is unclear whether Kaijser wants to say that the situation is related to that fact or that it is related to that fact. Either way, a factual explanation behind the differential (or preferential) resistance is, it seems, the proposition. And yet, as I demonstrate in the following sections, that farmland will be used, and mercury, or that ESS is radioactive does not in and of itself necessarily make it 
"worrying" (as Kaijser in this case puts it) or so locally. ${ }^{31}$ So who can say that ESS is radioactive? And who can say that ESS is radioactive, and how?

Looking at Sydsvenskan's texts, we may see that providing for a sense of "worry" involves, initially as a basis, descriptively modalising the "facts" in particular ways. Such modalisations are at times Sydsvenskan's own, sometimes figure as reports on how others have characterised ESS, and often also are made available in specific ways as citations. Thus, according to Sydsvenskan's articles:

a) ESS is located, not simply on farmland, but also on "the high-quality farmland north of Lund" (Sydsvenskan, 2004 June 17), on “one of the country's best arable farmlands" and thereby as using "about 100 hectares of Sweden's best terrain” (Sydsvenskan, 2007 March 1). What O’Dell (2013) considers as "just a wheat field" enters the ESS discourse through Sydsvenskan's texts as the "wheat field" of the country. Being (and remaining as) "just a wheat field", in other words, is accomplished as a moral imperative. Moreover,

b) ESS stands, not merely north-east of Lund, not merely on the outskirts, but also "just next to Lund" (Sydsvenskan, 2002 October 3), "where people live" (Sydsvenskan, 2005 March 29) or only "a stone throw away from Kungsmarken Nature Reserve" (Sydsvenskan, 2005 October 14); and "a few hundred meters from Lund's centre" - namely, "at home" (Sydsvenskan, 2014 January 15). These specifications do not merely provide a sense of how distant ESS is from Lund, people, or the nature reserve. Importantly, they also accomplish a sense of ESS as being too close for comfort. Furthermore,

c) ESS, not only uses mercury, but a whole "30 tonnes of it" (Sydsvenskan, 2005 March 29). To that extent ESS, not only "goes against the government's national and international efforts to completely stop the use of mercury" (Sydsvenskan, 2005 March 29), and thus, in a way, going above the Swedish government, above those efforts, and above the invoked but unspecified actors

\footnotetext{
${ }^{31}$ Talking about "radiation worries" with Melisandre Larsson (pseudonym) - a technician at the ESS Detector Group in Lund, she smiled, telling me "even bananas are radioactive". She gave me a list she had prepared with others while at CERN in Switzerland, which aimed to educate the lay public on radiation. According to Melisandre, hearing "radiation" automatically made people's alarm bells ring - and most of the time, she said, needlessly. She and her colleagues had prepared this list as a way to show that radiation is a normal feature of everyday life - like eating bananas or sleeping next to someone. In fact, according to this list, working or living next to CERN is less dangerous in terms of radiation than a transatlantic flight. Melisandre said that ultimately the list ended up in her personal computer archives. It was all just fun.
} 


\section{Accounting the Future}

involved in those efforts nationally and internationally, but also, with whole "30 tonnes of it", impudently so. Finally,

d) ESS is not ordinarily radioactive, but in the same sense and on the same level as is Barsebäck - a recently decommissioned nuclear power plant in Skåne (Sydsvenskan, 2009 February 2). In terms of radiation levels, ESS is "comparable" to the Fukushima accident, to Chernobyl (Sydsvenskan, 2014 Jaunary 15), as well as to "a nuclear fuel plant" - for example, Westinghouse in Västerås, Sweden (Sydsvenskan, 2018 April 26). More than fanciful ideas, these comparisons propose the kind of entity that ESS Scandinavia is getting to Lund. They provide for re-membering public understandings of nuclear power plants, the Fukushima and Chernobyl accidents, and nuclear fuel plants, whatever those understandings may be, as thoughts of the future with ESS in Lund.

We can see that ESS as a reason for "worry" (or to resist against) does not, as Kaijser (2016) says, arise directly from facts about ESS. In Sydsvenskan's texts, the "facts" about ESS are used as initial characterisations of the facility, and later on as descriptive resources for elaborating further characterizations. The ESS arises as "worrying" as the texts re-specify its features. It arises as "in Lund" becomes meddling with valuable farmland and too close for comfort; as its "target material" becomes impudence; and as its radioactivity becomes "nuclear".

It is important to stress that these are not simply "metaphors", appealing, as Linné (2013) and Liljefors (2013) argue, to our shared cultural notions of farmland, closeness, modesty and respect, and the nuclear to cast some particular light on ESS. Rather, they are features of ESS as an entity, and features as accomplished in particular ways in Sydsvenskan texts. If locals reading Sydsvenskan see ESS as dangerously radioactive, this is not because some pre-conceived cultural notion of radioactivity tells them "danger", but rather because they read Sydsvenskan texts that accomplish "dangerously radioactive" as a feature of ESS. They need not imagine that feature, they can read it as a relevant feature in Sydsvenskan. The next section examines how Sydsvenskan texts achieve "worry" as a feature of a local ESS community.

\subsection{2 "Worry" as a Community Feature}

I zoom in on the following Sydsvenskan text, reporting on a meeting taking place in 2002, in Lund, between Klas Malmqvist, a physics professor further identified in the text as representing ESS, and the citizens of Lund. It reads: 
[...] That 30 tonnes of mercury will be collected in the facility worries many.

A listener wondered what happens if an airplane crashes there or if terrorists should attack. Will there be a giant cloud over Lund?

Klas Malmqvist could not answer the question but only found that 30 tonnes per se could sound a lot, but that much larger quantities were handled within parts of the industry. $[\ldots]$

"Our main objection concerns deciding on a location just next to Lund - before making any proper safety assessment," said Bo Wennergren, active in a group working against locating ESS in Lund.

Sydsvenskan, 2002 October 3

A few key features of this excerpt:

a) That the indicated listener wondered "what happens if..." is made available as indexing "worry". And not this citizen's per se, but his as part of the also indicated "many". The statement introducing this listener's wondering as "worry" excludes an alternative reading to arise, for instance, of the listener merely wondering about the professor's response to such a hypothetical scenario.

b) Moreover, inserting in the sequence of text that, the professor "could not answer the question" excludes his finding as a possible or acceptable response to that "worry" qua "question". Bo's statement at the end retroactively operates on the professor's preceding it, discounting a reading of it as possibly a "proper safety assessment".

c) Finally, we read that the "group" that Bo represents does nothing else but "working against locating ESS in Lund". It is made available for the reader solely through that motive, and as thus motivated solely. This performs the "group" as a clear-cut opposition to ESS, being present at the meeting.

When reading this Sydsvenskan report for the first time I thought: How could Klas Malmqvist not answer that question? Also, his non-answering appeared audacious and inappropriate. It appeared so in virtue of being accomplished as done in a community in which answers follow questions, worries are properly attended by presenting adequate responses, and where particular parties are pre-designated to ask questions, vocalise their worries, while others are pre-designated (as a condition of their participation in this community) to respond to them by providing an answer. Note that, in this community, ESS, as made present in the text through the professor, 


\section{Accounting the Future}

is sanctioned from asking, demanding clarifications, setting topics, or commenting on whether or not particular questions are even worth answering. Within this community, their sole reason for being is to give answers to questions, and do this properly, in a way that is deemed fitting. If not so, the responses do not constitute answers. The non-answer appeared audacious, not because the related question could not be answered, but because within the community of actors performed through this text, the non-answer represented a breach in terms of membership.

The following excerpts are from a 2009 Sydsvenskan article. They organise a local stake in the European "game of who gets the research facility", and do this by way of locating the facility against the personal histories of local inhabitants. Here are the opening lines of this text:

Neighbours Split in the Face of ESS

It becomes like Barsebäck, we must move and the information is non-existent. But also: Lund docks on the world map, a progress for society and more jobs.

So it sounded when Sydsvenskan gathered those who will become neighbours to ESS if the facility is built on East Odarslöv, outside Lund.

Sydsvenskan, 2009 February 2

The "split" between neighbours is re-specified as a "split" in views as Sydsvenskan found them sounding. The specified soundings receive their meaning in terms of the indicated "split". "It becomes like Barsebäck" comes about as something negative and unwanted by virtue of standing on the other side of global visibility, societal and economic progress - which are positive and wanted. Moreover, being on the other side of "more jobs", becoming "like Barsebäck" cannot entail "more jobs" and moving from East Odarslöv elsewhere cannot positively be understood as in the name of societal progress or as entailing some kind of economic progress. That a set of statements are assembled and articulated together as on the one side suggests to the reader that an underlying thought unites them, together saying the same thing. It is not simply that these are differing expressions of how (by this point unnamed) individuals relate to ESS as future "neighbours". Rather, they are made available as different aspects of two singular polarised views of ESS as, on the one hand positive/wanted and, on the other, negative/unwanted.

Notice also the descriptive asymmetry mobilised in delivering these two sides. In the same article, it says, on the one hand: 
Bo Wennergren and Marianne Olsson Wennergren [...] have lived here since 1989 and if Lund wins the fight for ESS they cannot live [here any longer]. But the municipality has not initiated any information. "We are not asked," says Marianne Olsson Wennergren.

[...] Peder and Ulla-Britt Fyhr [...] live just outside the area, north of E22. "Building time will be a tough period. Those who live here will be disturbed for ten years," says Peder Fyhr.

Sydsvenskan, 2009 February 2

On the other hand:

"It's hard to be negative, because this can create huge progress for society and will bring many positive things to Lund. But we only talk about the negative. Had we always done that, we would still be living in caves. Where would Lund be today if you had stopped forty years ago?" says Nils-Bertil Offesson.

Jan Håkansson agrees: "We are getting new jobs, research blossoms, we get better researchers in other subjects as Lund University becomes more famous. I think that's positive, and not just for Lund's surroundings."

Sydsvenskan, 2009 February 2

The difference between these two presentations is not merely one of background information. Its differential provision also has a bearing on how we make sense of them. Why would the municipality "ask" the Wennergren's couple about anything if not on account of "living here since 1989", making it the right thing to do. And why should the reader take seriously Peder's complaint that "building time will be a tough period"? Not simply because he is a "neighbour" - but also, importantly, because he (and presumably his wife, Ulla-Britt) "live just outside the area". By contrast, nothing but a name stands behind Nil's and Jan's views. It appears that they have no personal reasons for thinking what they think. We cannot, from the article as written, derive how what they say or suggest might matter to them. Their initial characterisation as "neighbours" is rendered irrelevant; that is to say, it does not matter in relation to their views as cited. What they are saying may, indeed, be said by anybody and so, by nobody in particular. They are sanctioned from participating in the making of their statement as "neighbours" but figure, instead, as anybody only by happenstance living around there.

This Sydsvenskan article seems to favour a negative side, but making it seem so also comes at the expense of marginalising that side as such. The views are produced 


\section{Accounting the Future}

along a binary of specific/general. On the negative side, the "we" includes those "who are personally affected, whose houses will be levelled with the ground", who "live here" and specifically "just outside the area, north of E22". On the positive side, the "we" includes "society", "Lund" now - in the past or in the future; people generally as in "we only talk about the negative" or in "had we always done that we would have lived in caves", Sweden and potentially, the world as in "not just for Lund's surroundings". On the negative side, the views represent the specific couples; on the positive side, us. The negative side articulates a view from the position of living there; the positive side articulates a view which mobilises the reader as Lund's citizen, human, member of society. Nils-Bertil's and Jan's - and the statements of others with them on that side, perhaps are not neighbourly but then, they are anybody's.

\subsubsection{Disambiguating Views}

A Sydsvenskan article from the $24^{\text {th }}$ of April 2014 is entitled "Neighbours do not fear ESS". We discover that, by this time, three (unnamed) "homeowners" had already moved. The article provides little clue as to these homeowners' motives, except for the assertion that "they", simply, "did not want to live next door of ESS". But some, we are told, "stayed". Such as locals Hendrik and Lena Larsson, who "for 32 years had lived in a house on Odarslövsvägen" and who, during this period, had seen the many changes happening in/to this area. The facility MAX IV was now in their vicinity and "just a hundred metres away" from where they lived, a blue ESS flag was waving. Sydsvenskan also met neighbours Margareta Laderborg and Tomas Persson who had "moved here just two years ago". Sydsvenskan reminds us that "then, it was clear that ESS will be placed on the field in front of their house". One of them remembers calling Lena Larsson - a chairman of Odarslöv community (i.e. "stadlag"), and asking her "what do you think about this, can we move here?" From the article, we learn that Lena replied with "a calming message". Namely: "I replied that we did not feel worried. We've never really been negative to ESS. We've gotten good information all the time. That bit they've been doing well." However, as Sydsvenskan tells us, these locals' lack of "worry" might be premature:

ESS causes ionising radiation. One of several radiation sources is the accelerator.

According to Peter Jacobsson, Environmental and Safety Officer at ESS, ESS provides a radiation dose of 1-3 microscopies per year for the closest person, that is, 300 metres away from the facility. He compares this with a dental X-ray that gives about ten microseconds. According to ESS, the residents are not in danger. However, the Radiation Safety Authority has stated that the plans for accommodation near the 
facility are a potential risk in an event of an accident. They will test the radiation risks in several stages, the first decision is expected to arrive at the end of June/July.

But Hendrik Larsson takes all this with peace of mind. "Should it be dangerous, they would not have allowed people to work up there," he says. [...]

Sydsvenskan, 2014 April 24

That ESS is radioactive is asserted as a fact from the start. A view is presented, which maintains this assertion, but elaborates it - rendering radiation as non-problematic, benign. This view then is located against an institutional radiation risk assessment process in terms of where it is at, which proposes radiation risks as something as yet to be determined. The description of this process also works as a temporal horizon against which to locate the cited neighbour's take on this matter. The specified Radiation Safety Authority is mobilised as the risk determining entity in this locally organised community. The ultimate resolution is rendered as in the hands of a third party. This subtracts risk from being understood as an outcome of a "debate". The views of neighbours, or those of environmental officers at ESS such as Peter Jacobsson, are enacted as of no consequence on the determination of risk. Their status as agents in this process is subverted. Whatever view they have - including those cited, is rendered as premature. It is the Authority's view that ultimately matters. We can see that the text performs a community where this Authority is accountable for the determination of radiation. The neighbours' views are performed as just views.

At the end of the article, Sydsvenskan writes:

Building on Sweden's best arable land is by all four [neighbours] opposed.

"It would be better to build it on Revingehed, but it is a good prestige for politicians to have it in Lund. You want a dot on the map," says Hendrik Larsson.

Sydsvenskan, 2014 April 24

While interviewing various informants about ESS, I noticed how they came to occupy multiple positions on ESS. For instance, Jaime Falk (pseudonym) - a civil servant at Lund City Council, told me that building ESS on "that farmland" was problematic according to him, suggesting that good farmland in Sweden was scarce and it was inappropriate to use it for any other purpose than farming (Interview, 2016 September 9). Simultaneously, however, Jaime thought that, being a "greenfield", a land that has not yet been built on, "that farmland" provided opportunities for experimenting with sustainability. In Sydsvenskan's texts, however, such multiple views do not figure. For example, Bo cannot want global visibility for Lund and at 


\section{Accounting the Future}

the same time feel that living next to ESS is "like living near Barsebäck" (Sydsvenskan, 2009 February 2). And Nils cannot imagine a situation where the facility brings "many positive things to Lund" (Sydsvenskan, 2009 February 2) and feel like Bo does of living like next to a nuclear power plant. Where ambiguous views emerge, the organising narrative straightens them out. Consider the above instance. The introducing statement in significant ways modifies how readers should interpret what Hendrik is saying. Primarily, it supplies that a consideration of the land as "Sweden's best arable" is precisely what motivates the view. More importantly, however, it excludes the alternative interpretation that Hendrik thinks that, but also acknowledges how building ESS on that land is positive. The introductory statement removes Hendrik from participating in his "you" - i.e. together with "the politicians", as wanting "a dot on the map". Individuals may occupy different, alternative, mutually exclusive views with regards to ESS. The polarisation of "views" in this case is strictly the achievement of how the text is organised.

So, some people worry about the future with ESS in it and some do not. Sydsvenskan provides a way to relate to these futures. In so doing, it organises their capacity to affect us as readers. To what extent are those futures accountable? Is there something or somebody said to be in place to make certain that they happen or that they do not? We can answer that question in relation to the next excerpt from this Sydsvenskan article:

The neighbours remember how it was at the beginning, especially when different environmental groups protested against mercury being used in the facility. When the target material was exchanged for tungsten, the debate calmed down. (Sydsvenskan, 2014 April 24)

The excerpt above provides for understanding that futurity in the ESS context is monitored, remembered, kept track of, and to that extent, is reportable. It provides for understanding that there is a community (of neighbours) in place that, not only imagines futures in relation to ESS, futures with ESS in them, but also "looks at futures" (Brown et al 2000). This community makes notice of futures, identifies and records (in memory) how they turn out. See moreover how Sydsvenskan mobilises a neighbour's view:

"It is mostly others, further away, who have opinions. So it was when Barsebäck was about to be built. Then, one said that housing prices were to fall. Don't even get me started on the Öresund Bridge, it was the same resistance. One can have questions, but progress continues, and one has to go along," says Hendrik Larsson. (Sydsvenskan, 2014 April 24) 
We can see here that Hendrik locates futurity against a body of "others" elsewhere, far away. In this way, he positions himself as an outsider, observing the debates. He is looking at these debates as they pertain to Barsebäck and those pertaining to the Öresund Bridge, the futures articulated in relation to them, but also, by implication those imagined in relation to ESS. He observes them, analyses them for their similarities and differences, in such a way as to provide him with the possibility of comparing them, of comparing the resistance, and so on. From the perspective of the reader, this statement provides a sense of there being a community in place, of which Hendrik is a member as an ESS neighbour, which does that kind of accounting work. In other words, we can consider the use of Hendrik's view as a way of performing futurity in the ESS context as accountable.

\subsection{Conclusion}

This chapter looked at accounts of ESS in the local Swedish newspaper Sydsvenskan, to examine the ways in which these accounts performed accountability relations. My main research concern here was to understand how those relations provided for generating and sustaining Sydsvenskan's readers' sense of the future as familiar. I argued that futures, which initially appeared as "merely launched into the ether", were accomplished as accountable by performing an extended ESS community where actors not only imagined futures, but also monitored futurity over time and across spaces. These actors related futurity in the ESS context with futurity in other contexts, identifying and commenting on its successes and, importantly, also its failures. A broader reflection concerning this material is that it performs the future as unremarkable. It does this by displaying as usual (as it were, already seen) tendencies of variously distributed optimism and pessimism; contrasting interpretations as to what something means in relation to the future (that are not, and cannot be, resolved in the moment of their making); claims, assertions, and expectations about the future that unsurprisingly (at a matter of a deja vue) fail to meet future reality; worries and hopes, neatly attributed across opposing sides in the extended ESS landscape. The implication, generated and sustained in Sydsvenskan's texts throughout, is that this is all just talk. The texts maintain a sense of "the future" as something as yet to be seen, which provides for interpreting the displayed talk as just talk. 


\section{5}

\section{Performing "Coordinated Communities" through Futurity}

The previous chapter looked at accounts of ESS in Sydsvenskan to examine the ways in which performances of accountability relations provided for the readers' sense of familiarity with the future. I showed that public understandings of futurity as accountable emerged in relation to a performed ESS community where actors, not only imagined and speculated on futures but also monitored, recorded, analysed and reported futurity over time and across spaces. I extend the theme of community performance in this chapter, focusing more closely on coordination - "the organisation of the different elements of a complex body or activity so as to enable them to work together properly and well" (Oxforddictionaries.com).

Chapter 2 established the importance of coordination as a topic in social-scientific studies of futures. Some scholars articulate coordination as a capacity that inheres in expectations, for example when arguing that expectations "shape" or "direct" scientific and technological development (Brown et al 2003, Jasanoff \& Kim 2009, Macnaghten et al 2005, Pollock \& Williams 2010, Van Lente 2012). Others locate this capacity in the content of expectations, and specifically in relation to various "parameters" (Michael 2000, Van Lente \& Rip 1998). This chapter examines the relationship between expectations and coordination. My key research question is: How do performances of accountability relations accomplish coordination as a feature of ESS communities? And more specifically, to what extent is it possible to understand coordination as proceeding from the specification of expectations as situated action, rather than (merely) as a result of the content of expectations?

In order to unpack these questions, the chapter is organised as follows. First, I present analyses of accounts of expectations generated in the context of a multidisciplinary Workshop on Big Science and in interviews. The latter are accounts that informants generated in relation to interview questions about the ways in which expectations changed in the course of the informants' involvement with ESS. As I mentioned in Chapter 3, my aim with asking such questions was to encourage explicit reflection on the informants' part about the future. Drawing on this material I ask: What kinds of coordination work do statements of expectations invite? And to what extent, and how, does accountability figure in that coordination work? Second, I consider coordination as accomplished through and in relation to the 2014/2015 Call for 


\section{Accounting the Future}

Proposals of "instrument concepts" at ESS. As already indicated in chapter 3, this Call was "the last" opportunity to consider instruments for the initial suite of sixteen, and hence a kind of "last chance" for becoming a member of ESS through proposals of "instrument concepts". I analyse the document of the Call as a coordination device and, as such, for how it distributes accountabilities amongst the implicated actors. I ask in this relation: To what extent and in what ways can we consider this Call as an instance of community performance? Finally, I present analysis of an insider's account of the process of proposing "instrument concepts" at ESS generated in the context of an interview with an "instrument scientist" - a proposer of a successful "instrument concept" and at the time of the interview a leader of the team responsible for turning this "concept" into an actual ESS instrument.

\subsection{Expectations as Social Organisation}

According to Brown et al (2003), "once given voice to (uttered or otherwise inscribed) expectations appear to have a life of their own" (p 6). Namely: "their rhetorical content (and material obduracy) incites reaction, obliging certain forms of activity" (ibid). Likewise, Van Lente and Bakker (2010) argue that expectation statements, "because of their content, are able to coordinate action" and in this way "to shape developments in science and technology" (p 694). Furthermore, Van Lente and Rip (1998) claim that it is the content of expectations, in being a kind of "future script" which allocates roles and responsibilities to be taken up and played out, that "pulls actors together" in a coordinated unity (p 1). In their view, "when actors act in terms of the script/scenario, a structure emerges which shapes further action" ( $p$ 27). They stress that "this is coordination through content" (ibid). These scholars suggest that, in examining how expectations coordinate, we need to examine their content, how it allocates roles and responsibilities, and what actors do in relation. In the course of my fieldwork at ESS, however, I noticed a different kind of orientation. Actors were doing coordination, not in relation to the content of expectation per se, but rather in relation to the statement of expectation.

When, in 2015, participating in Exploring New Big Science - a multidisciplinary workshop organised by Sandell and others in Lund, I presented my intention then of studying expectations, Cersei Gunnarsson (pseudonym) - the first director of ESS, who attended this workshop as audience, made the following remark. She said: "At the beginning, everybody had high expectations about ESS - all from taxi drivers to hair-dressers." These expectations, according to her, were so high in fact that: "We 
had to work on diminishing them." Firstly, it was interesting, I thought, that the range of people "from taxi drivers to hair-dressers" should constitute "everybody" in this context. Secondly, it was interesting that the expectations (whatever they were) of that range of people, including taxi drivers and hair-dressers, was attended to as of some, even key, consequence in this context. I thought, did they actually go about asking taxi drivers and hair-dressers about what they expected from ESS? And, to the extent that they did, did the expectations of taxi drivers and hair-dressers matter so much as to force ESS to do all that work of playing those expectations down? Did those actors' expectations really matter as much? Perhaps, I thought, Cersei had a haircut that day, and used a taxi to get to her hairdressing salon.

More importantly, however, note how the very mentioning of expectations - in this case as a topic of investigation, is sufficient in inviting a performance of a particular social organisation around expectations. Cersei's response indicates that expectations are had and that how expectations are had can be given in terms of "everybody" and "we". That is to say, the statement of expectations invites the interpretation of an "other" as the actor having the expectations. The "we" that constitutes ESS, including Cersei, does not have the expectations. Moreover, her interpretation mobilises a set of actors into a particular dynamic where the "we" is active, working on the expectations, and "everybody" - distinct from "we" - is passive, simply having the expectations.

Note that, this binary distinction of "we" and "everybody", was also a feature of the context of this articulation. In the Big Science workshop, the participants engaged in doing "boundary work" (Gieryn 1983), for example in how they presented themselves before posing a question or when making a remark, providing in this way for a continuously clear sense of who was ESS and who was not. When recalling the expectations, Cersei seemed to be mobilising that sense and re-specifying it into a description of a particular "expectations dynamic" (Brown 2003). Differently put, through her description of such a dynamic, Cersei was performing the emerging social organisation of the workshop. Importantly, she was enacting this social organisation as harmonious: "everybody" has expectations, and "we"-ESS hear them, and respond to them. It seemed that Cersei was using the statement of expectations as an occasion to coordinate. Cersei came up again, as a figure, in the course of my interview with Robert Lundberg (pseudonym), to which I turn next.

Robert is a former Chancellor of Lund University and former Director General at VINNOVA - the Swedish governmental agency that administers state funding for research and development. For the bulk of the interview, Robert describes his 


\section{Accounting the Future}

experience with ESS over time. He began with "the very first time" he had heard of ESS. Thus, while at VINNOVA, "a group" approached Robert and introduced him to the idea of getting "this huge financing" to build "this very expensive thing" in Sweden, in Lund. He liked their idea, as he likes "bold ideas", but did not make much of it at the time. He says: "I didn't reflect so much on that this should be a reality." (Interview, 2016 May 11). This idea would come up again later on, during a meeting which took place in the home of Loras Olofsson (pseudonym) - then the chief ESS negotiator from the government. Robert, who attended the meeting, says it was "quite extraordinary". The meeting began at around six o'clock in the morning and ended eleven in the night. During this time, barely a break in the process, "international people", "a number of director generals", and "people from the department of education and research" considered ways of making the idea of ESS a reality - and, a reality for Sweden. Robert did not hear much about ESS after this meeting. Not until 2009, when he became Chancellor of Lund University. He reminisces how, in an interview concerning this position, somebody asked him: "Who should you act about [given] this huge investment that might come, that might be very expensive for us? What about the balance with the University?" Robert remembers his response: "Well, if you think the balance should always be that all the faculty in percent counted should be in the same percent, then no one could grow if all grow at the same time. So that's not possible. But what I have done before in my life is that, when a sector in a university part is growing, then you should take away some sort of money to give to the poorest, poorer part of the university."

I asked Robert to reflect on the role that expectations had played in making ESS happen. He points out:

In the beginning, before the decisions, I think it was very important, so to say, to sell ESS: And the first director of ESS [Cersei] was very skilful that way - selling, talking, negotiating with different countries, doing very good presentations, and so on. Then, after the decisions, it was not so much about selling, presentation, and so on. It was more about building. And then, we had a good timing because she - it was time for her to retire. We could recruit a new one with very good experience of building and all, having control in all these details and all these in-kind contributions from different countries. It was quite useful that there were high expectations because it made for some planning and support. Many municipalities around Skåne said that "we are planning for new houses and new areas because of ESS". But if you look in the math, of course, there will not be so many living in Ystad and Helborg. There will be some, of course. But on the other hand, it became very well supported. So it was very, very few voices saying that this was a wrong decision. These expectations for the future, I 
think that was necessary and Cersei was excellent on that. And that was very good for that time because if we hadn't got that strong support by the public we could have ran into some problems. Because there were some ideas from some scientists in Stockholm that this was a terrible and too costly idea. They were positive to MAX IV but not to ESS.

Interview, 2016 May 11

Robert's elaboration of the importance of "expectations for the future" performs a connection between the work of selling, talking, negotiating and presenting as done by Cersei and the "high expectations" as had by the indicated "many municipalities around Skåne". This connection is stated important, and is stabilised conditionally in relation to a time - namely, when some Stockholm scientists considered "this" to be a "terrible and too costly idea", and which Stockholm scientists were "positive to MAX IV but not to ESS". Note that, in constructing a response to my question, Robert does not specify the content of the expectations he encountered. He only suggests it when reporting what the "many municipalities around Skåne" said, as to do with the number of new residents in neighbouring villages and towns due to ESS. We can see that insofar as Robert evokes their content, he does this as a means to provide for communicating the overall sense of the expectations that the municipalities had as "high" and potentially as unreasonable. Also, we can see that Robert does not specify the mechanism of effect relating the "high expectations" to "support". Rather, as part of performing an ESS community (comprising ESS and the public) at the time as coordinated (against the indicated in Stockholm), Robert is re-specifying the communal dynamic. Namely, he is re-specifying the public, initially a passive actor having "high expectations", as now being an active force, giving "strong support" to ESS. It is this re-specification of "high expectations" as "strong support" that in this account accomplishes the sense of the ESS community as coordinated vis-à-vis another community, elsewhere.

Consider the accountability relations in this case. As a seller, talker, negotiator, or presenter, Cersei can be seen as accountable for what she sells, talks, negotiates, and presents. She can be seen as accountable for how she does this, and for the extent to which how she sells, talks, negotiates, and presents is effective. Which, in Robert's view, it was, given that it "made for some planning and support" during the kind of time described. Cersei is not also accountable for what in relation to her work is had as "high expectations" by others - that is, the "many municipalities around Skåne" constituting "the public". The statement "if you look in the math..." calls into question the plans for new houses and new areas as perhaps unreasonable, but not 


\section{Accounting the Future}

"that" (whatever this is, perhaps the "good presentations") in which Cersei is specified as "excellent" and in relation to which "that" those "high expectations" presumably have been had. We may argue, then, that, in performing a coordinated social ESS surrounding, Robert exempts Cersei from accountability for the futures (i.e. expectations) featuring this surrounding.

\subsubsection{Accounting for Shifts in Expectations}

This section presents three interview excerpts, each constructed as a response to the same question of recounting the expectations as the interviewee encountered them while working with ESS as part of ESS. I have grouped them together under a separate sub-heading as in each case the interviewee's response is constructed around a particular event - the start of the construction of ESS. I begin with Arya Lindqvist (pseudonym).

Formerly a Governess of Skåne, Arya is at the time of the interview a Strategic Advisor at ESS. In the interview, Arya (2016 May 11) describes her relationship with ESS over time. About sixteen years ago, in 2000, three neutron scientists - one from Linköping, the other from Lund, and the third from Chalmers University approached Skåne's Regional Council. They came with the following information: that something needed to be done in Europe concerning neutron source facilities. The plans for a European spallation source were already made, and Sweden could play a major role in their realization. The hosts at Region Skåne were puzzled at first. Arya, who was attending the meeting, reports their first thoughts: "Neutron facility! What are they talking about?" They were "somehow convinced", however, and soon after the meeting decided to establish and lead a lobby-group - ESS Scandinavia supporting the prospect of locating the facility in Lund. Arya recalls how the work of ESS Scandinavia "went up and down" over the years, and between 2006 and 2007, observed a "really negative trend". She reports a "very negative scepticism" coming from "the national level", as well as opposition to the project from the local Left and Green political parties. These "sceptics", as she puts it, argued against the implementation of ESS on financial and environmental grounds mainly. Arya emphasises, however, that even in the face of such a scepticism, Region Skåne was "with the ESS". She says: "we still sort of thought, down here, that of course this can happen. If you don't believe in it, of course it won't happen. You have to believe in the project." Arya recalls how positive attitudes towards ESS began to emerge more visibly in 2008, with the financial crisis that then hit Sweden. She thinks that the financial crisis might have helped ESS: "suddenly," Arya recalls, "on the national level, you needed something that looked at the future; that we could believe in." All 
of a sudden, officials wanted to do "something good for the future." Now, ESS is in construction - "we have a reality", says Arya, excited to play a part in its making.

In the interview, I asked Arya to reflect on how expectations had changed over time. She replied:

There was a public problem here in Lund about building this facility for a while, very early in the process. It was radiation. I mean, people were really against; sort of talked about that they are going to build a new Barsebäck in the middle of town, and things like that. And of course, if you don't really understand what a neutron facility is, what spallation, what neutron reactor. I mean, it is not easy to understand what is what here. And there were some people sort of being scared about this unknown thing that some people say is very dangerous and will be built in the middle of town. There was also discussion for MAX IV - not as big as with the ESS, but still. There were discussions, and "What is this?", "What will it be?" As soon as they started to actually build - they put the spade in the ground - that almost disappeared. We had almost the same feeling. The day we started to dig for the ESS, the whole discussion changed. I don't know if people think "Okay, they started to build it. Okay, this is for real. Okay, then it's probably good." I don't know. Maybe that is something for you to explain for me. You saw how the building went, then you only hear positive things. You never hear someone, maybe one, here and there, but not as before. I mean, then you could go to a meeting here in Lund and everyone was sort of "Oh, I am sceptic." and "Will this be? Isn't it a bit expensive?" and "Woo! Woo!", "What is it good for?" And after we started building, that kind of, it was maybe one in a hundred.

Interview, 2016 May 11

We can read this excerpt for how it performs coordination. Initially, this involves enacting disharmony, as a feature of the described ESS community at and up until a certain point, and is followed by an enactment of harmony, as a feature of that community after that point; i.e., when the various actors specified, ESS and the public (i.e. "the people"), originally disharmonious, were in line. Arya does this in reference to the start of construction, namely as what provided for the shift in "the discussions". The shift is articulated as a feeling, arising in two instances separately but in the same relation to the start of construction. Following Smith $(1974,1983$, 1987, 1990, 2001, 2006), we can think of this as a way of authorising the account: since the same feeling arose in reference to the same thing on two different occasions, then that thing must account for the feeling. Arya articulates a potential explanation for the shift as an account of people's thought - where "they started to build it" is respecified as signifying "this is for real", and this then as leading to a logical conclusion "then, it's probably good". This account resonates with that of ESS- 


\section{Accounting the Future}

neighbour Lena Glantz Larsson as presented in Sydsvenskan (see chapter 4, p 80), suggesting a consideration of public authorities in Sweden as responsible governors. It provides for taking that the start of construction means that public concerns with regards to ESS have already been accounted for (or else, construction would not have started) and that their continuation therefore is needless. It will become apparent towards the end of this section that the start of construction encodes another accountability relation, to do with membership in a Swedish political community. ${ }^{32}$

The next excerpt is from an interview with Brandon Dikson (pseudonym), a Senior Strategist at Skåne' Regional Council. Brandon's employment at the Council begins six years before the interview, in 2009, and one of his "specific tasks" there is to "work on ESS" (Interview, 2016 April 21). Within the scope of those tasks, Brandon is initially in charge of a project concerning "business life involvement in the facilities being built". After this project, Brandon continues working with the facilities on the political level, and, "for the lack of better words", he says, on "lobbying and the negotiations taking place on the national and international level". Again in reference to a question concerning the expectations he observed while working with ESS, Brandon responds:

Expectations changed from $\mathrm{x}$ number of new jobs to 'hurray, we can take a global position in a completely new and interesting research field'. From the beginning, everybody was concerned about the money and the number of jobs created. We actually had a huge study done by a consultancy and as consultancies do, they want to have like a really edgy final comment, and a really edgy executive summary. And one of those edgy comments was the whole issue of twenty thousand new jobs. And that is a huge amount of new jobs in Skåne. So everyone was really hesitant. Our statisticians were really reluctant to take up on that, and there were no real analysis to show that this was the correct number. That could be five thousand. It could be fifty thousand. But the smart thing was that they picked a nice round number. Twenty thousand. It was understandable. And for a couple of years, that was considered the truth. The figure was in the study, therefore it must be true. And it was very, very clever. Because, talking about twenty thousand new jobs makes for a very good start on a national level. It makes a really good start in Brussels, in the EU, etcetera, etcetera. Because, twenty thousand new jobs is good enough to be important, but it is

\footnotetext{
${ }^{32}$ Note also how, in producing an explanation for the shift in expectations, Arya also enacts a local accountability relation. For example, the item "maybe that is something that you can explain for me" provides for taking that she produces the account before me, as a social scientist who ultimately, as such, constitutes the actor in the local setting of the interview accountable for producing social explanations.
} 
not stupid like, say, two hundred thousand new jobs. Then, after a while, that was taken for granted and other things were becoming important. The buildings themselves were there, you could see them, and you could physically understand that those huge facilities would be filled up with people. And then, the sum per se wasn't really important anymore. [...] And from there, we have now gotten into a discussion where numbers aren't important at all. Except for those people who build the hotels, houses, roads, and bus stops. Then of course it is important if there will be twenty thousand workers or five thousand workers. For them it is still important. But for the discussion it is not important anymore. Now, what everybody is talking about is the ecosystem for innovation, the global position that Sweden and Europe can take. So it has turned from a very fixed number - twenty thousand - over six or seven years to a completely different discussion where you really talk about the future. You talk about the prospective twenty thirty, twenty fifty. And you talk about the global position, etcetera.

Interview, 2016 April 21

Brandon articulates an account of a shift from one harmonious state to another. In the beginning, "everybody was concerned about the money and the number of jobs created", just as now "everybody" is talking about "the ecosystem for innovation, the global position that Sweden and Europe can take." The change in expectations is accounted for in relation to "the facilities themselves" being there, providing for a physical understanding of "x number of jobs" and in this way rendering the number itself irrelevant as a topic of "the discussions".

Note how the harmony is being preserved given the change of expectations. There still are people for whom the numbers are important, but this is key: they are rendered as exceptions and as exceptions adequately. I.e., these are articulated as the "people who build the hotels, houses, roads, and bus stops" and for whom, as a matter "of course", numbers still as they normally do matter. "For them it is still important." Also, in accounting for the harmony, Brandon downplays the significance of "twenty thousand" as a representation of "x number of jobs" and stresses instead a few features of "twenty thousand" as a number as being the key force of coordination: i.e. in being a "really edgy final comment", a "nice round number" and thus "understandable", "good enough to be important" not "stupid like... two hundred thousand", as well as in being "clever". It is these features of "twenty thousand" that, in line with Brandon's account, have provided for making "a good start" on the multiple levels mentioned. 


\section{Accounting the Future}

We can see that accomplishing "twenty thousand" as a "good start" involves a statement of who, in this community, is accountable for knowing "twenty thousand" as a representation - namely, the statisticians. Insofar as they were concerned, that "could be five thousand. It could be fifty thousand." The statisticians are the only actors in the performed community that can react to "twenty thousand" as a representation, given that the features making "twenty thousand" problematisable as a representation (namely, the lack of real analysis) also are features that only the statisticians can know in this community as it is performed. From the perspective of "everybody" else constituting this community, "twenty thousand" merely appears as "a huge amount of new jobs in Skåne". For everybody else "x number of new jobs" appears as part of a study, and by implication suggests that a "real" study underlies it - "therefore it must be true".

In both Arya's and Brandon's accounts the coordination work involves, as a relevant moment, the start of construction, re-specified in Brandon's account as "the buildings themselves were there". This re-specification is important. It suggests the certainty of the future; i.e. that the start of construction can readily be taken for the future facilities themselves. In other words, it suggests that, with the construction started, we can see the future as if it were already there. Being able to see this, as I show below, is to do with the accountable rendering of the future. I show this in reference to an excerpt from my interview with Samwell Nilsson (pseudonym).

Samwell is a social scientist at Lund University. In this capacity, he participated in "this huge project called TITA" (Interview, 2016 May 10). Samwell explains that TITA stood for Growth, Innovation, Accessibility and Attraction, and aimed disseminating ideas about "the potential" from having ESS in the region. One part of this project, Samwell says, was about preventing ESS from becoming "just like any other research laboratory" and about finding ways of using ESS as a "tool for lifting the whole region"; i.e. for using ESS in rendering Skåne a "magnet" - "an international hub for innovation and science, attracting the best brains of the future from around the whole world". The other part of the TITA project, as Samwell remembers it, was about using ESS "for the citizens of the region". He says that "it used to be the future of the most talented kids to work in science, to become engineers". But increasingly over the years, "young talent goes to study media or the experience industry". The question this project oriented to then was "Could we use ESS to say that "We have the best research facilities in the world in science! You live here. You have an opportunity to become part of this region. Of course you should study science, because you live in Skåne where the ESS is situated.'?" A related third 
part of the TITA project was about inspiring local communities to make use of ESS. This was especially problematic, however, as, according to Samwell, for most citizens outside Lund University ESS was merely "that thing they are building next to the highway". Importantly, this was a bad thing - evoking for citizens "the bad image of the future", i.e. "people would get sick, and you'll take away the best land for agriculture. You'll create some kind of cold area, with cold people, radiation, risks - I mean, the bad image of the science of the future."

I asked Samwell if, at any point of his work with ESS, he too had such expectations. He replied:

I know that many people have been sceptical towards whether the ESS should be built or not due to the enormous amount of money to spend on it, the financial difficulties of the European Union. But I haven't been really engaged in it. And in a way, there is such a long tradition in Sweden especially: If you have decided on something big that should be done, you do it no matter what the consequences. Take this tunnel on the Hallandsåsen. It is more or less a stupid idea - it would take you ten minutes less to get to Gothenburg from here. It was a massive failure: pollution, dead fish, costed - I don't know how many billions more than expected. It was going on for 25 years. But there was so much prestige invested in it. So it was impossible to interrupt it. I mean the investment was totally absurd. And now it's completed. After 20 years of construction. A small tunnel in the north of Skåne. And the ESS is even more prestigious. So I haven't been that worried that the ESS would fail. But of course I can certainly be sceptical whether it would be this magnet or not. Is it that cool really, when you have it there? Would it be something that you just pass, like the head office of Sony Eriksson? We don't know. ${ }^{33}$

Interview, 2016 May 10

In this excerpt, Samwell draws together ESS, the European Union, Sweden, "this tunnel", pollution, dead fish, costs, time, and prestige to perform ESS as a morallycharged investment; as something you stick with, and stick through, no matter the difficulties and consequences on the way, and regardless of how much these suggest giving up as the proper thing to do. More than this, the excerpt enacts ESS as one in

\footnotetext{
${ }^{33}$ In the last part of this excerpt, Samwell expresses scepticism (or non-knowledge) about the somethingness of ESS in the future. It can become a thing, i.e. a "magnet", but also it can end up being just another building in the landscape, something "you just pass", like the head office of Sony Eriksson. I have attended two practices in the ESS setting, orienting in different ways to accomplishing the somethingness of ESS in the present - the "future walk through Brunnshög" and an organised visit to the construction site. I address these in the chapter 6.
} 


\section{Accounting the Future}

a series of other such investments, including the construction of that "small tunnel in the north of Skåne" and, in this way, it enacts its futurity. Just like those other projects happened, and regardless of their stupidity as ideas, this (and especially this) one too will happen. It will happen, not simply because those others have happened, but also because the morality of ESS as something you stick with (no matter what) suggests it is that kind of instance. Arya makes a similar point. She says:

Of course, you can have change of government. Then, you can have [...] someone else comes in and says 'I wasn't part of this, and I don't want this.' and 'I want to put the money somewhere else.' So, I mean, there are no a hundred percent guarantees. But you work like that to try and make a long term sort of investment or support. Most often, when it comes to this kind of investments, we feel respect for that, between the parties. I mean, you respect that. So you don't withdraw your support, even if you didn't really think that was a good project. But it's a sort of a kind of project that you don't sort of withdraw. It's like an infrastructure. I mean, if you build a road, and then you change governments, you don't just quit and say 'Oops, sorry.' You sort of, you finish the work.

Interview, 2016 May 11

In this excerpt, Arya performs politicians as constituting a community. And relevantly, enacts the relationship between them, that which makes them a community, as a pledge. Within this community, politicians are accountable for they are answerable for, have a responsibility for - finishing, for persisting through, for bringing to a close, what other politicians before them have started and as part of the moral makeup of this community as a community. More than simply enacting the start of construction, then, Arya's reference to "spade in the ground" (see p 91, this chapter) can be seen as enacting an ESS community. The point is that, it is in relation to this political community that the future of ESS is observable and reportable in relation to the start of construction as certain. The ESS facility will happen, despite any difficulty or consequence that says otherwise, because, given it has started, making sure that ESS happens is making sure that Sweden has the political community it does and because being part of this community, as a politician, involves, as a criterion of membership in it, being answerable for the completion of ESS as something involving (or starting within) that community. And by implication, not bringing ESS to a close, i.e. disrespecting that pledge, is like an act of selfexclusion from the political community. 


\subsection{Coordinating through Calls}

This chapter shows how accounts of expectations perform coordination as a feature of ESS communities, rather than a capacity that expectations have due to their content. Importantly, this work enacts accountability relations upon which the sense of the community as coordinated depends. Continuing on this theme, the remainder of the chapter provides analysis of the 2014/2015 Call for Proposals of "instrument concepts" at ESS. The Call, as I found it in 2015 while reading through the ESS website, is presented below in full. It is necessary to reproduce this text so as to examine the ways in which it enacts and sustains community performance. The original document contained hyperlinks. These hyperlinks are represented here as underlined words. Apart from that, Figure 1 preserves the features of the original Call document.

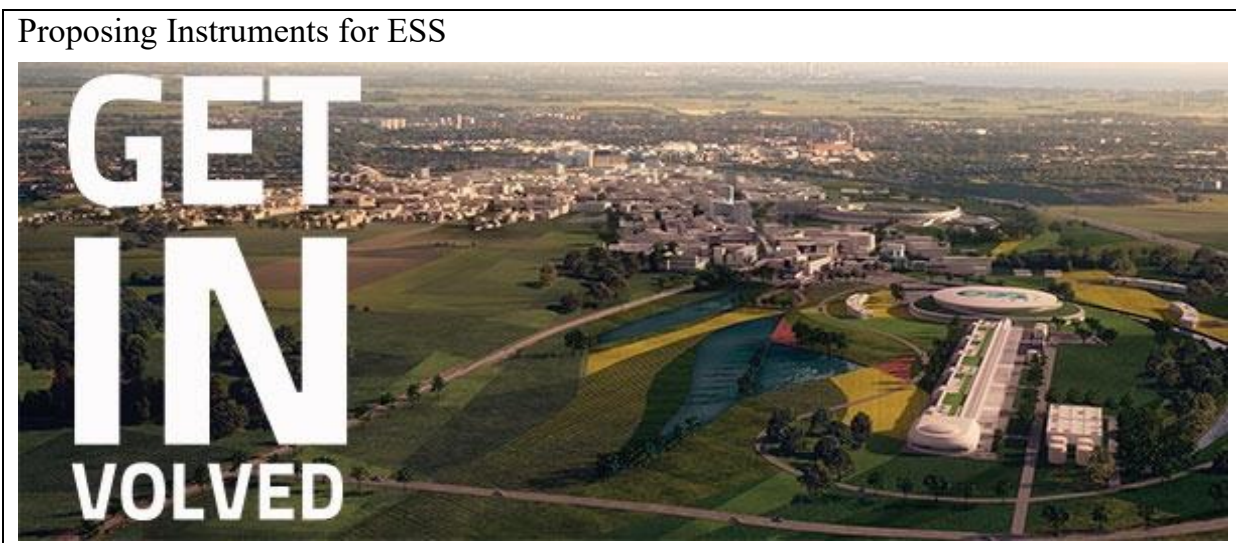

The 2014/2015 call for proposals of instruments to build at ESS is open. Below, please find information about the call, the proposal content and the review process, as well as the proposal template and guidelines.

The instruments built at ESS are selected from among the instrument concepts being developed at different labs in the partner countries. This selection is done through a call for proposals, followed by a review that engages expert reviewers from around the world. Each call results in a number of instrument projects being approved for incorporation into Phase 1: Preliminary Engineering Design and Baseline. This phase leads to a detailed engineering plan, reviewed at the end of the phase. 


\section{Accounting the Future}

From the 2012/2013 round, three out of the four proposed instrument concepts are now undergoing preliminary engineering design. In the 2013/2014 round, 16 instrument concept proposals were received from around Europe, 9 of which were recommended to move ahead. The 2015 proposal round, now open, will be the last one to consider instruments for the initial suite of 16. Further instruments will be decided upon later.

Here you will find information on what to expect when you propose an instrument concept for construction at ESS. The process is set up to help individual proposers prepare a high-quality proposal that will move through the selection system smoothly.

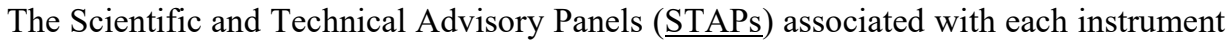
class play an important part in providing feed-back during the development of the proposal and again in the review process. The Scientific Advisory Committee (SAC) take the birds-eye view of the entire instrument suite, and make recommendations to ESS management on which instruments to advance into Phase 1. The ESS Steering Committee (STC) make the final decision. Both the STAPs and the SAC consist of experts in neutron science and instrumentation from facilities and universities world-wide.

Below, you'll find details on the review and decision process, the contents of the proposal, the members of the reviewing bodies, and more. By way of example, documents from the previous rounds are available.

Who can Propose an Instrument Concept?

The call for instrument proposals is open to professionals in partner countries. Consortia of scientists in different labs and from different countries are welcome to submit joint proposals.

The Proposal, Review and Decision Process

1. Prepare an instrument concept proposal. You are encouraged to submit a proposal to the STAP and ESS prior to first submission. ESS staff and STAP members are available to read and comment on the proposal at this stage.

2. Present the proposed instrument at IKON7. You are invited to present the draft proposal in a brief talk at IKON7, Sep. 15-17 2014.

3. Submit the instrument proposal by Jan. 15, 2015. The proposal is distributed to the STAP and to ESS: the coordinator of the instrument class, the Neutron Technologies groups and the Science Management Team.

4. The proposal is reviewed internally at ESS. The ESS Science Management Team evaluates the proposal and the Neutron Technologies groups consider technical feasibility and identify the R\&D needs associated with the proposed instrument. 
5. Present the proposed instrument at a review session at ESS, with the STAP present and the internal ESS reviewers represented.

6. The STAP prepares a preliminary review. The proposal is evaluated with respect to scientific and technical aspects, and any internal considerations raised are included in this review. If the STAP finds that too much information is lacking from your proposal, it will not move forward in the process. If your proposal needs relatively moderate modifications, you are given the opportunity to revise it, using the feedback from the review session and the STAP review.

7. Submit your final proposal by April 15th. It will be sent to the SAC, along with a final STAP review of the final proposal.

8. The SAC advises on whether to move the instrument concept into Phase 1: Preliminary Engineering Design. At the SAC meeting you have the opportunity to present your instrument proposal verbally. The STAP chair presents their review, including an overall strategy for that instrument class, and ESS presents their view. The SAC make their recommendations based on the STAP and ESS input, considering a larger perspective on the overall instrument suite and on the science best pursued at ESS. All proposals are made available to the SAC.

9. The Steering Committee makes the final decision on whether or not to enter the instrument into the construction project. ESS management submits a proposal to the STC on which instruments to incorporate into Phase 1, based on the advice given by the SAC. All instrument proposals that were made available to the SAC are also made available to the STC, along with the SAC recommendation. The final decision on whether or not to move an instrument concept forward is made by the STC.

\section{Figure 1 - The 2014/2015 Call for Proposals (ESS 2014a)}

Van Lente and Rip (1998) argue that "expectation statements" - i.e., any description of the future, including therefore the Call document above - are key tools for coordination in complex settings. Expectation statements coordinate, according to them, because they contain (or imply) a script, which provides for positioning the relevant actors, "exactly as characters in a story" ( $p$ 19). The document above can be seen as articulating such a script, mobilising various actors and specifying the relationships between them to be played out in and as the process of answering the Call. These are some of the features of this document as a script.

1) The document articulates the Call "open" only in a restricted sense in that, not all readers who happen to stumble across it are called upon to attend it but labs, professionals, and consortia of scientists from "partner countries". 


\section{Accounting the Future}

Moreover, it specifies that the instrument concepts are "selected from among those being developed at different labs in the partner countries". In this way, the Call provides for reading that an ESS-oriented community of prospective instrument proposers already exists, that the Call is "open" to members of that community, and that a pool of "instrument concepts" under development already exists within that community. That is to say, the Call not only organises a community prospectively, but it also calls to a community that already is organised in a particular way.

2) Also, the document makes available a list of nine items, and binds them together as a sequence of events, constituting "Proposing Instruments for ESS" as a "process". It frames these events prescriptively, specifying the relevant interactions between the implicated actors in the "process", either in relation to the instrument proposal itself or with respect to one another. We can see that, in so doing, the document performs, and maintains throughout, a separation between the development and selection of "concepts". Thus, it provides for reading that individual proposers will "prepare", "present", "submit" and "revise" the "instrument concepts", while the selection system bodies will "read" them, "comment" on them and provide "feedback", "review" and "evaluate" them, as well as ultimately make a "final decision" on whether or not to "recommend" a particular "instrument concept" for construction.

So far, our analysis is in line with Van Lente and Rip (1998). The document makes available a script for doing the Call as a process, where various actors are drawn together and implicated in particular roles, and where concepts are to "move" through a series of transformative interactions and endorsements. However, an analysis in line with Van Lente and Rip is limited. It only shows how an existing community of prospective proposers is represented in a document organising a future scenario for playing out a call in specific ways. Importantly, we need in addition to consider how the Call document also organises accountability relations between the various implicated actors. I consider this in relation to three aspects of the Call:

1) Performing proposers as "expecters"

I turn attention to the following statement - the most obvious "statement of expectation" (Van Lente and Rip 1998) in the Call - articulating:

Here you will find information on what to expect when you propose an instrument concept for construction at ESS. 
We can think of this statement as performing the "information" the Call provides as expectation, and the role of the proposer in the proposal "process" as expecter. Note that, the "information" concerns what the prospective proposers themselves should expect as participants in the "process" and not what is expected from them in this "process". We can read this as a way of making the proposers accountable for the realisation of the prospective community, the set of relationships between the actors in it, as performed in and through the document. The proposer-as-expecter is thereby inserted into the group of actors specified as responsible for making sure that the future scenario constituting the Call plays out: namely, the bodies STAP and SAC that respectively provide feedback and take a birds-eye view on the operation.

This provides for taking that, if in proposing an "instrument concept" the proposers find something that does not accord the pre-specified "information", it is (also) their responsibility to address this; to re-turn the process of "proposing instruments for ESS" to specification. That is to say, by the particular way in which the "information" is performed as expectation, proposers are made accountable for making it happen. We can argue then that the statement of expectation works to secure the happening of the prospective community as scripted in and through the Call document.

2) Performing quality as a "capacity"

In articulating "Proposing Instruments for ESS" as a "process", the Call provides for reading that the quality of the submitted proposals increases or improves over time, as an emerging effect of the interactions between the individual proposers and the bodies constituting "the selection system". The "process", in other words, can be seen as adding to the quality of the proposals. Or differently again, the process is not merely a way of recruiting high quality "instrument concepts", but can also be seen as a way of intervening towards a situation where this may be done.

For instance, the event "review", being positioned in the middle of the proposal "process", stands not only to evaluate concepts in terms of quality but also to enable proposers to act upon this evaluation as the "process" continues to unfold. The "review" event thus illustrates that selection has, not only normative but also a formative input to the "process" of proposing instrument concepts. Not all proposers can use the resulting evaluation formatively:

If the STAP finds that too much information is lacking from your proposal, it will not move forward in the process. If your proposal needs relatively moderate modifications, you are given the opportunity to revise it, using the feedback from the review session and the STAP review. 


\section{Accounting the Future}

I draw attention to three features of this passage, providing important considerations for how quality is to be understood as part of the proposal "process". Firstly, notice the co-constituting of success and failure by means of establishing a contrast between "too much information is lacking" and "needs relatively moderate modification". While configuring quality in this way as having to do with the demonstrated completeness of information and the need for modification, this contrast also indicates that such completeness and need will be found inside the proposal. Thereby, the Call document effectively blocks the possibility to arise that the success or failure of the proposal to "move forward" will be attributed to anything external to the proposal, including for example the proposers themselves, the labs where they are developing their "concepts", time, or indeed potential faults in the selection system. Secondly, notice the juxtaposing of the active role of the selection system body STAP with the passive used in articulating "you are given". This provides for reading that the quality which counts towards deciding that a proposal should indeed "move forward" is not that individual proposers have prepared, but that the selection system, as represented by STAP in this case, has found in the proposal and evaluated as sufficient for moving the proposal forward to the next stage. The active/passive construct disqualifies individual proposers from participating in the decision-making through which quality is being determined as in the proposal. Finally, notice how the passage refers to proposals by signifying belongingness: "your proposal". The possessive pronoun instructs that, in the process of selection, "concepts" are attended to as proposers' own, with the implication that any quality that the bodies constituting the selection system have found in them is a quality that the proposers themselves have achieved. The failure or success in yielding with "high quality" may not, in this way, be attributed to, say, the "feedback" that the STAP members have given, but to how individual proposers have used it in revising the "instrument concept" proposals as theirs. We can see that, with these three moves, the Call document performs the capacity of the prospective community to account for quality and also, importantly, it provides for exempting the bodies constituting the selection system from accountability for the movement of the proposal through the process. As I show later in the chapter, these accountability relations have turned out to be of consequence in some Call rounds.

\section{3) Visualisation as a performance of answerability}

The Call document articulates a future scenario with an image displaying a particular "view" (see Figure 1, p 99). The "view" provides for seeing over ESS, over Lund disappearing in the background, over the MAX IV facility there and the Öresund 
noticeable in the distance. The organisation of this "view" makes ESS present as one among other entities to be over-seen by a beholder outside the image. One of these entities is invariably recoverable from the image as the "ESS" referred to verbally in the Call document. This referential link delivers the image as bringing to one's sight not just a view, not any view, but a contextually relevant one. It fixes a local visual referent for the signifier "ESS", thus that ESS is nothing more, less, nor other than the visually available. The entity in the image locatable as ESS, is "ESS".

The image delivers ESS spatially as situated somewhere. To the extent that it is somewhere, it is so in relation to the other entities in the image (e.g. fields, roads, buildings, a town, the MAX IV facility in the background and so on) constituting together with them its "there". The image mobilises ESS in relation to these other entities to provide for recovering various relevant features, including: its temporality (as fully-fledged; but also, importantly, as together-with other entities), its scale (and expanse), remoteness (and so also a sense of its accessibility), and its distribution (before/after, back/front, first/second, etc.).

To some actors beholding this image, some of these features do not make sense and, more than this, they amount to a cause for concern.

Thus, Von Platen (2013) reports some of the frustrations amongst MAX Lab employees stemming from casually implicating both ESS and MAX IV when talking/visualizing futures. One frustration, as Von Platen reports, concerns the ordering of the facilities. Or, as an informant of hers puts it, "Journalists keep mixing us up. And the strangest part is when they write 'MAX IV, which will be placed next to the ESS.' That's not right. They're the ones that will be placed next to us." (p 131). "This perspective is so wrong!" (ibid). A second frustration for MAX Lab employees concerns the blurring of differences between the two facilities in public narratives that seek to promote their closeness and complementarity. Thus, according to one of Von Platen's informants: "The differences are enormous. We are a local and national facility and they are an international project that just happened to be placed in Lund. It is very unfortunate that this is not clearly communicated." (ibid).

Finally, a third frustration Von Platen reports concerns "the claims" that the facilities will contribute to the increase in population and employment, as well as industry collaborations in the Öresund region. According to Von Platen, MAX Lab employees are "not so convinced that this will actually be the case" (p 130). Explicitly, she points out, they distance themselves from those and such claims. Or, as one of her 


\section{Accounting the Future}

informants puts it: "They'll have to stand for that. We have never promised anything like that." (ibid).

We can think of these frustrations in relation to accountability. Not just visualising ESS in the future, MAX Lab employees apprehend images such as that the Call provides as rendering them accountable in specific ways and thereby also, as accountable for the future. In other words, we can think of the image in the Call as visually performing answerability. This evokes a question as to the ways and extent to which the prospective proposers of instruments can be seen (or held) as accountable for the future as the image, or the Call generally, performs it. I address this question further in the next section, where I present material from an interview with an "instrument scientist", Eddard Jensen (pseudonym), recounting his experience of proposing an "instrument concept" at ESS.

\subsection{Eddard's Account of Getting Involved with ESS}

Recall the line in the Call that says: "The instruments built at ESS are selected from among the instrument concepts being developed at different labs in the partner countries." (Emphases added). This line can be read as establishing the terms "selection" and "development" - by which the participants in the proposal "process" recognise and make accountable the rationality and objectivity of their doings. For example, we can argue that in making their "instrument concept" selectable, the proposer/s must make the conceptual work behind it accountable - i.e. recognisable, analysable, interpretable, reportable - as "development". So how is this conceptual work organised so as to perform a sense of "development"? To answer this question, I analyse an insider's account of the "process" of proposing "instrument concepts" at ESS. The account was given in interview with an "instrument scientist" - Eddard - a proposer of a successful "instrument concept" and, at the time of the interview, a leader of the team responsible for turning this "concept" into an actual ESS instrument. How, then, is Eddard's account of involvement with ESS performed as pertaining to the "process" of proposing an instrument for ESS?

I indicated in chapter 3 that, my strategy of interviewing involved starting with a question about the informants' involvement with ESS over time. Answering this question:

1) Eddard (Interview, 2016 November 28) began his story by recounting an early moment in his career - in high school, when he slowly began realising that 
"mixing liquids at a chemistry lab" was not interesting to him. Instead, he found physics intriguing. Pursuing this interest, he was focusing on $\mathrm{x}$-rays at first. Only as part of his post-doc project at the Paul Scherrer Institute (PSI) in Switzerland did he begin to engage with neutrons. During this time, Eddard took "the responsibility" to do work on an "in-house test reflectometer". While this machine was mostly for "playing around", his personal objective became one of "improving it". After half a year doing this, Eddard began to re-build the instrument. He says that this was his first instrument-building experience and stressed that this instrument "still works" today. A neutron optics project at the PSI gave Eddard the opportunity to apply his evolving know-how in this matter in developing a lens for a reflectometer which would focus on "small samples". Eddard explains that, because neutron-beams are normally "quite large", most neutrons get lost when targeting "small samples". He says: "They just don't get to hit the target." His working strategy, then, was to design an instrument - "a truly focusing reflectometer" - which would resolve that issue. The result was a pyramidal device - "nothing special", as Eddard puts it, "just two pieces of glass, slightly bent and coated with a supermirror". While "nothing special", this device gave "a gain in efficiency of two hundred percent".

When I first heard this account, I thought to myself: "How is this to do with Eddard's involvement with ESS?" On the surface of it, I could not see the connection. But as I continued thinking about this account, I began realising that it constituted an important way of claiming involvement. By starting with his professional development, the account was performing Eddard as a competent reflectometry specialist. It was a way of making Jochen accountable as an expert figure in a story of his involvement with ESS. He continued as follows:

2) In 2002, Eddard heard from a colleague of a "strong initiative" to build a spallation source in Europe. He did not give it too much thought at that time. He recalls, however, that shortly afterwards, in 2003, this initiative "stopped completely". Eddard reasons that the German government had decided not to invest in a spallation facility. The ESS project, he says, "died at that time." Then, after a couple of years, a new initiative emerged of "reviving the ESS" as part of a "next round investments in large-scale facilities". Eddard recalls that, in this period, "they" - he says "I don't know who they are, most likely a couple of scientists" - began organising workshops concerning ESS. The first was held during a winter, on a farm located on the island of Hven, between 


\section{Accounting the Future}

Denmark and Sweden. The rooms were not heated, says Eddard, so the participants had to keep their hands on the laptops to warm up. It was in his regard "the coldest workshop ever". The aim of this first workshop, as Eddard remembers it, was to discuss "different things to build in the future". He says he did not design "a clear instrument concept" then. But it was in the context of this workshop that Eddard presented his "first ideas about focusing". He attended another ESS workshop later on, in the Netherlands, holding a talk on neutron optics. Eddard characterises these two workshops as his "first involvement with ESS" - after which, he says, "it went on".

More than just recalling a time, we can see that the account performs a professional community (consisting of Jochen and his colleagues) in which such things as "initiatives" for the building, stopping, and reviving of ESS get heard, reasoned, or generally known in particular ways. The account, in other words, performs Eddard's "involvement with ESS" as an involvement in a community that hears and reasons about ESS as an "initiative", and discusses such matters as "things to build in the future". The comment that "most likely a couple of scientists" organised those discussions can be read as a way of maintaining the sense of the community as professional, or a sense of the community's involvement with the ESS "initiative" as professional. Eddard continues as follows:

3) In the process of developing his ideas for a "truly focusing reflectometer", Eddard found that earlier prospects on how this could be achieved did not work in practice, so he had to be inventive. In his office at PSI, "among all the drawings and papers", he would identify "the problems". Then, while cycling, i.e. "not fixed to a table, and without paper and pencil", Eddard would come up with ways to "get rid of the problems". It is on one such occasion that he thought of introducing a second ellipse in the design of his instrument. Returning to his office, he did some calculations and discovered that this solution worked. Eddard considered alternative ways to realise his reflectometer concept at his own Institute, the PSI. Soon, however, "ESS was wealthy again" and "they started asking for instrument proposals". In 2010, and building on his invention, Eddard began working on "an instrument for the ESS". This will become ESTIA (see below).

We can see that Eddard constructs an account of a work process. As constructed, the work process involves identifying and solving "problems". The account presents this process as spatially distributed, where the identification work is done in "the office" and the solving "while cycling". One way to read this account is as achieving a 
display of professional character, performing Eddard as somebody who has incorporated an aspect of everyday life, i.e. cycling, into work-life, as a way of solving work-related "problems" - so much so that he defines "cycling" as a negation of what "the office" is (or represents for him), namely "fixed to a table, and without paper and pencil". ${ }^{34}$ We can read this as accomplishing a sense of his intense communal involvement. Another key feature of Jochen's account is the suggestion of options concerning where to realise his "instrument concept", where ESS was one and the other his own Institute, the PSI. This can be read as performing ESS as a (personal) "choice".

A broader reflection concerning the accounts of informants' personal "involvement with ESS" is that they are organised so as to underline the significance of these involvements in the ESS context. In this connection, these accounts resonate with the stories about the so-called "helium-3 crisis" (see chapter 7) and, as I argue there, can be seen as a way of generating and sustaining a role in future-making. In this chapter, I am looking at the ways in which performances of accountability relations can be seen as accomplishing coordination as a feature of ESS communities. To that end, I return to Eddard's account of proposing instruments for ESS.

During the 2013/2014 round of proposals, ESTIA, Eddard's "instrument concept", was in competition with VERITAS - a high-flux neutron reflectometer with vertical sample geometry for a long pulse spallation source. Between these two "instrument

\footnotetext{
${ }^{34}$ Eddard's account resonates Aemon Löfgren's (pseudonym): "I was doing modelling and I had a mathematical model that didn't quite understand how to treat. So I knew what it was useful for and it had some really nice applications. The problem was that there was a numerical problem in how to deal with this particular set of equations. I was visiting a friend who was having a birthday party and I was there, late in the evening - playing darts, drinking whiskey. At three o'clock in the morning, I suddenly realised the solution to my problem. I've been working on this for - how much? - four or five months, trying to understand the mathematical structure of my problem and I had been beating my head against the wall about this. And then, I had this epiphany. In those days you didn't have computers at home, so I went straight from the party to the chemical centre where I had access to a computer. I was rather drunk, so I had a problem in doing the coding, because my fingers wouldn't do what I expected from them. But I was completely lucid in my mind, because it was such a shock for me to understand the solution to this problem. So I spent three or four hours coding the solution into a program which I ran, because I was also convinced that if I go to bed without doing this I would have forgotten it by the morning. The thing worked." (Interview, 2016 October 18).
} 


\section{Accounting the Future}

concepts", only ESTIA passed the selection "process" successfully. The other instrument was rejected. Here is how Eddard contemplates on the outcome:

One cannot say that the one instrument was better than the other. It was just that ESTIA was brilliant for small samples. So the focusing works fairly well for small samples. For large samples it won't work as well - not that good. And this is also why guides like VERITAS are still being built. Whenever you have a large sample, this might be better. So, my focus was on focusing ((laughs)) while the other instrument was not truly focusing. It was somehow, but not truly. Their aim was to have larger samples, and instead shorter counting times or higher measurement angles, or shorter wavelengths. So they optimised the instrument in a different direction. At the end, the decision was made for the instrument for small samples rather than the instrument for large samples.

Interview, 2016 November 28

Note that "the decision" is articulated as made - not for ESTIA per se, but specifically "for the instrument for small samples" which, only incidentally, ESTIA was. It is provided that the indicated "they" were not choosing between ESTIA and VERITAS, but primarily between "small" and "large samples". Note also that this suggests a situation where two differently optimised "concepts" are found to be equal in "quality". Eddard continues as follows:

It was just that they were thinking about the samples of the future. Samples are getting smaller and smaller. Especially if you have some new feature, you find a new property on a sample - normally, it's a small sample. It takes some time to grow it larger. If you can measure this, already on a small sample, you can publish one or two years before the larger samples exist. This is a big advantage. And another thing, small here means that the samples are of the size which is also used for x-ray measurements. Of course, the x-ray beams are much smaller. But the samples are a couple of millimetres squared. So you can measure the same samples here, and using x-rays, and on other devices. And with VERITAS you could measure large samples using neutrons. But if you take large samples, for example two inches, to an x-ray machine, they have no idea of how to put it in. It doesn't fit. So samples that you can measure with ESTIA are compatible with a lot of other methods. Just because of the size. This was as I understand it the reason for the decision to build ESTIA and not VERITAS. So ESTIA was not better or whatever. It was better suited for some special application, where they thought this might be the future of reflectometry.

Interview, 2016 November 28 
Eddard accomplishes the complementarity of ESS and MAX IV as a selectionrelevant feature of an ESS instrument. It becomes clear from these excerpts that ESS and MAX IV, while providing for the possibility of using two different techniques to study materials complementarily in the same geographical setting, this use needs to be achieved through the instrumentation of ESS. In another interview, Brandon Dikson (pseudonym), a civil servant at Skåne's Regional Council, described for me a future where a scientist casually walks from one "huge microscope" to yet another, "even bigger", using two complementary procedures - x-rays at MAX IV and neutrons at ESS - for studying the same material (Interview, 2016 April 21). In this way, Brandon suggests that walking from one facility to the next is the only technical difficulty the scientist will face in employing these techniques in such a complementary way. According to Brandon, "there is no other place in the world that has two complementary research facilities of this magnitude so close to each other." Here, however, Eddard suggests that such a future is still, due to differing sample sizes, not possible and in that sense, deciding on ESTIA rather than VERITAS can be understood as a move towards accomplishing such a future; i.e., a move of making such a future possible through ESS. Alternatively, we can think of Eddard's excerpts as denoting a situation where the selection system body "they" holds the proposers, the teams behind the two competing instruments ESTIA and VERITAS, accountable for such a future; or that, in choosing what "they" choose, they are enacting their answerability for making such a future possible. This decision, as I show below, resulted in complications.

A third instrument concept in the category reflectometry was FREIA ${ }^{35}$ - a fast reflectometer for extended interfacial analysis. Eddard tells me that Olenna Sandberg (pseudonym) was the proposer of this "instrument concept", but as he suggests in the following excerpt, also the assigned coordinator for the reflectometry category and a member of STAP, the selection body here referred to as "control group". As Olenna's "instrument concept" was constructed for measuring horizontal surfaces (e.g. of

\footnotetext{
${ }^{35}$ Note the names of the instruments mentioned. Not only is it an instrument, FREIA also is the ancient Norse goddess of love, fertility, and beauty. Similarly, ESTIA is the ancient Greek goddess of the hearth and, moreover, includes the focusing concept Selene - named after the ancient moon goddess. Other instruments at ESS selected into construction include THOR, LOKI, HEIMDAL, VOR, ODIN, SKADI, and BIFROST - all gods and goddesses from Norse mythology. Eddard says that he began this naming theme first, with Selene, and it took off from there. In certain ESS presentations of the instruments, the relationship between particular "instrument concepts" is presented metaphorically, as echoing that between the respective deities.
} 


\section{Accounting the Future}

liquids), FREIA formally was not "in a competition" with ESTIA and VERITAS, each designed for measuring vertical surfaces (e.g. of solids). Eddard reflects:

So, while I'm happy that my concept was chosen, so I did well ((laughs)), the other team [proposing VERITAS], they started to fight when they learned that theirs was not chosen. They went around and gave talks about the instrument. And a lot of people asked me "Isn't it already decided? What are they talking about?" And they were still improving the instrument concept. So they still spent work on the instrument to show that it's better. And strangely enough, not better than mine but better than FREIA. So, they even changed the science case for the instrument to somehow still get in. So they really got, sort of, obsessed with having this instrument built. [...] I think they changed the name from VERITAS to HERITAS. But it was also an intrinsic problem from the ESS because they asked Olenna to coordinate the reflectometers and in parallel she was asked to head the STAP which was the control group. And she was asked to develop her own instrument concept. So, she was in the control group, she was a coordinator, and she supplied her own concept. A conflict of interests. A very strong one. And at the end, I didn't care too much if that was okay. It was their problem. But the other guys, with VERITAS-HERITAS, they didn't like that.

Interview, 2016 November 28

We can observe two features as key to this excerpt. Firstly, notice how, in elaborating "the problem", Eddard mobilises the actors in the roles pre-assigned to them as participants in a formalised "process" of proposing instruments for ESS. We can argue that there is nothing intrinsically wrong about playing the role of proposer, coordinator, and controller. Principally, Olenna can be able to produce an "instrument concept" herself, and at the same time be able to evaluate the various "concepts" proposed objectively, in determining which "concept" to recommend for construction. Also, during the specific round, Olenna's "concept" FREIA was the only one in its application within the category of reflectometry. In other words, it did not have a rival. Conflict of interests emerges as a problem, however, in relation to the Call as formalised, which performs and maintains these as separate roles and, moreover, as roles that belong to two different dimensions of proposing instruments for ESS - "development" and "selection". We can think of the indicated "fight" centrally as being about holding the bodies constituting the selection system, and ESS generally, accountable for the Call as formalised.

Secondly, consider how, in framing the "fight", Eddard mobilises other people's expectations. "Isn't it already decided?" not only provides for saying that the "fight" is happening after the selection "process" has come to a close, that is after a decision 
on which instrument to "move forward" to construction has been made, but also, it signals people's expectations (as something performed on the occasion) concerning the temporal ordering of proposing instruments for ESS as a formal "process"; where fights, giving talks, changing scientific cases or names, and working on showing that the instrument is "better" precede decisions, and where decisions are final. In other words, the "fight" is made to appear nonsensical in relation to an expected formal framing that configures it as having a correct place in proposing "instrument concepts" as a "process", and in relation to which the "fight" is out of place. Differently again, what prevents the ESS community from collapse - what ensures its accomplishment as coordinated - is not solely that it is scripted in a formal Call, but also, and importantly, because the Call as a formal document performs a structure of accountability which keeps the community it performs in place. The following excerpt from my interview with Eddard (2016 November 28) elaborates this further:

Eddard: From the beginning, it was clear that there will be two reflectometers. Because you can optimise a reflectometer really well with respect to a single aspect only. And it was clear from the beginning that there was supposed to be one reflectometer for liquid surfaces. A liquid surface is flat. It's horizontal. You cannot do anything about that. So there is no compromise possible for that. So you build an instrument which is optimised for these measurements on liquid surfaces. So this was the change from VERITAS to HERITAS. The "V" was from the beginning "Vertical" and was changed to horizontal surface to HERITAS. So they just took the instrument and rotated it by ninety degrees. This was one thing. So it could do liquid surfaces. And then, they adapted all the guide geometrics, the optics, the detector, and so on, to the other science case.

Ivanche: So they changed the case and were back in the competition?

Eddard: No, no. It was decided already. They tried to get into competition again, but afterwards. So FREIA was selected and ESTIA. They changed the case, and they wanted to kick out FREIA. But they couldn't. You cannot decide for an instrument and say "Ha, ha. No. We don't do it." Nobody will trust you anymore. And they, they claimed they were better than FREIA. But in the meantime, FREIA also developed further. So there was never a finite comparison between these two. Because nobody decided to build another reflectometer. It was clear. Why should they start comparing? At some point, you have to decide what you want to do and then go that way. If you wait for the next better concept, you wait forever because there is still innovations every now and again. What you build at the end is never the best instrument because of newer concepts. But it's a reliable, robust thing that should work.

Interview, 2016 November 28 


\section{Accounting the Future}

We can see here that Eddard formulates the prospect of bringing VERITAS back in the competition as a breach in the accountability relations that constitute ESS as a community. "You cannot decide for an instrument and say '...We don't do it.", not simply because a decision already had been made, but also, importantly, because the relations that the term "trust" indexes hold decision-makers accountable for their decisions in this setting. It is these accountability relations that provide for the coordinated accomplishment of the Call document.

\subsection{Conclusion}

This chapter examined accounts of futurity generated in interview and other settings as made in relation to "expectation statements". My aim was to examine the ways in which performances of accountability relations could be seen as accomplishing ESS communities as "coordinated". I identified three key mechanisms through which accountability work gets distributed and done in this context. Firstly, this involves enacting a social organisation where such objects as "high expectations" are distributed across actors who are indicated as having expectations and actors who are said to respond to them; that is, it involves performing a community consisting of actors who, in relation to the object "high expectations", are passive (simply having the expectations) and actors who in that relation are active (e.g. responding, intervening, acting on the expectations). Secondly, it involves re-specifying "high expectations" as "strong support", and thereby also the initial communal dynamic. Initially passive, having the "high expectations", the actors are performed as active, giving "strong support", acting as a kind of ally. A third accountability mechanism involves re-specification of the "start of construction" as ESS, the "building itself", "being there". We have seen that performing accountability relations that bind the various implicated actors together into a Swedish political community provides for reading or hearing this statement as making sense. With regards to the Call, I showed that - not only do proposers perform the pre-specified roles, but also, in so doing, hold others accountable for performing their roles as enacted in the Call document. Performing the Call's script and its accountability relations, then, was what provided for a sense of a "coordinated" realisation of the ESS community. 


\section{"Nothing to See Here" - Accomplishing Futures as Sensible}

The previous chapter examined coordination work as done in and through accounts of expectations. My analysis showed that accomplishing a sense of coordinated orientation to the future involved a performance of "social organisation" (Smith 1974, 1983, 1987, 1990, 2001, 2006) around the object "expectations". I identified several features of this organisation, including the distribution of accountabilities as central. The accounts of expectations were organised so as to accomplish certain actors as accountable for having and others for acting on the expectations. I argued that the sense of alignment and cohesion of the ESS community in relation to the future arose, not so much due to the content of the expectations itself but rather as a result of the re-specification of these actors and the relationships between them.

In this chapter, I return to the phenomenon encountered at the very start of my study, that there was "nothing" in the ESS context to investigate. Of course, in this case, "nothing" does not simply index absence, i.e. of the ESS facility itself or the scientific practices "at ESS", but also can be understood as a statement of relevance, e.g. that I would not find anything of relevance in the ESS context that would help me understand the practices of Big Science. We can consider this advice, then, as a way of performing the value of the empirical context in relation to my research intentions. We may observe a similar performance of value in the reviewed literature in chapter 2. For example, we may read Van Lente's (2012) point that, "not just descriptive", statements about the future can also be understood as "doing something", as a way of performing such statements as of relevance, as having some kind of role in contexts of scientific and technological development and thus, also, as topics to be examined by social science. I argued in chapter 2, however, that this sense of role builds on and depends upon assumptions concerning the accountability of such statements. It was important, I argued, to ask: What accountability relations provide for making statements about the future sound/hear/read as sensible?

To address this question, this chapter is organised as follows. First, I critically assess the argument that some statements about the future are more accountable than others. Second, I present the "Future Walk through Brunnshög" - a do-it-yourself walk organised by Lund City Council, taking walkers through Lund's north-east, where ESS is currently being built. What accountability relations are performed in "future 


\section{Accounting the Future}

walks" and how do these make statements about the future sensible? And third, I present material from my visit to the ESS construction site, where I shadowed Jon Linden (pseudonym) - organiser of this visit, as he was taking two representatives of the Finnish mining industry through the ESS site. Specifically, I present a reading of "nothing to see here" - a statement Jon made on the visit occasion - and I outline the process through which that statement comes to count as saying (or as not saying) something in particular. What accountability relations are performed in assertions that nothing about the future is available to be seen, and how do these relations make such assertions sensible?

\subsection{Some Futures More Accountable Than Others?}

Brown (2003) suggests that actors have a stake when articulating expectations. Especially in the early stages of innovation, actors exaggerate their expectations as a way to "command sufficient interest to enrol allies" (p 6). Still, according to Brown, this comes at a cost. As time passes and circumstances change, "unforeseen problems emerge, and early hype gives way to varying levels of disillusionment" (p 11). When this occurs, argues Brown, the "communities of promise" often collapse, and can be seen to migrate to new technological and scientific areas, "unsullied by hype's eventual disappointments" (ibid). Along similar lines, Borup et al (2006) suggest that unrealizable expectations may damage credibility because by articulating such expectations, by making such promises, actors can potentially be "held to future account" (p 289). While for Pollock and Williams (2010) this feels right, they argue for a more nuanced way of expressing the relationship between expectations and their accountability.

Pollock and Williams (2010) claim that "it is unlikely that all expectations are accountable in the same way" (p 528). For example, according to them, "longer-term predictions may project too far into the future and be couched in too many technoscientific uncertainties for any group to be held responsible for their nonmaterialisation" (ibid). In their view, this indicates that expectations can be classified according to types, where each type relates to a certain degree of accountability. They identify three such types. The first is "infrastructural knowledge". In their view, this expectations type includes, for example, definitions and classification of technology markets; it is strongly institutionalised, authoritative, and (of necessity) "highly accountable". They consider a second type as "statements and their world". According to Pollock and Williams, this type of expectations includes different forms 
of assessment, for example, of buyers and suppliers within markets. They argue that, since such assessments produce "winners and losers", they "must be accountable" i.e. able to be explained, defended against criticism when challenged, and so on. Finally, a third type of expectations according to Pollock and Williams is "visions let loose". Contrasting the former types, the latter includes such expectations as "longitudinal predictions", and is characterised by "low accountability". They exemplify this type of expectations as follows.

Pollock and Williams (2010) examine how those who trade in future claims manage "failure", that is, inaccurate predictions of the future. To address this empirically, they draw on a keynote address given at an international IT conference. Of particular interest to them is an episode where the keynote speaker, addressing a large audience of about two hundred individuals, goes through some of the claims about the future he has made in the past, "to see whether they turned out to be 'accurate' or not" (p 536). I zoom in on the following excerpt from this keynote address as presented in Pollock and Williams:

"By 2001 distance learning will be a mainstream activity on $80 \%$ of the campuses."

How many of you think that one has come to pass? How many of you ((very few hands raised)) How many of you think it hasn't yet? ((Many more hands raised.))

Mainstream activity? Still not. Okay.

((The keynote speaker pauses for a few seconds))

How many of you though have a large percentage of either hybrid or blended courses on your campuses today? ((A few more hands are raised.))

Yeah. Okay. So part of it is coming there

Pollock and Williams (2010; p 536)

Pollock and Williams note that, the keynote speaker appears in this instance "to neither build upon nor defend this knowledge, but simply to let the claim go" (p 528). Their point is that the keynote speaker neither attempts to account for the claim nor the audience holds him accountable for it; merely, he (and the audience) is letting this vision loose. It follows for Pollock and Williams that claims about the future such as that indicated above are like provocative "signposts" - they are "transient" and "speculative" - and "appear not to be subject to the same levels of rigorous accountability as other kinds of promisory work" (p 543). In other words, they are the type of expectations that, simply, are "launched into the ether" (ibid). 


\section{Accounting the Future}

If we look closely at this empirical episode, however, we may produce a different reading. I draw attention to the performance of audience in relation to the future claim. Firstly, in asking "How many of you think that one has come to pass?" the keynote speaker is performing the audience as accountable for knowing this in the specific setting of the international conference. This is important, as it positions the audience as expert in the setting on the matter of "distance learning... on campuses". Secondly, in the transcript, the keynote speaker's question precedes the raising of hands in the audience, in this way rendering their reading as (nothing else but) a response. Thirdly, the keynote re-specifies the question three times, as "How many of you think it hasn't yet?", "Mainstream activity?" and "How many of you though have a large percentage of either hybrid or blended courses on your campuses today?" After each re-specification, more and more hands are being raised. Again, we do not read that the audience is more and more, say, confused, having more and more questions, but that they are answering the questions. The items "Still not", "Okay", "Yeah", "So part of it is coming there" display the keynote speaker's orientation to the hands being raised as answering the questions. What is more, we do not simply read that these are different answers to different questions, but that the answers observably pertain to the original question of "How many of you think that one has come to pass?" This amounts to providing for a sense that the audience thinks that the prediction has failed, but only to a particular extent; that, on some accounts at least, the prediction holds true. Not simply "letting the claim go" - which is Pollock and William's claim, we can read this address as also doing maintenance work - of accomplishing the prediction accountable as a prediction still, of rendering thereby the keynote speaker's authority in this setting as a competent predictor.

It is relevant to emphasise that that particular sense of "letting the claim go" derives from the accountability relations being assigned in and through the keynote address. The audience is performed as accountable for answering questions through raising hands. The keynote speaker is performed as accountable for asking questions, for interpreting what "many more hands raised" means, for deciding when or that the questions have been answered and how. The audience cannot hold the speaker accountable for the claim without violating the "social organisation" (Smith 1974, 1983, 1987, 1990, 2001, 2006) of the keynote address. This suggests that what Pollock and Williams (2010) refer to as "type" is a shortcut for diverse, spatially and temporally specific performances of communities, which, in subsuming those diverse performances, distracts us from addressing accountability as enacted through those performances. 
The following sections examine how accountability relations are assigned and distributed through accounts of statements about the future. Looking first at the "Future Walk through Brunnshög" and then at a visit to the ESS construction site, I examine how actors manage being held to account as a possibility in making future statements.

\section{2 "Future Walking" as Community Performance}

In 2014, the Swedish Research Council (Formas), the National Board of Housing, Building and Planning (Boverket), and Sweden's Green Building Council (SGBC) together organised a national competition to nominate "the best buildings and townships" in the country. Lund's "new development" Brunnshög made the list of ten winners, standing out in its goals of "minimising the development's impact on climate", of "balancing the use of good farmland", of "maximising experiences, sensory impressions and meeting points". Europe, we read in the competition's brochure, had "decided to place one of the world's foremost research centres", ESS, there; and Sweden had "decided to place the world's most powerful electronic microscope, MAX IV, right next to it" (Formas 2014). In the future, the Brunnshög project will situate these facilities in "an interesting, sustainable urban setting", making it "the world's foremost research and innovation environment". The project entails housing for up to 40,000 residents, workplaces, schools and recreation amenities densely packed together in an area covering 250 hectares of Lund's northeast, and a tram connection to the town's centre. It endeavours in this way to enhance "the attraction of the place" - and not only to "researchers" but also to "everyone else".

Not just describing a project, we can read the brochure as mobilizing some of the project's features in performing a community. Consider the last bit describing the project as being about enhancing "the attraction of the place". We can see that the description involves a statement of the social entities to whom "the place" counts as attractive - primarily researchers, but also "everyone else". The social entity "everyone else" does not include everyone. We can derive the sense of who constitutes "everyone" in relation to the social entity "researchers" - for example negatively, as comprising non-researchers. So not everyone falls into the category of non-researchers. The characterisations of "the place" as "the world's foremost research and innovation environment", as enveloping "the world's foremost research centre" and "the world's most powerful electronic microscope", the ESS and MAX 


\section{Accounting the Future}

IV facilities, further adds to the sense of who might constitute a "resident", a member of the community making this "place" that kind of place, and for whom that "place" might count as attractive. I.e., we can derive, from this community as organised, a sense of who might be accountable for accomplishing "the place" as characterised and therefore who, in the brochure's terms, counts as potential Brunnshög "resident".

One way to get to ESS in 2015 is on foot, passing through Brunnshög. But in 2015, Brunnshög evidently is not "Brunnshög" as described in that 2014 brochure.

Indeed, when walking through this area in the early autumn of 2015, I was mainly passing through an agricultural landscape. I.e. with fields and food crops growing on them, red-painted farm houses emerging on green groves - an image so characteristic of the Swedish rural environment; and a few industrial buildings such as Sony's head office here and there. And as I observed this, stepping on a road with cracks in the asphalt and trying to avoid the water puddles after last night's rain, I could locate in the midst of all this (what appeared to me in the first instance as) a Star-Trek spaceship lookalike - the MAX IV facility, rising tall over and above the largely unimpressive surrounding terrain. A few fields away, and I could "see ESS" as well - forbidding metal fence, cranes, bulldozers, dump trucks, and workers dressed in yellow uniforms all suggesting I was seeing ESS in-the-making, as currently only a construction site. The contrast between the facilities and where they were was individualising - much like placing a black object upon a white surface - and provided for a sense of looking on "something" against a homogeneous background of "nothing" around. It made MAX IV and the ESS construction site stand out as "something to see".

\subsubsection{Who Can Remember Brunnshög as Liveable?}

For Jaime Falk (pseudonym) - an architect, planner and a civil servant at Lund City Council working with the Brunnshög project, "the ESS and MAX lab are just facilities" (Interview, 2016 September 9). They do what facilities qua such facilities do - accelerating particles in the process of conducting scientific experiments. "But we," he points out, "are trying to build a city". Rephrases: "we want to build a city that will sort of place them in an almost urban context." Jaime elaborates that, as far as Lund City Council is concerned, "the life around these facilities is the most important" - adding: "both for Lund and for the facilities". According to him: "to just accelerate is really nice, but real science is done by people meeting each other". Jaime's statement can be read for how it performs "real science", as distinct from particle acceleration, thus from "these facilities", and then also as mundane, 
proceeding from the ordinary situation of "people meeting each other". In this regard, his statement echoes some of the conclusions from Exploring New Big Science - a multidisciplinary workshop organised by Sandell and others in Lund, in 2015, where on the basis of my ethnographic notes many of the participants seemed to agree on the characterisation of ESS - not as "big", but "small science" performed in a large building, with large instruments; where scientists "just went" to conduct research, but then "simply went home"; and where new ideas and projects emerged in coffee rooms, propelled by as little as "let's do this together".

In the interview, Jaime (2016 September 9) tells me that Brunnshög is "close to Lund" but it is uninhabited. "Nobody lives there. Almost nobody. Only a very few people live there." And this, he reckons, makes it "sort of a non-area". What is more, being outside Lund's ring, as would any such development there, it triggers for the citizens "the image of parking lots, shopping areas, and so on" - in short, "a sort of development on the outskirts". Lund City Council wants to change these perceptions. As Jaime tells me, they "don't want to plan a city, then build it, and then move the people there". Brunnshög is the end of "a slow process", he says, and the City Council wants "to bring people up there, even before it's built, so people know about it, and people start getting ideas about it." Their intention is that people have "memories of Brunnshög" - not as a cold industrial zone, but as "a liveable city" before it actually becomes a city where people live. A challenging prospect, however, for, as Jaime elaborates further, the planned area is currently just a farmland - which is "great" he says, but as such, it is not something that citizens normally want to visit. Jaime said: "I mean, it is just farmland". Before presenting some of the City Council's strategies for addressing that challenge, I turn to the performances of community in this section.

Jaime performs community that comprises "people". He suggests a sense in which the "city" is tried for the "people", particularly in the aspects providing for doing "real science" through enabling "meetings". We can see, however, that the item "people" mobilises (at least) three different entities. On the one hand, we have scientists who, as "people", have a "life" - i.e. have homes, drink coffee with others in coffee rooms, meet, and do things together including science. On the other hand, we have the current inhabitants of Brunnshög, who as "very few people" - "almost nobody" and "nobody" - live there. And, on the third hand, we have the citizens who, as "people", have certain ideas, perceptions and images, and knowledge as to what "being outside Lund's ring" is and feels like. Jaime organizes a community where the social entity "citizens" excludes the scientists and the people already living in the 


\section{Accounting the Future}

Brunnshög area. An important feature of this community performance is rendering "the citizens" as accountable for knowing, perceiving, and remembering Brunnshög as "livable". That is to say, it is in their terms that Brunnshög counts as "sort of a non-area" - as "cold" and as "just farmland" - and also, it is in their terms that the area can count properly as "livable". The terms of the farmers, for example, or generally the people living or who have lived there already, and who might therefore have a certain perception, knowledge or memory of it as "livable", do not count towards Jaime's characterization of the area.

\subsubsection{The "Future Walk through Brunnshög"}

Lund City Council manages a "Future Walk through Brunnshög". It is a walking route in the north-east of Lund - also called Brunnshög, providing visitors to the area an opportunity to gain insight into the "new development" as the City Council sees it. Jaime (Interview, 2016 September 9) tells me that he was not there when the "first walk" was conceived, in 2012, but that he has photos from that time.

Looking into his computer files, Jaime tried to find some of those photos to show them to me, but he could not find any. While he was doing this, Jaime was thinking about the origins of the "Future Walk". He thinks it all started with the observation that "people were interested" in getting guided tours of the site. As today, these were "local people" mostly. "They were curious about it." Jaime also mentions people who "were involved with the projects professionally" - "somebody working with the MAX lab" or "somebody doing some planning for ESS" - tourists in Lund who asked "what else is there to see?" as well as "groups with a particular interest", for example political parties representatives, NGOs "with interest in landscaping or growing crops", or schools. Jaime says that, as this interest grew, organising the "Future Walk" as a do-it-yourself activity was a way of making tours possible "at any time" and individually, without the presence of a tour guide. But in this way, he could only guess who did the walking.

Not just a list of social entities walking, we can think of Jaime's elaboration as performing a community of and around future sight. Each of the mentioned walkers are specified in terms of their stake in seeing the future. So, not just listing various walkers, Jaime elaborates walkers in such a way as to perform a constellation of actors held together as a community by their differing interest in seeing what is not yet there. Note for example the actor "local people". While saying that "local people" were interested, i.e. "curious about it", Jaime also suggests that these "people" were interested in seeing the future for and in being "local". Similarly, we can identify the 
other walkers constituting this community in relation to their professional, explorational (as tourists), political, agricultural, and educational interests. What are the accountability relations in this case? Who in this community is "accountable for" and how? Note how Jaime particularises agricultural interest. The "local people", possibly farmers, growing (or having grown) crops - possibly on the fields around MAX IV and ESS, or the fields on which ESS is now being built, might have such an interest. However, in the community as Jaime performs it, it is the NGOs specifically - and not the "local people" - that are rendered accountable for having a "particular interest" in growing crops. The "local people" are simply curious about the future, and simply for being locals. This is not to say that Jaime suggests thereby that the local farmers' interests in the farmland used for building ESS or surrounding the facilities do not matter. It is to say, rather, that in the community performed in this specific instance, the farmers as "local people" do not have that kind of accountability.

At the beginning, Jaime (Interview, 2016 September 9) tells me, the "Future Walk" comprised wooden posts with plastic folders on them, displaying images and written information about the Brunnshög development. Lund City Council published ten Youtube films about it in 2013. These remain unchanged to date. As MAX IV became a construction site during that year, the City Council rerouted the "Future Walk" so as to take visitors outside and around the site - not through it as it did before. By 2014, the old posts had collapsed. Winds and rain gradually wore down the wood and paper. Jaime notes additionally that these posts were "difficult to spot". At this point, the City Council decided to implement a "more visible and permanent solution" in the form of tall metal posts with round tin boards attached on them to display the information. The result was the "Future Walk" as I walked it in the late spring of 2016. During 2016, the "Future Walk" was a "to do" thing on Lund's Tourist Centre's printed brochures. It was suggested as an activity on visitlund.se and on other websites, all presenting it as a tourist attraction. These pages contained a link to the City Council's website, ${ }^{36}$ which more fully described the "Future Walk" including instructions on where to start, how to get there, a map of the route downloadable as a PDF (thus printable and foldable as a small brochure to take on the way), and a list of hyperlinks to all ten Youtube films. According to the City Council's (2014) description, the "Future Walk" was designed "to let you get a feel for how the area looks today and what the plans are for its future."

\footnotetext{
${ }^{36}$ This page no longer exists on that website, but a list of "happenings" there includes a "guided future-walk through Brunnshög" - suggesting, it is still an ongoing matter.
} 


\section{Accounting the Future}

The City Council's website suggested two main ways of taking part in the "Future Walk". The first involved walkers' physical presence in Brunnshög. Prospective walkers were to download a map overviewing the route and following it then to reach ten destination points, one after another in a pre-determined sequence as shown in Figure 2. At each of these points stood a metal signpost displaying written descriptions and illustrations or photographs informing about the past and future of the places in sight. Each of the signposts displayed a QR-code which, provided the appropriate reading technology (e.g. mobile phone apps), enabled access to additional descriptions (both in Swedish and in English) in the form of the short Youtube films. Once they reached a signpost, walkers could pause to read the available information and then pull out their mobile phones to watch the related film. In the films, a male voiceover accompanied artistic drawings and photographs to point out the various areas within the present landscape observable from that viewpoint and described how they would change in the future. It wrote on the City Council's (2014) website that, "the combination of being in the physical landscape and seeing the films with information and some artistic visions for the area is an excellent way of understanding how the development is being thought out." Alternatively, walkers could watch the Youtube films without actually going to Brunnshög - but, in this way, "you will need to rely on your imagination" because, in articulating the development, "the films use the landscape, as seen from the places where the signs are." In so juxtaposing sight with the imagination, the City Council's website instructed that the landscape in "use" was simply there to be seen. By implication, any and all references to this landscape, as articulated in the films or otherwise, were to be taken merely as pointers to what actually stood out there and untainted by the act of its "use".

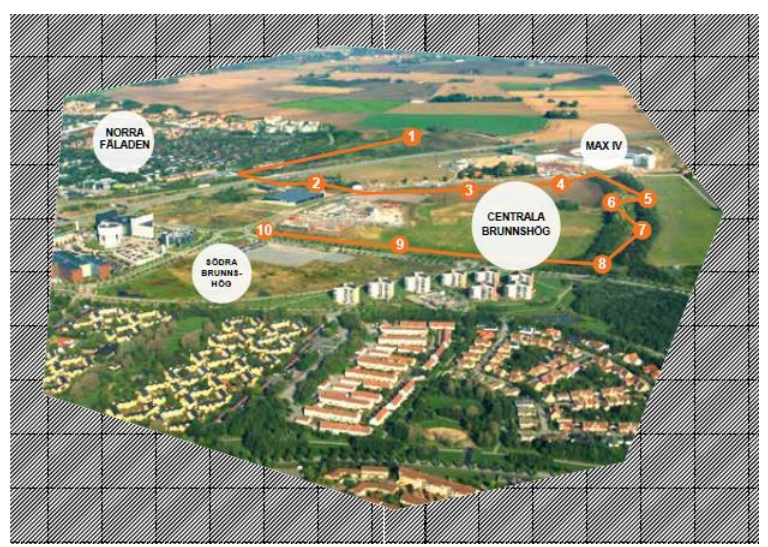

Figure 2 - A map of the

"Future Walk" (Lund City

Council 2014) 
Notably, ESS is absent from this map. Jaime explains that, when designing the "Future Walk" route, the Council was "not sure about ESS" (Interview, 2016 September 9). The ESS was planned, he says, but "nobody knows for sure" - not, that is, "until there is a shovel in the ground". According to Jaime, "if you start shovelling in Sweden, it will happen" ${ }^{37}$ Primarily, however, excluding ESS from the "Future Walk" route, in Jaime's view, was to do with physical distance. "To take a foot tour like this," he remarks, "the ESS is just too far away."

The following section examines how the "Future Walk" performs accountability relations in providing for a sight over the future.

\subsubsection{Making Future Sight Accountable}

Klosterängshöjden - an artificial hill just on the outskirts of Lund, was my "Future Walk's" point of departure. I headed there on foot and moments after leaving the hotel where I was staying, situated in the vicinity, I was there. The area I encountered was somewhat forested, with unpaved paths leading in various directions up and around the hill. I would take one, and end up in a field - take another, and head in a wrong direction, away from the hill. I could visually locate the "Future Walk's" signpost standing on that hill's top, but finding my way up to it proved surprisingly puzzling. Other walkers - perhaps not necessarily doing the "Future Walk", would pass by me and nod a greeting. I would nod back, feeling somewhat embarrassed for my lack of proper orienteering skills. ${ }^{38}$ Upon several unsuccessful attempts, I finally

\footnotetext{
${ }^{37}$ I analysed this point in chapter 5 (p 90-96).

${ }^{38}$ My notebook, keeping a record of my impressions during my "Future Walk", contains frequent references to my confusion, notes that I was lost, as well as complaints about the wind and highway noise (preventing me from hearing the voiceover in the films) and the pain in my legs (due to five hours walking). For Jaime, these affective aspects of the "Future Walk" are important. He says: "to only look at the map is one thing. But to physically be tired and feel the distances is very important." And elaborates: "Because it becomes part of you. If you only look at the plans, you can just go to the next. But if you physically lived or interacted with the site - gone up that hill, gone under, heard the noise and heard the silence, passed these roads, seen the huge MAX Lab at the end of the green spaces - that gives a different perception of the whole area. You can have a lecture on the area in an hour. But being on site, and now, seeing all the construction [of ESS] is also part of the experience. There's a lot of movement and cranes and noises. And that's a symbol of development - actually see things moving around.” (Interview, 2016 September 9). Note that, in this way, Jaime suggests that a primary virtue of the "Future Walk" is conveying the reality of ESS as happening, or alternatively, demonstrating the somethingness of ESS in the present. I return to this proposition - that being there provides a sense of ESS that contrasts its "nothingness" as not-yet later on in the chapter.
} 


\section{Accounting the Future}

found my way up, and approached the first signpost. It displayed as a summary the following text:

The world's finest research facilities right here: ESS and MAX IV. The area is to be a European best practice for sustainable urban development: Brunnshög, the mixed city with high environmental demands. (Signpost 1, Lund City Council 2014)

Facing the signpost while reading on it "the area" unambiguously provides for taking the area so faced as that indicated on the signpost. Within that spatio-temporal arrangement, the item "area" can be understood as indexing walkers' (and in this case, my own) sight. Figure 3 frames this sight in the aspect constituting its most salient and characteristic features: the MAX IV facility and ESS construction site. As we can see, the sight is framed so as to provide for looking over "the area", against the receding fields. This renders the city of Lund unavailable in the back and, from that viewpoint makes the ESS construction site appear as far in the distance. In these aspects, the "Future Walk" contrasts a more prevalent visualisation of "the area", as I have addressed it in the previous chapter (see pp 102-104), which organises viewing over ESS towards Lund, thereby placing emphasis on their closeness.

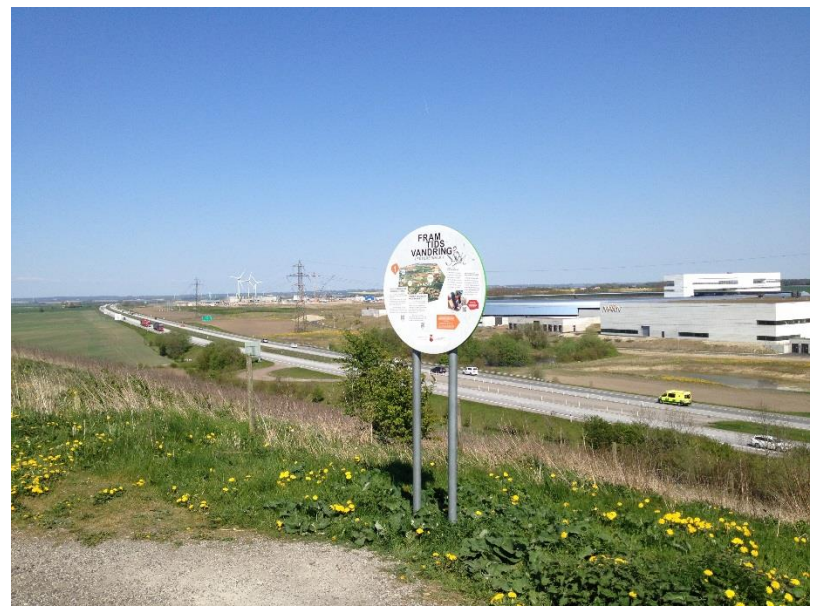

Figure 3 - Facing the first "Future Walk" signpost (Dimitrievski 2016)

Reading these differing sights together provided that I took the "Future Walk's" viewing arrangement as a kind of political intervention; that, at a time when various publics perceived ESS as being "too close" to Lund for comfort, this arrangement played a role of working out a competing perspective. During the interview with Jaime (2016 September 9), I asked him to reflect on whether or not that was the case. 
He said, that selecting Klosterängshöjden as the walking route's starting point primarily was to do with convenience - enabling an overview of "the area" and in this way, the possibility of pointing things out, for example "the existing Sony Eriksson there", "the forest all the way in the background", and "the end, where ESS is being built". I draw two effects from this.

Firstly, Jaime's reflection performs the walker as somebody, who, in standing on top of that hill and facing "the area", cannot, on their own, see Sony Eriksson, the forest, or the ESS for where it is being built, but instead, needs these to be pointed out and specified by somebody else to be recognised for what and where they are. This makes an interesting juxtaposition with Jaime's earlier elaboration that the "Future Walk" was (and is) mostly done by "local people" who, we might argue, in being local, knew "the area" already and thus its constituent landmarks too. Secondly, in performing the walker in this way, Jaime assigns an accountability relation. Note that, it is the tour guide, and in their absence the voiceover and descriptions, that in this set up are accountable for specifying what aspects of the landscape are relevant, what can be pointed out as foreground, what as background, and in what ways; in other words, it is these actors - not the walkers themselves - who are accountable for constituting what is being seen. These two effects amount to overriding my characterisation of the viewing arrangement as a political intervention, and perform it instead as just a convenient introduction.

For me, however, the feeling that the "Future Walk" was doing something more than merely pointing out stayed throughout. Consider the following excerpt:

This area used to be the location of a large farmhouse which had horses, cows, pigs, and chickens in the middle of the 20th century. In the Brunnshög development, this area is planned to become a schoolyard for elementary school to be built nearby. (Youtube Film 8, Lund City Council 2014)

As a preliminary to articulating what it will become - i.e. "a schoolyard", the statement mobilises the indicated "area" in terms of what it used to be: namely, "the location of a large farmhouse". For the walker, the relation of transformation emerges as from what this "area" is no more towards what it is planned to be one day, "in the Brunnshög development". Everything in sight, in other words, indexes in connection to the statement the absence now of "a large farmhouse", of "horses, cows, pigs, and chickens" - i.e., of such and such a location. The walker is instructed to see, for instance, the hedges of tree and bush and grassy meadows extending under one's feet - not as making present the land (as that kind of place) but in the aspect 


\section{Accounting the Future}

of how they are de-placing what, not long ago in the 20th century, used to be a particular kind of place. We could read this statement then as organizing the walker's sight of the plan of turning "this area" into a schoolyard as from the position of now being nowhere and nothing in particular. For me, while doing the "Future Walk", the statement had an obvious resonance with the media discourse that any development there would destroy the land (see chapter 4, p 75). Consider that, articulating "this area" as formerly a farm site induces no particular objection to the indicated plan of turning it into something else than that. Phrasing it as the land, however, can be understood as a cause for protest against such a plan. We could read the statement, then, as intended to appease public uproar.

When I asked Jaime (Interview, 2016 September 9) about the choice of emphasis in this instance, he remarked: "you can say that it's about trying to get the focus away from the fact that $[\ldots]$ we use the farmland". Nevertheless, in his view, the specific detail in how the plans were articulated throughout the "Future Walk" were just artefacts of the planning process. "There was a lot of debating" - explains Jaime, concerning whether or not "to build on the farmland" and the planning took that into account. Here, the elaboration does not so much override the interpretation of it as a political intervention as it performs the kind of intervention that this statement can be read as instantiating. It is not, according to Jaime, about appeasing public uproar by removing focus but rather, about engaging with public concerns in a serious way, as what the City Council draws on when planning for the future. Jaime's elaboration can be understood as performing the City Council's accountability as a responsible governor of Lund, listening to its citizens' concerns.

A similar re-interpretation may also be observed in relation to these statements:

The oldest traces of human settlement, crafts, and farming stretch as far back as 6000 years. The most active years were during the New Stone Age and the Iron Age but this area was never entirely uninhabited. The fields towards the sea were filled with streams and wetland and here on the last slopes of Romele ridge it was easier to pass. (Signpost 1, Lund City Council 2014)

South from here, lies a part of Brunnshög called Höjdpunkten. This area will contain office spaces for nearly 3000 people. By building in a compact manner, space is used efficiently so that there is a room for a green square in the middle of the area. Brunnshög is planned to be a green-blue city, with plants and water in the urban space. In Höjdpunkten, the inner courtyards and alleys will have plenty of greenery with trees and waterways. (Youtube Film 2, Lund City Council 2014) 
We can see that the past of the area in sight, textually and visually given on the signpost, and the future, orally and visually articulated in the film, are made to echo one another. This strategy of information delivery is repeated throughout the "Future Walk": the areas are communicated for the walker in identical descriptive terms (trees, wetlands, etc.) - simulating a kind of wild - and in juxtaposition to what those areas can currently be seen as -i.e. not that. This not only evokes a contrast between the seen and the written, said, or illustrated, but also situates the seen as in between past and future sights. By descriptively establishing a continuity between past and future sights, the presently seen is made available as a break in the natural state and progression of the attended place. The rhetoric is not merely one of change, but that of returning and restoration. So it can be seen as lending legitimacy to the plan of turning this area into something else than what it is now. ${ }^{39}$

For Jaime, displaying descriptions of the past as historical information and of the future as the plans for Brunnshög provides the practical benefit of not needing to update the signs every time that a change occurs in the landscape. Additionally, argues Jaime, organising the information in terms of futures and pasts is attractive for walkers - "that was interesting", he says some of them say. Still, contrasting the unchanging written (or articulated) texts of the "Future Walk" with a landscape that changes also provides for seeing misalignments. Consider this instance:

\footnotetext{
${ }^{39}$ As a strategy of performing legitimacy, this resonates with Samwell Nilsson (pseudonym), a social scientist at Lund University mobilized by ESS to provide insights into the local's "mindset" as part of the TITA project (see chapter 5, p 94). Samwell describes the following scenario: "there was an old windmill in the area - the first one of its kind in Sweden. It was in a bad shape, so the idea initially was to get rid of it. Let's just tear it down and build a new fancy science village. But, as part of that project, we did an inventory of the folklore archives and it came up that this windmill was the first of its kind and it's been used for the innovations of the past. There was the establishment of the first windmill there. And then, there was the first locomobile - which is some kind of, you know, really locomotive used in agriculture for taking the kernel from the straw. Established at the very same place. There was even a specific song written about this windmill. We found that in the music archives. So the message was: you are always focusing on new buildings, science. In a way, for many people, this was the bad image of the future: you know, people would get sick, and you'll take away the best land for agriculture. You'll create, well, some kind of cold area, with cold people, radiation, risks - I mean, the bad image of the science of the future. But with this image of connecting it to the past and say - instead of this being brand new, high-tech stuff, this is the place where innovations have been born for centuries - and it seemed like this idea was planted in fertile soil. So now the windmill is going to be there. It's going to be in the middle. So, it's now part of the official image of the ESS - as the place where innovations always have been born. So instead of being this new thing - you know, tearing down all the rest - at least an attempt [is made] to interconnect the history and the present and the future with this kind of image of the innovative region." (Interview, 2016 May 10).
} 


\section{Accounting the Future}

The red building in front of you - La Strada - was built at the beginning of the twentieth century. Early on, it was a schoolhouse, but during the fifties and sixties it had turned into a hostel and pub. As you can see this once beautiful building is very worn down. But with the coming development of Brunnshög, the city is looking into the possibility of restoring the house, and once again having a school environment here. In the planning of the Brunnshög area, solutions are looked for where old houses and gardens can be preserved as historical points of interest in the modern city environment. (Youtube Film 3, Lund City Council 2014)

For the walker, the indicated "red building" becomes "La Strada" - thereby a name, then "a schoolhouse" and "a hostel and pub", and ultimately "this once beautiful building". The statement does not merely point this object out - not merely as a "building". In so doing, it also includes it in vision as a kind of object, with specific qualities, relevance and cultural value - and as such, it articulates it as in ruin, as "very worn down". The specified "possibility of restoring the house" orients, initially, to what is given here as its original use of being "a school-house". But, as it becomes apparent later in the "Future Walk", also to meeting the growing demand for schools that already exists in nearby areas in Lund and to handling the increase of this demand, expectable with the influx of new residents.

Even though it was specified as being "in front of" me, I did not manage to see La Strada. When asking Jaime about it, he said "very unfortunately" - about two years ago, he thinks - "it burned down". Showing me a picture of La Strada, Jaime points out the red bricks on the windows intended to prevent people from entering. But somehow, "someone" went in and set it on fire. The fire could not have started otherwise, suggests Jaime, for "there is no electricity there". Actually, they do not know what had happened really - "we haven't investigated this matter further". He looks again at the picture and says: "We need to update this sign."

It is relevant to emphasise that Jaime's elaboration of what happened with La Strada provides for the sense of it as just indicating that the signpost needs updating. It derives from how he performs accountability. The building was protected - the City Council cannot be held accountable for the burning of La Strada on account of not protecting it. Somebody went in nevertheless, somehow. The City Council can be held accountable for not protecting it well. But that kind of accountability depends on elaborating the break-in. Who is accountable for determining how precisely the indicated someone went in to set La Strada on fire? Not the police, in this case - the City Council. They have not investigated this further, although Jaime's elaboration suggests that there has been some kind of investigation. Specifically, where the City 
Council 1) has found that La Strada was not connected to the electricity grid, 2) has deduced thereby a different cause of the fire, and 3) has made a verdict as to the case being "someone" breaking and entering. As the investigator, the Council cannot be held accountable for the "someone" breaking and entering. These accountability relations jointly provide for the sense that, simply, the signpost needs updating.

I have thus far shown that future walking, and sight of/over the future as part of it, are "socially organised". Their "social organisation" (Smith 1974, 1983, 1987, 1990, 2001, 2006) involves a performance of accountability relations, accomplishing who in the "future walking" community sees, who can determine what is being seen, as well as whose vision matters and how. It shows that the sense of what particular statements about the future are and are doing - legitimising or just indicating a need to update - derives from that "social organisation".

Note, however, that my analysis of the "Future Walk" statements, and of their readings, presumes that the statements analysed are about the future. Seeing that they are describing futures, I have taken these statements also as being about the future. There are important indications in the material presented that the case might be different. For example, Jaime notes that walkers often find "that was interesting". Rather than about the future, this suggests that the statements can be read as being possibly, perhaps primarily, about presenting something interesting. Additional indications as to such a reading can be found against the locating of the "Future Walk" on tourist brochures, as a kind of tourist attraction providing "something else in Lund to see or do". This changes how we can consider the accountability relation between authors and their statements. To the extent that La Strada is about showing something interesting to walkers, that La Strada burned down is, as Jaime puts it, indeed "unfortunate" but does not evoke the same sense of accountability as it does when orienting to La Strada as being about the future - as a plan, an investment, intention, and so on. The next sections investigate in this matter further, by presenting a close reading of "nothing to see here". What accountability relations are performed in assertions that nothing about the future is available to be seen, and how do these relations make such assertions sensible?

\subsection{Accounting "Nothing"}

On one occasion, I was invited to attend a meeting between the ESS and two representatives from the Finnish mining industry. The meeting took place on the ESS construction site, on January 26, in 2017, and aimed to identify possibilities for future 


\section{Accounting the Future}

cooperation between these two parties. When the meeting was over, the organizer Jon Linden (pseudonym), invited me and the Finns to visit the MAX IV facility which stood close to the ESS construction site. We headed there on foot and, as we were leaving the construction site, we stopped to take one last look at it. Before us cranes, bulldozers, dump trucks, and workers dressed in yellow uniforms proceeding with their daily work on the site. Jon said in that moment: "nothing to see here". And we moved along, heading towards the MAX IV facility. What accountability relations are performed through this assertion, and how do these relations make this assertion sensible?

\subsection{1 "Nothing to See Here" as Community Performance}

"Nothing to see here" is a trope widely used in literature, in film, newspaper comics, etc. Famously, it is used in The Naked Gun where actor Leslie Nielsen, in the role of detective Frank Drebin, tries to do the following in front of an exploding fireworks factory. The film segment begins with a gathering street crowd; in the background sounds of explosions and light flashes reflected on people's faces. Frank, obviously with a stake in what is happening, is pushing his way through the crowd saying "Excuse me. Excuse me." As he manages his way through, he takes a good look at the situation - a red flash illuminating his stunned face, and turns around to face the crowd. He says: "Alright, move on. Nothing to see here." In that moment, the camera reveals the background - a burning building and people jumping from it in a run for their lives. His hands raised as if to hinder the sight, Frank makes one final appeal: "Please disperse. Nothing to see here. Please." (Zucker, 1988).

What main features of this performance accomplish "nothing"? There is an apparent and spontaneous crowd formation, presumably around the same thing. This amounts to rendering of whatever it is that is looked at as a "thing", and this thing as "something" - even before the camera reveals what "it" is and that it really "is" something. In other words, the viewer does not have to wait for the revelation to understand that something is happening. Moreover, this crowd consists of mostly random, as it were people on the streets, who all do the same thing - that is, looking at something and nothing else but that - and this crowd is growing. Whatever it is that is being looked at can be read as "noticeable" - in that it captures the attention of random people and requires no special vision or insight to be spotted - and in such a way as to provoke a spontaneous crowd formation, just by its very occurrence. The phrase "nothing to see here" contrasts the effect that what is being looked at rather $i s$ something. 
We can think of "nothing to see here" as an act of community performance. When stating "nothing to see here", Frank assumes accountability for the characterization of the scene - the exploding fireworks factory - as of no interest. He makes the gathering crowd accountable for staying away. We-as-viewers can see the irony in what he is doing - that what he determines as "nothing" is in fact "something" - we can see that the crowd sees with us that the exploding fireworks factory is "something", but also, importantly, we can see that Frank cannot see the irony. His recurrent use of "nothing to see here" suggests that Frank is merely appropriating the organizational tactic - a phrase a police officer says to a crowd gathering at a scene of an accident or crime and who the officer wishes to disperse without communicating the cause of the crime or accident - thinking that in just saying it, it would organize the crowd in this way. His inability to see the irony is why he cannot see that his organizational tactic does not work.

Frank's persistent attempts to organize the crowd, his recurrent failure to do so constitute what makes this movie scene funny. In Jon's case, "nothing to see here" worked. He said it, and we moved along. So what made it work? What made it a successful community performance?

\subsubsection{Accomplishing ESS as "Something"}

There are parallels between the dramatic performance of the trope in The Naked Gun and that in the fieldwork situation I am considering. Most notably, for example, the organising of a visit to the ESS site - instead of, say, its offices in Lund - precisely aims to produce the effect of "something to see". Thus, in interview, I asked ESS Science Communicator Catelyn Hagen (pseudonym) - who attended the visit as the presenter for ESS, to reflect on the role of location; namely, why the meeting took place where it did. She said:

I think often, when we bring people to site, they feel the urgency. They feel that this is happening. When we sit here, in these offices, do you really sense that we are building anything? Right now, do you? It's like, okay, here are our offices. And then we sit here and we talk about this huge construction site, but where is it? But when you are out there, and you talk about it, you sort of feel. You hear the equipment. You see the mud. You see how big it is. You see all these workers everywhere. You can say, "Wow! Things are happening."

Interview, 2017 March 10

What features of the account accomplish "something"? The account is organised so as to suggest that hearing the equipment, seeing the mud, the size of the construction 


\section{Accounting the Future}

site, and the "workers everywhere" provide for a feeling of urgency, happening, and building. This feeling is conveyed by the statement: "Wow! Things are happening." That the latter statement conveys a feeling of happening (as opposed to, say, a surprise) arises in relation to the middle part of the account where Catelyn assumes accountability for determining the sense of building in relation to "these offices". Her characterisation of what it is like "in these offices" (retroactively) accomplishes the hearing of "Right now, do you?" as a rhetorical question. She makes the point that there is nothing to see (or to feel) here, "in these offices", when it comes to urgency, happening, and building. She is, then, accomplishing the somethingness of the construction site in relation to the accomplished nothingness of "these offices".

Note that, in this way, she is not simply suggesting that construction is happening, but rather that ESS, as indexed by the term "things", is happening. Over the course of the fieldwork, I realised that, for some informants, the happening of ESS - its existence and somethingness - was a key point to make. I consider this in relation to my interview with Jon and excerpts from his presentation during the site visit.

Jon is by training a political scientist and working as a civil servant at Skåne's Regional Council - Region Skåne. He says two main themes run through his work there. The one is cross-border collaboration, focusing on forging alliances between industry, academia and the public sector in Skåne. And the other is research and innovation. Jon notes that, as a kind of "system change agent", he is frequently dealing with such questions as "how can we make a change in the innovation system?", "how can we stimulate growth in the region?" and "how can we develop an ecosystem for innovation which is capable of harvesting the effects of existing and future research?" (Interview, 2016 May 9). At the Regional Council, his work revolves around materials science, and specifically around utilising the ESS and MAX IV facilities as "vehicles for growth and innovation".

Early on in the interview, Jon and I engage in the following conversation:

Ivanche: As I understand it, this is about making links between different entities like industry, research institutes, the universities, and so on, basically, in order to bridge research with innovation. But in the context of ESS, there is no research yet

Jon: ((interrupts abruptly)) Oh yes, there is. The research is not from ESS or MAX IV. The research is at the universities. And MAX IV and ESS, well, they only will be instruments. You could say, "No, there is no research at ESS because it doesn't exist yet and MAX IV doesn't exist yet - until this fall". But there will be a lot of research 
done at the facilities, and that exists already in neutron groups around universities across Europe. So you could say, already today, there is research.

Ivanche: At ESS?

Jon: Not at ESS. But that will use ESS - research for ESS exists already.

Ivanche: Could you tell me more about that?

Jon: We have other, not spallation sources but neutron sources around the world. For example, we have the one in Grenoble, the Institut Laue-Langevin, ILL. So, they have big research neutron-user groups that do experiments with neutrons to study materials. And that science exists. It exists around the universities. And when ESS will be built, they will transfer and work with ESS. Probably. So the research exists. But it will be increased when ESS comes.

Ivanche: I see.

Jon: But you are right. There is no research at ESS today. So we can't do anything. We can prepare for what will happen. If we talk geography. But if we talk science community, they say "We have a lot of neutron sources today that are only waiting for ESS to open". "Until it opens, we are continuing with our research".

Interview, 2016 May 9

Jon reacts to the statement "in the context of ESS, there is no research yet" - and in particular, to the categories of "context" and "research". Consider that, "context" is a broader category than "at ESS", and so is "research" when compared to whatever activities will be done "at ESS". The statement "in the context of ESS, there is no research yet" holds true - not in any general sense, but to the extent that "context" merely indicates "at ESS" (which does not yet exist) and "research" includes only the set of activities performed there with it (which set there too, is non-existent). The reaction "oh yes, there is" - "already today, there is research", is rendered appropriate a) by way of extending the notion of "context" to include "at the universities", "in neutron groups", "in companies" (thus not necessarily or strictly "at ESS") and b) by re-specifying ESS as "only an instrument", and so "research" as broader in scope than that done at ESS itself, as using it, as orienting to ESS in different ways (e.g. as in waiting to open), and which may count as "for ESS", but which does not depend on it as a condition for its existence (e.g. "until it opens, we are continuing with our research").

Through the account above, futurity is preserved with respect to "research" - it is yet to come, not temporally from the future to the present but spatially, from one location 


\section{Accounting the Future}

(e.g. the neutron sources across Europe) to another (e.g. "at ESS", where it is being constructed today). Its mode of becoming is specified as one of "transferring" (not, say, making). Research need not be made (for it exists), merely transferred from elsewhere (where already, it exists). This is not merely to say that what is future somewhere, for some, is present elsewhere, for others. For Jon, it was important to establish that ESS science was already happening. Consider Jon's presentation of ESS and MAX IV to the Finns:

The reason we [at Region Skåne] decided to focus on smart materials is, of course, these two facilities you are visiting. But the point is, ESS and MAX IV - they are user facilities. The research is done at the universities and at companies. And that is done already today.

Now MAX IV exists and will start having its first users this year. But ESS will be, it's a long time - 2019 or 2020 the building will open, and the first users will come 2023. So it's a bit down the line.

So, what we do in this innovation focus is, we start: "What do they have today in leading research and in leading industry?" and how we can develop an ecosystem around this and within the area that is connected to MAX IV and ESS. Because we don't know what will come out of these two facilities. We don't know that today.

Jon's Presentation at MAX IV, 2017 January 26

A regional focus on "smart materials" is presented as having been established on account of "the facilities" being there. In the discussion later on, one of the Finnish industry representatives points out that "the facilities cannot be moved". The indicated research is located spatially as outside - "at the universities and at companies" - and temporally as current. Jon stresses that "that is done already today". That MAX IV is specified as existing and as "this year" having its "first users" works so as to evoke a sense of just starting. The starting of ESS - in terms of when "the building" opens and the coming of "users" - is located against the starting of MAX IV, and from this vantage point as "long time" until then. Both of these configurations contribute to producing a sense of time for developing "an ecosystem around this" and "within this area". That the indicated "we" does not know "what will come out of these two facilities" works as to legitimise why it is important to develop an ecosystem both "around this" and "within the area". The point is that actors, not strictly "within the area", too may benefit from partaking in the specified "ecosystem". Later on in the presentation, Jon points out that: 
The smart materials specialization area has the facilities as a big part, but takes its starting point in: How can we unleash the power of technology? How can technology help us address our challenges of today and tomorrow? And the way we focus on the business interest in ESS and MAX IV is threefold. The companies can deliver to the facilities - they can be suppliers. Then we work on use. How can companies use the facilities to collaborate with the universities? The third area is: How can the facilities be an attractor? In the Danish national strategy they say that most companies will not use the MAX IV and ESS - but they are interested in the innovation and research environment nearby. So how can we develop that ecosystem nearby, where materials in different aspects are discussed, and where you can meet and attract? And then, ESS and MAX IV can be one piece in the puzzle. [...]

So what is happening? The ecosystem is already existing, with universities; MAX IV is existing, and companies are interested and involved. But there is some ongoing development issues. In the delivery part, it is about creating a better matching between the companies, and it is about competence: How can we develop competence to be able to deliver on the procurement? In the use area, we need to have preparation facilities. So, in Sweden, we work on a project on: How can we develop support labs around? How can existing labs connect and open up to industry? In the attraction focus we are working with: How can we talk more global challenges as a starting point and not science? We have different methods for that ((inaudible)) for example IKEA and NASA, these big players are interested. [...] So that's kind of the pitch of what's ongoing development and $a$ lot of different actors are involved.

Jon's Presentation at MAX IV, 2017 January 26

The "facilities" are described as a "technology". This technology is attended to as having a certain "potential" but which "potential" needs to be "unleashed". This unleashing is teleologically specified as in the service of "addressing our challenges of today and tomorrow" and the technology, given its "potential", as "helping" towards realizing that cause. What is described as "business interest", and the three possibilities specified for its realization, is made internal to the cause. The businesses, in using the facilities do not merely realise their interests, they also participate in addressing the indicated "challenges of today and tomorrow". The existence of interest and of involvement is repeatedly established. The rhetoric is one of joining an existing "ecosystem" rather than forming a not-yet-existing one, and in so doing, of being in the company of "a lot of different actors" - as "different" as IKEA and NASA, "these big players". In orienting to the unleashing of the potential in the ESS and MAX IV - as "user facilities", as "technology", as "instruments" there is an implicit assumption as to who constitutes the "actors". Jon says that these 


\section{Accounting the Future}

are "different actors", but his exemplification narrows them down to "players" such as the indicated, namely IKEA and NASA. This provides for the mobilizing effect of being in the company of actors as those.

\subsubsection{What is "Nothing to See Here" (Not) About?}

If the visit to the ESS construction site was organised so as to show that there was something to see, what is the statement "nothing to see here" doing in relation to that intention? What is it about? What is it not about? How does it come to be about something in particular? In this case, answering these questions involved asking Jon to provide an account of "nothing to see here". The following is the inquiry, as I sent it to Jon via email on the 3rd of July, 2017:

Dear Jon,

Thanks for agreeing to this follow up. My question is rather simple actually, and relates to something that you said in passing during the Finnish visit to ESS this year. The context is roughly like this:

After Catelyn's presentation of ESS, we were heading down to MAX IV for the second part of the visit. Just as we were exiting ESS, still on the construction site, you said: "there is nothing to see here". Now, I do not remember precisely the conversation (perhaps you remember it better and can remind me), but your statement intrigued me and I would like to know more about it. Could you perhaps reflect on these questions: How do you understand what you said? And, could you think of what you wished to convey when you said "nothing to see here"?

I do not expect that you will remember every detail exactly. But in that case, you could describe perhaps what you might have wished to convey to the visitors with that statement.

As you may see, I am trying to understand your take on the situation above - as you see it. I would very much appreciate your deliberation, perhaps a few paragraphs in relation to the questions.

Thanks, Ivanche

Email Communication, 2017 July 3

As becomes evident from reading this email, the inquiry involves a reconstruction of the occasion. This is not the occasion itself, but the occasion as reduced to the detail contextualizing the inquiry. It provides that Jon made the statement; that he did this after Catelyn's presentation of ESS, and on the way out to MAX IV, but still on the ESS construction site, and as part of a certain conversation. The reconstruction 
contextualizes - not simply the statement, but Jon's saying of it in terms of what, where, and when he made it. It orients the inquiry to the act of saying such a thing then and there - and not to the content of what was said; in other words, it so asks Jon to account for what he had done/conveyed in saying what he said. In this way, the specification of the act's setting and timing figure - not merely as a reminding detail but also perform the act in suggestive ways. For example, that Jon said this after (and not during) Catelyn's presentation, on the point of exiting the ESS construction site and walking towards MAX IV, may suggest favouring of the latter facility over the other; it may be taken as suggesting that the visit to the ESS site was uninteresting, that the really interesting stuff is yet to come elsewhere, at MAX IV. And so on. That the saying is done "in passing" becomes potentially revelatory.

Before delivering Jon's reply, it is relevant to make explicit the following three features. Firstly, at the time he articulated "nothing to see here", none of the visitors - including myself, stopped to ask, for example, "what do you mean nothing?" or "what about those cranes over there, are they not something?" We all continued our walk as if nothing of consequence was said or suggested; as if what was said was of no notice at all. Secondly, there was a few months difference between this event and the email. Which suggests to the organiser - who is called to account for it, that the statement he made on that day was of some notice - since it is brought up now - or that it was considered significant enough to be remembered all this time. And finally, at the point of reading my email, and thinking up a reply, Jon might anticipate that I already have in mind some possible interpretations.

The phrase "nothing to see here" opens to multiple interpretations: as a diversion; apologetically; as a way of evoking somebody's appreciation of something; an assessment; to suggest that one's expectations have not been met, etc. The statement may be used sarcastically, as in "nothing to see here, move along folks" - i.e. as what a person articulates when detecting a hidden, deeper meaning to a story or event that the reporter or authority on that story/event wishes to conceal, possibly to avoid upsetting a public. In principle, the statement is interpretatively flexible, which is not to say ambiguous. Note that, nobody reacted to it on the occasion. Some might have picked it up, and understood it in a particular way (how precisely, we will never know) while others might not have noticed it at all and, if asked about it, they might not even remember this statement. Indeed, that he said it does not, in and of itself, suggest that Jon was even making a particular point or statement.

That said, consider how in his email reply Jon (2017, July 4) does the interpretive work of establishing what "nothing to see here" is and is not about. He says: 


\section{Accounting the Future}

I remember my remark on the site. Sometimes I say this. It is just a comment containing two aspects. First, the ESS site is right now mainly a construction site. It looks like most construction sites. Second, the visit was about to continue at MAX IV, where we would get a tour of the facilities. That is not possible at the ESS, not yet anyway. I just want to emphasise that my remark was not said to diminish the importance of the ESS. On the contrary: ESS will be an interesting and large facility. Just only today we can only see the glimpse of it.

Email Communication, 2017 July 4

Jon's account preserves some of the features of the occasion as the preceding inquiry reconstructs them. The setting is maintained as a "construction site"; the occasion, a "visit"; its timing, on the way to MAX IV; and the mode of the statement's delivery as saying - or remarking and commenting, rather than, say, asserting, arguing, suggesting, pointing out, and so on. But his account also reworks these features.

Initially, the re-working involves authorization - he remembers this statement qua remark; he is not, for example, guessing or imagining what he might have meant in saying this. Jon's response, in other words, performs him as accountable for remembering "nothing to see here". He fashions an account of the remark (comment, that he said it, what he said) from the point of remembering the remark. And also, extends the temporality of the statement; in saying that sometimes he says this, Jon discounts the interpretation of the statement as a unique instance. Rather, his utterance is organised so as to imply its membership in a set of other instances. "Sometimes I say this" comes about as explaining how come he remembers it.

Jon's account provides that "nothing to see here" is sometimes used and that it is just a comment. It provides that, articulating the statement - i.e. that he said it, is not an extraordinary occurrence but something he ordinarily does. It situates the statement as a "comment" within the set of some-times he has used it, rendering it as a figure of speech. Hereby, he specifies the "aspects" contained in what he said. On the one hand: that he used "nothing to see here" as a way to indicate the ordinariness (nothing-specialness) of ESS at present - i.e. in being, "right now mainly a construction site" and which site "looks like most construction sites". And, on the other: that he used "nothing to see here" as a way to introduce the next step and location in the visit, the tour at the MAX IV facility, as comparably something. To reiterate Jon's statement, such a tour "is not possible at the ESS, not yet anyway".

Not only something Jon sometimes says - not only because ESS is (for the time being) just a construction site, "nothing to see here" is also delivered as something 
which is appropriate to say on the particular visit occasion. The occasion is to be apprehended in the detail as Jon outlines it, namely "the visit was about to continue to MAX IV" and "where we would get a tour of the facilities". The implication is that MAX IV, by contrast to ESS, already is or already provides for "something to see". The statement is rendered as introductory to the already-somethingness of the something which on the occasion was about to be seen. The extraordinariness of what was about to be seen is mobilized as a way to characterize the ordinariness of what was said on this occasion. Note that this disambiguates the statement's focus. From potentially being about ESS, it gets rendered as being merely about MAX IV; or rather, about the visit continuing there. If it could be understood as saying something significant about ESS - or as making a particular point about it, as "diminishing the importance of the ESS" - it does not.

\subsection{Conclusion}

This chapter used documentary and interview materials from "future walks" and a pre-organised visit to the ESS construction site to continue my examination of the ways in which performances of accountability relations made statements about the future sensible. I showed that sight of/over the future was socially organised, in the particular sense that it involved assigning accountability concerning who was seeing, who could determine what was being seen and why, as well as whose vision mattered and how. The chapter showed that the sense of what particular statements about the future were, and were doing - for example, legitimising or just indicating "a need to update" - derived from that social organisation and were particular to it. I argue in this relation that we should be cautious when attributing ideological significance to statements about the future, for example in a priori determining that they are (not just describing but also) legitimising, or generally "doing something". A close examination of the statement "nothing to see here" showed how the dynamics of accountability achieved the relevant somethingness (i.e. the MAX IV facility) in relation to which that statement made sense and could be heard as noncompromising, uninteresting and ordinary. 


\section{The Ordinary Making of the Not-Yet}

The previous chapter looked at "future walks" and a visit to the ESS construction site to examine how performances of accountability relations made particular assertions about the future sensible in such settings. It showed that the sense of what statements about the future were about, and were doing, depended on performing a social organization constituting who was seeing, who could determine what was seen, as well as whose vision mattered and how. Whereas the thesis has thus far examined futuring practices which explicitly contend the nature and existence of a future phenomenon, we have said little about the wide range of activities which might be said to implicate the future without direct reference to it. So this chapter focuses on the mundane, ordinary practices normally marginalized in studies of the future, the daily, routine and local work of scientists and technicians. In what sense, and to what extent, can these practices be seen as making the future? Who says they are futuremaking, and how? How best can we understand the connection between the specificities of accomplishing something locally, in the now, and the time-and-placeextensive distribution of future-making? To answer these questions, I examine documents, interview and conversational extracts pertaining to the ESS Detector Coatings Workshop - an in-house facility formed by ESS in 2014, in Linköping, and tasked with manufacturing "thin film coatings" for the "next generation" neutron detectors to be used at ESS in the future.

This chapter is organised as follows. As the context against which I developed research interest in studying the mundane, ordinary practices at the Coatings Workshop, I begin this chapter by introducing the "helium-3 crisis". Specifically, I examine a Power Point slide, looking at the ways in which the visual features of the slide are organised so as to accomplish a sense of accountability. In the same section, I also recount an interviewee's story of a key event that, according to him, made the Coatings Workshop possible. The next section looks at two texts - an ESS web-based article, announcing the opening of the Coatings Workshop, and an article by Linköping University, crediting one researcher specifically for the achievements of the Coatings Workshop in relation to ESS. The section examines how, in performing relationships between the "helium-3 crisis" and the Coatings Workshop, these texts accomplish a sense of a better tomorrow. Then, I zoom in on stories told about the "helium-3 crisis" in interviews and conversations in the context of the Coatings 


\section{Accounting the Future}

Workshop itself. The various stories examined can be seen as textual renderings of a "future present" (Adam 2005), as a way of implicating "big futures" (Michael 2017) in performing the Coatings Workshop's reason for its existence. The chapter continues by examining ordinary practices at the Coatings Workshop - looking specifically at an episode of measuring "coating thickness" - and aims to explicate some of the ways in which these practices can be seen as generating and sustaining its role in future making.

\subsection{Accountability Relations in Stories about a "Helium-3 Crisis"}

Normally, neutron detectors are helium-3 based. Unfeasible to extract from natural resources, virtually all helium-3 in use today is of industrial origin, a waste-product from the decay of the gaseous tritium. Tritium is a radioactive hydrogen isotope used as a booster for nuclear weapons. Driven by the arms race in the Cold War, Russia and the US produced and stored large amounts of this substance, decaying with a half-life of 12 years to helium-3. Initially, due to the absence of a designated purpose, helium-3 simply was released into the environment. Realising its potential as a neutron detector, the US then began accumulating it and, for many years, the supply of helium-3 outdid the demand for it. After the terrorist attacks of 9/11 in 2001, the US government began deploying neutron detectors at their borders to help secure the country against smuggled radioactive material. This created a novel demand for helium-3. The use of helium-3-based medical imaging technology also increased. As a consequence, the size of the stockpile shrank, leading to restrictions on the distribution of helium-3 and to major price increases. Broadly, and among the developers of ESS neutron detectors, this increase in the demand and cost for helium3 and parallel decrease in its availability is referred to as a "helium-3 crisis".

Figure 4 is from a PowerPoint presentation I found on the ESS Website in October 2016. The title of the presentation is "Detectors at the European Spallation Source: the Story so Far" and the author Tywin Hansson (pseudonym) - Head at the ESS Detector Group in Lund. He presented it in 2012, during a workshop on neutron detection at CERN.

How does this slide perform accountability? To answer this question, I look at the visual constitution of the slide. As we can see, the slide is organised as a collage of statements, a graph, and an image. A preliminary reading is that the space of the slide is divided in two halves. The bulk of entities is distributed on the left side, suggesting that whatever sense the slide is performing, it does it on the left. It directs the eye of 
the reader or beholder there. The font size used to articulate the statements is bigger on the top than on the bottom, which suggests a top-down direction of reading. The statements which frame the graph - namely, "...Old News Now...", "He-3 Crisis", and "Little or None Available" - all are of the same font size. This suggests that, together with the graph, they form a single meaningful unit. Moreover, the graph spatially extends to the right, into the space that the image occupies on the slide, suggesting in this way a meaningful connection. It performs the image as a visual extension of the unit of items on the left. Some readers may recognise this image as Munch's, The Scream. The sense of agony and torture that this image conveys is appropriated here to visualise: "... an appropriate initial reaction..." The object of (or motive for) such a reaction is made discoverable on the graph, by way of the item "since ca. 2009". It corresponds with the item "FY'09", the part on the graph that performs a shift in the balance of "supply" and "demand". The organisation of the slide, in other words, provides for the sense that the reaction, as illustrated, is because of that shift. We can see that the graph not only is descriptive, but also predictive. The last item on the graph, FY'18, roughly corresponds with the time ESS will "need" the helium-3. This "need" is visually enacted in relation to the sudden upsurge in the "demand" for the substance.

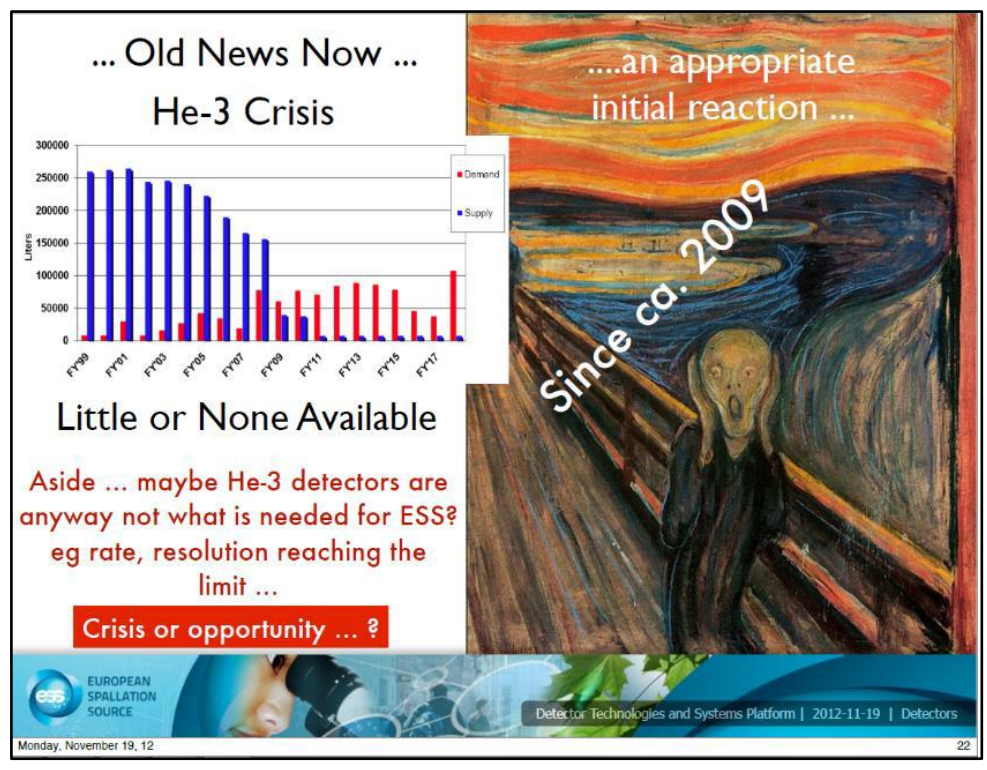

Figure 4 - A visual rendering of the "He-3 crisis" (Tywin 2012) 


\section{Accounting the Future}

It is important to emphasise several more features from this arrangement. The item "He-3" performs an audience that can recognise it as an abbreviation for "helium-3" - the helium isotope; an audience, therefore, that can read the categories "supply" and "demand" as pertaining to helium-3; and, an audience that is sufficiently familiar with the significance (or use, relevance, import) of this helium isotope to infer the sense in which the lack of it, which lack the graph performs, might summon for somebody such a reaction as the illustrated. Finally, the item "...Old News Now..." performs the audience as by now or already familiar with the characterisation of the shift in the supply/demand of helium-3 as a "crisis". The items on the bottom left corner are marked in red, signifying another unit different from that constituting the "He-3 Crisis". The item "Aside..." suggests that the proposition "maybe He-3 detectors are anyway not what is needed for ESS" is a sensitive proposition, and therefore a proposition that is to be taken as between the presenter and the audience. It suggests, in other words, that there are such actors at ESS or about who think that "He-3 detectors are... what is needed for ESS" and who are not supposed to hear what the presenter-Tywin - is telling to the audience. He is performing the audience as accountable for keeping this within the setting in which it is being articulated, between the actors hearing it. He is entrusting them with that statement.

We see how Tywin's visual depiction of the crisis includes the use of imagery to position the audience as knowledgeable, as capable of recognising the choices that have to be made; and as trustworthy. In his presentation, Tywin states two possible alternatives to helium-3, namely the gaseous boron trifluoride and a solid, boron carbide. "For detectors to be built now," he points out, the first is "probably the right choice". A gas, as he puts it, boron trifluoride could easily replace helium-3 (also a gas) without requiring dramatic modification in the existing detector technology. Still, notes Tywin, there are "very good reasons" not to use this gas; if only for the fact that "it can kill you in a large number of competitive ways". He says, "given that there is a time for R\&D before ESS construction needs to start, it would be a huge lost opportunity not to replace this". "Above all," according to him, "the safety implications are that you have to think about this all the time". As the safer, more convenient and there-is-time-to-develop-it alternative to helium-3, Tywin proposes boron-10-enriched boron carbide. Interestingly, at the time of this presentation, in 2012, ESS was already actively working on developing a detector technology based on boron carbide. In part, that work was, as it still is, done at the ESS Detector Coatings Workshop in Linköping. I turn now to how Davos Svensson (pseudonym), a professor at the Thin Film Physics division at Linköping University, remembers how this started. 
During interview Davos (2017 February 28), tells me how in 2009 he attended a "users meeting" at what was then MAX Lab, now the MAX IV facility. In the course of a coffee break, he met Stannis Eklund (pseudonym), the Science Director for ESS. Stannis approached him, looked at his name tag - identifying Davos as a Professor in Thin Film Physics and - "just out of the blue" - asked him: "Oh! So you are making thin films. Can you make boron films for us?" The description of the situation leads us to infer that the name tag provided for Davos's accountability as someone who is able to make thin films, and make boron-based thin films. When I asked him to reflect on how this "just out of the blue" kind of question came about Davos gave me this account. He explained that Stannis's question signified a "very urgent need at that time". They (he did not say who "they" were) already had decided that ESS "should come to Sweden". At the same time, he notes further, "this lack of helium-3 had become apparent". That "lack" was known by then and for a long time, according to Davos, but was ignored deliberately; as it were, kept "under the carpet". He says: "I guess it's not so easy to argue for such a large infrastructure if you present the problems" first. But now that ESS was given a green light, "they had to solve this problem". They had to solve that "problem" because, as Davos reports it: "if there was no alternative to helium-3, the whole ESS project might fail." He tells me that the cost of purchasing helium-3 simply is too high given the size of the future ESS detectors. Even if cost is not an issue, he says, there simply will not be "enough" of this material available for detectors of such a scale. Davos, who had "some experience with boron", replied outright to Stannis: "No. I can't make boron films. But I can make something much better". This, he says, is thin films based on boron carbide.

Elemental boron, according Davos (2017 February 28), is a "crappy material" when it comes to making thin film coatings. It oxidises quickly, he says, and then it falls off the substrate. In the 1990s, Davos had supervised a doctoral candidate working on a procedure for making pure boron-based thin film coatings. This doctoral candidate was unsuccessful. Davos also points out that, in collaboration with ESS, detector developers at the Institut Laue-Langevin (ILL) had tried this, but they too had failed. Despite this, when Davos met these detector developers on one occasion, "they were still talking boron, boron, boron". According to Davos, boron carbide too can be problematic when it comes to making thin film coatings. Thus, in the 1990s, he had worked with another doctoral candidate on making x-ray mirrors, using boron carbide as coating. "Stress" - namely, the contractions and expansions of the substrate during the coating process - as Davos explains, had been a major issue in this case, causing the film to fall off the mirrors. But eventually, he and the doctoral 


\section{Accounting the Future}

candidate had managed to solve that problem. Based on those experiences, Davos knew that boron carbide was the "better alternative". A couple of weeks after the coffee break, Stannis had invited Davos to discuss the possibility of making boron carbide-based thin film coatings for the detectors at ESS. And after a month from this event, they had an "agreement" concerning hiring a post-doc who would conduct an initial research on this matter. This post-doc was Brienne Jacobsen (pseudonym, see below).

\subsubsection{Success Stories, or Who Saved Tomorrow}

Throughout my fieldwork, I encountered three instances of implicating the ESS Detector Coatings Workshop, the work on inventing boron-10 as a "next generation" neutron detection technology, into a success story. Albeit vaguely, one success story was indicated to me by Robert Lundberg (pseudonym) - a former Chancellor of Lund University and former Director General of VINNOVA. At the time of the interview, Robert was "back" to being a Professor at Lund University and, as part of this position, he was involved in many projects. Some of these projects, he said, had "a lot to do with social innovation". ESS, according to him, was very much about social innovation. In fact, as he put it, one such involved Linköping University, concerning finding a way to replace "something" with "something else" which, as Robert commented, was "much smarter and not so expensive" (Interview 2016, May 11). This "something" intrigued me, and investigating in the matter further, I came across this second success story. In 2014, the ESS website had published a short document, announcing the opening of an "in-house manufacturing facility" in Linköping - the Coatings Workshop. The following is the announcement as I found it published on the ESS website in late 2016. It wrote:

[...] At ESS, researchers will examine materials at the molecular level using neutrons. However, neutrons penetrate most materials and are scattered, making it difficult to detect where they are. Detectors need special materials to absorb and detect neutrons. Before these thin films of boron carbide were developed in Linköping, the rare and very expensive gas helium-3 was used in all neutron detectors. But helium-3, a byproduct when making nuclear weapons, is not available in the amounts ESS will require for its materials research. Starting in 2010, representatives from ESS, in close collaboration with experts from the Institut-Laue Langevin (ILL) began work through an EU funded project to develop a new generation of detectors. They asked Professors Davos Svensson (pseudonym) and Bronn Nordin (pseudonym) at the Thin Film Physics division at Linköping University to develop an alternative made of thin layers of the solid material boron-10. Brienne Jacobsen (pseudonym), a then new PhD in thin film physics, was assigned the task to develop a method to produce micrometre- 
thin coatings of boron carbide on a large scale. Now, four years later, the process is ready for initial production. [...] (ESS 2014)

The announcement displays the contours of a success story. It articulates an antagonist - helium-3, which not only is necessary, not only "rare and expensive" and unavailable in the amount that ESS will need, but also is a "by-product when making nuclear weapons" and thus, ominous in its very origins. The story articulates protagonists too - the representatives from ESS, the ILL experts, the indicated Professors, and the PhD Brienne, who, supported by EU, together set on a (noble) quest of developing "a new generation of detectors". The story ends on a hopeful note, with the protagonist somehow defeating the antagonist, replacing helium-3 with proposedly a more virtuous material, boron-10 thin films. We leave the story with a sense of a better tomorrow, as the method for producing such films on a "large scale" is in place and "the process is ready for initial production". How does the announcement provide for that sense?

Firstly, the sense of a better tomorrow derives from the asymmetrical performance of the implicated "materials" - helium-3 and boron-10. Both are indicated "special", as providing for the absorption and therefore detection of neutrons, but also "special" in different ways. Thus, as features of helium-3, the story makes available: that it is a "gas" (i.e. its physical state); that this gas is "rare and very expensive"; that it is "used in all neutron detectors"; that it is "a by-product when making nuclear weapons"; and that it is "not available in the amounts ESS will require for its materials research". By (a dramatic) contrast, the only feature of boron-10 (and by extension of boron carbide) that the story makes available is its physical state, i.e. that it is a "solid". On the one hand, this provides for taking that what replaces the ominous, economically unviable, and scarce helium-3 is just (and nothing else but) a solid, boron-10, and hence the sense of a better tomorrow. On the other hand, the story provides in this way that the single issue the protagonist social actors had to deal with was making a solid usable in predominantly gas-based neutron detection technology. And this is presented as precisely what the protagonists of the story have achieved: i.e. having developed "an alternative made of thin layers of the solid material".

Secondly, how the story distributes the social actors is also asymmetrical. As working to replace helium-3, it makes available: the "representatives from ESS", "experts from the Institut Laue-Langevin (ILL)", the EU, "Professors Davos Svensson and Bronn Nordin", (and these Professors as part of) "the Thin Film Physics division at Linköping University", and Brienne Jacobsen, "a then new PhD 


\section{Accounting the Future}

in thin film physics". Conversely, nobody stands behind helium-3, that is, in the way of the protagonists' work as they were replacing it. And also, importantly, nobody (and nothing) stands in the way of this becoming "a new generation of detectors" as "the process is ready" and "initial production" may start. There is nothing in the story itself that can be read as possibly preventing the tomorrow of the story to come into being.

Who is accountable for making this tomorrow happen, and how? The story provides clues for reading it, not only as a story-like way of performing an announcement, but also as a kind of assurance and a pledge. We can see that the "work" of replacing helium-3 is temporally specified as "starting in 2010". The readiness of the "process" is temporally specified as being "four years later". The events specified as occurring between those four years are written in the past tense, suggesting that the author of the story - ESS - was all along keeping track of those events, of the work that the various protagonists were doing. The last item in the story - i.e. "Now, four years later, the process is ready for initial production" - not only announces, but also (formally, publicly) sanctions (approves, authorises, endorses) the readiness of that "process". We may argue that, in publishing this story, ESS assumes accountability for making sure that a better tomorrow happens.

Investigating the connection between ESS and Linköping, I came across a third success story, the article given in Figure 5, enacting their relationship closer to home. Published in 2014 on Linköping University's website, the author of this article is Linköping University. Similar to the ESS announcement, the article performs a success story. Again, it articulates helium-3 as the antagonist - for its origins, being a "bi-product in the manufacturing of nuclear weapons", emphasising its connection to the Cold War. As in the ESS announcement, the central significance of finding an alternative to helium-3 for neutron detection also is emphasised. This alternative is boron-10 thin films. But in this case, the story more centrally revolves around a single protagonist, identified as Linköping University's own, researcher Brienne Jacobsen, who, as the title of the article specifies, had "helped ESS out of a fix". In so doing, the article performs Brienne as accountable for ESS having a tomorrow. How does the article accomplish this sense? To answer this question, let us consider the first few lines of the article and its accompanying image.

In line with Smith $(1974,1983,1987,1990,2001,2006)$, we can analyse the title as a "preliminary instruction". It instructs that we read the article as telling a story about how someone helped ESS avoid or escape from some troublesome, difficult, or dangerous position or situation. Following the title and date, the article specifies that 
situation. Two features of the situation perform it as dangerous for ESS - i.e. as presenting it with a "major setback". Firstly, the article presents "the problem" as a problem of supply. Previously, we saw that the problem with helium-3 in this context has as much to do with the demand of this material as it does with the supply. As Tywin's graph shows, the supply of helium-3 has decreased, but in parallel with the increase in its demand. The point is that, presenting this as a problem of supply only removes from considering a re-distribution of helium-3 as a possibility for ESS. Secondly, the article identifies ESS as a "major project", suggesting in this way that it needs "major" supplies of helium-3, when such supplies are limited, or scarce, or non-existent. These two features together contribute to the sense that there was no way out for ESS; that its tomorrow was in danger.

\section{She helped ESS out of a fix}

\section{August 2014}

When the cold war ended and the production of nuclear weapons virtually stopped, the supply of the isotope helium-3 plummeted. For the major project ESS - European Spallation Source - this could have been a major setback. But Linköping University researcher Brienne Jacobsen (pseudonym) solved the problem.

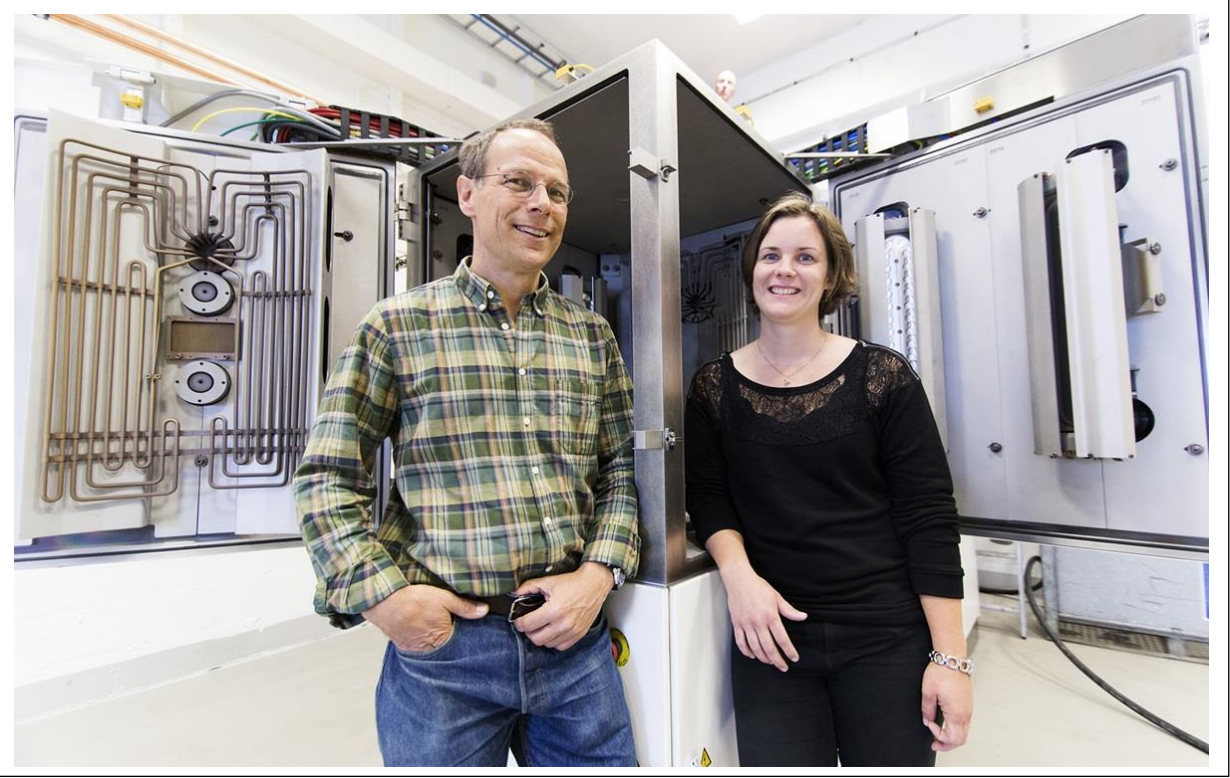

Figure 5 - Linköping University's article (Linköping University 2014) 


\section{Accounting the Future}

We are analysing this article for how it provides for the sense of ESS as having a tomorrow. How, in other words, does the article perform the sense that "the problem" has been "solved", that ESS has been "helped"? In this relation, I focus attention on the image in Figure 5.

The image displays two human entities - a man and a woman - and one technical entity. The latter is positioned in the middle of the visual composition, its edge cutting the image in two halves. Its various components are organised in a way which provides for a sense of visual symmetry. The man and woman are displayed as standing on either side of the technical entity, and as displaying similar bodily postures, thus contributing to the overall sense of visual symmetry. What is more, their symmetrical distribution on the image suggests their complicity, their joint involvement, in the indicated achievement of "helping" ESS, of "solving the problem". The man and woman are displayed as smiling, which further adds to the sense that the problem has been solved. However, the two preceding references to a female figure - "She helped..." and "researcher Brienne" - can be read as attributing credit to the female figure; rendering the displayed woman (and not the man) accountable as the someone who "helped ESS", who "solved the problem". The title "She helped ESS out of a fix", moreover, reads like a recorded statement, as something that somebody has said about the female figure. This provides for the sense that it is not the article itself (or Linköping University, the author behind it) that is doing attribution of the credit, but that it records that credit is attributed to the female figure of the article. This provides for the interpretation that the male figure is giving the credit to the female figure for "helping" ESS, as making her accountable for "solving the problem". The appropriation of "she saved ESS out of a fix" as this article's title suggests institutional (i.e. Linköping University's) acknowledgement of these credit and accountability. It performs a sense that Brienne and her contribution have been recognised by the institution.

When I interviewed Davos, I asked him about this article. I shared with him my sense while reading it as attributing a particular significance to Brienne as having made the vision of ESS (in relation to detection at least) possible. Interrupting me, Davos said:

It is correct. But it's not thanks to Linköping University in particular. It is more thanks to the coincidence that someone knows a solution, like me, and also, I am willing to put some extra effort to start working on it. I mean, of course, I'm working at Linköping University. I want to give LiU the credit. Of course. I don't mind that. It's not what I'm saying. I'm just saying that Linköping University is of course exploiting this now, that there is some contribution from Linköping University. But it could have 
been Uppsala. If I had been working in Uppsala and I sat next to him [Stannis Eklund], it would have been the same thing. It had nothing to do with any central wind from the University. Really, they have been uninformed. They hadn't known anything about this. I mean, I talked to the University and they were like "Oh! Did you use that kind of money for this?" ((Laughs)) Also, when I hear them talk, I can also hear that they are not really understanding what we have done.

Interview, 2017 February 28

Davos was validating the article's message, while assuming accountability as somebody who (originally) made such a message possible. We can see that he does this in relation to Linköping University, and does it carefully. He is careful to point out, for example, that he works at Linköping University, that he wants to give them credit, and that he doesn't mind that. Also, Davos implies in this excerpt that it is Linköping University's money that made "what we have done" possible (we can read this as a kind of implicit recognition of Linköping University's involvement). What is more, Davos is careful to specify the sense in which Linköping University has not been involved; namely, that "it had nothing to do with any central wind from the University". He accomplishes this sense, firstly, by mobilising the ordinariness of the situation of how "what we have done" came about, as a "coincidence" - as, initially and primarily, having to do with an ordinary, mundane situation of sitting next to someone. Of course, the achieved ordinariness of this situation depends on disregarding the non-ordinary context, the MAX Lab "users meeting", and the nonordinariness of the people involved in it, namely Davos as a Professor in Thin Film Physics and Stannis as the Science Director for ESS, making such a situation and such an outcome possible in the first place. Secondly, Davos specifies that "they" Linköping University - "have been uninformed". We do not hear this as indicating an irregularity in how Linköping University's funds were used, but rather as contributing to the sense of non-involvement. It hears in this way because, we rely on the accountability relation performed through the excerpt. Davos assumes accountability for determining the "understanding" that "Oh! Did you use that kind of money for this?" displays - i.e. a lack of understanding as to "what we have done" and not, say, an irregularity in how "that kind of money" was used.

\subsection{The Everyday Practices of the Workshop as Future Making}

Given the significance which these stories were attributing to the invention of boron carbide thin films - i.e. as what secured a tomorrow for ESS or rather, a better 


\section{Accounting the Future}

tomorrow through ESS - I realised it was necessary to pursue this matter further. I contacted Brienne to this end who, noting how happy she was that "somebody in Linköping" was interested in the work of the Coatings Workshop, was delighted to allow my presence there as an ethnographer. I too was happy for meeting somebody in Linköping who like me (albeit differently) was involved with ESS. When trying to talk about ESS in Linköping, the response typically was a question: "What is that?" Davos thinks that the overall absence of ESS from Linköping is, first of all, "natural" (2017 February 28). He says: "the reason why it is important in Lund is of course because it [the facility] is in Lund". He continues: "I mean, there is no way that you can miss Lund", especially as Lund University "pays a lot for it; Region Skåne is also contributing with millions and millions". According to Davos, "this is a big thing in Skåne" and therefore, it is "natural that it will be on people's minds". By contrast, Linköping and Linköping University, according to Davos, are far from ESS geographically, but also in terms of institutional involvement. He says, projects such as the ESS are "important for universities that have research activity in nuclear physics". Except for providing some lectures in this area, argues Davos, "Linköping University doesn't have nuclear physics." For this reason, he says, "there hasn't been any big excitement about ESS in general" in the Linköping context.

I met three individuals at the ESS Detector Coatings Workshop - Brienne Jacobsen, Meera Pettersen (pseudonym), and Robb Karlsen (pseudonym). Brienne was the Workshop's Head, but on most occasions, the others considered her role there as that of "the scientist". Robb would often emphasise, for example, that Brienne's responsibility was to do science and research - i.e. to invent "coating processes", to write scientific publications on this subject, and to attend science meetings and conferences on behalf of ESS. Meera was the manager of production. The others understood her role as involving planning and supervision of the process of largescale manufacturing of coatings. As she had taken a sick-leave, however, I met Meera on only a few instances during my six-work-weeks stay at the Coatings Workshop. I would spend most of my time with Robb. His title was a "production technician". Robb emphasised repeatedly, however, that the definition of "production" and so, his role as a "production technician" had changed over time. Thus, two years ago, when Robb began his employment at the Coatings Workshop, "production" (as he understood it) referred to the process of large-scale manufacturing of coatings for the "actual ESS detectors" (personal communication, 2017 February 20). He took this to exclude the making of "detector prototypes". All to do with detector prototypes was, according to Robb, "science and research" and therefore Brienne's job - not his. He said that, given that understanding, he would spend his first few months of 
employment "in front of the computer" - getting familiarised with the coating equipment - and, in this way, preparing for the start of "actual production". Robb said this start never came about and, as Meera was taking another sick-leave at the time, it meant that Brienne was the one that "did all the work". This situation caught the attention of Tywin - the Head of the ESS Detector Group in Lund, their "boss" - who, in a meeting with the three of them, explained that "production" included all coating-related activities, including doing coating for the detector prototypes. Since then, Robb "did everything" that Brienne did earlier, for example receiving detector substrates, cleaning and mounting them for coating, dismounting them after coating, doing measurements of thickness and the related paperwork, as well as packing and shipping the coated substrates at the end. Brienne had assigned me the task of "helping" Robb in performing these and such activities.

\subsubsection{Performing Orientation through Talk about the "Helium-3 Crisis"}

I encountered references to the "helium-3 crisis" twice during my stay at the Coatings Workshop. Brienne brought it up the first time, at the beginning of my fieldwork at the Coatings Workshop, as a kind of introduction to how this Workshop came about. She said:

When this project started, there was an urgent need for alternatives to existing detectors. The ones we used before were based on a gas called helium-3, which is one of very few materials that can absorb neutrons. [...] It is a gas that you only get when you produce nuclear weapons. It's a by-product. And since the end of the Cold War, when they decided to produce less weapons, the production of helium-3 went down. So, you can say, our only source of helium-3 is the US. And the helium-3 that is available goes to Homeland Security, as a priority, and there it's used at the border controls, to scan for radioactive or nuclear material that they smuggle into the country. So, there is no helium-3 available for ESS and that's why there was a need to find an alternative.

They realised that, if they don't find a solution to this helium-3 crisis, as they call it, they cannot build ESS in the way they had planned.

Boron, which is not a gas but a solid material, is one of few materials that can do the same thing as helium-3. So we are building something similar to the old technology but instead of a gas we have something solid. So what we started with was finding a process to actually make these coatings that we do with this boron. Initially, we asked ourselves "Is it possible to do this?" And then we quite quickly realised that it was. We have developed quite a few different detectors which are based on this technology. 


\section{Accounting the Future}

And now we have this facility here, where we can actually produce these coatings for many thousands square meters detector area at the ESS.

Interview, 2016 December 2

When hearing this for the first time, I thought that Brienne simply was reiterating "the same" success story I read in the ESS announcement (see page 146, this chapter) and Linköping University's article (see page 148, this chapter). Returning to it, however, I began noticing subtle differences that suggested she was performing two stories - one about a "helium-3 crisis", and another, about the Coatings Workshop. Together, these two stories were performing a sense that something important had been done. To show how this excerpt accomplishes such a sense, I zoom in on the middle part of the excerpt above, namely:

They realised that, if they don't find a solution to this helium-3 crisis, as they call it, they cannot build ESS in the way they had planned.

Note the item "this helium-3 crisis". Retroactively, this item performs the preceding story as story of a "helium-3 crisis". With the key provision, however, that Brienne does not assume accountability for this story. In saying "crisis, as they call it", Brienne performs distancing from that characterisation. As far as she is concerned, a "crisis" might or might not have been the case. Also, in saying "they realised that..." she performs distancing from that realisation. The facts of the case, as elaborated through the story, might or might not have justified realising that "if they don't find a solution... they cannot build ESS in the way they had planned". We can see, in other words, that she is reporting somebody else's story. The terms "we" and "our" used in conveying it, are made available as somebody else's implicating terms. This is different from the previous iterations of the helium-3 crisis. In the ESS announcement and Linköping University's article, the "helium-3 crisis" and its implications are performed as facts. As facts, they have implications, not for ESS specifically but also for everyone else needing or using helium-3. In this case, Brienne performs them as features of somebody else's story. As does this one, the previous iterations perform a "need" for finding alternatives to helium-3. But in the previous iterations, that "need" is performed as stemming from the facts; thus as a general need. By underemphasising facticity, Brienne performs specifically ESS as in need. She provides for the sense that that was what mattered at that time, "when this project started". The "we" of the second story, then, has not so much saved ESS (as in "helped ESS out of a fix") as it has responded to ESS as somebody in need; that is to say, done them a kind of favour. 
In the account above, the second story differs from the first in that it is no longer somebody else's but Brienne's as part of a "we". Different from Linköping University's article (Figure 5), Brienne does not assume accountability for what has been done. Her second story accredits accountability to the unspecified constellation of actors implicated through the item "we". They are performed as accountable for the story as Brienne tells it; i.e. for the claim that boron "can do the same thing" as helium-3, that the technology they are building is "similar" to the old, for the realisation that the technology was possible with boron, for the claims that "different detectors" have been developed on this basis and that the facility "actually can" produce coatings on a large scale. All this amounts to a sense in which the "they" of the first story is indebted to the "we" of the second story. The stories, as conveyed, perform the "we" as an agent - as having a place in ESS - and not simply or merely a production facility, doing coatings for ESS.

To consider how this might be of some significance, I turn to the following excerpt from my interview with Davos:

I don't know how it works at ESS, but I think that they have people working with the in-kind contributions. So they have all the different academic institutions around Europe that are contributing with parts of the instruments. They are really well catalogued. I mean they know exactly how many Euro every university, every country, will contribute to each instrument. But because we are not in-kind contributor, we don't provide anything that they make accounting about what we contribute. So we are never appearing. When they are talking about collaborations, Linköping University is a very minor player in their eyes, because we don't contribute with anything. We are just a research collaborator. Although we have done a lot of work together which is very essential to ESS. They don't really focus on keeping working with us, until the next problem appears, I guess ((laughs)) I just feel a little bit annoyed that we never get credit for it. We get credit when Tywin is presenting. In his presentations now and then he gives credit. But if you talk to anyone else, at ESS, Linköping University is hardly ever mentioned. Because each instrument is the in-kind contribution of different countries, and all those that are contributing there, they are making a book-keeping about how much is their contribution. Linköping is not part of that. According to them, we are not contributing, although we have contributed with a lot. And we still have agreements for research collaboration... this is not known generally at ESS that we have these things. It is not important to ESS apparently.

Interview, 2017 February 28

This excerpt offers us insight into the accountability relations providing for the visibility of the Coatings Workshop as a "contributor". It performs the "people 


\section{Accounting the Future}

working with the in-kind contributions" as accountable for making contributions visible in the ESS setting. To the extent that Linköping University does not count as an in-kind contributor, the Coatings Workshop's contributions, no matter how "essential to ESS", are invisible to those "people", to their book-keeping and accounting practices making "contributions" visible. We can see that there is a localisation and temporalisation of the Coatings Workshop's practices as futuremaking. They are future-making "when Tywin is presenting", "in his presentations", "now and then". They are future-making to that extent, but not always and not everywhere: "if you talk to anyone else, at ESS, Linköping University is hardly ever mentioned" - "this is not known generally at ESS".

I encountered a reference to the helium-3 crisis for the second time, later on, in the course of the following conversation:

Ivanche: When did you decide to use boron carbide instead of helium-3?

Brienne: It has been a long process, and there are still people who are not convinced. So it's like step by step. We are trying to convince people that from a price point of view and from a technology point of view, this is something that they should use. But then there are always people who say "But we have used helium-3 for fifty years, so why would we change? We know that it works." It's always a risk to take a new technology which hasn't been tested for many years. In the end, it's the instrument scientists who decide what they want.

Ivanche: Is it possible that one of these instrument scientists says "I want my instrument with helium-3"?

Brienne: But then they need to pay for it. They have a budget and the budget has a limit. And if they say they want it from helium-3, then they will get a very small detector compared to what they would get with boron-10. So that's up to them to decide. We can just recommend.

Ivanche: But most people agree with using boron carbide, I guess

Brienne: Yeah, I think so

Robb: Sooner or later, they have to do the change anyway, I think. If they don't find a helium-3 source elsewhere

Brienne: Maybe there will be a new source again

Robb: ((looks at Brienne, puzzled)) of helium-3?

Brienne: Yeah. Now that there is a president who wants some nuclear weapons 
The Ordinary Making of the Not-Yet

Robb: Ah, yeah-yeah, yeah - yeah

((Laughter))

Personal communication, 2017 February 13

This conversational excerpt is interesting because it shows how "a new source of helium-3" almost becomes a possibility, as made available by the indication of "a president who wants some nuclear weapons" ${ }^{\prime 0}$, only to get dismissed quickly as a joke. We can see that the entire conversation builds on a running sense of a helium3 crisis (or shortage), forcing the choice of boron-10 on not-yet decided instrument scientists. In other words, the instrument scientists are performed as having to make a choice in the face of circumstances which restrict decision-making. When Robb specifies that sense, Brienne contradicts it, saying "Maybe there will be a new source again". Quickly, in laughter, this gets performed as a joke, discounting that as a possibility. We can see, however, that Robb does not get it at first, seeming puzzled. He displays, in this way, an orientation to Brienne as somebody who, in this setting, the Coatings Workshop, is accountable for knowing such things as (alternative, emerging) sources of helium-3. If such a thing as "a new source of helium-3" came about, Brienne ought to know about it. The conversation developed as follows:

Ivanche: Okay, but what changed their minds? Who changed their mind? How?

Brienne: But that's why we are- we've built so many different prototypes now. And every prototype, like you get a question, "If you do this"- Okay ((turns towards a poster with a graph on it)) you have this very high [radiation] background; this is never going to be as good as the black line ((points at the graph)). And then, yeah, I agree, this is much higher. What is the reason? We need to find the reason. And then you have the reason and you can say, "Okay, we had the reason, we know what to do about it, we got rid of that problem - now this is improved." Improve all the time,

\footnotetext{
${ }^{40}$ The president is not specified. Even when Robb signals his understanding of the reference, the president's name is not specified. What, then, provides for this understanding? It has to do with a taken-for-granted sense as to what counts as a "source of helium-3". Note that, in principle, there are multiple presidents out there having control over nuclear weaponry, and perhaps many others who "want some nuclear weapons". Principally, all those presidents might be a potential source of helium-3. However, in the Coatings Workshop setting, this is not the case. As a reminder, consider again Brienne's earlier point that: "you can say, our only source of helium-3 is the US" (see p 153, this chapter). In relation to this shared assumption, the sense of who "a president who wants some nuclear weapons" refers to becomes apparent. Of course, the time at which the exchange occurred is important in making the joke work. The exchange occurred around the time Donald Trump had just been elected.
} 


\section{Accounting the Future}

and with every new prototype you show something else, and hopefully in the end there are no questions left.

Ivanche: What other questions have you answered?

Brienne: This thickness uniformity was one question we had - like, when you don't mount the samples in the centre [of the coating machine] you get a thinner coating, top and bottom. That's one question that was answered. Radiation damage - what happens if you bombard samples with neutrons for the lifetime of the detector? Will the coating be destroyed? Will you consume all the boron-10 atoms? Eh, what else? The adhesion. Can you make coatings that stick to the substrate? If you can't, then we don't need to think about the whole technology. If it's not possible to coat boron carbide onto aluminium, you don't need to think about building a detector like this. That was the first question we studied. Then we needed to show that we can do this on a large scale. It doesn't help if you can do something which is just a few centimetres big, if you want something that is, I don't know, fifty square metres big. You need a slightly different thinking for these very large areas. So, yeah, there were many questions.

Ivanche: I would think that with the goal of having the first neutrons fired by 2019 many of these decisions should have been made already.

Brienne: As long as somebody decides what they want, we are free to develop and make it better. And I think we have a solution that works and are somehow confident that it will work. We've been ready for two years. So we are mainly waiting for others to decide exactly what they want. I think those decisions are not really here. They are, the instrument scientists or the people deciding in Lund what they actually want.

Personal communication, 2017 February 13

This conversational extract achieves the orientations of the Coatings Workshop's practices in particular ways; it renders them with a telos, beyond the immediate, local aims. For example, the practice of "mounting detector substrates" becomes available in and through the conversation as contributing to a process, beyond the everyday practices of mounting themselves, of "answering questions". This process of "answering questions" then is made available as contributing, or as tied to a decisionmaking process said to be happening elsewhere, with others - i.e. the instrument scientists - as the decision-makers. The features of the decision-making process are organised so as to perform a future (of decisions being made) that is unclear in terms of time. The orientation of the Coatings Workshop in relation to this future is specified as "waiting". More than rendering passive the Coatings Workshop's 
activities, this distributes relations of accountability. For example, it excludes the Coatings Workshop from accountability in the eventuality that ESS gets delayed due to coating, and makes accountable the instrument scientists instead, in not-yet being decided even though the technology is working.

How is the sense of these "questions" as "answered", or as "non-questions", "nolonger questions" accomplished through the ordinary practices of the Coatings Workshop? To answer this, the next section presents analysis of three conversational extracts, taken from my involvement in measuring coating thickness.

\subsection{Accomplishing Thickness as a Non-Question}

The participants at the Coatings Workshop measured coating thickness on a silicon wafer. To this end, firstly, the silicon was removed from its plastic packaging, then broken to four smaller plates, and cleaned. Cleaning involved removing the organic impurities from the plates with acetone, then removing the so-produced inorganic impurities with isopropanol, and finally removing the residual alcohol by air-blowing it from each plate individually. Upon cleaning, the handler would draw several lines on each of the silicon plates using a regular black or blue marker. The participants say that the ink is "easily removable" from the plates once they have undergone coating, making it possible to expose sections of silicon surface on the plates which are free of coating.

The marked silicon plates were then wire-mounted on "reference samples" - pieces from the substrates used for the purpose of holding the silicon plates during coating. These "reference samples", together with the silicon plates wired on them, were then mounted on a special construction called "table" and would go through the same coating process as the rest of the detector substrates on it. Once they underwent this procedure, the silicon plates were dismounted from the "reference samples" carefully and then subjected to a second cleaning process. The purpose of cleaning them this time was to expose the non-coated silicon surface. The exposing was performed manually, by finger-rubbing the ink using a piece of cloth dipped in isopropanol. This would provide for measuring the height difference between coated and noncoated parts. The measured difference constituted the coating thickness relative to that specific measurement.

To consider how thickness is generated and maintained as "non-question", the next section presents three conversational extracts. 


\section{Accounting the Future}

\subsubsection{An Occasion of Measuring Coating Thickness}

(EXTRACT 1). Earlier, Brienne had assigned me with the task of removing the coating from the silicon plates. Approximately, this would take me half an hour. During this time, Brienne and I are engaging informally in work-related gossip. As I am finger-rubbing the plates, Brienne is measuring the thickness of a ready sample using a special machine she calls a profilometre. The first conversational extract begins when I feel that I have removed the coating from the silicon.

Ivanche: Brienne, what do you think? Are they okay?

Brienne: If you see some holes, then it's okay.

Ivanche: ((shows the samples to Brienne)) are they okay? No, eh?

Brienne: It's only in this one. Can I?

Ivanche: Where? ((With her finger, Brienne points on the silicon plate, identifying the hole.)) Is this the hole?

Brienne: You don't need to be so careful ((picks up a tissue and starts rubbing the sample)) this ((rubbing sound)) is hard to get out

Ivanche: But I am not certain as to what we are getting off. Oh, so, should it be like this? Wait

Brienne: You should get the

Ivanche: Like this?

Brienne: You should get the coating off, here, and sometimes it helps to make a scratch ((screeching sound from the needle cutting through the silicon))

Ivanche: Okay, so I've been ((rubbing sound)) so I've been rubbing it for ((laughs explosively))

Brienne: These have been etched, so

Ivanche: Oh, so it's really difficult to take it out

Brienne: But it looks like ((rubbing sound)) I think you have, like here, all these, is I think a coating off and these stripes here- there is no coating. So hopefully we canand here it looks better

Ivanche: Oh, okay, so, but then now I know what I'm doing, okay

Brienne: ((rubbing sound)) but it is tricky to get this off. You see here it also startsyou have something- so we can have a look. Sometimes you need to redo it 
Ivanche: Okay, okay. But then I can start doing it properly ((laughs explosively)) I've been doing it for half an hour, sorry

Personal communication, 2017 January 24

EXTRACT (2). The second conversational extract begins as Brienne places the silicon sample I had "cleaned" in a device she introduces on this occasion as a "profilometre". This, she says, is "just a very little tip which scans the profile of the surface". On a different occasion, Robb (personal communication, 2017 February 13 ) told me that the "correct definition" for a profilometre is a "pick up" - like on an old gramophone. Profilometre, he pointed out, is "basically a really advanced record player" - less the music.

Brienne: what we usually do is- you have this, due to the sample holder, you have this rod which is in the centre in front of it, so usually we have a thinner coating, like, here in the middle. So we usually measure to the left or right. We have that as a standard. So I will measure on different positions here on the right side. And first we are lowering this, and then we need to find the places where the coating is removed. We do that by looking here on the screen. See? So ((points on the screen)) here's still the pen and the coating, and there you have just the silicon

Ivanche: So the coating is, uh

Brienne: And the normal coating is here and here

Ivanche: Okay, okay

Brienne: So you see it's very flat, here. And here you have this pen and the coating on top. So that's very rough compared to the rest. And here it's coating again

Ivanche: Yes. Okay

Brienne: So we will scan from- we want to see the height difference between the coating and the silicon. So the silicon was where we, without coating, and the pen is usually very thick compared to the rest

Ivanche: Uhm, uhm

Brienne: So you would think that a line with a pen is very thin ((laughs))

Ivanche: Yeah ((laughs))

Brienne: For us it's very thick

Ivanche: So, so the coating is thinner than a line 


\section{Accounting the Future}

Brienne: We will see that. It depends on how thin the coating is. But it [the line] is usually very rough. And then you see here, this was pen and coating so it's almost twice the thickness. You don't really get a uniform thickness with a pen

Ivanche: No.

Brienne: Sometimes you get like this, and sometimes like that. But this was very thin. Eight hundred and sixty six. Eh, we wanted nine hundred. Let me see. I will just get the

((Stands up, leaves, and after a few seconds returns with a paper; writes down the number))

Ivanche: So was it too thin?

Brienne: It's just one position. So we will, we take the average of quite a few measurements. So, uhm, we are in position three, on sample A, and we are on the right side. Position three was this sample, on the right side, sample A, and the first measurement is eight hundred and sixty six.

Personal communication, 2017 January 24

EXTRACT (3). During this time, Bran Karlsson (pseudonym) - the below indicated "client" - joins. As this sequence demonstrates, however, his presence as of a "client" is not immediately apparent. The conversational extract below begins after Brienne has performed a few measurements and averaged them to generate a numerical value, constituting the thickness of the coating for the particular coating run.

Brienne: So, eight hundred ninety nine point six. That's very close to nine hundred, eh?

Ivanche: We want nine hundred, right? That was specified by the client.

Brienne: The client is standing behind you ((laughs)) ((the client is non responsive))

Bran is eight hundred ninety nine point six okay?

Bran: Eight hundred

Brienne: Eight hundred ninety nine point six

Bran: It's okay.

Brienne: I would be impressed if you could see a difference ((laughs))

Bran: Zero point four

Brienne: Nanometres 
The Ordinary Making of the Not-Yet

((Bran and Brienne start laughing))

Personal communication, 2017 January 24

What can these conversational extracts tell us about the relationships between accountability, futurity, and ordinary practices?

\subsubsection{Implicating Futurity in Ordinary Practices}

Not everyone who requests coating at the Coatings Workshop is somebody for whom thickness qua "question" is "answered". And yet, the very possibility of boroncarbide to remain competitive in the eyes of instrument scientists, the decisionmakers - as it were, to remain in the game with helium-3 - depends on the sense of thickness qua "question" as already "answered", as no longer a "question", on not becoming re-opened as a "question". So, how is the sense of "thickness" as "answered" accomplished through the ordinary, everyday practices of measuring coating thickness at the Coatings Workshop? One way of understanding this is to look at the "little futures" (Michael 2017) being accomplished in and through measuring coating thickness. The conversational extracts make identifiable three sets of "little futures": situational, local, and non-local.

1) Situational futurity

A first set of "little futures" is performed as futures particular to the situation; we can call them, situational futures. Consider the following conversational segment:

Ivanche: Brienne, what do you think? Are they okay?

Brienne: If you see some holes, then it's okay.

I invite Brienne to make an assessment of the samples, in terms of whether or not they are "okay". Brienne responds with providing a condition, oriented to enabling me to "see" that for myself. This performs the "okayness" of the samples as a potential future in the particular situation.

One noticeable component of this performance is deference. Not merely a display of politeness, deference for Goffman (1956) is a way of performing social relationships between actors. It constitutes, according to him, "that component of activity which functions as a symbolic means by which appreciation is regularly conveyed to a recipient of this recipient, or of something of which this recipient is taken as a symbol, extension, or agent" ( $p$ 477). Deference, argues Goffman, represents one way in which "an actor celebrates and confirms his relation to a recipient" (ibid). Not merely inviting Brienne to make an assessment, then, my question as to the 


\section{Accounting the Future}

"okayness" of the samples can be understood as a display of deference to her as somebody who in the particular setting has that kind of authority. It performs Brienne as accountable for knowing whether or not the samples are "okay".

Brienne enacts that accountability through her response. Note the use of the item "okay". In my initial address, I am asking Brienne if "they", i.e. the samples, are "okay". Brienne's response, however, involves an "it" that is "okay" on the condition that "some holes" can be seen on the samples. Here, the "it" indexes the use of the samples in the process of measuring coating thickness. The samples, in other words, are "okay" to the extent that they make the thickness of the coating measurable through that process. While I am looking for holes on the samples to see if the coating is removed or not, i.e. for the extent to which I have been successful in cleaning the samples, Brienne is looking for features on the samples that provide for the measurability of thickness. "If you see some holes, then it's okay" can be understood as performing her sight over measuring coating thickness.

Note also that making such an assessment is a situated act. Holes may be seen on the silicon samples. The silicon samples might be assessed as "okay", i.e. as having enough many holes on them to provide for the possibility of performing a measurement of thickness. But ultimately, their "okayness" is tested through the process of measuring thickness itself. And this, as Brienne indicates when saying "so we can have a look" and shows in the second extract, involves a profilometre.

I turn attention to another situational future; another mode of displaying deference, through deferral; i.e., the act of keeping something from occurring until some future time. Consider this conversational segment:

Ivanche: So, so the coating is thinner than a line

Brienne: We will see that. It depends on how thin the coating is.

My statement about "the coating" being "thinner than a line" proceeds as a conclusion from the preceding comparison of the thickness of coating to that of a line drawn with a pen. Brienne's response "We will see that" displays her orientation to my statement as concluding about the thickness of the coating generally, and performs the assessment "thinner than a line" as something that is to be seen later on, as a situational future, as the measuring of thickness draws to an end. In so doing, Brienne conveys an appreciation of my role in this situation as a learner. For example, retroactively, she performs my statement as an aspect of that role, i.e. as prematurely concluding on the basis of a single instance of measurement, and invites 
me that I suspend judgment until measuring is done and the thickness of the coating is seen. The statement "it depends on how thin the coating is" emerges thereby as a lesson.

Few other features of the conversational segments can be seen as performing deference/deferral. Note that the occasion is performed at once as a demonstration of a procedure for measuring coating thickness and an instance of measuring coating thickness. ${ }^{41}$ As performing demonstration, the measuring of coating thickness differs in significant ways from how doing measuring coating thickness is performed normally at the Coatings Workshop. For example, the participants do not normally verbalise what they are doing as they are doing it. Brienne does this here in deference to me as a learner, and repeats some of the verbalisations (not included here) in deference to Bran, when he joins the occasion. Also, a normal procedure for doing measurement of coating thickness involves fewer individual measurements. Brienne does more measurements than usual so as to demonstrate for me, as a learner, the procedure through which this is done; so that I learn it, and shall be able to perform it later on, on my own. The number of measurements multiplies when Bran joins. Brienne is deferring the conclusion to the measurement, in other words, as a display of her appreciation for us as learners/observers.

These analyses explicate the social organisation of situational futurity. Of course, the point is not simply that situational futures are socially organised. The juxtaposition of these two conversational segments helps us see that the very understanding of those futures as the situational futures depends on performing and maintaining that social organisation. We can read, for example, the second conversational segment as an instance of reclaiming accountability for specifying the futures of the situation. Because I enter the situation as somebody who does not know about measuring, as somebody who is learning and/or wants to learn about measuring, I am not accountable for specifying the futures of measuring. When I am heard as doing that,

\footnotetext{
${ }^{41}$ Collins (1988) differentiates between experiments and experiments as rendered publicly, suggesting that the latter are better understood as "demonstrations". According to him, while experiments are intended to reveal something previously unknown, in the process facing the unruly character of nature, public experiments merely demonstrate what already is known in the guise of experiment. In the current example, the demonstration neither is performed as an experiment nor does it seek to demonstrate a prior knowledge of thickness. Rather, it seeks to demonstrate the act of measuring itself in its procedural unfolding. And in the process, it performs measuring. Ultimately, as is indicated at the end of the second conversational extract, the measured thickness is recorded, and this record then is sent to "the client" to be used as a reference in the process of assembling and testing the neutron detector prototypes.
} 


\section{Accounting the Future}

as claiming such a position, Brienne re-claims her standing as the situational futuresspecifier and re-asserts mine as the learner/observer's. But how are these "little" situational futures connected to the "big future" (Michael 2017) of ESS detectors being made with boron carbide and not helium-3, therefore connected to the "big future" of neutron science being independent of nuclear weapons? To begin to answer this question, we need to look at a second set of futures: the local futures.

\section{2) Local futurity}

We can see from the conversational extracts that, not only are situational futures performed, but also performed as instantiating and as drawing on local futurity. Consider this conversational segment:

Ivanche: So was it too thin?

Brienne: It's just one position. We will, we take the average of quite a few measurements.

The first line can be read as a question about the thickness of the coating relative to the particular measurement. Brienne's response, however, displays an orientation to my question as a statement, concluding about the thickness of the coating generally, for that sample (and by extension, that coating run). It performs the measurement as a first in a succession of not-yet others, which in average will constitute the thickness of the coating. Again, thereby, Brienne displays an appreciation of me as a learner who, for making such a statement, is being heard as not knowing that multiple measurements and averaging are involved and needs that kind of information in order to be able to follow the measuring procedure.

Note also the re-specification of "we will" to "we take". The item "we will" specifies the taking of "quite a few measurements" as what Brienne and I (and later Bran) will do on that occasion; we can say, it performs that future as situational. The item "we take", on the other hand, specifies the taking of "quite a few measurements" as something normally done at the Coatings Workshop, as a kind of regularity there; in other words, it performs that future as local. Not merely a slippage in tense, then, the re-specification of "we will" to "we take" can be read as providing for the sense that the situational instantiates local futurity. Moreover, the two specifications implicate different sets of members. Thus, the "we" in "we will" includes me, Brienne, and then Bran too as insiders to the situation of doing measurement of thickness. The "we" in "we take", however, positions me and Bran as outsiders, external to the setting in which such an act is a regularity. We can consider the re-specification of 
"we will" to "we take", then, also as a way of performing me and Bran as external observers of the Coatings Workshop, specifically in the aspect of how many measurements are taken when measuring thickness.

The Coatings Workshop constitutes an object of observation for its members, insiders, too. For example, Robb thought that the difference between "research" and "production" was important to maintain and address. Consider his take on the process of doing measurement of thickness.

For a scientist like Brienne, Robb pointed out, it was important that "quite a few" measurements were being done each time, and for every coating run, so that ultimately, the "measured thickness" would be as representative of the "actual thickness" as possible (personal communication, 2017 February 22). But in conditions of large-scale manufacturing of coatings, he said, involving many and parallel coating runs, under strict deadlines, there would not be much time to spend on doing so many measurements, and doing that for every single run. In other words, according to Robb, one could not do "production" while "thinking like a scientist". According to him: "It is impossible to do research on every run." As a technician, Robb thought that a single measurement should suffice, be relied on, and that the Coatings Workshop should, in anticipating the start of "production", be involved in producing a standardised method for performing such a single measurement. Robb said: "I would prefer to have a procedure made that, okay, you mount the reference samples like this, you put them here and there and you measure those and those points." And stressed: "Every time. No exception. And you take that number as the reference for the whole run." According to Robb "that is the only way that you can use a number in production." In his view, then, with respect to the issue of doing measurements of thickness, the Coatings Workshop was not-yet ready for the future of large-scale manufacturing of coatings for the neutron detectors at ESS.

We can see that Robb makes such an observation from the position of participating in the local futurity of the Coatings Workshop. I or Bran are not accountable for making such observations because, while as observers we participate in the situation of measuring coating thickness, also we are external to the Coatings Workshop whose features this situation is performed as instantiating. While in, we are kept outside. To further consider the import of performing situational futures as in line with local futurity, I turn to this conversational segment:

Brienne: due to the sample holder, you have this rod which is in the centre in front of it, so usually we have a thinner coating, like here in the middle; so we usually 


\section{Accounting the Future}

measure to the left or right. We have that as a standard. So I will measure on different positions here on the right side.

Brienne performs situational futurity ("So I will measure on different positions here on the right side") as drawing on local futurity, indicated in the line "so we usually measure on the left or right". On the one hand, this performs the choice to measure on the right side of the sample as non-random. She is not choosing any place to measure from, but a particular place - left or right - typically chosen when doing measuring in the local setting of the Coatings Workshop. She does it as it is usually done. On the other hand, this performs her choice as legitimate. It is in line with a formal (or sanctioned/sanctionable) procedure (that is, a "standard") of how measuring of thickness is being and should be done in the Coatings Workshop's setting and in this particular situation as part of that setting. The consequence is that, by virtue of these two effects, the choice of which side to measure on carries the weight of ordinariness and approval - the unspecified actors and the processes involved in establishing and maintaining that as a standard - and in this way makes it non-objectionable. I or Bran, "the client", may object, but the objecting can always be met by evoking the standard, as that which must be problematized first in rendering the choice as illegitimate.

We can now begin to see how the practices of the Coatings Workshop may be seen as future-making. Relying on the ordinary, routinised and sanctioned features of those practices provides for disregarding the variation in thickness that may re-open "thickness" as a question. However, the connection between the "little", situational and local futures and the "big future" of boron-based detection and nuclear independence is still not fully apparent. To make it apparent, in addition to situational and local futures, we also need to look at a third set of futures - the non-local futures at play here.

3) Non-local futurity

To consider non-local futurity, I turn attention to the following segment:

Brienne: But this was very thin. Eight hundred and sixty six. Eh, we wanted nine hundred.

Brienne makes available a non-local future: "nine hundred". This future is non-local in the sense that originally "the client", and not, say, the participants at the Coatings Workshop, specifies it; it is "the client", in other words, that specifies the desired thickness of the coating. This is done textually, in the form of coating request sheets. Brienne appropriates these non-local futures as situational - as aims of the coating 
practices, by textually specifying them in a coating process sheet. This sheet is then used as the basis for organising the coating operations. ${ }^{42}$

And another:

Ivanche: We want nine hundred, right? That was specified by the client.

Brienne: The client is standing behind you ((laughs)) ((the client is non responsive)) Bran is eight hundred ninety nine point six okay?

I initially specify the future "nine hundred" as an aim, as what "we want", and then re-specify it as a non-local future, i.e. as that "specified by the client". Brienne's response "the client is standing behind you" is not merely a reminder of his presence in the setting, on the occasion. It displays deference to Bran as somebody who, in the role of "client", may respond for himself to my (or generally, to such a) question. Interestingly, Bran remains silent at first - not recognising himself in the role "client". His presence as that of "the client" gets inserted into the occasion as Brienne, after recognising his non-responsiveness, calls him out (by his name) to step into this role and, as such, to reply to the question of whether "eight hundred ninety nine point six" is "okay". Namely:

\footnotetext{
${ }^{42}$ The work of organising and running a coating process was for the most part done by Robb, but other participants often "helped". The writing of coating processes, however, was exclusively Brienne's task. Writing coating processes involved translating the clients' coating requests into deposition parameters, including thickness. As most clients wanted "similar things", Brienne often only had to authorise an already written process - often making minor changes in it, and then pass the specification to Robb. He then used it to execute the particular coating run. With requesting a specific thickness, the clients were also asked to report the uniformity of this thickness; namely, the extent to which the actual coating thickness was allowed to vary from the requested. The participants were frustrated, however, as the clients would often either not specify uniformity or say "do your best". This was frustrating as accomplishing uniformity in the coating thickness required time and a resource-consuming procedure. As Brienne explained, most of the boron carbide particles would concentrate in the mid-regions of the particle "cloud" during deposition. The substrates interacting with these regions would receive the thickest coating, i.e. most closely meeting the requested thickness. By contrast, the substrates interacting with the lower and upper regions of the cloud would by default be thinner, i.e. more widely diverging from the requested thickness. If uniformity was important, then, the participants had to mount all the substrates in the centre of the "table". This simply meant more coating runs - and with this, more hours spent in mounting, more boron carbide wasted, more measurements, etc. If uniformity was unimportant, however, the participants could mount on all positions of the table, in this way saving time and other resources.
} 


\section{Accounting the Future}

Brienne: Bran is eight hundred ninety nine point six okay?

As the conversational segment shows, I am excluded from participating in the performance of "okayness":

Bran: Eight hundred

Brienne: Eight hundred ninety nine point six

Bran: It's okay

Brienne: I would be impressed if you could see a difference

Bran: Zero point four

Brienne: Nanometres

((Bran and Brienne are laughing))

In laughing, Brienne and Bran enact an agreement around the thickness as "okay". In this case, "okay" is not simply an assessment of the numerical difference between the numbers. Rather, it suggests that the numerical difference between the requested and actual thicknesses will not make a practical difference in how the detector detects. By saying "I would be impressed if you could see a difference", Brienne performs accountability for the non-local future of seeing difference in how the detector works, which seeing will be performed elsewhere, at another time. This difference is so insignificant it is laughable. Its laugh-ability gets emphasized at the end with the emphasis on "Nanometres" - which in this case performs scale (it hears "so small"). In so doing, on the other hand, Bran and Brienne are performing the thickness of the coating being measured, and by extension that of the substrates which is not itself measured. A more refined, or different value for the thickness can come about if more measurements are performed, if other samples are measured, if the measuring is done on the substrates themselves. However, to the extent that "eight hundred ninety nine point six" is "okay", the process of measuring the thickness stops there. "Eight hundred ninety nine point six" is the thickness.

\subsection{Conclusion}

This chapter has asked in what ways and to what extent are futures built into the ordinary everyday practices which are antecedent to explicit depictions of the future. Stories about the rationale for, and the invention of, boron carbide thin films are organised to project the resolution of a crisis which would hinder, if not prevent, the 
successful completion of ESS. The mundane work of the Coatings Workshop is not replete with explicit declarations about the future ESS, yet a close analysis of the laboratory work and associated materials shows how everyday practices nonetheless implicate what the future can come to be. My analyses of the Coatings Workshop suggest that, not simply a "signpost" - like a desirable "target" according to which actors organise their work, "big futures" also, and perhaps rather, are a way of performing actors as agents who have a place in a broader context of significance and influence. The analyses also suggest that, rather than inhering in ordinary practices as mere "potential" to be yielded by speculatively modifying those practices so that they become non-ordinary (Michael 2017), the very possibility of "big futures" depends on the achieved ordinariness of those practices. It involves, as this chapter has shown, actively sustaining "big futures" through everyday work. 


\section{8}

\section{Conclusion: Towards a Different Politics of Futurity?}

This thesis began with a curiosity concerning how to come to terms with the future. What underlines that initial sense that it cannot be examined? How best to examine it? More broadly, what kinds of processes generate and sustain robust versions of the future? The aim of my thesis was to explicate those processes.

My critical assessment of the existing literature (chapter 2) suggests that, in examining such questions, we need to look at futuring practices, the forms of action and agency constituting senses of the future in the present. The existing literature also sensitises us to the various "informal" ways of performing the future endogenous to particular examined settings. It suggests that, in examining the ways in which futures are done, we should not look solely into such "formal" practices as, say, Foresight. Finally, and relatedly, the existing literature invites us to consider the role of the "little futures" of everyday, local practices which, as is suggested, tends to be disregarded - in public discourses of the future prominently, but also in the social science literature engaging with the topic.

Still, while it appeals to a sense of the future as ordinary and familiar, the existing literature tells us rather little about the practices generating and sustaining that sense, the processes enacting the future as the particular presence we all know and can relate to in the dealings constituting our everyday life - reading newspapers, taking walks, or finger-rubbing silicon plates at work. Some of the reviewed scholars claim that statements about the future play a key role in technological and scientific development, for instance coordination, yet this claim, as I showed in chapter 2, builds on unexamined assumptions concerning the accountability of such statements. Moreover, the terminology the reviewed scholars use to designate statements about the future is slippery. Using the terms "promises", "expectations", "visions", "imaginations", etc., interchangeably and as semantic synonyms misses their specificity as phenomena produced and consumed in the real world. Finally, even when making the general point that the future is achieved through ordinary, mundane practices, the literature explains little about how such practices can be seen as futuremaking.

My critical assessment of the current literature generated the following main research questions: 


\section{Accounting the Future}

1) What accountability relations provide for sustaining our familiarity with the future?

2) How do performances of futurity, and of accountability relations as part of it, accomplish a sense of communities as coordinated?

3) What accountability relations provide for making assertions about the future (sound, seem, read as) sensible?

4) In what ways, and to what extent, can ordinary, mundane practices, the local work of scientists and technicians, be seen as future-making?

To answer these questions, I examined futurity as done through newspaper accounts of ESS; in calls for "instrument concept" proposals and in interviews with "key people" at ESS; in "future walks", site visits and emails; in announcements, articles, and as part of such mundane practices in this context as thin film coating and doing measuring of thickness.

As a means to make sense of these materials, I drew on the scholarly work of feminist sociologist Dorothy Smith, and specifically on her concept of "discourse" as practical activities conducted in accounts in various forms. Approaching discourse in this way, as I showed in chapter 3, compels us to broaden our understanding of what counts as empirical material. I showed, for example, that "gaining access", typically addressed as a methodological concern, a technical issue to be resolved before actual fieldwork begins, already tells us something about accountability in the ESS context. This enables us to identify deferral as one crucial mechanism through which accountability work gets done, achieving a sense for the social spatiality of futurity in this context; namely, who in it counts as an adequate "teller of the future" - as well as a sense for futurity as something that is (appropriately) accountable on such occasions as interviews and through methods of interviewing (as opposed to, say, foresight methods of prediction). This, I argued, results in the researcher's enrolment into a specific ESS organisation to follow (and adhere to) as the method of "gaining access to ESS" and to futurity in it as a context.

Following Smith, chapter 4 looked at accounts of ESS as generated in the local Swedish newspaper Sydsvenskan to examine how these accounts provided for generating and sustaining Sydsvenskan's readers' sense of familiarity with the future. I argued that futures, which initially appeared as "merely launched into the ether", were accomplished as accountable by performing an extended ESS community where actors not only imagined futures, but also monitored futurity over time and across spaces. These actors related futurity in the ESS context with futurity in other contexts, identifying and commenting on its successes and its failures. A broader 
reflection concerning this material was that it performed the future as unremarkable. It did this by displaying as usual (as it were, already seen) tendencies of variously distributed optimism and pessimism; contrasting interpretations as to what something meant in relation to the future (that were not, and could not be, resolved in the moment of their making); claims, assertions, and expectations about the future that unsurprisingly (at a matter of a deja vue) failed to meet future reality; worries and hopes, neatly attributed across opposing sides in the extended ESS social landscape. The implication, sustained in Sydsvenskan's texts throughout, was that this was all just talk - they maintained a sense of "the future" as something as yet to be seen, which provided for interpreting the displayed talk as just talk.

Chapter 5 looked at accounts of expectations to examine the ways in which performances of accountability relations could be seen as accomplishing a sense of ESS communities as coordinated. I identified three key mechanisms through which accountability work got distributed and done in this context. Firstly, this involved enacting a social organisation where such objects as "high expectations" were distributed across actors who were indicated as having expectations and actors who were said to respond to them; i.e., it involved performing a community consisting of actors who, in relation to the object "high expectations", were passive (simply having the expectations) and actors who in that relation were active (e.g. responding to the expectations). Secondly, it involved re-specifying the object "high expectations" into "strong support", and thereby also the initial communal dynamic. Initially passive, having the "high expectations", the actors were performed as active, giving "strong support" - thus acting as a kind of ally. A third accountability mechanism involved re-specification of the "start of construction" as ESS, the "building itself", "being there". We saw that performing accountability relations that held the various implicated actors together into a Swedish political community provided for reading this statement as making sense. With regards to the Call for Proposals, I showed that - not only did proposers perform the pre-specified roles, but also, in so doing, held others accountable for performing the scripted play as a whole. Performing the script and its accountability relations, then, was what ensured a coordinated realisation of an ESS community.

Chapter 6 used documentary and interview materials from "future walks" and a preorganised visit to the ESS construction site to examine some of the ways in which accountability relations were being performed in such settings and how these made statements about the future sensible. I showed that sight of/over the future was socially organised, in the particular sense that it involved assigning accountability 


\section{Accounting the Future}

concerning who was seeing, who could determine what was being seen, as well as whose vision mattered and how. The chapter showed that the sense of what particular statements about the future were, and were doing - for example, legitimising or just indicating a need to update - derived from that social organisation and was particular to it. I argued in this relation that we should be cautious when attributing ideological significance to statements about the future, for example in a priori determining that they are (not just describing but also) legitimising, or generally "doing something". A close examination of the statement "nothing to see here" showed how the dynamics of accountability achieved the relevant somethingness (i.e. the MAX IV facility) in relation to which that statement made sense and could be heard as noncompromising, uninteresting and ordinary.

Finally, chapter 7 looked at thin film coating and measurements of thickness at the ESS Detector Coatings Workshop, to examine the ways and extent to which mundane, ordinary practices could be seen as future-making. Stories about the rationale for, and the invention of, boron carbide-based thin films were organised to project the resolution of a crisis which otherwise would hinder, if not prevent, the successful completion of ESS. The mundane work of the Coatings Workshop was not replete with explicit declarations about the future ESS, yet a close analysis of the laboratory work and the associated materials showed how everyday practices nonetheless implicated what the future could come to be. My analysis of the Coatings Workshop suggested that "a potential" did not simply inhere in ordinary, everyday practices. Rather these practices involved active work of maintaining "big futures" such as that suggested through the various success stories - as potential. I argued that making "big futures" possible in and through the mundane work constituting the Coatings Workshop's practices was not about speculatively modifying those practices so that they became non-ordinary, future-making. Rather, the very possibility of "big futures" depended on the achieved ordinariness of those practices. The chapter concluded that, not simply a "signpost" - like a desirable "target", according to which different actors organised their work - the future also, and perhaps rather, could be seen as a way of performing actors as "agents", with a place in a broader context of significance and influence.

The results of these empirical analyses argue for the importance of generating and sustaining relations of accountability in futuring practices, for understanding how the future is imagined and made to come about. My analyses suggest that the difficulties with studying the future are not primarily ontological or epistemological as tends to be assumed in much of the literature on futures but are essentially practical and 
social. This is because we encounter the future as we engage in interactions with the entities constituting the everyday life of our work. We encounter senses of the future as we talk with others, in reading anthologies and newspapers, in taking walks, while learning how to do measurements of coating thickness, in interviewing others and during conversations. The features of the future - be they its certainty and uncertainty, its optimism and pessimism, or its methodicity (i.e. its property of being able to be studied in a particular way or ways) - all are achieved in those interactions. This thesis focused on particular aspects of that interaction: the situated assumptions, distributions, deferrals, attributions, acknowledgments, claims and re-claims, in short the various ways of performing accountabilities.

This thesis should thus be read as charting a territory for the examination of the situated acts of describing, stating, indicating, implying, remembering, recognizing, reading, and designating futures - i.e. for the examination of the organizational properties of futures as accounts-in-the-making. The thesis has thus argued for widening the scope of research to include those acts as key to understanding futurity - rather than simply or only focusing on the content of what is described in and through them. This thesis has argued that it is insufficient to look at statements about the future (and their content) only; we should pay attention to what makes us drawn or oriented to particular statements, the underlying processes that enact our interest in them. We should be especially careful to illuminate the advices, recommendations, referrals and deferrals we follow in being drawn to particular statements about the future, to specific people with whom to talk about the future, or to particular interpretations of those statements. These, I argued throughout the thesis, are not just methodological matters or issues. They perform and enact the social spatiality of futurity.

The people (and things) telling me that, in being future, the scientific practices "at ESS" cannot be studied constitute instances of community performance. The statement that there is "nothing (about or of ESS) to see" performs a community that sees ESS in this way. But as I have shown in this thesis, not everybody is a member of such a community. In chapter 6, for example, we saw that Jon thought that ESS science existed, it was important to establish this on various occasions (including the interview with me and the meeting with the Finns), and, to the extent that ESS science was future, it was for him spatially (and not temporally) so. We also saw that, for Jon, "future" was a version of ESS that, on the particular occasion of the visit, needed to be re-specified (by rendering certain aspects of ESS as non-future, or as future in some specific ways) so as to be able to bring people together productively. The thesis 


\section{Accounting the Future}

therefore argues for the importance of asking: For whom is it important to say or to think that "nothing" about the future is available to be seen, why, and how?

The thesis shows that a good deal of practical work goes into accomplishing ESS as the kind of entity that doesn't yet exist; the ESS that adequately can be addressed as future. This has some important consequences. Among other things, designating entities as future provides for producing a sense of time. We could see this in relation to Jon's presentation in chapter 6, but also in relation to Tywin's Power Point slide in chapter 7, where he suggested that the not-yetness of ESS, its property of being in the future, meant time for developing an alternative form of neutron detection; also, we could see this in connection to the Call for Proposals in chapter 5, where a sense of time could be derived against such items as "initial suite of 16" (p 98). Albeit not explicitly addressed in the thesis, one important consequence of performing entities as future is the temporalisation of technical issues and the deferral of solutions into the future. One phenomenon in relation to which to investigate this is "prototypes". I indicated in chapter 7 that the Coatings Workshop produced coatings for detector prototypes. Their designation as prototypes can be seen to provide for the acceptability or tolerability of the coatings' technical imperfections (e.g. the lack of thickness uniformity) in the present. The solutions are thereby deferred into the nearor far-term future; as something to be addressed when assembling the detectors or to be resolved at the time of making the actual ESS detectors.

Taking the above observations into account, it is possible to speculate as to four main ways in which the "political implications" of future work can be addressed.

1) In chapter 4, we saw how Sydsvenskan's texts made the future accountable as talk, or rather as hopes-, expectations-, estimates-, and worries-in-talk. The organisation of futurity in Sydsvenskan can be understood as inviting readers to suspend their own anticipation and engage instead in observation of talk as the readers' mode of futuring. This accomplishes readers as observers of, thus non-participants in futuring. It can be understood as a move of circumscribing futurity and thereby, of removing the reader-as-the-general-public from it. At the same time, Sydsvenskan's texts were organised so as to maintain a sense of the future as yet-to-be-determined, as yet-to-happen. This provided for the sense of the displayed talk about it as just talk. We can designate this as a way of organising public response-ability, in the particular aspects of de-sensitising to topic, suspending protest, objection, or other forms of intervention, and in these ways, a way of letting things happen. In other words, we can think of this move as producing public indifference. This provides for perpetuating 
social relations over time, including, for example, those drawn (or implied) between the social categories of "citizens" and "locals", "town" and "province", "somebody" and "everybody" or "anybody".

2) My analyses suggest a spatiotemporal patterning of future-making. The sense of specific actors and practices as makers-of-the-future, I argued, was not simply or solely to do with the actors' relative accessibility to material and/or rhetorical resources. The analyses in this thesis identified other factors as crucial, including, for example, the differential attribution and distribution of relevance and "rights" of story-telling. Brandon's characterisation of the listed informants as being "in this from the beginning" (chapter 3 ) could be seen as constituting a kind of political right over accounting for ESS and the future in the ESS context. This suggested a need for re-specifying the idea that actors (just) compete with one another by making differing accounts of futurity. We saw that not all actors could do so or were seen as right in or for doing so. It is important to point out that, in doing social science research, we necessarily rely on the relations of accountability we enact as we engage in interactions with our (human and non-human) informants. If the analytical (or critical) focus of our research is simply the content of how our informants describe the future, those accountability relations remain unexamined. Consequently, our research risks reproducing the relations on which it depends, even when a goal of the research is to "help" those that are not represented - be this "the general public" or "the people on the streets of Lund".

3) Several of the thesis chapters suggest a way of seeing futurity as a locus for accomplishing actors' visibility. Thus, in chapter 3, I argued that the choice of interview setting could tell us a lot about the accountability of the future; for example, that it was not confidential, that it could be shared, and shared publicly, that it was not therefore a sensitive topic, or at least not a disturbing one - that the interviewees could be seen talking about it. Moreover, chapter 4 showed how Sydsvenskan's texts could be read as accomplishing a (disengaged) sight over people talking about the future in relation to ESS. In chapter 5, the statement "nothing to see here" was analysed as a way of making "somethingness" (fore-) seen. These insights suggest that, in the ESS context, an actor counts (as future-maker) in relation to how the actor is seen but also, crucially, to the extent that that actor is seen. In many of the examined accounts, the informants were attributing accountability for being seen to organisations and institutions (such as ESS and Linköping University), to actual persons (e.g. Tywin), or to circumstances (such as that of Linköping 


\section{Accounting the Future}

University not having a nuclear physics program, of Region Skåne investing monetarily in ESS, or of the accounting system of ESS being organised in some specific ways).

4) The various accounts I have examined in this dissertation include the performance of both actual persons and organisations as accountable for the future. This can be seen to represent a version of the structure versus agency problem, in which the allocation of accountability for the future struggles with a practical, public, and deeply ethical problem. Namely, who is to blame if (or when) the futures of ESS turn out differently than expected? And, following this assertion, who (if anyone) should be punished? These questions are exceedingly problematic. We might argue that answers lie in finding more adequate ways of managing the complexity of the systems determining the future. We might designate and articulate the problem in terms of a-temporal decision-making the adoption of which may act as an integrative mechanism between nature and the social. The solution may well lie in developing new models of engagement, that make imaginaries of the future explicit to the public, and which productively integrate the voices of both ESS people and the public.

These few examples hint at the possibility of a rather different way of understanding the "politics" involved in future work. By looking in detail at the practices of generating and sustaining accountability relations, we may be better able to see how agency and capability-to-affect the future is distributed, built, eroded, and attributed. 


\section{References}

Adam, B. (2004a). Memory of Futures. KronoScope, Vol 42, pp 297-315.

Adam, B. (2004b). Minding Futures: An Exploration of Responsibility for Long Term Futures. ESRC PF Paper. Retrieved from: http://www.cf.ac.uk/socsi/futures/

Adam, B. (2005). Futures in the Making: Contemporary Practices and Sociological Challenges. Paper presented at the ASA conference, Philadelphia. 1-17. Retrieved from http://www.cf.ac.uk/socsi/futures/conf_ba_asa230905.pdf

Adam, B. (2006a). Futures Told. Retrieved from www.cardiff.ac.uk./socsi/futures/

Adam, B. (2006b). Futures Tamed. Retrieved from www.cardiff.ac.uk./socsi/futures/

Atkinson, P. \& Coffey, A. (2011). “Analysing Documentary Realities”, pp 77—92, in Qualitative Research by David Silverman (Ed.). London: Sage Publications.

Atkinson, P. \& Hammersley, M. (1995). Ethnography. London: Routledge.

Atkinson, P. (2015). For Ethnography. London: Sage.

Barben, D., Fisher, E., Selin, C. \& Guston, D.H. (2008). "Anticipatory Governance of Nanotechnology: Foresight, Engagement, and Integration," in The Handbook of Science and Technology Studies by Hackett, E.J., Amsterdamska, O., Lynch, M. \& Wajcman, J. (eds). Cambridge, Massachusetts \& London, England: The MIT Press.

Bell, W. \& Olick, J.K. (1989). An Epistemology for the Futures Field. Problems and Possibilities of Prediction. Futures, pp 115-134.

Bell, W. (1996). The Sociology of the Future and the Future of Sociology. Sociological Perspectives, Vol. 39, No. 1, pp. 39-57.

Bell, W. and Mau, J. (1971). The Sociology of the Future: Theory, Cases, and Annotated Bibliogaphy. New York: Russell Sage Foundation.

Borup, M., Brown, N., Konrad, K. \& van Lente, H. (2006). The Sociology of Expectations in Science and Technology. Technology Analysis \& Strategic Management, Vol. 18, pp. 285-298.

Brown, N. (2003). Hope against Hype - Accountability in Biopasts, Presents, and Futures. Science Studies, Vol. 16, No. 2, pp. 3-21. 


\section{Accounting the Future}

Brown, N., Rappert, B. \& Webster, A. (2000) Contested Futures. A Sociology of Prospective Techno-Science. Aldreshot: Ashgate.

Brown, N., Rip, A. \& van Lente, H. (2003). Expectations in \& about Science and Technology. A Background Paper for the 'Expectations' Workshop of June 13-14, 2003.

Callon, M. (1986). "Some Elements of a Sociology of Translation: Domestication of the Scallops and the Fishermen of St. Brieuc Bay." In Power, Action and Belief A New Sociology of Knowledge? by J. Law (ed.). London: Routledge and Kegan Paul.

Collins, H.M. (1988). Public Experiments and Displays of Virtuosity: The Core-Set Revisited. Social Studies of Science, Vol. 18, pp. 725-748.

Coordination [Def. 1]. (n.d.). In English Oxford Living Dictionaries. Retrieved September 24, 2017, from https://en.oxforddictionaries.com/definition/coordination

Czarniawska, B. (2008). Organizing: How to Study it and How to Write about It. Qualitative Research in Organizations and Management: An International Journal, Vol 3, No 1, pp 4-20

De Laat, B. (2000). "Scripts for the Future: Using Innovation Studies to Design Foresight Tools", pp 175-208, in Contested Futures. A Sociology of Prospective Techno-Science by N. Brown, B. Rappert, and A. Webster (Eds.). Aldershot: Ashgate.

Doubleday, R. (2007). Organizing Accountability: Co-production of Technoscientific and Social Worlds in a Nanoscience Laboratory. Area, Vol 39, No 2, pp 166-175

Elwood, S.A. \& Martin, D.G. (2000). "Placing” Interviews: Location and Scales of Power in Qualitative Research. The Professional Geographer, Vol. 52, No. 4, pp 649-657.

ESS. (2014). ESS Opens a New Facility in Linköping to Make Materials for Advanced Neutron Detectors. Retrieved from https://ess-publiclegacy.esss.se/sites/default/files/press_release_ess_linkoping_pdf_0.pdf

ESS. (2014a). Proposing Instruments for ESS. Retrieved from https://europeanspallationsource.se/ 
ESS. (2017). ESS \& MAX IV: Cross Border Science and Society. Retrieved from https://europeanspallationsource.se/

Fairclough, N. (1992) Discourse and Social Change. Cambridge: Polity Press

Formas, Swedish Research Council. (2014). Sweden Builds for Sustainability: Ten winning cases from a competition. Sweden: Retrieved from

https://formas.se/download/18.312567aa167c666b4248711/1549956108168/SB14 Catalogue_PREVIEW_spreads.pdf

Geels, F. W. \& Smit, W. A. (2000). "Lessons from Failed Technology Futures: Potholes in the Road to the Future," pp 129-155, in Contested Futures. A Sociology of Prospective Techno-Science by N. Brown, B. Rappert, and A. Webster (Eds.). Aldershot: Ashgate.

Gibson, J. J. (1982). Reasons for Realism: Selected Essays. New Jersey: Lawrence Erlbaum Associates.

Gieryn, T. (1983). Boundary-Work and the Demarcation of Science from NonScience: Strains and Interests in Professional Ideologies of Scientists. American Sociological Review, Vol. 48, pp 781-795

Goffman, E. (1956). The Nature of Deference and Demeanor. American Anthropologist, Vol. 58, pp 473-503.

Griffith, A. \& Smith, D. (1987). "Constructing Cultural Knowledge: Mothering as Discourse", pp 87-103, in Women and Education: A Canadian Perspective J. Gaskell and A. McLaren (Eds.). Calgary, Alberta: Detselig.

Grint, K. \& Woolgar, S. (1997). The Machine at Work. Technology, Work and Organisation. Oxford, UK \& Malden, USA: Blackwell Publishers Ltd.

Haider, J. \& Kjellberg, S. (2016). "Data in the making: Temporal aspects in the construction of research data", pp 71-96, in New Big Science in Focus. Perspectives on ESS and Max IV by V.J., Rekers and K., Sandell (Eds). Lund, Sweden: Lund Studies in Arts and Cultural Sciences 8.

Hallonsten, O. (2012a). "Introduction. In pursuit of a promise," in In Pursuit of a Promise. Perspectives on the political process to establish the European Spallation Source (ESS) in Lund, Sweden, by O. Hallonsten (Ed.). Sweden, Lund: Arkiv förlag. 


\section{Accounting the Future}

Hallonsten, O. (2012b). "Contextualizing the European Spallation Source: What we can Learn from the History, Politics, and Sociology of Big Science", pp 81-108, in In Pursuit of a Promise. Perspectives on the political process to establish the European Spallation Source (ESS) in Lund, Sweden by O. Hallonsten (Ed.). Sweden, Lund: Arkiv förlag.

Hallonsten, O. (2013). "Myths and Realities of the ESS Project: A Systematic Scrutiny of Readily Accepted 'Truths"', pp 43-66, in Legitimizing ESS: Big Science as a Collaboration across Boundaries by T. Kaiserfeld and T. O'Dell (Eds.). Sweden, Lund: Nordic Academic Press.

Jasanoff, S. \& Kim, S.H. (2009). Containing the Atom: Sociotechnical Imaginaries and Nuclear Power in the United States and South Korea. Minerva, Vol. 47, pp 119146.

Jasanoff, S. (2015). "Future Imperfect: Science, Technology and the Imaginations of Modernity", pp 1-47, in Dreamscapes of Modernity: Sociotechnical Imaginaries and the Fabrication of Power by S. Jasanoff and S.H. Kim (Eds.). Chicago: Chicago University Press.

Kaijser, A. (2016). "Can Big be Made Sustainable? Environmental Contestations over the ESS and MAX IV", pp 71-96, in New Big Science in Focus. Perspectives on ESS and Max IV by V.J., Rekers and K., Sandell (Eds). Lund, Sweden: Lund Studies in Arts and Cultural Sciences 8.

Keiserfeld, T. \& O’Dell, T. (2013). "Introduction. The European Spallation Source." In Legitimizing ESS: Big Science as a Collaboration across Boundaries by Thomas Kaiserfeld \& Tom O’Dell. Sweden, Lund: Nordic Academic Press.

Latour, B. \& Woolgar, S. (1979). Laboratory Life: The Social Construction of Scientific Facts. London: Sage.

Latour, B. (1983). "Give me a laboratory and I will raise a world", pp. 141-170, in Science Observed by K. Knorr-Cetina and M. Mulkay (Eds.). London: Sage.

Latour, B. (1988). "The politics of explanation - an alternative", pp 155-176, in Knowledge and Reflexivity: New Frontiers in the Sociology of Knowledge by S. Woolgar (Ed.). London and Beverly Hills: Sage. 
Law, J. (1999). “After ANT: Complexity, Naming and Topology”, pp. 1-14, in Actor Network Theory and After by J. Law and J. Hassard (Eds.). Oxford: Blackwell.

Law, J. (2004). After method: Mess in social science research. London: Routledge

Lefebvre, H. (1947). Critique of Everyday Life. London: Verso.

Liljefors, M. (2013). "Believing in the ESS. Scale, Vision, and Pioneering", pp 85104, in Legitimizing ESS: Big Science as a Collaboration across Boundaries by T. Kaiserfeld and T. O’Dell (Eds.). Sweden, Lund: Nordic Academic Press.

Linköping University. (2014). She helped ESS out of a fix. Retrieved from https://liu.se/en/article/she-helped-ess-out-of-a-fix

Linné, T. (2013). "The ESS in the Local News Media. Expectations, Investigations, and Mobilization”, pp 85-104, in Legitimizing ESS: Big Science as a Collaboration across Boundaries by T. Kaiserfeld and T. O’Dell (Eds.). Sweden, Lund: Nordic Academic Press.

Lund City Council. (2014). Future Walk. Retrieved from http://www.lund.se/Brunnshog/Hamta-material/Future-Walk/

Lynch, M. (1993). Science and Ordinary Action. Ethnomethodology and Social Studies of Science. UK \& USA: Cambridge University Press.

Lynch, M. (2000). Against Reflexivity as an Academic Virtue and Source of Privileged Knowledge. Theory, Culture \& Society, Vol. 17, No 3, pp 26-54.

Macnaghten, P., Kearnes, M.B. \& Wynne, B. (2005). Nanotechnology, Governance, and Public Deliberation: What Role for the Social Sciences? Science Communication, Vol. 27, No. 2, pp 268-291.

Merz, M. \& Knorr-Cetina, K. (1997). Deconstruction in a 'Thinking' Science: Theoretical Physicists at Work. Social Studies of Science, Vol 27, pp 73-111

Michael, M. (2000). "Futures of the Present: From Performativity to Prehension", pp 21-42, in Contested Futures. A Sociology of Prospective Techno-Science by N. Brown, B. Rappert, and A. Webster (Eds.). Aldershot: Ashgate.

Michael, M. (2017). Enacting Big Futures, Little Futures: Toward an ecology of futures. The Sociological Review, Vol. 65, No. 3, pp 509-524. 


\section{Accounting the Future}

Moerman, M. (1965). Ethnic Identification in a Complex Civilization: Who Are the Lue? American Anthropologist, Vol 67, No 12, pp 15-30.

Neyland, D. \& Woolgar, S. (2002). Accountability in Action? The Case of a Database Purchasing Decision. British Journal of Sociology, Vol 53, No 2, pp 259274.

Nowotny, H. (2016). The Cunning of Uncertainty. UK \& USA: Polity Press.

Noy, C. (2008). Sampling Knowledge: The Hermeneutics of Snowball Sampling in Qualitative Research. International Journal of Social Research Methodology, Vol 11 , No 4, pp 327-344

O’Dell, T. (2013). "Mobile Spaces of Affect. A Cultural History of the Future”, pp 67-84, in Legitimizing ESS: Big Science as a Collaboration across Boundaries by T. Kaiserfeld and To. O’Dell (Eds.). Sweden, Lund: Nordic Academic Press.

Pollock, N. \& Williams, R. (2010). The Business of Expectations: How Promissory Organisations Shape Technology and Innovation. Social Studies of Science, Vol. 40, No. 4, pp 525-548.

Rankin, J. \& Campbell, M. (2009). Institutional Ethnography (IE), Nursing Work and Hospital Reform: IE's Cautionary Analysis. Forum Qualitative Social Research, Vol 10, No 2, pp 1-20

Region Skåne. (2009). The ESS in Lund - its Effects on Regional Development.

Sweden: Region Skåne.

Rekers, V. J. \& Sandell, K. (2016). "New Big Science: Opportunities and Challenges," in New Big Science in Focus. Perspectives on ESS and Max IV by Rekers, V.J. \& Sandell, K. (Eds). Lund, Sweden: Lund Studies in Arts and Cultural Sciences 8 .

Sandell, K. (2013). "Designing for the Future. Scientific Instruments as Technical Objects in Experimental Systems”, pp 163-186, in Legitimizing ESS: Big Science as a Collaboration across Boundaries by T. Kaiserfeld and To. O'Dell (Eds.). Sweden, Lund: Nordic Academic Press.

Selin, C. (2008). The Sociology of the Future: Tracing Stories of Technology and Time. Sociology Compass, Vol. 2, No. 6, pp 1878-1895. 
Shove, E. (2003). Comfort, Cleanliness and Convenience. Oxford: Berg.

Smith, D. (1974). The Social Construction of Documentary Reality. Sociological Inquiry, Vol 44, 257-268.

Smith, D. (1983). No One Commits Suicide: Textual Analysis of Ideological Practices. Human Studies, Vol 6, No 4, pp 309-359.

Smith, D. (1987). The Everyday World as Problematic. A Feminist Sociology. Boston: Northeastern University Press.

Smith, D. (1990). Texts, Facts, and Femininity: Exploring the Relations of Ruling. London and New York: Routledge.

Smith, D. (2001). Texts and the Ontology of Organizations and Institutions. Studies in Cultures, Organizations and Societies, Vol 7, No 2, pp 159-198

Smith, D. (2006). "Incorporating Texts into Ethnographic Practice", pp 65-88, in Institutional Ethnography as Practice by D. Smith (Ed.). Rowman \& Littlefield Publishers, Inc.

Star, S.L. (1991). "Power, Technologies and the Phenomenology of Standards. On Being Allergic to Onions". In A Sociology of Monsters. Essays on Power, Technology and Domination by J. Law (Ed.). London: Routledge.

Stenborg, E. \& Klintman, M. (2012). "Organized Local Resistance: Investigating a Local Environmental Movement's Activities Against the ESS”, pp 173-192, in In Pursuit of a Promise. Perspectives on the political process to establish the European Spallation Source (ESS) in Lund, Sweden by O. Hallonsten (Ed.). Sweden, Lund: Arkiv förlag.

Stocking, G. \& Chinnery, E. (1982). Gatekeeper to the Feld: E.W.P. Chinnery and the Ethnography of the New Guinea Mandate. History of Anthropology Newsletter, Vol 9, No 2, pp 3-12.

Sydsvenskan. (2002, March 23). Ett litet steg närmare för ESS. Sydsvenskan. Retrieved from https://www.sydsvenskan.se/

Sydsvenskan. (2002, October 03). ESS - riskfyllt skrytbygge eller drömprojekt. Sydsvenskan. Retrieved from https://www.sydsvenskan.se/ 


\section{Accounting the Future}

Sydsvenskan. (2003, February 07). Mörk framtid för ESS-projekt. Sydsvenskan.

Retrieved from https:/www.sydsvenskan.se/

Sydsvenskan. (2003, January 30). Besked om ESS försenas minst ett år.

Sydsvenskan. Retrieved from https://www.sydsvenskan.se/

Sydsvenskan. (2003, July 26). ESS-konsortiet måste banta. Sydsvenskan. Retrieved from https://www.sydsvenskan.se/

Sydsvenskan. (2003, March 19). ESS ingen het fråga för regeringen. Sydsvenskan. Retrieved from https://www.sydsvenskan.se/

Sydsvenskan. (2004, June 17). Förhandlingar nära om ESS. Sydsvenskan. Retrieved from https://www.sydsvenskan.se/

Sydsvenskan. (2005, March 29). ESS möter nytt motstånd. Sydsvenskan, Retrieved from https://www.sydsvenskan.se/

Sydsvenskan. (2005, October 14). Tungt nej till ESS - för landets anseende.

Sydsvenskan, Retrieved from https://www.sydsvenskan.se/

Sydsvenskan. (2007, March 01). Debattinlägg: "Säg nej till ESS-anläggningen".

Sydsvenskan, Retrieved from https://www.sydsvenskan.se/

Sydsvenskan. (2009, February 02). Grannarna splittrade i synen på ESS.

Sydsvenskan. Retrieved from https://www.sydsvenskan.se/

Sydsvenskan. (2013, April 14). Ett ESS i rockärmen. Sydsvenskan. Retrieved from https://www.sydsvenskan.se/

Sydsvenskan. (2014, April 24). ESS Grannar räds inte strålande forskningsanläggning. Sydsvenskan. Retrieved from https://www.sydsvenskan.se/

Sydsvenskan. (2014, January 15). ESS jämförbart med Fukushima. Sydsvenskan, Retrieved from https:/www.sydsvenskan.se/

Sydsvenskan. (2018, April 26). ESS jämförbart med kärnbränslefabrik.

Sydsvenskan, Retrieved from https://www.sydsvenskan.se/

Van Lente, H. \& Bakker, S. (2010). Competing Expectations: The Case of Hydrogen Storage Technologies. Technology Analysis \& Strategic Management, Vol. 22, No. 6, pp 693-709 
Van Lente, H. (2012). Navigating Foresight in a Sea of Expectations: Lessons from the Sociology of Expectations. Technology Analysis \& Strategic Management, Vol. 24, No. 8, pp 769-782.

Van Lente, H. and Rip, A. (1998). "Expectations in Technological Developments: an Example of Prospective Structures to be Filled in by Agency", pp 195-220, in Getting New Technologies Together by C. Disco and B. J. R. van der Meulen (Eds). Berlin, New York: Walter de Gruyter.

Von Platen, S. (2013). "Reaching the Inside from the Outside? Member Identification and Auto-communication During Organizational Transition", pp 123142, in Legitimizing ESS: Big Science as a Collaboration across Boundaries by T. Kaiserfeld and T. O’Dell (Eds.). Sweden, Lund: Nordic Academic Press.

Waskow, A. (1967). The Historian's Role in Future Research. Futures, vol. 1, No. 2 , pp. 117-124.

Wilton D. (2004). Word Myths: Debunking Linguistic Urban Legends. Oxford University Press.

Woolgar, S. \& Neyland, D. (2013). Mundane Governance: Ontology \& Accountability. Oxford: Oxford University Press.

Woolgar, S. \& Pawluch, D. (1985). Ontological Gerrymandering: The Anatomy of Social Problems Explanations. Social Problems, Vol. 32, pp 214-227.

Woolgar, S. (2002). After Word? - On Some Dynamics of Duality Interrogation Or: Why Bonfires Are Not Enough. Theory, Culture \& Society, Vol. 19, No. 5/6, pp 261270.

Zucker, D. (1988). The Naked Gun: From the Files of Police Squad! United States: Paramount Pictures. 


\section{List of Interviews}

Aegon Jansson

Detector Scientist

Date: 2017 March 10

Location: Lund (his office at ESS)

Aemon Löfgren

Chemistry Professor at Lund University

Date: 2016 October 18

Location: Lund University (a lunch room at Lund University)

Aerys Jönsson

Detector Scientist

Date: 2017 March 10

Location: Lund (his office at ESS)

Arya Lindqvist

Strategic Advisor at ESS, formerly Governess of the Skåne region

Date: 2016 May 11

Location: Lund (a lunch room at the Medicon Village Science Park)

Bran Karlsson

Neutron Scientist from the Institut Laue-Langevin

Date: 2017 January 24

Linköping (fika room at Coatings Workshop)

Brandon Dikson

Strategist at Region Skåne, Civil Servant

Date: 2016 April 21

Location: Lund (a coffee bar)

Brienne Jacobsen

Head of the ESS Detector Coatings Workshop, Thin Film Scientist

Date: 2016 December 02

Location: Linköping (a "fika room" at the Coatings Workshop) 
Catelyn Hagen

Science Communicator for ESS

Date: 2017 March 10

Location: Lund (her office at ESS)

Davos Svensson

Professor in Thin Film Physics at Linköping University

Date: 2017 February 28

Location: Linköping (a meeting room at the Coatings Workshop)

Eddard Jensen

Instrument Scientist, Reflectometry Specialist, Team Leader behind ESTIA

Date: 2016 November 28

Location: Lund (a meeting room at ESS)

Jaime Falk

Architect, Civil Servant, "Future Walk" Guide

Date: 2016 September 09

Location: Lund (a lunch room at Lund City Council)

Jon Linden

Political Scientist, Civil Servant at Region Skåne

Date: 2016 May 09

Location: Lund (a coffee bar at Lund's Central Train Station)

Robert Lundberg

Physics Professor at Lund University, formerly Chancellor of Lund University

Date: 2016 May 11

Location: Lund (a meeting room at Lund University)

Samwell Nilsson

Social Scientist at Lund University, participant in the TITA project

Date: 2016 May 10

Location: Lund (his office at Lund University)

Sansa Lindberg

Doctoral Candidate in Crystallography, Student of Aemon Löfgren

Date: 2017 January 31

Location: Skype 


\section{Acknowledgments}

I was an adjunct lecturer in Greece when I got this $\mathrm{PhD}$ position. Reading the email at 2 o'clock in the morning, I was overwhelmed by joy. So much so, that I woke everybody up in the building where I lived. With Greek music, and a lot of alcohol, we celebrated the great opportunity I was given. By the time I was finalizing my dissertation, four years later, I became a walking disaster. I was careful to use every opportunity I got to complain about my physiological and psychological well-being. There are many important figures I wish to acknowledge here, for providing me the opportunity to grow as an academic in a context as wonderful and accepting as is TEMA-T, and for helping me rise above myself when things got tough.

I extend my most profound gratitude to Steve Woolgar, my main $\mathrm{PhD}$ supervisor. Steve took all my professional interests seriously. With care and patience, he guided my growing fascination with the tools of textual analysis, ethnomethodology, and institutional ethnography. Through the many and inspiring meetings, discussions, and interactions with him, Steve helped me discover the possibilities and directions of my work. His creative input, attention to detail, and his belief in me throughout these four year-long academic journey made my work possible, manageable, and, most importantly, enjoyable. Steve listened when I was expressing my concerns, doubts, and anxieties and he met them, always calm, never dismissively, with support and encouraging advice. For all this, and much (much) more, Steve, thank you.

Also, I wish to extend my gratitude to Ericka Johnson, my second PhD supervisor. Ericka contributed to my academic growth in many ways, but I wish to stress this particular. When things were getting too tough to handle, when the complexity and scale of the work I needed to accomplish were becoming overwhelming, Ericka told me: "Ivanche, take a day off. Put your fingers in the dirt - plant a tree." I carried this advice with me throughout these years. It became an important reminder of the value of taking a step back as part of the academic work. Ericka supplied my academic interests with piles of books. She read my work critically and attentively. Her advice on how to organise and articulate it became invaluable as contributions to its development. For all that, and for being there for me, Ericka, thank you.

Thanks to the opponents and readers who have taken the time to read my work in its earlier phases and provide constructive feedback: Kristin Zeiler, at my three-term review; Catelijne Coopmans, Jelmer Brüggemann, and David Moats, at my 60\% seminar; Brian Rappert, Alan Irwin, Catelijne Coopmans, and Claes-Fredrik 
Helgesson, at my $90 \%$ seminar. These opportunities for feedback have been crucial for my PhD studies and I thank you for devoting your time to my work.

I have been so lucky to spend these four years at TEMA-T. My colleagues from the start, the people I met in this context also became my friends. Darcy Parks, Johan Niskanen, Elin Björk and Fredrik Backman - my PhD cohort, made this academic experience an adventure. Exploring the terra incognita of STS with you was always fun. I will never forget our passionate discussions concerning bees and honey, kings and queens, lords and ladies, and various other creatures of the imagination.

Steve Woolgar, Claes-Fredrik Helgesson, Teun Zuiderant-Jerak, Francis Lee, Jeffrey Christensen, Nimmo Elmi, Lotta Björklund, Else Vogel, David Moats, Fredy Mora, Sara Bea, Francesco Colona, and Camilo Castillo - the members of my TEMA-T seminar group Values, were key to my personal as well as academic growth. Our joint readings of papers, theoretical and analytical deliberations, made every Wednesday a day to look forward to; your careful and caring engagement with my work, your insight, was formative and always, deeply appreciated. Amelia Mutter, Harald Rohracher, Lisa Lindén, Simon Haikola, Fredrik Endvall, Réka Andersson, Katharina Reindl, Kajsa Ellegård, Lisa Guntram, Jenny Gleisner, Kristina Trygg, Eva Törnqvist, and of course, Eva Danielsson and Josefin Frilund - it's been a pleasure sharing a work-space with you. Thank you all for making these four years a memorable part of my life.

None of this would have been possible without Suzana Dimitrievska, my mother, who ignited my passion for education; without Ace Dimitrievski, my father, who weekly intervened for my psychological well-being, sending me countless photos of my trees in North Macedonia; and without Nenad Dimitrievski, my brother, whose nonchalance and loving dismissal of my personal anxieties and fears made everything more manageable. In countless ways, they supported my personal growth. All these years, they carried my academic career on their shoulders. Thank you for the days and nights - for your battles against the winds and sun of Ovche Pole - that made my past, present, and future futures possible.

I wish to thank Monika Lopez, my life partner and source of strength these years. Her emotional and intellectual support, the time and effort she invested in caring for our family - for Lucas, our child - the unconditional love and never-failing belief in me constitute her input in the making of this dissertation. Thank you for making these years meaningful. Finally, I extend my heartfelt gratitude to Lucas. Lucas, if one day you read this, I want you to know that every time I returned home from work and 
looked at you, every time I saw you smiling, I could feel how all my troubles and anxieties were melting away into thin air. Because of you, I could see a future. 


\section{FACULTY OF ARTS AND SCIENCES}

Linköping Studies in Arts and Sciences No. 771, 2019

Department of Thematic Studies - Technology and Social Change

Linköping University

SE-581 83 Linköping, Sweden

www.liu.se

The thesis investigates the social processes involved in the practices of futuring. It addresses the question of how social practices contribute to the production and maintenance of robust versions of the future. It asks how best should we study futurity, including expectations, imaginations, promises and visions. Existing research tells us rather little about how ordinary practices render the future as a particular, publicly available and accountable presence or absence. In what ways do people achieve situated performances of certainty about the future? The thesis addresses these questions by drawing upon recent theoretical themes in Science and Technology Studies (STS), notably accountability relations and mundane practices in science and technology. The empirical focus of the thesis is an extended ethnographic study of the European Spallation Source (ESS) - a major neutron-based science research facility currently under construction in Lund, Sweden. The methods used are a combination of participant observation, interviews, documentary analysis, and ethnomethodologically inflected textual analysis. The thesis reports findings in relation to each of four aspects of ESS work: 1) the textual practices rendering the future of the ESS in local newspaper coverage; 2) documentary analysis of a 2014/2015 Call for ESS Instrument Proposals; 3 ) observations from visits to ESS and participation in staged "future walks" and 4) the mundane laboratory practices of measuring thickness in an ESS Detector Coatings Workshop in Linköping. The results of these empirical analyses are used to argue for the importance of generating and sustaining accountability relations in futuring practices, for understanding how the future is imagined and made to come about. The thesis concludes that looking at practices in this way has political implications - among other things, it allows to see how agency and capability-to-affect the future is distributed, built, eroded and attributed. 